\title{
UICN
}

\section{Directrices para áreas bajo protección privada}

Brent A. Mitchell, Sue Stolton, Juan Bezaury-Creel, Heather C. Bingham,

Tracey L. Cumming, Nigel Dudley, James A. Fitzsimons, Delphine Malleret-King, Kent H. Redford y Pedro Solano

Craig Groves, Editor de serie

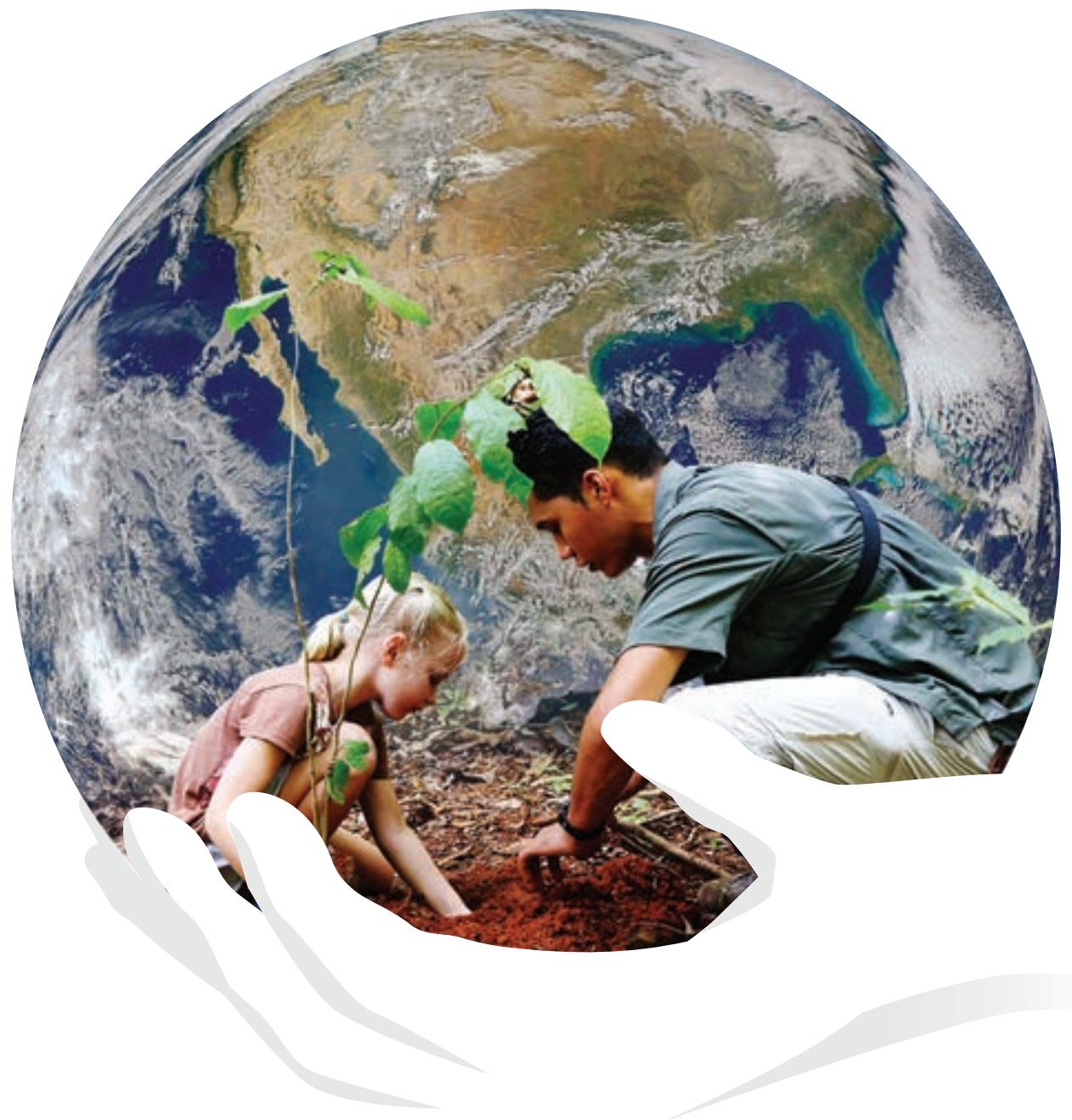




\section{SERIE DIRECTRICES SOBRE BUENAS PRÁCTICAS EN ÁREAS PROTEGIDAS DE LA CMAP UICN}

Las Directrices sobre Buenas Prácticas en Áreas Protegidas de la Comisión Mundial de Áreas Protegidas (CMAP) son el recurso autorizado en el ámbito mundial para los gestores de áreas protegidas. Como resultado de un trabajo de colaboración de profesionales especialistas dedicados a apoyar la mejor implementación en campo, las directrices condensan aprendizajes y consejos de toda la UICN. Aplicadas en campo, contribuyen al desarrollo de capacidades institucionales e individuales para gestionar los sistemas de áreas protegidas de manera eficaz, equitativa y sostenible, y para hacer frente a infinidad de retos que se encuentran en la práctica. También sirven para ayudar a los gobiernos nacionales, las agencias de áreas protegidas, las organizaciones no gubernamentales, las comunidades y los aliados del sector privado a lograr sus compromisos y objetivos y, especialmente, los del programa de trabajo sobre áreas protegidas del Convenio sobre la Diversidad Biológica (CDB).

El conjunto completo de las directrices está disponible en: www.iucn.org/pa_guidelines

Recursos complementarios en: www.cbd.int/protected/tools/

Para aportar al desarrollo de capacidades para un Planeta Protegido dirijase a: www.protectedplanet.net/

\section{DEFINICIÓN DE LA UICN DE ÁREA PROTEGIDA, CATEGORÍAS DE GESTIÓN Y TIPOS DE GOBERNANZA}

La UICN define área protegida como:

Un espacio geográfico claramente definido, dedicado y gestionado por medios legales y otros medios eficaces para lograr la conservación a largo plazo de la naturaleza y de los valores culturales y los servicios de los ecosistemas asociados.

La definición se amplía por medio de seis categorías de gestión (una de ellas con una subdivisión) que se resumen como sigue: la Reserva natural estricta: establecida para proteger estrictamente la biodiversidad y también posiblemente otras características geológicas/geomorfológicas, donde la presencia humana, sus usos e impactos son controlados y limitados para asegurar la protección de los valores de conservación.

Ib Área silvestre: usualmente corresponde a extensas áreas no modificadas o ligeramente modificadas, que conservan su carácter e influencia natural, sin presencia humana permanente o significativa, protegidas y gestionadas para preservar su condición natural. II Parque nacional: extensas áreas naturales o casi naturales que protegen procesos ecológicos a gran escala con especies y ecosistemas característicos, y que también ofrecen oportunidades espirituales, científicas, educativas, recreativas y turísticas que son ambiental y culturalmente compatibles.

III Monumento o característica natural: áreas reservadas para proteger un monumento natural específico que puede ser un accidente geográfico, una montaña submarina, una caverna submarina, una característica geológica como una caverna, o una característica viva como un manglar antiguo.

IV Área de gestión de hábitats/especies: áreas para proteger especies o hábitats en los que la gestión refleja esta prioridad. Muchas de estas áreas requieren intervenciones activas habituales para abordar las necesidades de especies o hábitats, pero no es un requisito de la categoría.

V Paisaje terrestre o marino protegido: donde la interacción de los seres humanos y la naturaleza ha producido con el tiempo una característica distintiva con valor significativo de orden ecológico, biológico, cultural y estético; y donde salvaguardar la integridad de esta interacción es vital para proteger y mantener el área y la conservación de la naturaleza y otros valores asociados.

Vı Áreas protegidas con uso sostenible de los recursos naturales: áreas que conservan ecosistemas junto con los valores culturales y los sistemas tradicionales de gestión de los recursos naturales asociados a ellos. Normalmente son extensas, con la mayor parte del área en condiciones naturales, en las que una parte cuenta con una gestión sostenible de los recursos naturales y donde uno de los objetivos principales del área es el uso no industrial y de bajo nivel de los recursos naturales, compatible con la conservación de la naturaleza.

La categoría depende del principal objetivo de gestión, el cual se debe aplicar por lo menos a tres cuartas partes del área protegida - la regla del $75 \%-$

Las categorías de gestión se aplican junto con una tipología de gobernanza - que es una descripción de quién detenta la autoridad y la responsabilidad del área protegida-. La UICN define cuatro tipos de gobernanza:

Tipo A. Gobernanza por parte del gobierno: ministerio o agencia nacional o federal a cargo; ministerio o agencia subnacional a cargo; gestión delegada por el Gobierno (ej. a una ONG).

Tipo B. Gobernanza compartida: gobernanza en colaboración (distintas formas de influencia pluralista); gobernanza conjunta (órganos de decisión pluralistas); gestión transfronteriza (diversos niveles a lo largo de fronteras internacionales).

Tipo C. Gobernanza privada: áreas conservadas establecidas por propietarios individuales; por organizaciones sin ánimo de lucro (ej., ONG, universidades, cooperativas); por organizaciones con fines de lucro (ej., propietarios corporativos).

Tipo D. Gobernanza por parte de pueblos indígenas y comunidades locales: territorios y áreas conservados por pueblos indígenas - establecidos y administrados por pueblos indígenas -; territorios y áreas conservados por comunidades locales - establecidos y administrados por comunidades locales-.

Para más información sobre la definición de la UICN, las categorías y los tipos de gobernanza consultar en Dudley (2008). Directrices para la aplicación de las categorías de gestión de áreas protegidas que puede ser descargado de www.iucn.org/pa_categories

Para más información sobre tipos de gobernanza ver Borrini-Feyerabend, et al., (2013). Gobernanza de áreas protegidas: De la comprensión a la acción, que puede ser descargado de https://portals.iucn.org/library/node/29138 


\section{Directrices para áreas bajo protección privada}

El Grupo de Especialistas en Áreas Bajo Protección Privada y Gestión de la Naturaleza le dedica este volumen a nuestra querida colega Elisa Corcuera 


\section{UICN}

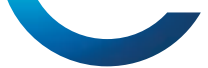

\section{Unión Internacional para la Conservación de la Naturaleza (UICN)}

La UICN contribuye a encontrar soluciones pragmáticas para los principales desafíos ambientales y de desarrollo que enfrenta el planeta. El trabajo de la Unión se centra en la biodiversidad, el cambio climático, la energía, el sustento de la gente y el reverdecimiento de la economía mundial por medio del apoyo a la investigación científica, la gestión de proyectos de campo en todo el mundo, y el encuentro entre los gobiernos, las ONGs, las Naciones Unidas y las empresas con miras a desarrollar políticas, leyes y prácticas óptimas. La UICN es la organización medioambiental más antigua y más grande del mundo, con más de 1.300 miembros, gubernamentales y no gubernamentales, además de unos 13.000 expertos voluntarios. Para su labor, la UICN cuenta con el apoyo de un personal compuesto por cerca de 900 empleados repartidos en 50 países y cientos de asociados del sector público, no gubernamental y privado de todo el mundo.

\section{www.iucn.org/es}

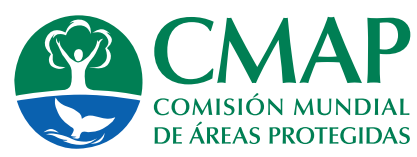

\section{Comisión Mundial de Áreas Protegidas (CMAP)}

La Comisión Mundial de Áreas Protegidas (CMAP) de la UICN es la red principal de especialistas en áreas protegidas a nivel mundial. Es administrada por el Programa de Áreas Protegidas de la UICN y tiene más de 2.500 miembros en 140 países. La CMAP ayuda a los gobiernos y otras entidades a planear las áreas protegidas e integrarlas en todos los sectores, proporcionando asesoramiento estratégico a los responsables de políticas, fortaleciendo la capacidad junto con la inversión en áreas protegidas y convocando a los diversos grupos interesados en las áreas protegidas para tratar temas desafiantes. Durante más de 60 años, la UICN y la CMAP han estado a la vanguardia de la acción mundial relacionada con las áreas protegidas. La Serie Directrices sobre Buenas Prácticas en Áreas Protegidas es uno de los principales productos de la Comisión, entregando orientaciones oportunas sobre todos los ámbitos asociados a la planificación, gestión y evaluación de áreas protegidas.

www.iucn.org/wcpa

\section{PRIVATELY \\ PROTECTED AREAS \\ PRIVATE MEANS - PUALLIC BENEFT}

Grupo de Especialistas en Áreas Bajo Protección Privada y Gestión de la Naturaleza

Este de Grupo de Especialistas de la Comisión Mundial de Áreas Protegidas (CMAP) de la UICN tiene como objetivo mejorar el entendimiento y el reconocimiento del papel que juegan los enfoques privados en la conservación de la naturaleza, así como también aumentar la efectividad de las áreas bajo protección privada y de conservación por medio de la recolección de información y su diseminación a nivel global.

\section{privateconservation.net}

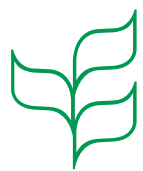

Convenio sobre la Diversidad Biológica

\section{Convenio sobre la Diversidad Biológica (CDB)}

El Convenio sobre la Diversidad Biológica (CDB), abierto para su firma durante la Cumbre de Río en 1992, y puesto en vigencia en diciembre de 1993, es una convención internacional para la conservación de la biodiversidad, el uso sostenible de los componentes de la biodiversidad y la distribución equitativa de los beneficios derivados del uso de los recursos genéticos. Con 196 Partes, el convenio cuenta con una participación casi universal entre los países del mundo.

\section{www.cbd.int}

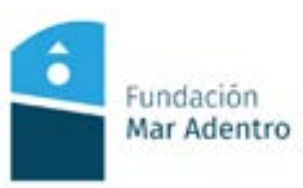

\section{Fundación Mar Adentro}

Fundación Mar Adentro es una fundación privada sin fines de lucro, basada en Chile y dedicada al desarrollo de programas educativos multidisciplinarios que integran arte y naturaleza para explorar estrategias de conservación de la biodiversidad presente en Chile, crear conciencia y, también, alentar un cambio en el valor otorgado al patrimonio natural y cultural.

\section{www.fundacionmaradentro.cl}




\section{Equilibrium RESEARCH}

\section{Equilibrium Research}

Equilibrium Research ofrece soluciones prácticas para enfrentar los desafíos vinculados a la conservación, los que abarcan desde el concepto mismo hasta la implementación y la evaluación de impacto. Con socios que van de comunidades locales a agencias de la ONU en todo el mundo, Equilibrium explora y desarrolla enfoques para la gestión de recursos naturales procurando un equilibrio entre las necesidades de la naturaleza y las personas. Para sus fundadores, Nigel Dudley y Sue Stolton, la conservación de la biodiversidad es una responsabilidad de carácter ético, que además puede promover el bienestar humano.

www.equilibriumresearch.com

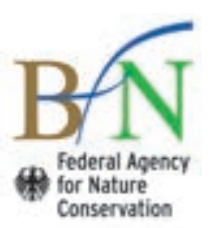

\section{Bundesamt für Naturschutz (BfN)}

La Agencia Federal Alemana para la Conservación de la Naturaleza (Bundesamt fur Naturschutz, BfN) es la autoridad científica alemana a cargo de la conservación de la naturaleza nacional e internacional. La BfN es una de las agencias de investigación del gobierno y le rinde cuentas al Ministerio Federal de Medio Ambiente (BMUB, por su sigla en alemán). La agencia le brinda al ministerio asistencia profesional y científica en ámbitos relacionados con la conservación de la naturaleza y la gestión del paisaje, además de ofrecer actividades colaborativas internacionales. La BfN promueve sus objetivos llevando a cabo investigaciones científicas relacionadas y también está a cargo de una serie de programas de financiamiento. Además, realiza un trabajo importante en torno al cumplimiento de acuerdos internacionales sobre conservación de las especies y la naturaleza, tales como el Tratado Antártico y el German Genetic Engineering Act.

www.bfn.de/en

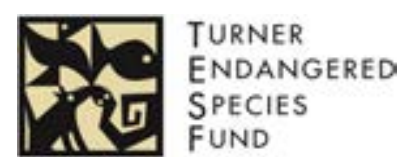

The Turner Endangered Species Fund (TESF)

Fundado en 1997, el TESF tiene como misión conservar la diversidad biológica, asegurando la persistencia de especies en peligro y sus hábitats con especial énfasis en las tierras privadas. Nuestras actividades van desde acciones de conservación de una especie hasta la restauración de comunidades ecológicas y ecosistemas funcionales. Nuestra singularidad recae en que nuestros esfuerzos están puestos en destacar el significativo papel de las tierras privadas en la conservación ecológica. Nuestro objetivo es utilizar los mejores recursos científicos para conservar la biodiversidad y diseminar información científica confiable y sobre políticas. Estamos decididos a establecer un nuevo nivel de efectividad para los esfuerzos público-privados para revertir la crisis de extinción.

tesf.org

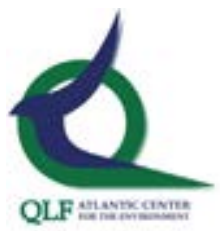

\section{QLF Atlantic Center for the Environment}

El QFL tiene como propósito promover el desarrollo de liderazgo global, apoyar a las comunidades rurales y al medio ambiente en el este de Canadá y Nueva Inglaterra, y crear modelos para la gestión de los recursos naturales y el patrimonio cultural que puede ser compartido con el resto del mundo. La Quebec-Labrador Foundation está registrada como una organización sin fines de lucro de tipo 501 (c)3 en los Estados Unidos y como organización de beneficencia en Canadá. Desde su sede principal en Massachusetts, el QLF Atlantic Center for the Environment maneja el Grupo de Especialistas en Áreas Bajo Protección Privada y Gestión de la Naturaleza de la Comisión Mundial de Áreas Protegidas (CMAP) de la UICN.

www.qlf.org 



\section{Directrices para áreas bajo protección privada}

Brent A. Mitchell, Sue Stolton, Juan Bezaury-Creel, Heather C. Bingham,

Tracey L. Cumming, Nigel Dudley, James A. Fitzsimons, Delphine Malleret-King, Kent H. Redford y Pedro Solano

Craig Groves, Editor de serie 
La presentación del material en esta publicación y las denominaciones empleadas para las entidades geográficas no implican en absoluto la expresión de una opinión por parte de la UICN o de otra organización participante sobre la situación jurídica de un país, territorio o zona, o de sus autoridades, o acerca de la demarcación de sus límites o fronteras.

Los puntos de vista que se expresan en esta publicación no reflejan necesariamente los de la UICN o de otra organización participante.

Esta publicación ha sido posible en parte gracias a la financiación de Bundesamt für Naturschutz (BfN), Turner Endangered Species Fund, y Fundación Mar Adentro.

La UICN y las organizaciones participantes declinan cualquier error u omisión en la traducción de este documento de la versión original en inglés. En caso de discrepancia, remítase, por favor, a la edición original. Título de la edición original: Guidelines on privately protected areas. (2018). Publicado por: UICN, Gland, Suiza. DOI: doi.org/10.2305/IUCN.CH.2018.PAG.29.en

Publicado por:

Derechos reservados:

Citación:

ISBN:

DOI:

Traducción al español:

Fotografía de cubierta anterior:

Fotografía de cubierta posterior:

Diseñado por:

Impresión:

Disponible en:
UICN, Gland, Suiza

C 2019 UICN, Unión Internacional para la Conservación de la Naturaleza y de los Recursos Naturales

Se autoriza la reproducción de esta publicación con fines educativos y otros fines no comerciales sin permiso escrito previo por parte de quien ostenta los derechos de autor, siempre cuando se mencione la fuente.

Se prohíbe reproducir esta publicación para la venta o para otros fines comerciales sin permiso escrito previo de quien ostenta los derechos de autor.

Mitchell, B.A., Stolton, S., Bezaury-Creel, J., Bingham, H.C., Cumming, T.L., Dudley, N., Fitzsimons,J.A., Malleret-King, D., Redford, K.H. y Solano, P. (2019). Directrices para áreas bajo protección privada. Serie Directrices sobre Buenas Prácticas en Áreas Protegidas No. 29. Gland, Suiza: UICN. xii + 100pp.

978-2-8317-1999-3 (PDF)

978-2-8317-2000-5 (versión impresa)

https://doi.org/10.2305/IUCN.CH.2018.PAG.29.es

Catalina Echaurren y Fundación Mar Adentro

(C Lapa Ríos, Península de Osa, Costa Rica

Voluntarios de conservación de la Nature Conservancy of Canada plantando (Ammophila breviligulata) () Mike Dembeck

Miller Design

A Impresores

Unión Internacional para la Conservación de la Naturaleza (UICN)

Programa Mundial sobre Áreas Protegidas

Rue Mauverney 281196

Gland, Suiza

Tel +41229990000

Fax +41229990002

wcpa@iucn.org

www.iucn.org/resources/publications 


\section{Contenidos}

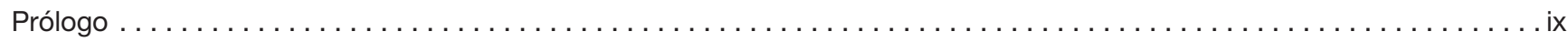

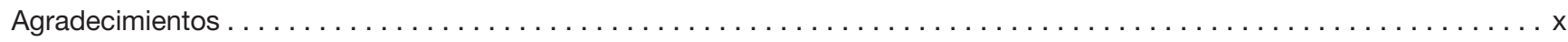

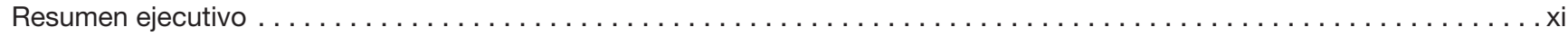

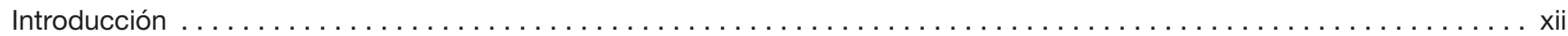

Parte A ¿Qué es un área bajo protección privada? . . . . . . . . . . . . . . . . . . . . . . .

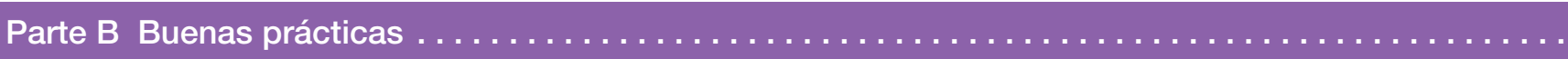

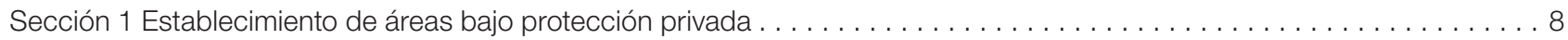

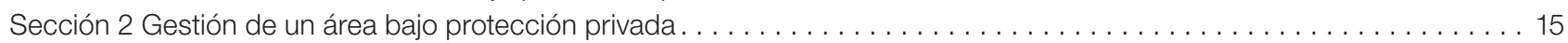

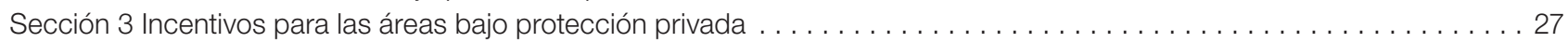

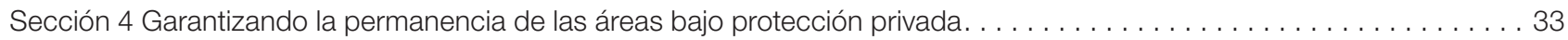

Sección 5 Temas relacionados con subtipos específicos de áreas bajo protección privada . . . . . . . . . . . . . . . 38

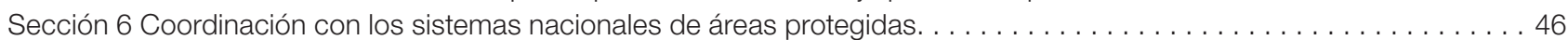

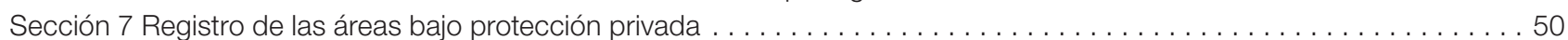

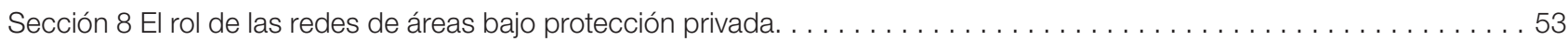

Parte C Perspectivas futuras: Oportunidades para concretar el potencial de las áreas bajo protección privada. .

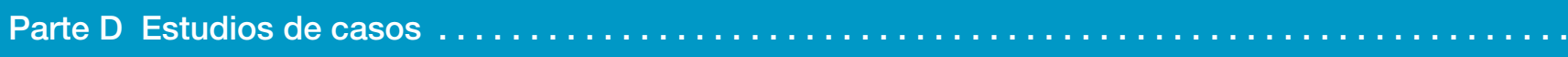

1 El Sistema Nacional de Reservas de Áreas Protegidas Públicas, Privadas e Indígenas de Australia . . . . . . . . . . . 62

2 Reservas Privadas del Patrimonio Natural de Brasil: La iniciativa privada como política pública . . . . . . . . . . . . 64

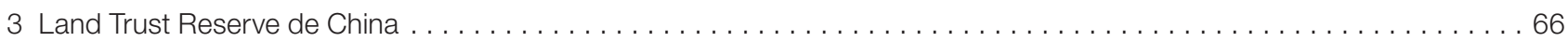

4 APP y turismo: Un ejemplo in situ en Lapa Ríos, Costa Rica. . . . . . . . . . . . . . . . . . . . . . . . 68

5 La National Natural Heritage: Contribuyendo al compromiso privado en la conservación de la naturaleza en Alemania. . . . . 70

6 Un modelo exitoso de gestión de conservación de la vida silvestre: Lewa Wildlife Conservancy, Kenia . . . . . . . . . . 72

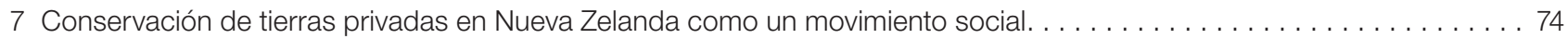

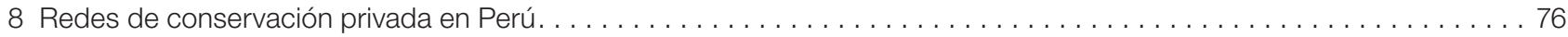

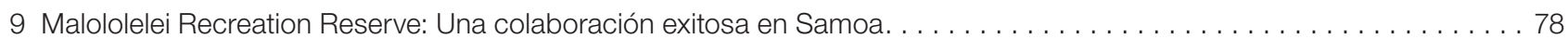

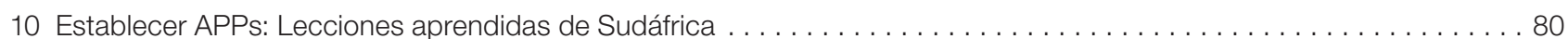

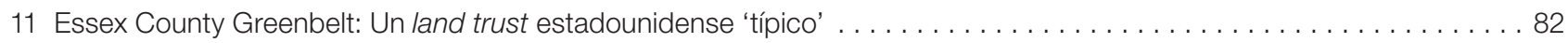

12 Cómo realzar a las APPs: Incorporación de APPs a la WDPA en el Reino Unido $\ldots \ldots \ldots \ldots \ldots \ldots$

Parte E Recursos

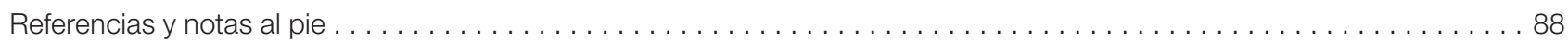

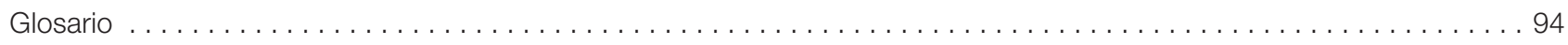

Apéndice 1: APPs y otras medidas eficaces de conservación basadas en áreas $\ldots \ldots \ldots \ldots \ldots \ldots \ldots$

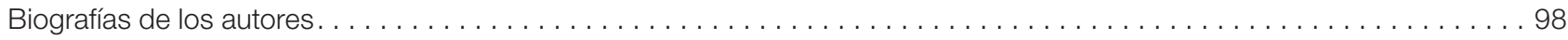

\section{Cuadros}

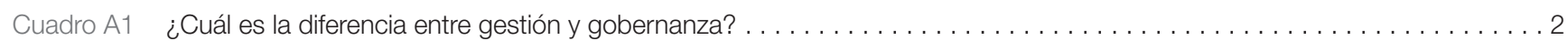

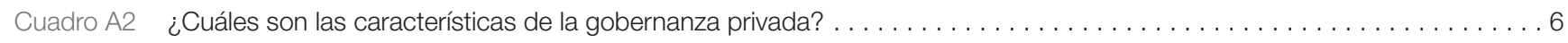

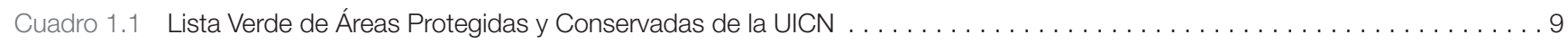

Cuadro 1.2 Apoyando la conservación y el desarrollo económico en Sudáfrica $\ldots \ldots \ldots \ldots \ldots \ldots \ldots \ldots \ldots \ldots \ldots \ldots \ldots$

Cuadro 1.3 BioMap: Mapeo de prioridades para adquisición de terrenos en el estado de Massachusetts, EE. UU. . . . . . . . . . . . 10

Cuadro 1.4 Estrategias regionales de conservación de la naturaleza en la Unión Europea $\ldots \ldots \ldots \ldots \ldots \ldots \ldots \ldots \ldots \ldots \ldots \ldots \ldots \ldots$

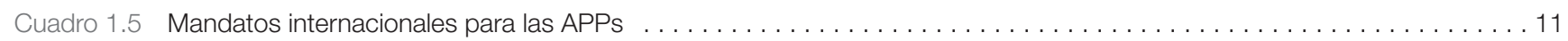

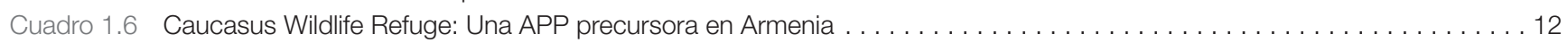

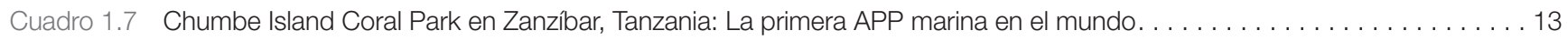

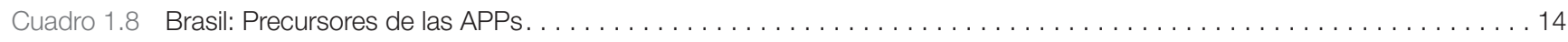

Cuadro 1.9 Ingula Nature Reserve South Africa: Una historia de éxito de compensación corporativa . . . . . . . . . . . . . 14 


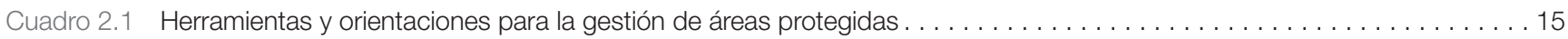

Cuadro 2.2 Buena práctica de gestión y requerimientos legislativos en el contexto de las APPs de Sudáfrica $\ldots \ldots \ldots \ldots \ldots \ldots \ldots$

Cuadro 2.3 Fuentes de datos de conservación global para complementar datos nacionales $\ldots \ldots \ldots \ldots \ldots \ldots \ldots \ldots \ldots \ldots \ldots$

Cuadro 2.4 Conocimiento ecológico tradicional y Bush Heritage Australia $\ldots \ldots \ldots \ldots \ldots \ldots \ldots \ldots \ldots \ldots \ldots \ldots \ldots$

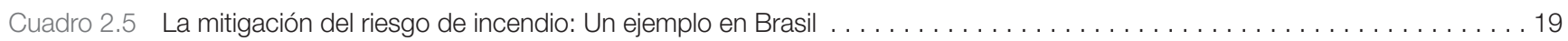

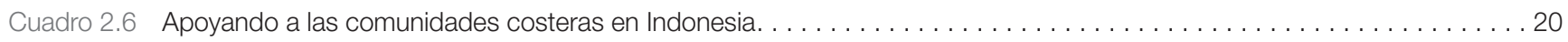

Cuadro 2.7 Monitoreo en Haller Park, Mombasa, Kenia . . . . . . . . . . . . . . . . . . . . . . . . . . . . 21

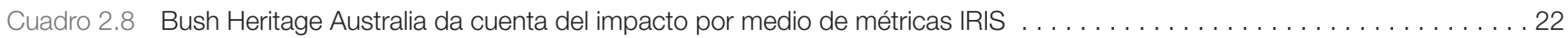

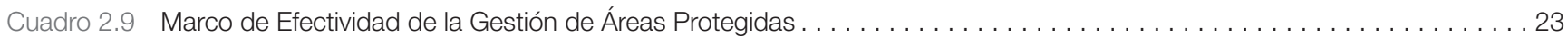

Cuadro 2.10 Lecciones aprendidas a partir del trabajo con voluntarios: Namibia, Brasil y Canadá . . . . . . . . . . . . . . . . . . 25

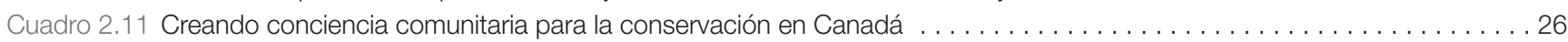

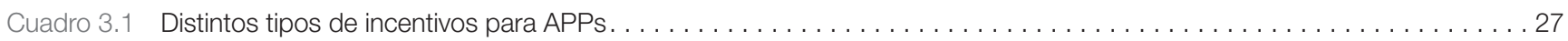

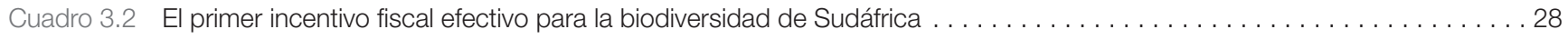

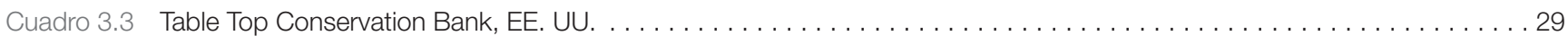

Cuadro 3.4 Uso de pagos por servicios ambientales para financiar APPs $\ldots \ldots \ldots \ldots \ldots \ldots \ldots \ldots \ldots \ldots \ldots \ldots \ldots \ldots \ldots$

Cuadro 4.1 'Comprar-proteger-revender': Una estrategia de conservación de The Nature Conservancy . . . . . . . . . . . . . 37

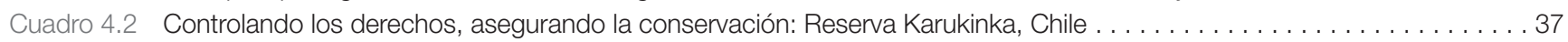

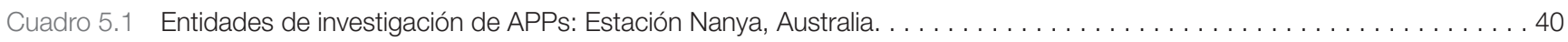

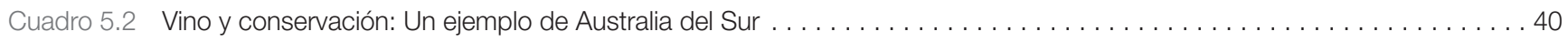

Cuadro 5.3 Recreando el hábitat tras la extracción de arena y grava: Attenborough Nature Reserve, Reino Unido . . . . . . . . . . . . 41

Cuadro 5.4 Creando seguridad financiera a largo plazo para la gestión de la Borana Conservancy, Kenia . . . . . . . . . . . . . . 43

Cuadro 5.5 Trabajando con donaciones religiosas para el establecimiento de APPs: Jabal Moussa, Líbano . . . . . . . . . . . 4 45

Cuadro 6.1 Creando conexiones: El Northeast Biological Corridor en Belice $\ldots \ldots \ldots \ldots \ldots \ldots \ldots \ldots \ldots \ldots \ldots \ldots \ldots \ldots \ldots$

Cuadro 6.2 Colaboración entre tipos de gobernanza de áreas protegidas para salvar al cocodrilo del Orinoco en Colombia . . . . . . . 49

Cuadro 7.1 Base de Datos Mundial de Áreas Protegidas y Base de Datos Global para la Eficacia en el Manejo de Áreas Protegidas . . . . 50

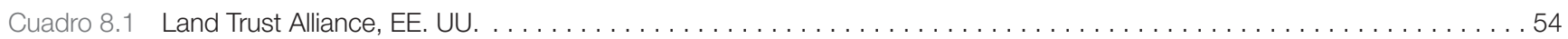

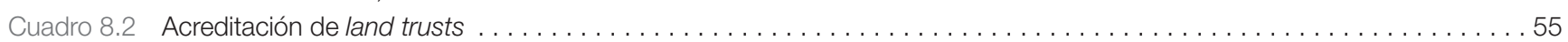

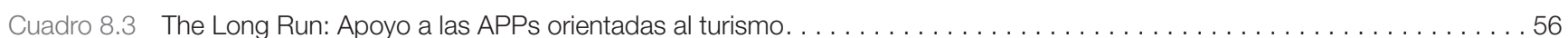

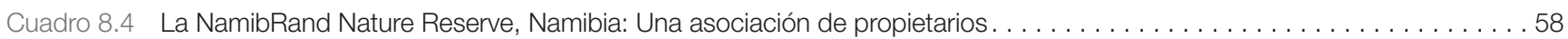

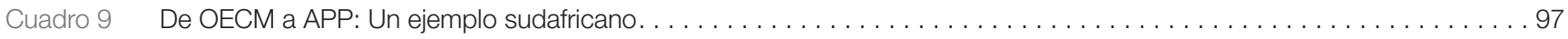

\section{Tablas}

Tabla 1

Tabla 2

Tabla 3

Tabla 4

Tabla 5

\section{Figuras}

Figura 1

Figura 2

Figura 3

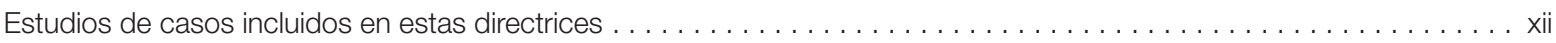
'La matriz de áreas protegidas de la UICN': Categorías de áreas protegidas

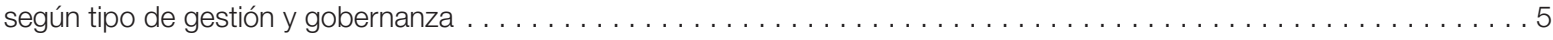
Resumen de criterios para distinguir a las APPs de otras APs bajo distintos tipos de gobernanza $\ldots \ldots \ldots \ldots \ldots$

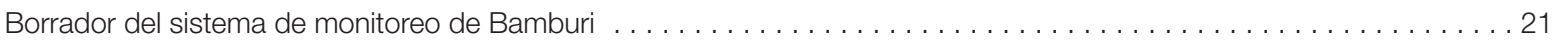

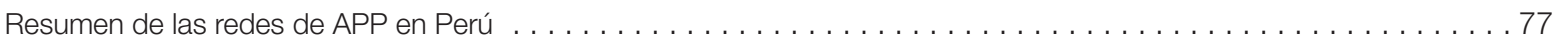

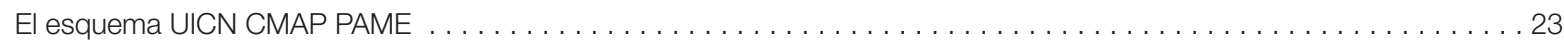

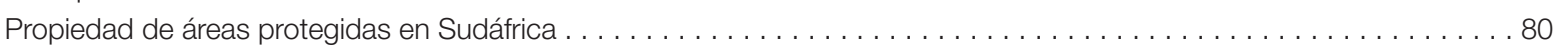
Jerarquía de los acuerdos de custodia de la biodiversidad. La custodia de la biodiversidad representa la detallada estructura institucional y el marco de implementación práctica de Sudáfrica que permite el

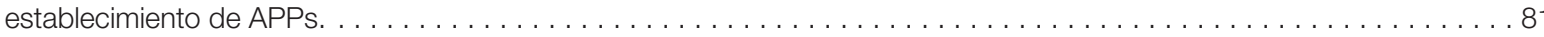




\section{Prólogo}

La Unión Internacional para la Conservación de la Naturaleza (UICN) define un área protegida como: Un espacio geográfico claramente definido, reconocido, dedicado y gestionado, mediante mecanismos legales u otro tipo de medios eficaces para conseguir la conservación a largo plazo de la naturaleza y de sus servicios ecosistémicos y valores culturales asociados. El Convenio sobre la Diversidad Biológica (CDB) también pone énfasis en que las áreas protegidas se gestionan y regulan con el fin de lograr objetivos específicos de conservación.

Las áreas protegidas pueden incluir distintos regímenes de gobernanza y gestión. Por su parte, los tipos de gobernanza pueden incluir: gobernanza por parte del gobierno, gobernanza privada, por parte de pueblos indígenas y comunidades locales, junto con varias formas de gobernanza compartida. Existen múltiples orientaciones generales sobre la gestión de áreas protegidas, sin embargo, las directrices aquí presentadas se enfocan específicamente en aquellas áreas que cumplen con la definición de la UICN y que, además, se caracterizan por estar bajo gobernanza y gestión privadas. Pueden ser propiedades pertenecientes y gestionadas por personas que poseen el título de la propiedad, por ONGs u otras instituciones, incluso, empresas, incluyendo operaciones comerciales del sector privado que poseen derechos de gestión bajo tenencia o un arrendamiento a largo plazo. Al igual que con otras áreas protegidas, se espera que las áreas bajo protección privada (APPs) se mantengan como espacios de conservación permanentes, aun cuando quien ostente el derecho de propiedad pueda cambiar. En definitiva, el factor común que comparten es que todas están establecidas bajo gobernanza privada.

Las APPs ya son conocidas dentro del patrimonio de conservación en los Estados Unidos, Australia y partes de América Latina, Europa y África, y en otros lugares están emergiendo como un nuevo modelo de conservación. Sin embargo, actualmente solo 28 países han registrado APPs en la Base de Datos Mundial de Áreas Protegidas (WDPA, por su sigla en inglés). La identificación y el reconocimiento de las APPs permite complementar las redes de áreas protegidas nacionales y, de este modo, contribuir también a la generación de un mosaico de áreas terrestres, costeras y humedales que promueva la conectividad y la conservación de la biodiversidad.

Estas directrices, preparadas por el Grupo de Especialistas en Áreas Bajo Protección Privada y Gestión de la Naturaleza de la Comisión Mundial de Áreas Protegidas (CMAP) de la UICN, ofrecen una serie de buenas prácticas para establecer APPs y asegurar su conservación de modo eficaz y a largo plazo,

\section{Kathem Mackinnow}

Dr. Kathy MacKinnon,

Presidenta, UICN/Comisión Mundial

de Áreas Protegidas además de brindar orientaciones específicas, incluyendo acuerdos legales e institucionales pertinentes y reflexiones útiles relacionadas con los mecanismos de financiamiento.

Los propietarios privados pueden tener diversas razones para querer establecer una APP, las que van desde un interés personal u organizacional por la conservación de la vida silvestre, hasta operaciones de turismo comercial. Para que un área de propiedad privada sea declarada como APP, debe cumplir con la definición de área protegida de la UICN, o con criterios equivalentes bajo leyes nacionales, e incluir el compromiso de lograr conservar la naturaleza a largo plazo. El logro de este grado de permanencia, por lo general, requiere un compromiso, un contrato, estatutos jurídicos, un acuerdo de conservación, servidumbres registradas a favor de la conservación de la naturaleza sobre el título de la propiedad, un memorando de entendimiento $\mathrm{u}$ otro instrumento vinculante para los sucesores actuales o futuros del título en el largo plazo.

Cabe destacar que las directrices utilizan el término área bajo protección privada, en lugar de área protegida privada, para enfatizar que estos territorios ofrecen numerosos beneficios públicos, a pesar de ser establecidos y gestionados por entidades privadas en tierras privadas. En algunos casos, la legislación nacional reconoce y apoya estos esfuerzos voluntarios para la conservación de la biodiversidad por medio de incentivos tributarios, subvenciones para el uso de la tierra u otras contribuciones financieras. En otros, existe la opción de introducir nuevos mecanismos para el reconocimiento de estas áreas y, así, mantener y aumentar su eficacia.

Las directrices aquí tratadas discuten diferentes opciones e instrumentos para el establecimiento y la gestión de APPs, a partir de la variedad de APPs en el mundo. Se espera que los profesionales se basen en y contribuyan a estas buenas prácticas, enriqueciendo el conjunto de ejemplos e inspirando una nueva aplicación de los principios y las orientaciones.

Mientras los países aumentan sus esfuerzos por cumplir las Metas de Aichi para la Biodiversidad y comienzan a considerar la agenda y las obligaciones post-2020, en virtud del Convenio sobre la Diversidad Biológica, se vuelve más evidente que el establecimiento y el reconocimiento de APPs ofrece grandes oportunidades para involucrar a más partes interesadas en los esfuerzos de conservación y, de este modo, expandir el patrimonio de conservación. Todo ello permite proteger y gestionar importantes áreas de biodiversidad que se escapan de los límites de las áreas protegidas gobernadas y gestionadas por el Estado.

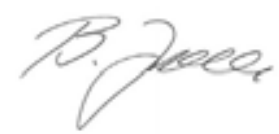

Prof. Dr. Beate Jessel,

Presidente de la Agencia Federal para la Conservación de la Naturaleza, Alemania 


\section{Agradecimientos}

Participantes del taller de diseño de la International Academy for Nature Conservation, German Federal Agency for Nature Conservation, Vilm, Alemania, junio 2017: Juan Bezaury-Creel (The Nature Conservancy, México); Nandipha Bhengu (Departamento de Asuntos Ambientales, Sudáfrica); Heather Bingham (Centro Mundial de Vigilancia de la Conservación de las Naciones Unidas, Reino Unido); Carlos Chacón (Asociación Costa Rica por Siempre); Tracey Cumming (BIOFIN PNUD, Sudáfrica); Tilmann Disselhoff (European Land Conservation Network, Alemania); Nigel Dudley (Equilibrium Research, Reino Unido); Nicole Ellena (MVMT, Chile); André Ferretti (Fundação Grupo Boticário, Brasil); James Fitzsimons (The Nature Conservancy, Australia); Ralf Grunewald (BfN International Academy for Nature Conservation, Alemania); Mike Jebson (Queen Elizabeth II National Trust, Nueva Zelanda); Laura Johnson (International Land Conservation Network, EE. UU.); Delphine Malleret-King (The Long Run, Reino Unido); Lisa McLaughlin (Nature Conservancy of Canada); Brent Mitchell (QLF Atlantic Center for the Environment, EE. UU.); Kiragu Mwangi (BirdLife, Reino Unido); Miquel Rafa (Fundació Catalunya-La Pedrera, España); Oswaldo Sabido (Belize Association of Privately Protected Areas); Pedro Solano (Sociedad Peruana de Derecho Ambiental); Gisela Stolpe (BfN International Academy for Nature Conservation, Alemania); Sue Stolton (Equilibrium Research, Reino Unido); John Waithaka (Comisión Mundial de Áreas Protegidas de la UICN, Kenia).

Participantes de la sesión de APPs en el Congreso Mundial del International Land Conservation Network, Santiago, Chile, enero 2018, liderado por Brent Mitchell y James Fitzsimons: Mark Anderson (The Nature Conservancy, EE. UU.); Alan Bannister (Parque Tantauco, Chile); Jessica Brown (New England Biolabs Foundation, EE. UU.); Beatriz Bustos (Fundación Mar Adentro, Chile); Kristijan Čivić (Eurosite, Holanda); Mike Daniels (John Muir Trust, Escocia); Michael Dowling (Land Trust Alliance, EE. UU.); Anton Gazenbeek (Comisión Europea, Bélgica); Lance Gloss (Universidad Brown, EE. UU.); Jennifer Gooden (Universidad de Oxford, Reino Unido); Ana González-Rojas (Reserva Biológica Huilo Huilo, Chile); Roberta Guagliardi (Programa de RPPN de Río de Janeiro, Brasil); Tim Hughes (South Endeavour Trust, Australia); Olivia Humphreys (Parque Tantauco, Chile); Madeline Hurtado (Fundación Mar Adentro, Chile); Ruben Khachatryan (Foundation for the Preservation of Wildlife and Cultural Assets, Armenia); Catherine Kenrick (Parque Andino Juncal, Chile); Judy LaBelle (Glynwood, Inc., EE. UU.); Rosa Madera (Empatthy, Chile); Victoria Marles (Trust for Nature, Australia); Rodrigo Mata (Reserva Biológica Huilo Huilo, Chile); Lisa McLaughlin (Nature Conservancy of Canada); Carlos Mendoza (Fundación Mar Adentro, Chile); Florencia Morales (Red Argentina de Reservas Naturales Privadas); Flávio Ojidos (Confederação Nacional das Reservas Particulares do Patrimônio Natural, Brasil); Miquel Rafa (Fundació Catalunya-La Pedrera, España); Loring Schwartz (Friends of Spannocchia, EE. UU.); Henrique Seixas Barros (Consultor, Brasil); Marion Leticia B. Silva (Fundação Grupo Boticário, Brasil); Jin Tong (The Nature Conservancy, China); Agus Utomu (BirdLife Indonesia); Grace Weatherall (QLF Atlantic Center for the Environment, EE. UU.); Geoff Wescott (Universidad de Deakin, Australia) y Mike Williams (Nature Conservation Trust of NSW, Australia).

Participantes que realizaron comentarios en el segundo borrador: Thora Amend, Alemania; Rafael Antelo, Colombia; Hari Balasubramanian, Canadá; María Paula Bertolini, Argentina; Renata Bomfim, Brasil; Alejandra Carminati, Argentina; Melissa Carmody, Chile; Subir Mario Chowfin, India; Benjamin Cooke, Australia; Kalilou Dama, Mali; Pierre Doumet, Libano; Kate Fitzherbert, Australia; Anton Gazenbeek, Bélgica; Jennifer Gooden, EE. UU./Reino Unido; John Gordon, Reino Unido; Yogani Govender, Puerto Rico, EE. UU.; Ben Guillon, EE. UU.; Mat Hardy, Australia; George Holmes, Reino Unido; Harry Jonas, Reino Unido/Indonesia; Daniel Marnewick, Sudáfrica; Rossana Merizalde, EE. UU.; Lisa McLaughlin, Canadá; Beto Mesquita, Brasil; Flávio Ojidos, Brasil; Nils Odendaal, Namibia; Jessica Owley, EE. UU.; Juan Pacheco, Chile; Ceclia Riebl, Australia; Sibylle Riedmiller, Tanzania; Juan Carlos Sandino, Colombia; Carolina Sans, Uruguay; Karina Schiaffino, Argentina; Michael Schuett, EE. UU.; Edji Seyoum, Canadá; Anna Spenceley, Sudáfrica; Candice Stevens, Sudáfrica; Stan Stevens, EE. UU.; Philip Tabas, EE. UU.; Christophe Tourenq, Australia; Francis Vorhies, EE. UU./Francia; Paul Walker, Belice; Maria Cristina Weyland Vieira, Brasil; Dale Wright, Sudáfrica; Noelia Zafra-Calvo, España.

Autores de los estudios de caso: Australia: James Fitzsimons, The Nature Conservancy, Universidad de Deakin, Australia. Brasil: Renata Bomfim, RPPN Reluz, Beto Mesquita, consultor independiente, Flávio Ojidos, Confederação Nacional das Reservas Particulares do Patrimônio Natural (CNRPPN) y Maria Cristina Weyland Viera, Associação de RPPNs de Minas Gerais. China: Jin Tong, Programa China de The Nature Conservancy China. Costa Rica: Delphine Malleret-King, The Long Run y Karen Lewis, Lapa Ríos. Alemania: Gisela Stolpe BfN Vilm, Karin Reiter, BfN Bonn y Tilmann Disselhoff, NABU. Kenia: Tuqa Jirmo, Lewa Wildlife Conservancy. Nueva Zelanda: Mike Jebson, Queen Elizabeth II National Trust. Perú: Christel Scheske y Bruno Monteferri, Sociedad Peruana de Derecho Ambiental con la colaboración de José Vargas, Martín Vasquez, Fernando Arévalo y Karina Pinasco. Samoa: Moeumu Uili, Ministerio de Recursos Naturales y Medioambiente (MNRE, por su sigla en inglés). Sudáfrica: Candice Stevens, BirdLife South Africa. Reino Unido: Sue Stolton, IUCN UK National Committee. EE. UU.: Brent Mitchell, Presidente, Grupo de Especialistas en Áreas Bajo Protección Privada y Gestión de la Naturaleza de la Comisión Mundial de Áreas Protegidas (CMAP) de la UICN y Ed Becker, Essex County Greenbelt Association.

Pares examinadores: Geoff Wescott y Andrew Knight y UICN CMAP (Sarina van der Ploeg; Trevor Sandwith; Kathy MacKinnon; Craig Groves).

Asimismo queremos agradecer al equipo de traducción al español: Alberto Yanosky, Ariel Genovese, Camila Matta, Catalina Echaurren, Carlos Mendoza, Mara Brcic, Maya Errázuriz, Paula Jaramillo, y Pedro Solano. 


\section{Resumen ejecutivo}

Estas directrices abordan el establecimiento y la gestión de áreas bajo protección privada (APPs) y están dirigidas a profesionales, o responsables de diseñar políticas públicas, que estén vinculados con APPs.

De acuerdo con la UICN, una APP es un área protegida bajo gobernanza privada. Esto puede incluir: gobernanza por parte de personas o grupos de personas; organizaciones no gubernamentales (ONGs); corporaciones, incluyendo empresas comerciales o pequeñas empresas establecidas para gestionar grupos de APPs; propietarios con fines de lucro, tales como empresas de ecoturismo; entidades de investigación, como universidades y estaciones de campo, o entidades religiosas. Es importante, sin embargo, indicar que no todas las iniciativas de conservación llevadas a cabo por privados pueden o deben convertirse en APPs.

Las buenas prácticas están agrupadas bajo 34 principios, los que se resumen a continuación. Cada buena práctica contiene un texto descriptivo y ejemplos, incluyendo cuadros y fotos. Debido a la variedad de personas y organizaciones involucradas en la gobernanza privada, cada sección identifica de modo explícito el público principal al que están dirigidos los principios y las buenas prácticas. Luego, se presentan 12 estudios de casos de diversas partes del mundo que proporcionan detalles sobre las buenas prácticas aplicadas en cada caso.

\section{Principios}

Sección 1: Establecimiento de áreas bajo protección privada

1.1: Una APP debe cumplir con la definición de área protegida

1.2: Los propietarios y gestores de APPs deben articular objetivos de conservación claros desde el inicio

1.3: Las APPs se desarrollan mejor dentro de un marco institucional claro y de apoyo que empodere la gobernanza y la gestión

1.4: Las APPs pueden ser establecidas a través de una variedad de mecanismos

1.5: Todas las APPs deben establecerse con una estrategia a largo plazo y financiamiento sustentable

Sección 2: Gestión de un área bajo protección privada

2.1: Los actuales y futuros propietarios de una APP deben tener claridad sobre lo que ocurre tanto dentro como alrededor del área antes de desarrollar actividades de gestión

2.2: Los sistemas de gestión deben enfocarse en el logro de objetivos definidos para la APP

2.3: Los costos totales y los beneficios de la APP deben entenderse como la base de la gestión

2.4: La gestión debe ser adaptativa

2.5: La creación de un equipo debe ayudar a desarrollar capacidad de gestión para la APP

2.6: La información sobre la gestión de la APP debe comunicarse ampliamente

Sección 3: Incentivos para las áreas bajo protección privada

3.1: Los incentivos para las APPs se deben diseñar, comunicar e implementar con prudencia para asegurar su efectividad

3.2: Los incentivos se deben diseñar para motivar tanto el establecimiento de la APP como su gobernanza y gestión a largo plazo
3.3: Identificar y evitar los incentivos perversos

3.4: El reconocimiento y el apoyo son incentivos clave para las APPs

3.5: La gestión directa y el apoyo técnico para la gestión de una APP son incentivos que favorecen el compromiso a largo plazo

3.6: El apoyo en marketing es un incentivo eficaz para APPs con el potencial de generar ingresos

3.7: Los incentivos financieros son importantes para el establecimiento y la gestión de las APPs

Sección 4: Garantizando la permanencia de las áreas bajo protección privada

4.1: La gobernanza de una APP debe representar el compromiso de alcanzar la conservación a largo plazo

4.2: Muchos instrumentos de conservación privada pueden contribuir a la permanencia de la APP

Sección 5: Temas relacionados con subtipos específicos de áreas bajo protección privada

5.1: Los subtipos específicos de APPs pueden requerir modos de reconocimiento, apoyo y motivación a medida

5.2: Las APPs corporativas pueden generar beneficios para las empresas y viceversa

5.3: Las APPs gestionadas por industrias extractivas deben demostrar su contribución a la conservación de la biodiversidad

5.4: Las APPs establecidas por compañías o empresas con fines de lucro deben asegurarse de alcanzar sus resultados específicos de conservación

5.5: Las entidades religiosas pueden aportar a la conservación por medio del desarrollo de APPs en su propia tierra

Sección 6: Coordinación con los sistemas nacionales de áreas protegidas

6.1: La conservación se beneficia cuando las APPs se coordinan con otros tipos de áreas privadas dentro de un sistema nacional de áreas protegidas

6.2: Las APPs pueden complementar otros tipos de gobernanza de áreas protegidas para desarrollar sistemas nacionales eficaces de áreas protegidas

Sección 7: Registro de las áreas bajo protección privada

7.1: Las APPs deberían ser registradas en la Base de Datos Mundial de Áreas Protegidas (WDPA)

Sección 8: El rol de las redes de áreas bajo protección privada

8.1: Las redes pueden ser mecanismos eficaces para representar los intereses y las preocupaciones de los propietarios

8.2: Las redes pueden entregar estructuras de apoyo para los propietarios de APPs

8.3: Las redes pueden incidir en el monitoreo y la verificación de APPs

8.4: Las redes pueden jugar un papel importante en la promoción de productos de APPs

8.5: Las redes de APPs deben procurar que las estructuras y la gobernanza coincidan con su misión y objetivos

8.6: Las redes de APPs, como cualquier organización, deben encontrar maneras de apoyar y sustentar sus actividades 


\section{Introducción}

Estas directrices abordan la planificación y la gestión de áreas bajo protección privada (APP). De acuerdo con la UICN, un área bajo protección privada (es decir, [u]n espacio geográfico claramente definido, reconocido, dedicado y gestionado, mediante mecanismos legales u otros tipos de medios eficaces para conseguir la conservación a largo plazo de la naturaleza y de sus servicios ecosistémicos y valores culturales asociados) es un área bajo gobernanza privada. Esto puede incluir gobernanza por parte de personas o grupos de personas; organizaciones no gubernamentales (ONGs); corporaciones, incluyendo empresas comerciales y pequeñas empresas establecidas para gestionar grupos de APPs; propietarios con fines de lucro, tales como empresas de ecoturismo; entidades de investigación, como universidades y estaciones de campo, o entidades religiosas. No todas las iniciativas de conservación llevadas a cabo por privados pueden o deben convertirse en APPs.

Las orientaciones están dirigidas principalmente a responsables del diseño de políticas públicas, o bien, profesionales que están o podrían estar vinculados con APPs, incluyendo:

- $\quad$ Propietarios de cualquier tipo:

a Personas o grupos de personas

a Organizaciones no gubernamentales (ONGs)

a Corporaciones, empresas comerciales y, en ocasiones, también corporaciones constituidas por grupos de propietarios privados para gestionar conjuntos de APPs

a Propietarios con fines de lucro

a Entidades de investigación (por ejemplo, universidades y estaciones de campo)

a Entidades religiosas

- Funcionarios de gobierno (agencias de gestión y autoridades legislativas y de política)

- Grupos de interés asociados (por ejemplo, ONGs para la conservación)

- Puntos focales de acuerdos internacionales (como el Convenio sobre la Diversidad Biológica).
Esta publicación brinda orientaciones sobre todos los aspectos relacionados con el establecimiento, la gestión y la entrega de reportes de APPs, e incluye principios y buenas prácticas con ejemplos extraídos de diversas partes del mundo. Tras la introducción (Parte A), la Parte B se centra en los temas principales que afectan a las APPs, los que están desarrollados por medio de una serie de buenas prácticas organizadas según los principios que las engloban. En la Parte C, se presenta una visión futura para las APPs y algunos objetivos de conservación globales. Finalmente, los principios y las buenas prácticas de la Parte $\mathrm{B}$ se abordan en mayor profundidad mediante una serie de estudios de casos (Parte D) que ilustran experiencias reales (ver Tabla 1).

El objetivo de estas directrices es encauzar la aplicación de la política y los principios de la UICN hacia resultados de conservación más eficaces, con foco en los gestores y administradores de APPs. Algunas de las orientaciones serán más aptas para administradores senior que establecen las condiciones regulatorias o legales de las APPs, mientras que otros aspectos serán más útiles para gestores de las áreas. En la Parte $\mathrm{B}$, el público objetivo se destaca al comienzo de cada sección. Es posible que no todas las orientaciones sean aplicables a todos los contextos sociales, políticos y económicos. No obstante, aprender de las mejores prácticas de otras partes del mundo y pensar en cómo aplicarlas a escala local o nacional puede, desde luego, dar luces sobre cómo mejorar las condiciones de las APPs, para capitalizar las oportunidades que ofrecen y, de este modo, aumentar las probabilidades de éxito de la conservación privada. Como parte de una larga serie de guías de la UICN sobre mejores prácticas en áreas protegidas, en su mayoría, estas directrices no repiten orientaciones universales para las áreas protegidas en general o cubiertas ya en otros volúmenes de esta serie. ${ }^{1}$

Tabla 1: Estudios de casos incluidos en estas directrices

\begin{tabular}{|c|c|c|c|c|c|c|c|c|}
\hline \multirow[t]{2}{*}{ Estudio de caso } & \multicolumn{8}{|c|}{ Subsecciones de la Parte B } \\
\hline & $\begin{array}{c}\text { Estableciendo } \\
\text { una APP }\end{array}$ & $\begin{array}{c}\text { Gestionando } \\
\text { una APP }\end{array}$ & $\begin{array}{l}\text { Incentivando } \\
\text { las APPs }\end{array}$ & $\begin{array}{l}\text { Garantizando } \\
\text { permanencia }\end{array}$ & $\begin{array}{l}\text { Subtipos } \\
\text { específicos } \\
\text { de APPs }\end{array}$ & $\begin{array}{c}\text { Coordinando } \\
\text { con sistemas } \\
\text { nacionales de } \\
\text { APs }\end{array}$ & $\begin{array}{l}\text { Registro } \\
\text { de APPs }\end{array}$ & $\begin{array}{c}\text { Redes } \\
\text { de } \\
\text { APPs }\end{array}$ \\
\hline \multicolumn{9}{|l|}{ 1. Australia } \\
\hline \multicolumn{9}{|l|}{ 2. Brasil } \\
\hline \multicolumn{9}{|l|}{ 3. China } \\
\hline \multicolumn{9}{|l|}{ 4. Costa Rica } \\
\hline \multicolumn{9}{|l|}{ 5. Alemania } \\
\hline \multicolumn{9}{|l|}{ 6. Kenia } \\
\hline \multicolumn{9}{|l|}{ 7. Nueva Zelanda } \\
\hline \multicolumn{9}{|l|}{ 8. Perú } \\
\hline \multicolumn{9}{|l|}{ 9. Samoa } \\
\hline \multicolumn{9}{|l|}{ 10.Sudáfrica } \\
\hline \multicolumn{9}{|l|}{ 11. EE. UU. } \\
\hline 12. Reino Unido & & & & & & & & \\
\hline
\end{tabular}




\section{¿Qué es un área bajo protección privada?}

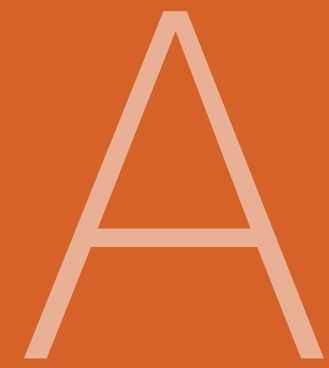

- arencer cocende

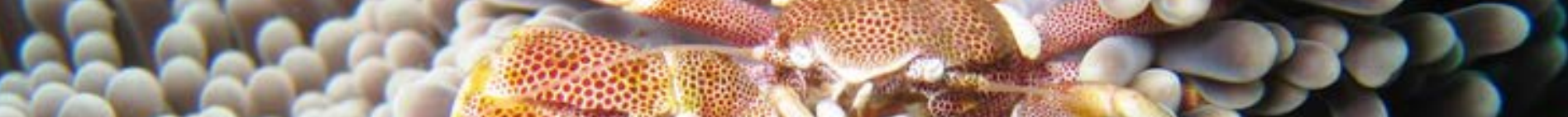

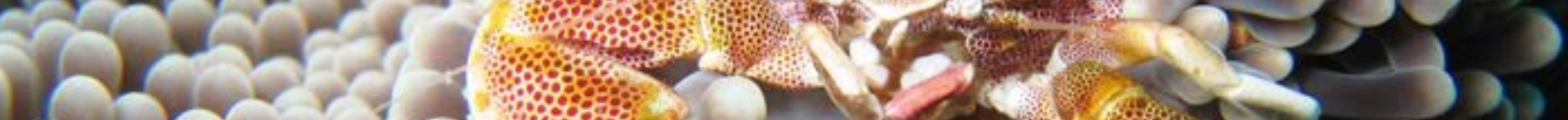

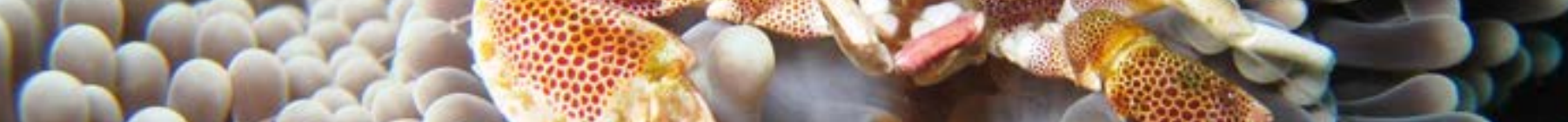

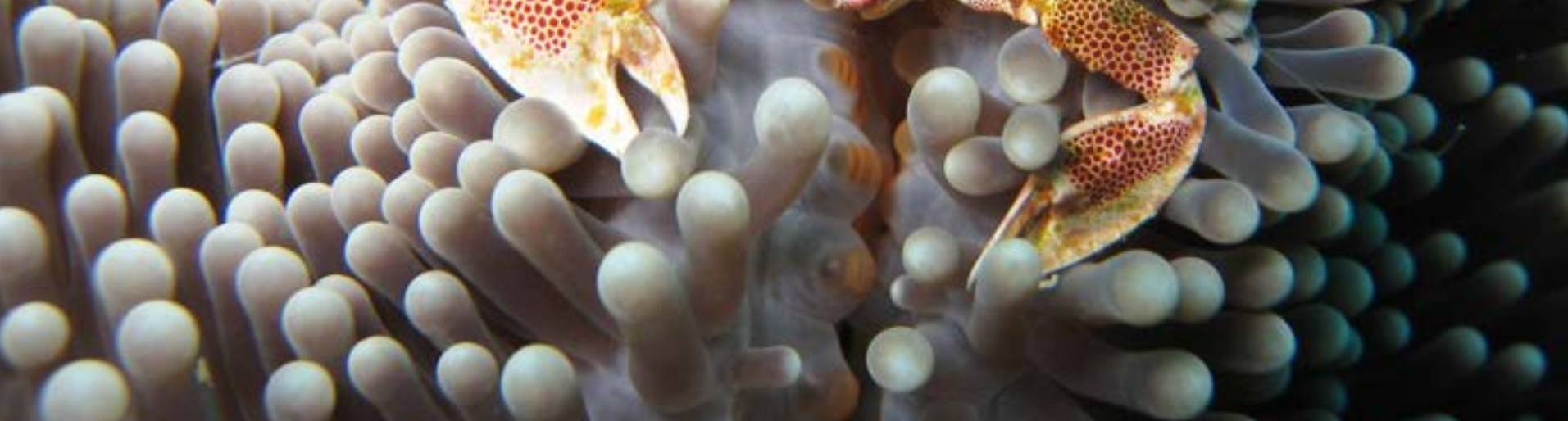

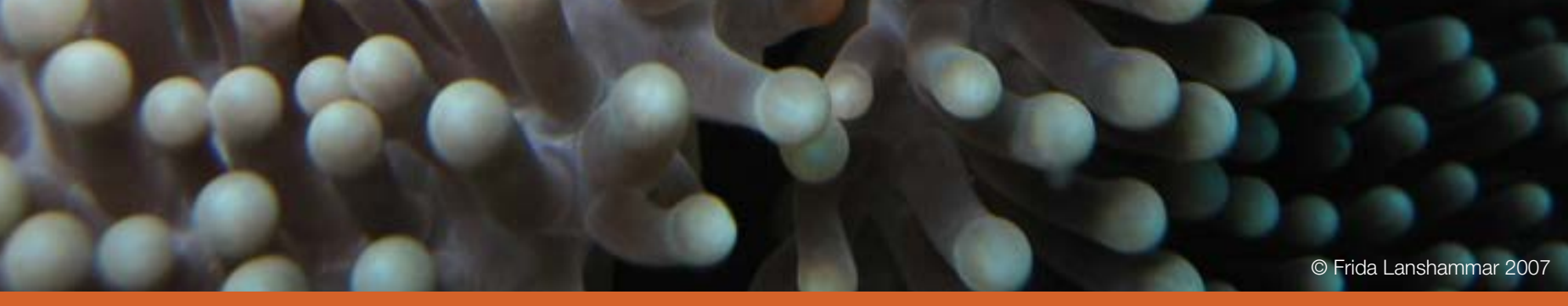




\section{Entendiendo las áreas protegidas}

La UICN ha pasado varias décadas intentando definir el concepto (Dudley, 2008): "Un espacio geográfico claramente definido, reconocido, dedicado y gestionado, mediante mecanismos legales u otros tipos de medios eficaces para conseguir la conservación a largo plazo de la naturaleza y de sus servicios ecosistémicos y valores culturales asociados". En esta definición se declara de forma patente que la conservación de la naturaleza es la función principal de las áreas protegidas, lo cual se recalca por medio de un principio asociado que indica: "Para la UICN, solo aquellas áreas en las que el objetivo principal es la conservación de la naturaleza pueden considerarse áreas protegidas; se pueden incluir muchas áreas con otros objetivos al mismo nivel, pero en caso de conflicto la conservación de la naturaleza será la prioridad". Pese a que en cada país su aplicación es voluntaria, esta definición ha sido respaldada por los miembros de la UICN por medio de la resolución (WCC-2012Res-040-SP: Aprobación y aplicación uniforme de directrices para la gestión de áreas protegidas) y las decisiones del Convenio sobre la Diversidad Biológica (CDB); entre ellas, la Decisión VII/28, que reconoció "el valor de un único sistema de clasificación internacional de áreas protegidas".

El Centro Mundial de Vigilancia de la Conservación (UNEPWCMC, por su acrónimo en inglés) es el organismo encargado de recopilar los datos sobre las áreas protegidas

\section{Cuadro A1 \\ ¿Cuál es la diferencia entre gestión y gobernanza?}

En el contexto de un área protegida, la gestión se refiere a lo que se realiza para lograr ciertos objetivos (es decir, las acciones y los medios utilizados para alcanzar dichos objetivos); mientras que la gobernanza se refiere a las personas o entidades que deciden cuáles serán esos objetivos, qué harán para conseguirlos y a través de qué medios. Algunos ejemplos de decisiones que se toman desde la gobernanza pueden incluir:

- El establecimiento de un área privada

- El objetivo a largo plazo (visión) del área protegida

- El objetivo principal de manejo

- El modo en que se relacionarán los objetivos con el sustento y desarrollo local

- El modo en que se sancionará un plan o sistema de gestión

- Decidir quién implementará la gestión

- Garantizar los recursos humanos y financieros para alcanzar los objetivos

- Establecer de qué modo el imperio de la ley y las legislaciones internacionales más amplias (incluyendo los derechos humanos y de los pueblos indígenas) se deben respetar y cumplir (Borrini-Feyerabend et al., 2013). de todo el mundo, además de administrar la Base de Datos Mundial de Áreas Protegidas (WDPA) junto con la UICN (UNEP-WCMC, 2017).

De acuerdo con la definición de la UICN, las áreas protegidas se agrupan en cuatro tipos de gobernanza, basados en los derechos de tenencia y, por consiguiente, en los derechos de las personas para ejercer el poder de decisión sobre un área y sus recursos (ver Tabla 2). Estos cuatro tipos comprenden la gobernanza por parte del gobierno, la gobernanza compartida, la privada y la de pueblos indígenas y comunidades locales. En algunos casos, donde los derechos de tenencia no están claros o se superponen debido a motivos históricos, son disputados o no se han reconocido oficialmente, la gobernanza se puede conducir de facto por actores locales particulares, aunque los derechos legales o consuetudinarios de gobernanza pueden ser de jure (BorriniFeyerabend et al., 2013).

Las mejores prácticas discutidas en estas directrices están enfocadas en la 'gobernanza privada' y en situaciones donde los acuerdos de gobernanza compartida incluyen un elemento de gobernanza privada (Borrini-Feyerabend et al., 2013). Para proporcionar una mayor comprensión y apreciación de este tipo de área protegida, el Grupo de Especialistas en Áreas Bajo Protección Privada y Gestión de la Naturaleza de la Comisión Mundial de Áreas Protegidas (CMAP) de la UICN desarrolló el informe técnico, Áreas bajo protección privada: Mirando al futuro (Stolton et al., 2014). Su definición de APP fue confirmada en una Resolución de la UICN (ver Cuadro 1.5): "un área bajo protección privada es un área protegida, según lo define la UICN, bajo gobernanza privada (es decir, personas y grupos de personas); organizaciones no gubernamentales (ONGs); corporaciones, tanto compañías comerciales existentes como, en ocasiones, corporaciones establecidas por grupos de propietarios privados con el fin de administrar grupos de APPs; propietarios con fines de lucro; entidades de investigación (es decir, universidades, estaciones de campo) o entidades religiosas", o de modo más sucinto: los territorios terrestres o marinos gestionados para la conservación bajo gobernanza privada pueden constituir una APP solo si se trata de un área protegida tal como lo define la UICN y si, además, su gobernanza es privada.

De un total de seis categorías de gestión, la UICN le asigna una o más a las áreas protegidas, dependiendo de sus objetivos. Estas categorías de gestión van desde la protección más estricta hasta aquellas que permiten múltiples usos del área. La gobernanza privada se puede aplicar a cualquiera de las seis Categorías de Gestión de Áreas Protegidas de la UICN. La Tabla 2 permite visualizar la matriz de categorías de áreas protegidas y tipos de gobernanza según los define la UICN.

En la práctica, no todas las áreas encajan perfectamente en las categorías y hay muchas instancias de gobernanza compartida que involucran una gobernanza privada en combinación con otras clases de gobernanza, dependiendo del contexto legal e institucional de conservación de 


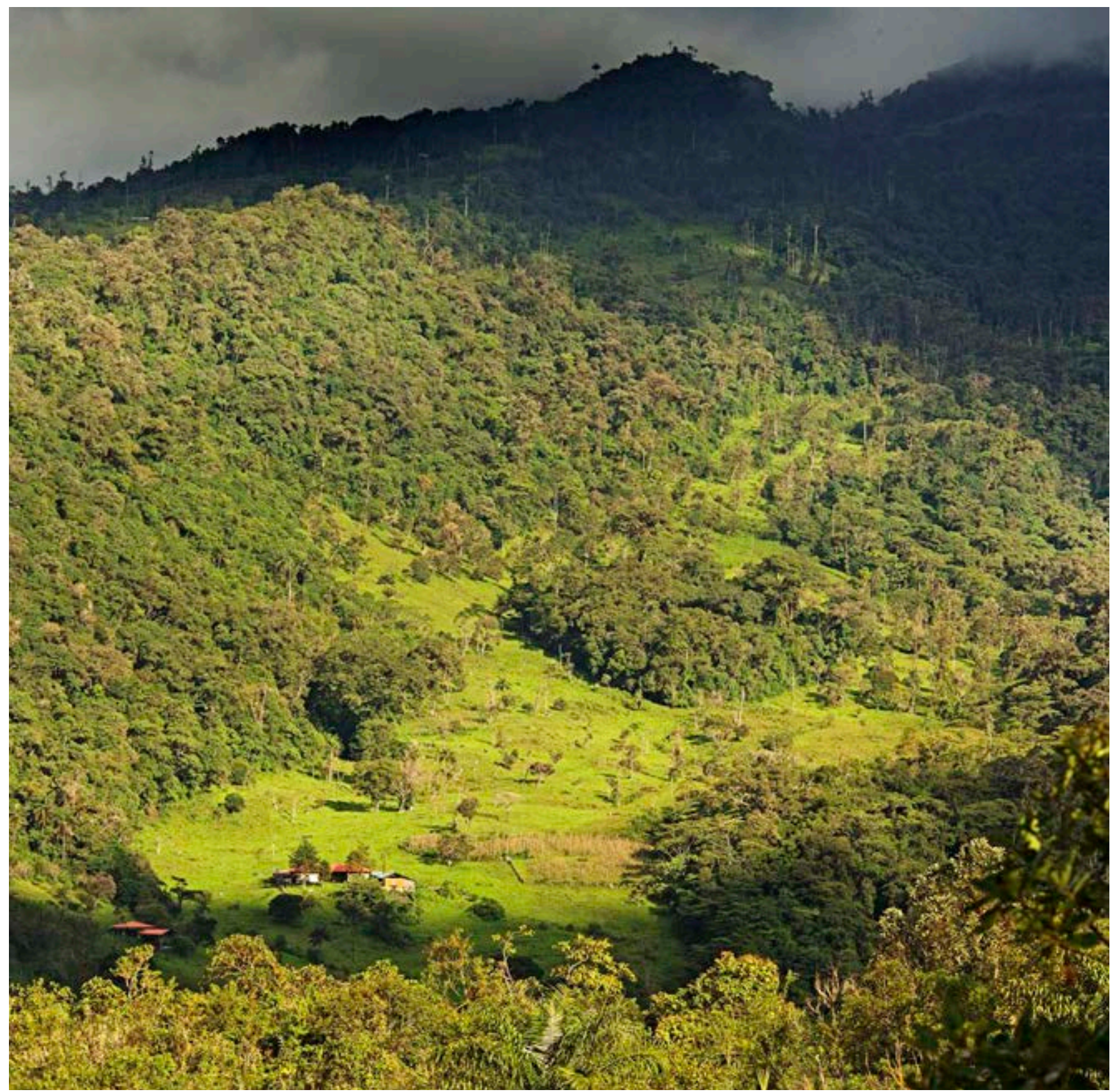

La APP Bosque Berlín, ubicada en Amazonas, Perú, es un hábitat que alberga al choro de cola amarilla (Lagothrix flavicauda), una especie endémica y en peligro crítico. Conservamos por Naturaleza realizó una campaña de crowdfunding para recaudar 10.000 dólares con el fin de ayudar a su dueño a comprar tierras colindantes para aumentar la conectividad del paisaje @ @ Walter $\mathrm{H}$. Wust

cada país. Las distinciones no siempre son precisas o permanentes. Algunas APPs pasan a manos del gobierno voluntariamente; esto sucedió recientemente con una gran APP en Chile. ${ }^{2}$ Otras están sujetas a políticas de Estado que determinan la gestión. Además, cuando propietarios privados se agrupan para conformar juntos un área privada, no siempre queda claro si esta simplemente conforma una APP o si es un área protegida de la comunidad local. La gobernanza compartida también puede ser compleja, y en su ejercicio puede surgir falta de claridad sobre el poder de toma de decisiones entre las diferentes partes interesadas. Las áreas protegidas más grandes a veces contienen múltiples tipos de gobernanza. Por ejemplo, la Tallgrass Prairie National Preserve, ${ }^{3}$ con una superficie de 4.408 hectáreas (ha), se estableció en 1996, en Flint Hills, del estado de Kansas,
EE. UU., como parte del Sistema Nacional de Parques de aquel país. El Sistema Nacional de Parques gestiona la propiedad junto con la ONG The Nature Conservancy (TNC), un patrón bastante común en todo el mundo. No obstante, casi toda la tierra es propiedad de un socio privado, un patrón de propiedad opuesto al de la mayoría de los acuerdos de gobernanza compartida. La Tallgrass Prairie National Preserve se inclina fuertemente hacia ser una APP. Asimismo, hay muchos ejemplos en los que un área presenta tanto características de una APP como de una gestionada por pueblos indígenas y comunidades locales (conjuntamente denominadas Indigenous and Community Conserved Areas, ICCA, en inglés), dependiendo de los derechos de tenencia y el tipo de gobernanza que tengan las áreas de este último tipo. En algunos países, como Perú, la legislación 


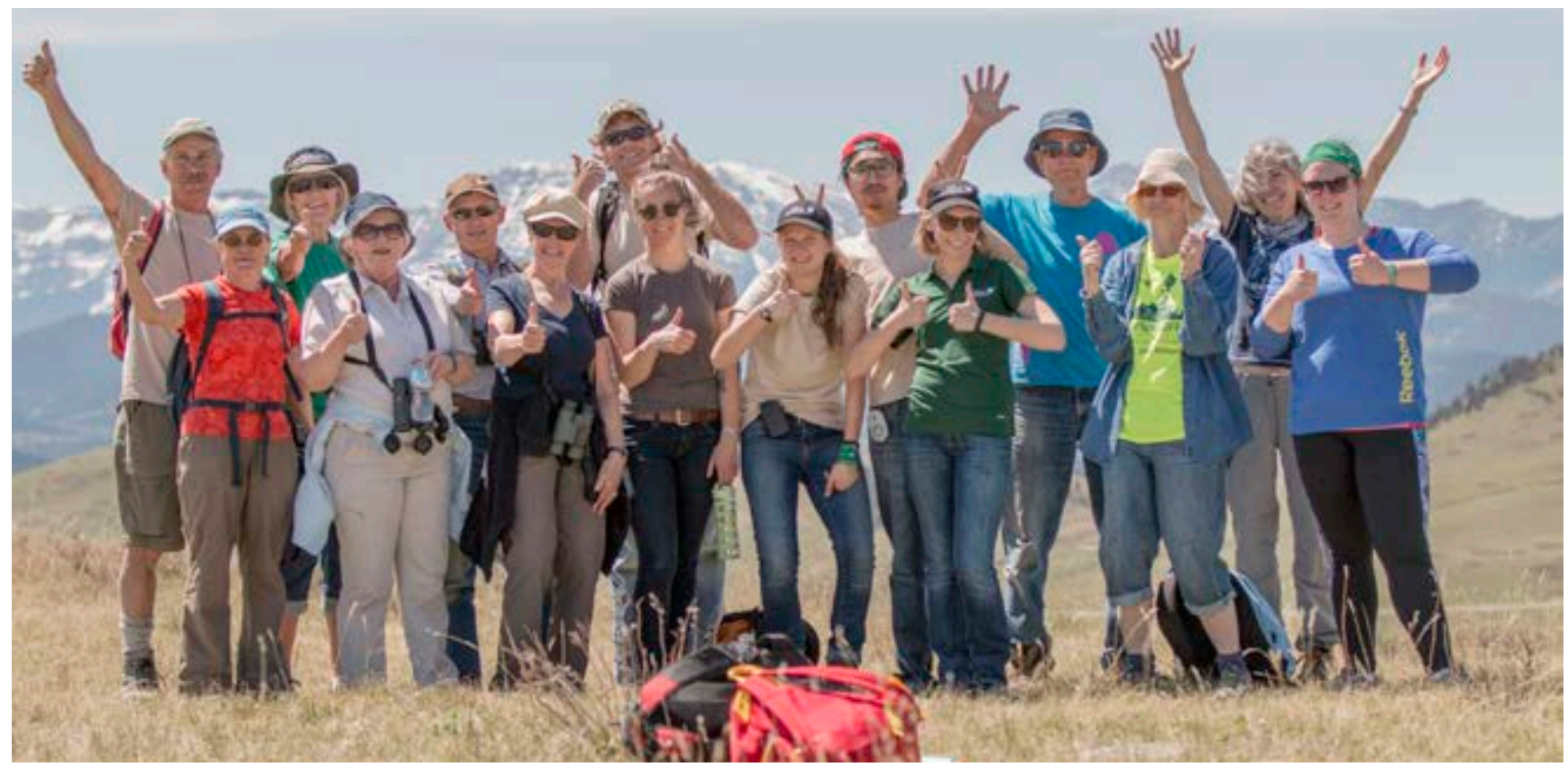

Algunos de los muchos voluntarios de The Nature Conservancy of Canada en el Waldron Conservation Project, Alberta @ NCC

no hace distinción entre las áreas protegidas privadas e indígenas. La Tabla 3 resume algunas de las distinciones discutidas anteriormente.

\section{¿Qué no clasifica como APP?}

El tipo de gobernanza de las APPs no pretende incluir todos los esfuerzos de conservación privados, sino distinguir aquellos que coinciden con la definición de área protegida de la UICN. Hay muchos tipos de iniciativas privadas que pueden contribuir a la conservación, pero que no clasificarían como una APP según esta descripción (por ejemplo, Fitzsimons, 2015; Mitchell et al., 2018). Los tipos de territorios terrestres/marinos conservados por privados que pueden estar en el límite (de la definición) incluyen, por ejemplo, algunas estancias de vida silvestre en Sudáfrica, Namibia y Kenia, donde la caza intensiva de animales está estrechamente relacionada con prácticas agrícolas comerciales e involucra campamentos internos cercados, corrales de engorde y eliminación de depredadores.

Aquellos lugares donde la conservación natural no es el objetivo principal no serían considerados APPs. Asimismo, las operaciones forestales responsables pueden conservar hábitats clave, luchar contra la caza furtiva y albergar especies amenazadas, sin embargo, en general no se consideran APPs si la conservación no es su objetivo principal (ver Parte B, Sección 1).

\section{¿Por qué son importantes las APPs?}

A la fecha, la gran mayoría de áreas protegidas se ha establecido en territorios terrestres y marinos públicos. A pesar de estos esfuerzos, un número importante de ecorregiones tiene poca representación en la red global de áreas protegidas. De este modo, muchos de los lugares más significativos para la biodiversidad (y geodiversidad) se localizan fuera de las áreas protegidas formales (Dinerstein et al., 2017) y en tierras privadas, comunales o de pueblos indígenas. Por ejemplo, las Áreas Importantes para las Aves y Biodiversidad (IBAs, por su sigla en inglés) en Sudáfrica, abarcan más de 14 millones de ha, lo que equivale a un 11,6\% de la superficie terrestre del país. Más de un $60 \%$ de esta superficie terrestre no está protegida formalmente y corresponde mayoritariamente a tierras privadas (Marnewick et al., 2015).

A pesar de que existen miles de APPs en el mundo (Bingham et al., 2017), y se siguen estableciendo otras nuevas, continúan siendo un recurso bastante escondido; algunos gobiernos las ignoran y, a veces, incluso son omitidas por mecanismos de registro de conservación internacionales, además de ser marginadas de estrategias de conservación regionales (Stolton et al., 2014). El reconocimiento de esfuerzos de conservación privados y el establecimiento de nuevas APPs a menudo pueden llenar importantes vacíos en los sistemas nacionales de áreas protegidas en términos de cobertura geográfica, representación ecológica y protección de hábitats y especies en peligro de extinción. En comparación con los largos procesos gubernamentales de designación de áreas protegidas, la compra o donación de territorios terrestres y marinos realizada por personas con frecuencia puede significar mayor velocidad de respuesta frente los desafíos de conservación (Pasquini et al., 2011). Además, también atraen a una amplia variedad de partes interesadas en los esfuerzos de conservación, lo que permite que, por un lado, ciudadanos privados contribuyan directamente en iniciativas de conservación, por medio de procesos surgidos desde las bases, y que, por otro, las entidades privadas colaboren en pos del bien común. 
Tabla 2: 'La matriz de áreas protegidas de la UICN': Categorías de áreas protegidas según tipo de gestión y gobernanza (Dudley, 2008)

\begin{tabular}{|c|c|c|c|c|c|c|c|c|c|c|c|}
\hline \multirow[b]{2}{*}{$\begin{array}{l}\text { Categorías de } \\
\text { áreas protegidas }\end{array}$} & \multicolumn{3}{|c|}{$\begin{array}{l}\text { A. Gobernanza por } \\
\text { parte del gobierno }\end{array}$} & \multicolumn{3}{|c|}{$\begin{array}{l}\text { B. Gobernanza } \\
\text { compartida }\end{array}$} & \multicolumn{3}{|c|}{ C. Gobernanza privada } & \multicolumn{2}{|c|}{$\begin{array}{l}\text { D. Gobernanza de } \\
\text { pueblos indígenas y } \\
\text { comunidades locales }\end{array}$} \\
\hline & 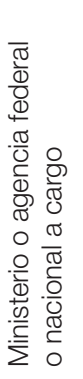 & 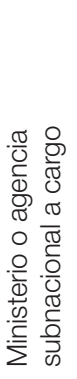 & 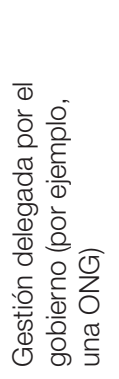 & 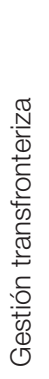 & 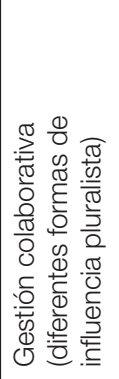 & 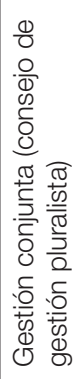 & 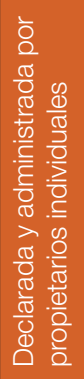 & 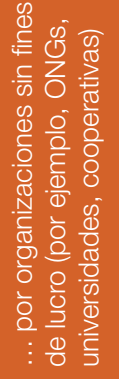 & 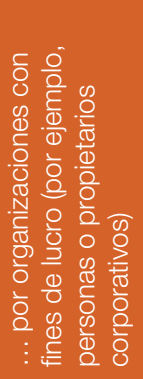 & 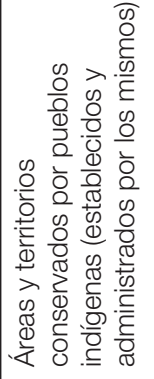 & 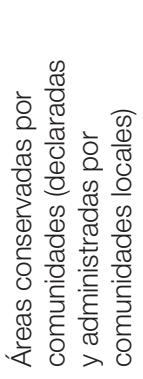 \\
\hline \multicolumn{12}{|l|}{$\begin{array}{l}\text { la. Reserva natural } \\
\text { estricta }\end{array}$} \\
\hline \multicolumn{12}{|l|}{ Ib. Área silvestre } \\
\hline \multicolumn{12}{|l|}{ II. Parque nacional } \\
\hline \multicolumn{12}{|l|}{ III. Monumento natural } \\
\hline \multicolumn{12}{|l|}{$\begin{array}{l}\text { IV. Gestión de hábitat/ } \\
\text { especies }\end{array}$} \\
\hline \multicolumn{12}{|l|}{$\begin{array}{l}\text { V. Paisaje terrestre/ } \\
\text { marino protegido }\end{array}$} \\
\hline $\begin{array}{l}\text { VI. Área protegida de } \\
\text { recursos gestionados }\end{array}$ & & & & & & & & & & & \\
\hline
\end{tabular}

Tabla 3: Resumen de criterios para distinguir a las APPs de otras APs bajo distintos tipos de gobernanza (adaptado de Stolton et al., 2014)

\begin{tabular}{|c|c|}
\hline Criterio de APP & Subcriterio \\
\hline Área protegida & $\begin{array}{l}\text { - El área se designa legalmente y gestiona según la definición y los principios asociados de la UICN. } \\
\text { - } \\
\text { El área se gestiona según la definición y los principios asociados de la UICN, y aunque no esté designada } \\
\text { legalmente, es reconocida como una APP. }\end{array}$ \\
\hline $\begin{array}{l}\text { Entidades privadas } \\
\text { involucradas }\end{array}$ & $\begin{array}{l}\text { - Persona o grupos de personas, ONGs, corporaciones, propietarios con fines de lucro, entidades de } \\
\text { investigación o religiosas. }\end{array}$ \\
\hline Gobernanza & $\begin{array}{l}\text { - } \quad \text { El propósito principal del área es la conservación de la naturaleza. } \\
\boldsymbol{Y} \\
\text { - } \quad \text { Los gestores de las APPs están al tanto de cualquier derecho de uso fuera de su control y deben realizar } \\
\text { esfuerzos por garantizar que dichos usos no afecten los objetivos generales de conservación. }\end{array}$ \\
\hline Permanencia & $\begin{array}{l}\text { - El área es designada legalmente a la protección permanente de la conservación de la naturaleza } \\
\text { (por ejemplo, leyes). } \\
\text { - } \quad \text { La designación a la conservación de la naturaleza se realiza mediante un acuerdo permanente } \\
\text { (por ejemplo, acuerdo de conservación o servidumbre). } \\
\text { - } \quad \text { La designación a la conservación de la naturaleza se realiza mediante un acuerdo renovable con el propósito } \\
\text { de permanencia (por ejemplo, acuerdo de conservación o servidumbres de plazo definido). } \\
\text { - El compromiso a largo plazo/permanencia está declarado de modo explícito en los contratos, estatutos } \\
\text { jurídicos, memorandos de entendimiento, objetivos y planes del área y se refleja en la política y el mecanismo } \\
\text { financiero del propietario. }\end{array}$ \\
\hline
\end{tabular}




\section{Cuadro A2}

\section{¿Cuáles son las características de la gobernanza privada?}

La gobernanza privada de la naturaleza surge bajo sistemas de tenencia que otorgan derechos sobre una propiedad a propietarios privados (ver Glosario para más información sobre este término en relación con todos los sistemas de tenencia). Estos derechos pueden materializarse, por ejemplo, mediante un título o un arrendamiento a largo plazo. El propietario tiene derecho a la ocupación exclusiva y al uso del área, de asignar o ceder estos derechos a otros por medio de un arrendamiento u otros acuerdos, junto con vender o enajenar la propiedad a los sucesores del título. Por consiguiente, los propietarios pueden ser:

- Una persona o personas que posean el título o arrendamiento de una propiedad

- Una organización constituida legalmente que posea la propiedad o cuente con un contrato de arrendamiento, incluyendo ONGs, asociaciones de dueños de propiedades, organizaciones de custodia de tierras y fundaciones

- Una empresa o corporación que posea una propiedad/arrendamiento acorde a las leyes bajo las que se establecen empresas en la jurisdicción, incluyendo empresas sin fines de lucro, comerciales o con fines de lucro.

A su vez, estos propietarios pueden arrendar o delegar las responsabilidades de gobernanza o gestión a otros, incluyendo a los actores privados descritos anteriormente. Usualmente, los propietarios tienen el derecho de determinar el uso de la tierra, incluso, con fines de conservación de la naturaleza. Esto puede implicar el establecimiento de un área como APP tal como lo define la UICN o en términos de la legislación relevante en la jurisdicción, lo que, por su parte, puede permitir la designación del área como APP o zona de planificación del uso de tierra limitado a la conservación de la naturaleza. Por el contrario, los derechos de los propietarios pueden ser restringidos por las leyes prevalecientes de planificación de uso de tierra, las que regulan el tipo de actividades que pueden ser llevadas a cabo en la propiedad privada.

La rendición de cuentas relacionada con el área, las actividades ejecutadas en ella y los impactos sobre propiedades aledañas es responsabilidad de los propietarios. Se suele suponer que la conducción de actividades de conservación está, generalmente, a cargo de los propietarios, aunque el reconocimiento oficial de este uso de tierra, y los costos y beneficios asociados, pueden estar sujetos a una legislación específica para la conservación de la naturaleza o del patrimonio.

Para que un área de propiedad privada sea designada o declarada como APP, debe cumplir con los requerimientos de área protegida según la definición de la UICN, o bien, según las leyes equivalentes, incluyendo una declaración

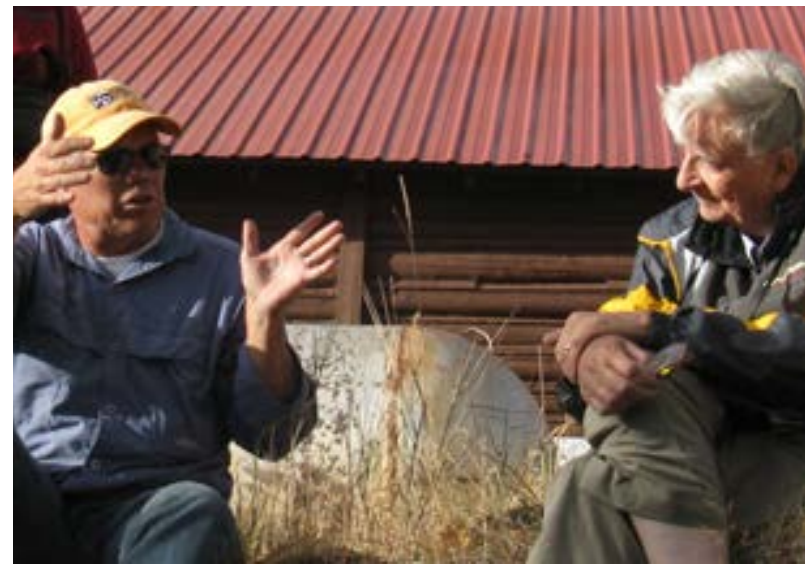

Mike Phillips y E.O. Wilson conversando sobre proyectos de conservación para especies en peligro en el Flying $D$ Ranch, un área de conservación privada de 46.000 ha, ubicada en el suroeste de Montana, EE. UU., de propiedad de R.E. (Ted) Turner ( ) Turner Endangered Species Fund

escrita que explicite la intención de realizar una gestión de conservación a largo plazo. Alcanzar este grado de permanencia, por lo general, requiere de un instrumento vinculante para los sucesores actuales y futuros del título a largo plazo. Este instrumento puede ser una declaración de intención, compromiso, contrato, estatuto jurídico, acuerdo de conservación, servidumbres a favor de la conservación de la naturaleza sobre la escritura de la propiedad, un memorando de entendimiento u otro instrumento específico (ver Tabla 3). Las múltiples opciones para establecer permanencia se discuten en mayor detalle en la Parte B, Sección 4, mientras que los diversos instrumentos para el establecimiento de APPs, tanto por medio de la declaración voluntaria, como con el apoyo de legislación relevante, se detallan en los Estudios de casos, en la Parte D.

Por su parte, los dueños de la propiedad y, por consiguiente, los signatarios del acta de fundación pueden organizarse para ejercer sus responsabilidades. Esto se puede realizar mediante un directorio, una junta directiva, un comité u otro tipo de entidad de composición, poderes y deberes particulares, que, a la vez, puede asignar, participar, contratar, delegar o comisionar la gestión cotidiana del área a un equipo compuesto por voluntarios o empleados, $u$ otra agencia de gestión contratada. La responsabilidad de gobernanza no ha de ser confundida con la de llevar a cabo la gestión cotidiana. Sin embargo, debido a que la agencia de gestión a menudo es el representante público de la APP, en la práctica, suele haber confusión, especialmente cuando la misma entidad o personas asumen tanto la gobernanza como la gestión. En estos casos, es necesario entender sobre quién recae la responsabilidad legal y moral final de la APP, lo que constituye un factor de los acuerdos específicos de gobernanza privada (Borrini-Feyerabend et al., 2013).

Autor: Trevor Sandwith, UICN 

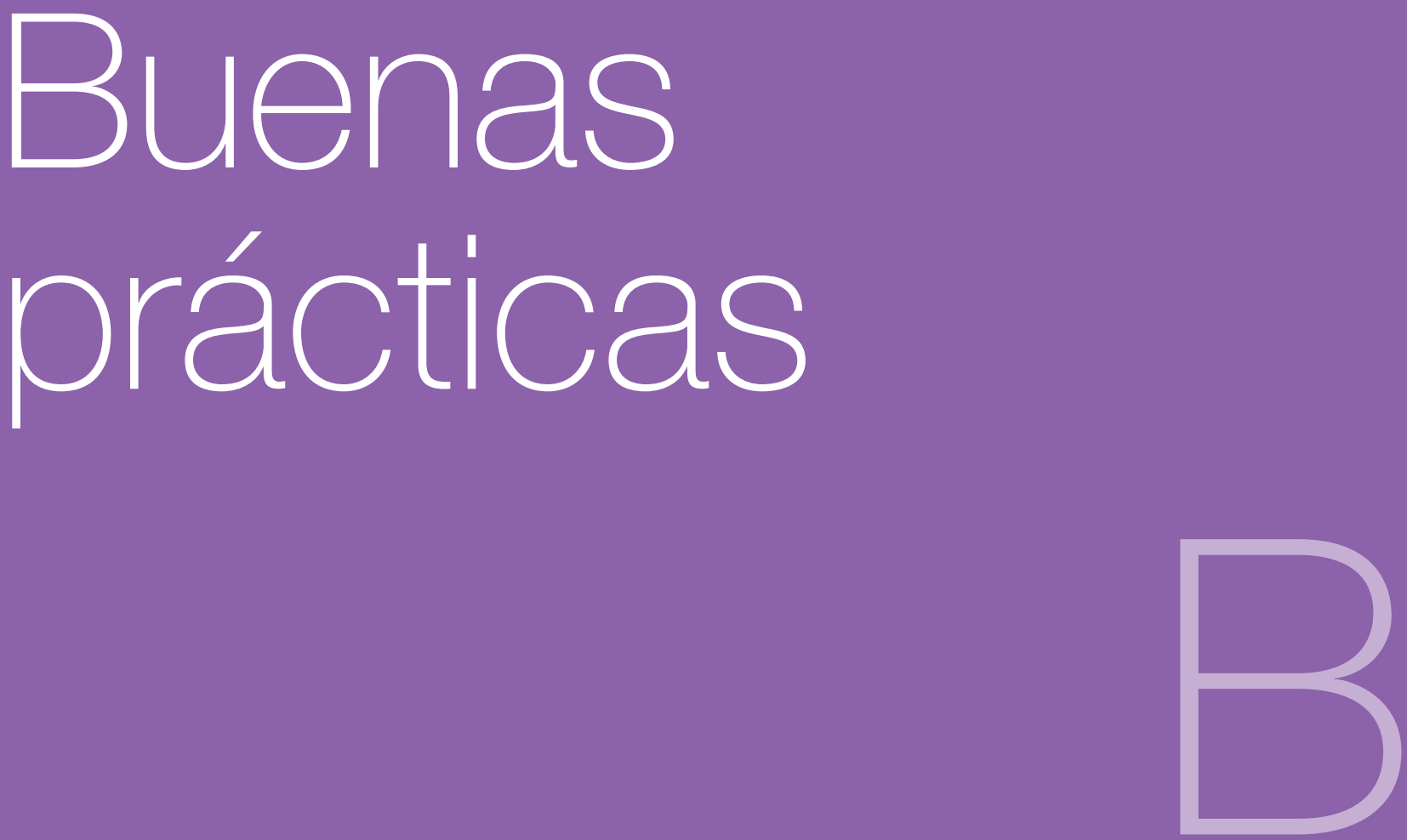

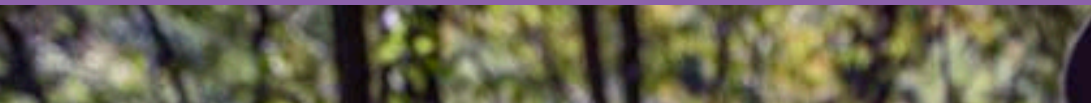

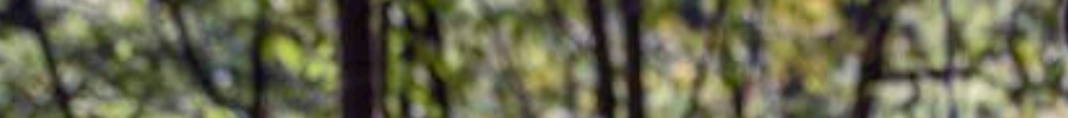

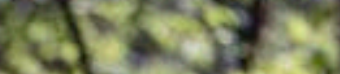
$\sin ^{2} \rightarrow \sin ^{2}$ $7 x^{2}+30$

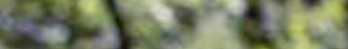

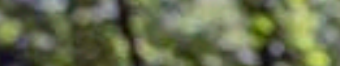
pirs 3its $x$

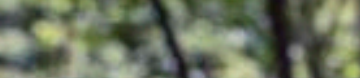
arosid: as $x=8$

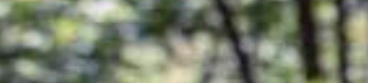
$\operatorname{sen}(x+1) \sin 3$ cos at comat espell

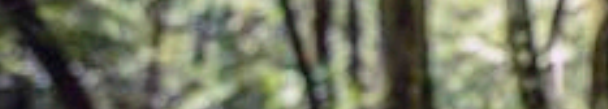
is

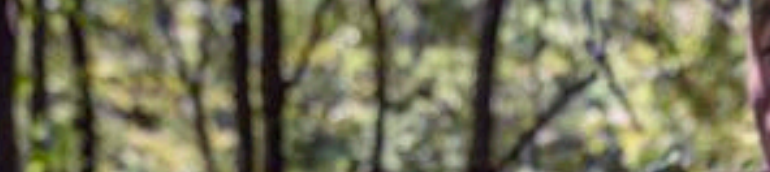
a: $\{x \mid$

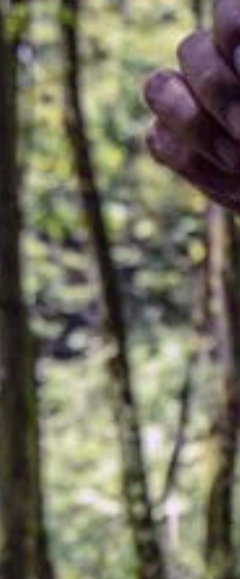

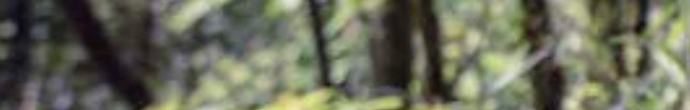
tores 1013

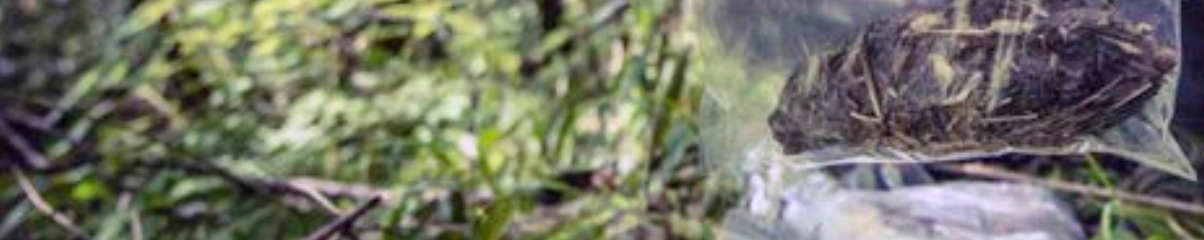

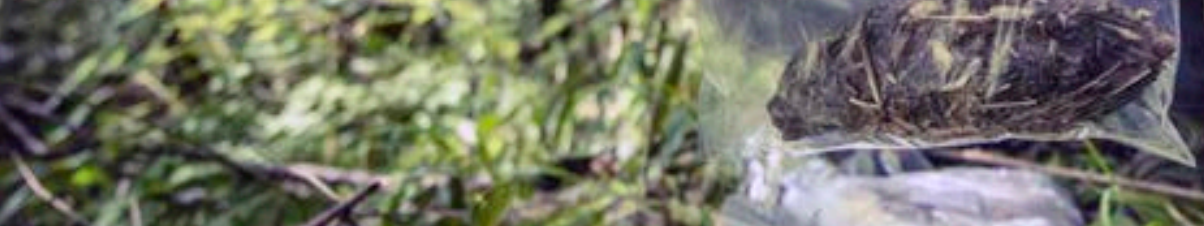
1.

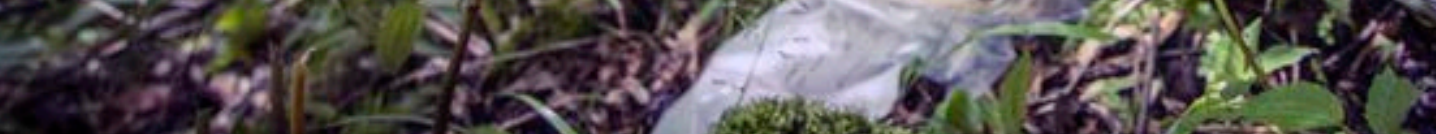

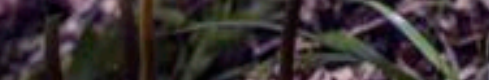
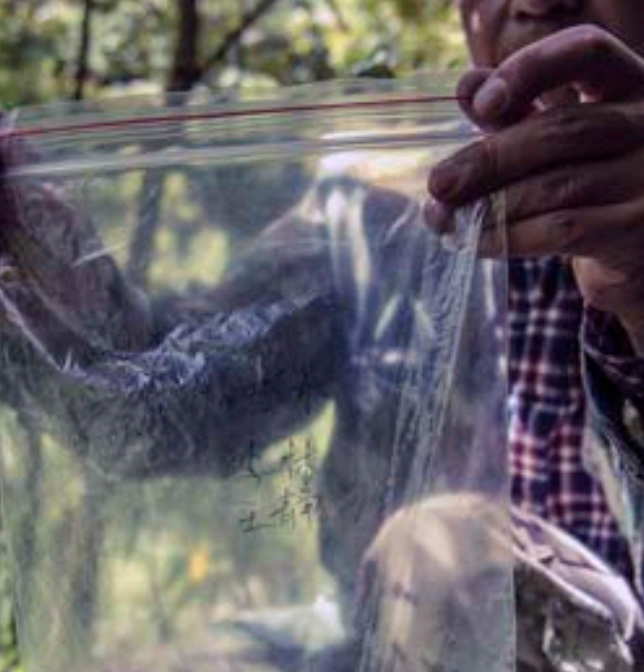

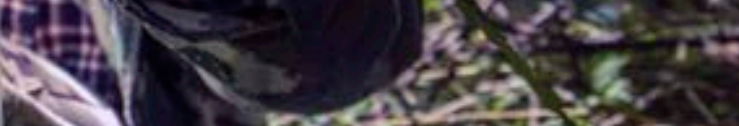
2.

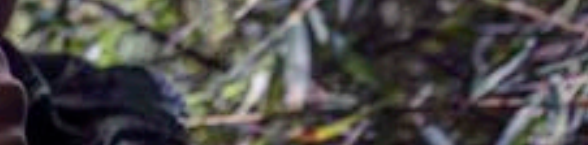

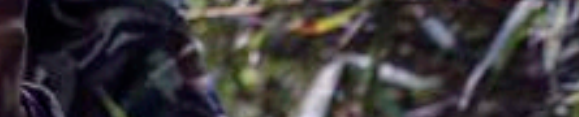

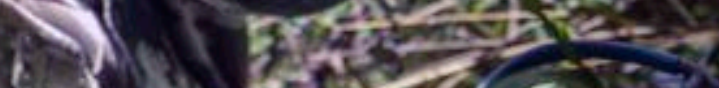

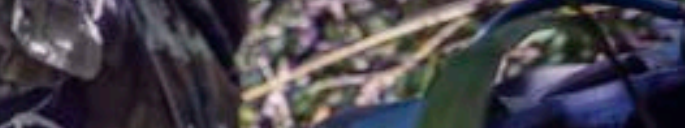
is

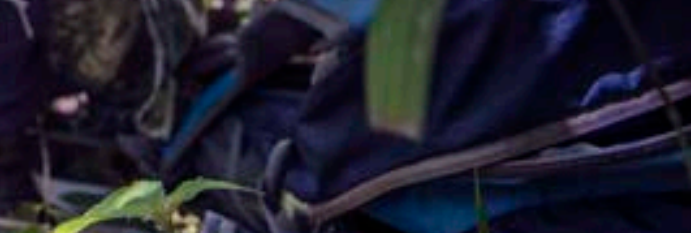




\section{Sección 1: Establecimiento de áreas bajo protección privada}

\section{¿Hacia quién está dirigida esta sección?}

Hacia cualquier persona vinculada con el establecimiento o la gestión de una APP, ya sean propietarios o autoridades gubernamentales encargadas de colaborar en el establecimiento de APPs. Cabe precisar que, pese a que no todas las buenas prácticas aquí presentadas podrán aplicarse a todos los tipos y tamaños de APPs, estos ejemplos, extraídos de experiencias de todo el mundo, sí ofrecen orientaciones sobre algunos de los aspectos más importantes en el establecimiento de una APP.

Una parte importante de desarrollar buenas prácticas en el establecimiento de APPs es entender la variedad de razones que motivan a las personas a crearlas. En cierto sentido, el establecimiento de una APP se asemeja al de otros tipos de áreas protegidas, pero hay diferencias clave. Las APPs pueden establecerse, y usualmente así es, unilateralmente por un solo individuo; otras pueden involucrar grandes grupos de personas (por ejemplo, trabajadores de empresas u órdenes religiosas), u organizaciones (por ejemplo, ONGs) a menudo con una cantidad numerosa de miembros voluntarios. Estas directrices contienen ejemplos de APPs establecidas por distintos grupos.

Los propietarios tienen diversas motivaciones para desarrollar una APP. Si bien estas pueden responder a incentivos y catalizadores externos (ver Sección 3), la experiencia y la investigación (por ejemplo, Farmer et al., 2011; Leménager et al., 2014; Selinske et al., 2015; Farmer et al., 2016) indican que para muchas personas las razones principales son personales e intrínsecas, suelen ser complicadas y abarcan desde el altruismo hasta creencias espirituales o religiosas. Los mecanismos para el reconocimiento y establecimiento de una APP, en tanto, varían dependiendo de los marcos legales y normativos de cada país (o la ausencia de los mismos) (Mitchell, 2005). Las APPs se establecen voluntariamente, y esta sección describe algunas de las condiciones y los catalizadores comunes que este proceso suele conllevar.

\section{Principio 1.1: Una APP debe cumplir con la definición de área protegida}

Para ser reconocida internacionalmente por la UICN y, luego, registrada en el Centro de Monitoreo de la Conservación Mundial del Programa de las Naciones Unidas para el Medio Ambiente (UNEP-WCMC) (ver Sección 7), una APP debe cumplir con la definición de área protegida de la UICN (ver Parte A). En otras palabras, el objetivo principal debe ser la conservación de la naturaleza. Las áreas que no cumplen con la definición no son áreas protegidas y, en ese sentido, las áreas privadas no difieren de las gubernamentales. Las áreas que no cumplen con la definición pero que contribuyen eficaz y permanentemente a la conservación pueden categorizarse como otras medidas efectivas de conservación basadas en áreas (OMECs), tal como se presentan en la Meta 11 de Aichi para la Biodiversidad del Convenio sobre la Diversidad Biológica (CDB) (Jonas et al., 2014; Mitchell et al., 2018; Jonas et al., 2018) (ver Apéndice 1).

\section{Buena práctica 1.1.1: Las APPs deben ser reconocidas oficialmente por una entidad fiable}

A menudo el reconocimiento proviene del gobierno (ver Caso 1 de Australia y 7 de Nueva Zelanda, junto con Buena práctica 1.2.1), lo que resulta altamente deseable si la información sobre el área ha de ser entregada a la Base de Datos Mundial de Áreas Protegidas (WDPA) por medio de canales oficiales (ver Sección 7). No obstante, esta no es la única opción, a veces los propietarios de APPs deciden no vincularse con procesos estatales diseñados específicamente para el reconocimiento de APPs (Clements et al., 2018). Así, el reconocimiento independiente también puede ser otorgado por organizaciones internacionales como la UICN (ver Caso 12 del Reino Unido y Buena práctica 7.1.8) o redes de APPs regionales/nacionales/locales (ver Sección 8). Cualquier entidad de reconocimiento debe ser independiente del propietario, es decir, el reconocimiento no puede ser autootorgado. Pueden hacerse excepciones en caso de tierras bajo dominio pleno de ONGs de conservación, siempre y cuando cuenten con algún tipo de acreditación que demuestre su misión y función. Contar con múltiples partes en un acuerdo de APPs puede aumentar la seguridad de la protección.

Buena práctica 1.1.2: El reconocimiento independiente de terceros puede operar en paralelo al reconocimiento gubernamental de una APP

La UICN y el Centro Mundial de Vigilancia de la Conservación (UNEP-WCMC) están estableciendo un sistema para mejorar el registro de APPs en la WDPA, en paralelo a los procesos gubernamentales y utilizando a expertos independientes (para más detalles, ver Sección 7 y Caso 4 de Costa Rica). Se pueden establecer sistemas similares a escala nacional (Bingham et al., 2017). 
Buena práctica 1.1.3: Los programas de certificación pueden otorgar reconocimiento adicional a una APP

El reconocimiento no siempre es lo mismo que la certificación. El reconocimiento puede certificar el cumplimiento de los requerimientos legales mínimos. La certificación va más allá. Mide la gestión y la gobernanza de un modo más detallado, por medio de evaluaciones periódicas. Una certificación de terceros suele acreditar el cumplimiento de un área, negocio o producto respecto de estándares específicos de desempeño (ver Buena práctica 2.4.3). A la vez, asegura la transparencia y brinda seguridad, permitiendo al público, a las autoridades y a otras partes interesadas (incluyendo el gobierno) confiar en que los objetivos declarados se están cumpliendo. Algunos modelos útiles para APPs incluyen: el reconocimiento del Global Ecosphere Retreats (ver Cuadro 8.3), la Lista Verde de Áreas Protegidas y Conservadas de la UICN (LVAPC) (ver Cuadro 1.1) y los Land Trust Alliance Standards and Practices (ver Cuadro 8.2).

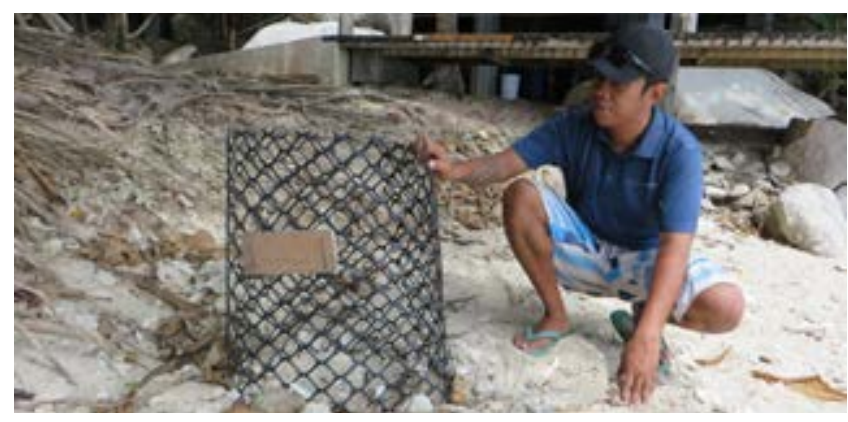

Construcción de nidos de tortugas en uno de los sitios miembros de The Long Run (c) Nikoi Island, Indonesia

\section{Cuadro 1.1}

\section{Lista Verde de Áreas Protegidas y Conservadas de la UICN}

El Programa Lista Verde de Áreas Protegidas y Conservadas de la UICN ${ }^{4}$ tiene como objetivo incentivar y lograr el establecimiento de áreas protegidas y conservadas, eficaces, equitativas y exitosas en el cumplimiento de los resultados de conservación. El Estándar de la Lista Verde, aprobado por el Consejo de la UICN en noviembre de 2017, se organiza sobre la base de cuatro componentes que reflejan una conservación de la naturaleza exitosa en áreas protegidas y conservadas. Los componentes base son:

- Buena gobernanza

- Diseño y planificación pertinente

- Gestión eficaz

- Resultados de conservación exitosos

El Manual de Usuario5 (IUCN WCPA, 2016) describe: cómo se desarrolló el Estándar de la Lista Verde de la UICN; el programa de apoyo; cómo se evalúan las áreas protegidas de acuerdo con el Estándar, por medio de un conjunto de indicadores adaptados, y cómo se verifican el cumplimiento de las reglas y los procedimientos del Manual. El Caso 6 de Kenia es un ejemplo de la forma en que se ha aplicado la Lista Verde en una APP.

\section{Principio 1.2: Los propietarios y gestores de APPs deben articular objetivos de conservación claros desde el inicio}

Las razones para establecer APPs son diversas, y es importante que los propietarios de las APPs (y titulares de servidumbres y acuerdos de conservación) articulen objetivos de conservación de manera clara al inicio del proyecto (Buena práctica 2.2.1). Por ejemplo, las ONGs para la conservación - como los land trusts - pueden enfocarse en áreas específicas y particularmente importantes para la biodiversidad u otros valores de conservación. Por el contrario, puede que los propietarios decidan proteger su propiedad por motivos personales, sin importar su prioridad en la estrategia nacional. En otros casos, los conservacionistas pueden movilizarse para adquirir y proteger parcelas de tierra bajo amenaza de cambio de uso de tierra. No obstante, todos deben ser capaces de demostrar su intención de conservación, independientemente de los otros usos que le puedan dar a la tierra (ver Principio 1.1 y Cuadro 1.2).

\section{Cuadro 1.2 \\ Apoyando la conservación y el desarrollo económico en Sudáfrica}

Las áreas protegidas sudafricanas bajo programas provinciales de gestión de la biodiversidad ofrecen una serie de actividades económicas y comerciales, dependientes del nivel de restricciones de protección y uso de la tierra prescritos. Frente a este escenario, el Business Case for Biodiversity Stewardship (SANBI, 2015) presenta argumentos sólidos a favor del establecimiento de APPs por medio de programas de gestión de la biodiversidad, para estimular el crecimiento o sostenibilidad rural a través de una economía basada en la vida silvestre. Como resultado, las APPs en Sudáfrica suelen apoyar actividades vitales y económicamente sostenibles, aun cuando su objetivo principal es la conservación.

Ubicado en las praderas del noreste del Estado Libre, el Sneeuberg Nature Reserve ${ }^{6}$ declaró la conservación de la naturaleza como su fin último, mientras que su uso de suelo lo destinó a ganadería. Si bien las APPs en Sudáfrica requieren de un plan de manejo que incorpore aspectos como la administración de praderas y la rehabilitación del hábitat, estos objetivos también permiten a los propietarios realizar actividades económicas en la tierra, siempre y cuando sean compatibles con su condición de APP. Por ejemplo, el plan de manejo de Sneeuberg incluye tanto gestión ambiental de praderas y humedales, como la producción comercial de alimentos. Además, ha propulsado el desarrollo económico del turismo local basado en la observación de aves. Este modelo facilita una conservación eficaz de la naturaleza y, a la vez, brinda sustento y desarrollo económico, basados en la vida silvestre, la seguridad alimentaria y la participación en el sector agrícola, lo que contribuye significativamente al producto interno bruto de Sudáfrica.

Autor: Daniel Marnewick, BirdLife South Africa 
Buena práctica 1.2.1: En caso de ser posible, al establecer una APP y desarrollar sus objetivos de manejo, se recomienda conectarlos al sistema nacional o subnacional de conservación de la naturaleza

La mayoría de los países cuenta con Estrategias y Planes de Acción Nacionales en Materia de Diversidad Biológica $(E P A N D B)^{7}$ y otros instrumentos de planificación, los que suelen incluir algún grado de priorización para el establecimiento de nuevas áreas protegidas, por ejemplo, la identificación de ecosistemas subrepresentados en áreas protegidas. De existir, dichas prioridades deben orientar el establecimiento de metas de la APP, particularmente en el caso de las ONGs de conservación que adquieren tierra con tales propósitos o que priorizan el establecimiento de acuerdos de conservación/ servidumbres. Los gobiernos pueden facilitar este proceso. En México, por ejemplo, el reconocimiento formal de una APP requiere de la existencia de un plan de manejo que demuestre la importancia biológica del área en el contexto del Sistema Nacional de Áreas Protegidas (SINAP) y la participación de todas las partes interesadas (Hora et al., 2018). En los EE. UU., las agencias de gobierno proporcionan lineamientos estratégicos a las organizaciones que están estableciendo y gestionando una APP, muchas de las cuales adoptan prioridades alineadas con las estrategias identificadas por el gobierno (ver Cuadro 1.3). Sudáfrica cuenta con orientaciones similares (ver Caso 10). En Australia, el financiamiento gubernamental para la adquisición de una APP está vinculado con las biorregiones prioritarias (ver Caso 1). La Red Natura 2000 de la Unión Europea también opera así (ver Cuadro 1.4).

\section{Cuadro 1.3 \\ BioMap: Mapeo de prioridades para adquisición de terrenos en el estado de Massachusetts, EE. UU.}

La Mancomunidad de Massachusetts, EE. UU., y The Nature Conservancy llevaron a cabo ejercicios de mapeo exhaustivos para identificar:

- Hábitats para especies raras, vulnerables o poco comunes

- Comunidades naturales prioritarias

- Hábitats de humedales, estanques vernales, costeros

- Ecosistemas de bosques intactos

- Los bloques de paisaje más grandes en cada una de las ocho ecorregiones y las zonas de altura aledañas que amortiguan los hábitats de humedales, acuáticos y costeros.

El ejercicio identificó más de un millón de hectáreas de importante biodiversidad a lo largo de todo el estado. Desde 2010, el BioMap ha establecido las prioridades de las subvenciones gubernamentales para la adquisición de tierras de conservación y, como resultado, la mayoría de los land trusts han alineado sus estrategias con las del BioMap (Commonwealth of Massachusetts y The Nature Conservancy, 2010).

Autor: Brent Mitchell, QLF

\section{Cuadro 1.4 \\ Estrategias regionales de conservación de la naturaleza en la Unión Europea}

Mediante la definición de hábitats y especies de importancia para Europa, y la formulación de metas para alcanzar un estatus de conservación favorable, la Red Natura 2000 de la Unión Europea identifica prioridades de conservación de carácter continental. Estas, luego, se implementan a escala nacional y regional, por medio de programas de trabajo locales, prioridades (Marco de Acción Prioritaria) y financiamiento. Todas las grandes ONGs europeas que adquieren, poseen o gestionan tierras de conservación utilizan sus listas, metas y mapas de distribución para afinar sus propios programas de trabajo. El programa LIFE, dirigido por la Comisión Europea, otorga hasta un 75\% de cofinanciamiento a las ONGs de conservación, y a otras entidades privadas, como asociaciones de agricultores o silvicultores o empresas comerciales privadas (siempre y cuando puedan garantizar de forma apropiada que puede acceder a experticia en gestión científica) que desean adquirir tierra con hábitats/especies importantes en Europa con el fin de establecer una APP (Tasos et al., 2014).

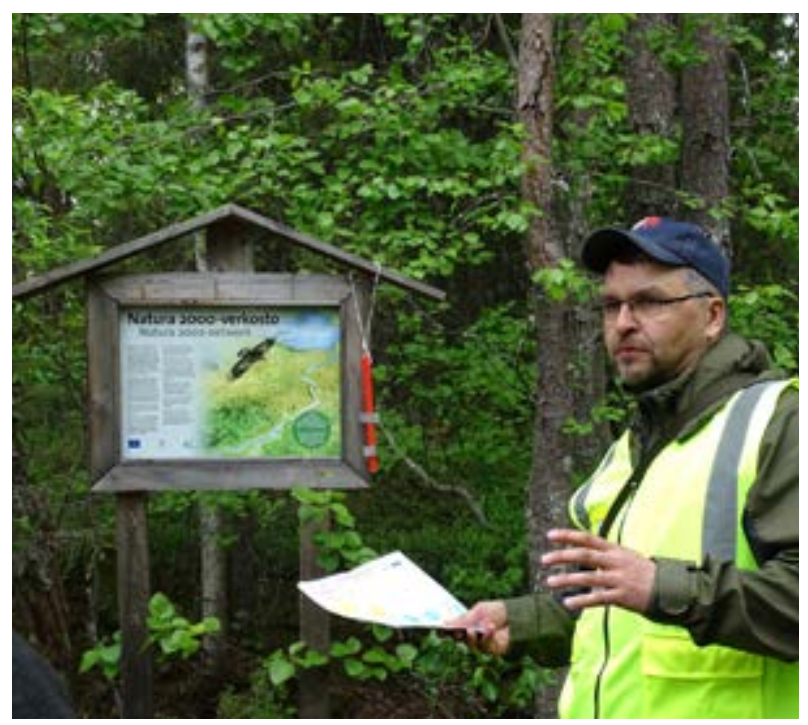

Sendero natural Kätkävaara, Finlandia @ Sue Stolton

Buena práctica 1.2.2: Cuando no existen prioridades nacionales, o están incompletas, los ejercicios de priorización de conservación reconocidos internacionalmente pueden ayudar a determinar el establecimiento de una APP

Ante la carencia de prioridades nacionales, los procesos de priorización reconocidos internacionalmente pueden ayudar a definir el establecimiento de una APP. Por ejemplo, las Áreas Clave para la Biodiversidad (ACB) son sitios que contribuyen significativamente a la persistencia global de la biodiversidad (UICN, 2016). Las áreas califican como ACB si cumplen con uno o más de los 11 criterios, agrupados en cinco categorías: biodiversidad amenazada, biodiversidad geográficamente restringida, integridad ecológica, procesos biológicos y carácter 
irremplazable. Los criterios de las ACB pueden aplicarse a especies y ecosistemas en ambientes terrestres, de agua dulce y marinos, además de contribuir a identificar sitios prioritarios para el establecimiento de una APP. La asociación de las ACB está compuesta por numerosas organizaciones de conservación, incluyendo la UICN. La Base de Datos Mundial de las ACB ${ }^{8}$ proporciona información sobre la ubicación (ver Cuadro 2.3). Las Áreas Importantes para las Aves y la Biodiversidad (IBAs, por su sigla en inglés) se basan en un concepto similar y se han desarrollado y aplicado por más de 30 años. ${ }^{9}$

Buena práctica 1.2.3: Si bien los gobiernos deben incentivar el establecimiento de APPs en áreas que forman parte de las prioridades nacionales o subnacionales, no deben excluir el establecimiento de APPs en áreas consideradas de menor prioridad

El mundo está experimentando rápidos cambios, cuyos resultados aún no se comprenden a cabalidad. Gran parte de la planificación de conservación, realizada hasta ahora, está sujeta a ser sobrepasada por los efectos del cambio climático, irrupciones repentinas de especies invasoras, o simplemente por alguna especie no registrada que se ha desplazado al área inesperadamente. Contar con un área protegida lo más amplia posible puede ser esencial para el futuro éxito de la conservación, y del manejo adaptativo, además de contribuir a la conectividad y conservación en general. Así, las personas o entidades pueden elegir priorizar la adquisición de tierras donde los precios de suelo sean relativamente baratos (como en Chile, donde hay pocas APPs en zonas de alta prioridad, como las áreas mediterráneas de alto costo; pero hay más APPs en zonas de baja prioridad, como las áreas patagónicas que son de bajo costo). Alternativamente, pueden escoger lugares donde el rendimiento económico tiene mayor potencial, como el caso de reservas privadas de caza en algunas partes de Sudáfrica. Los datos sobre factores humanos y sociales (por ejemplo, la voluntad de participar de un propietario) pueden ser tan importantes para la identificación de una APP como las prioridades de conservación (Knight et al., 2010, 2011), al igual que la información sobre los mecanismos de apoyo disponibles (Pence et al., 2003; Wilson et al., 2007).

\section{Principio 1.3: Las APPs se desarrollan mejor dentro de un marco institucional claro y de apoyo que empodere la gobernanza y la gestión}

El establecimiento de una APP se vuelve más expedito cuando las naciones y regiones cuentan con condiciones sociales y los marcos institucionales son favorables (ver Caso 10 de Sudáfrica y los Cuadros 1.2, 1.3 y 1.4). Estos no solo incluyen la legislación específica concerniente al establecimiento de una APP, sino que también un amplio apoyo para la gestión en desarrollo, incentivos financieros seleccionados cuidadosamente (ver Sección 3), alguna clase de auditoría e instituciones para el aprendizaje social.

\section{Cuadro 1.5}

\section{Mandatos internacionales para las APPs}

Párrafo 2 de la decisión XII/19 de la Conferencia de las Partes del CDB del 2014 (UNEP/CDB/COP/DEC/XII/19 17 de octubre 2014): "Reconoce la contribución de las áreas protegidas privadas, además de las áreas públicas y conservadas por comunidades indígenas y locales, a la conservación de la diversidad biológica, y alienta al sector privado a que continúe desplegando esfuerzos para proteger y gestionar de forma sostenible los ecosistemas para la conservación de la diversidad biológica".

A partir de esta afirmación, una resolución del Congreso Mundial de la Naturaleza 2016 de la UICN (WHC2016-036 "Apoyando a las áreas bajo protección privada") anima a los Estados Miembros de la UICN a:

a) adoptar políticas que reconozcan, incentiven y monitoreen las áreas bajo protección privada como una contribución clave para las metas de conservación nacionales e internacionales, y también a implementar mecanismos para integrar las áreas bajo protección privada a los sistemas nacionales, provinciales y locales de áreas protegidas;

b) crear o promover incentivos legales y financieros, incluso por medio de una reforma legal según corresponda, para la mantención y el fortalecimiento de las áreas bajo protección privada, particularmente en países donde existen restricciones o ambigüedad en la legislación nacional; $y$

c) trabajar en conjunto con organizaciones de la sociedad civil para establecer en la agenda pública la importancia de la conservación voluntaria de tierras privadas, sobre la base del concepto de subsidiaridad del sector privado, no gubernamental, en las políticas nacionales para la conservación (UICN, 2016b).

Buena práctica 1.3.1: El reconocimiento internacional de las APPs puede apoyar su establecimiento y reconocimiento

Tanto el CDB como la UICN han respaldado un mayor desarrollo de APPs a través de decisiones recientes (ver Cuadro 1.5). Otras convenciones internacionales (por ejemplo, Ramsar, ${ }^{10}$ Patrimonio de la Humanidad ${ }^{11}$ y el Programa sobre el Hombre y la Biosfera ${ }^{12}$ ) pueden otorgar un reconocimiento internacional muy necesario para APPs pioneras.

Buena práctica 1.3.2: Las APPs individuales pueden convertirse en modelos que incentiven un mayor desarrollo de otras APPs

Hay veces en que tan solo se necesita a una persona u organización pionera que establezca una APP para dar inicio a todo un movimiento (ver Cuadros 1.6, 1.7, 1.8 y 5.5 y los Casos 3 de China, 4 de Costa Rica, 6 de Kenia y 9 de Samoa). Así, en Perú, la Reserva Ecológica de Chaparrí13 fue establecida en 2001. En ese entonces, resultó ser un proyecto innovador que inspiró, por un lado, al gobierno a desarrollar regulaciones apropiadas y, por otro, a los propietarios a crear nuevas APPs (Solano y Wust, 2005). 


\section{Cuadro 1.6}

\section{Caucasus Wildlife Refuge: Una APP precursora en Armenia}

En 2010, la Fundación para la Preservación de la Vida Silvestre y los Bienes Culturales ${ }^{14}$ (FPWC, por su sigla en inglés) estableció el Caucasus Wildlife Refuge ${ }^{15}$ (CWR, por su sigla en inglés) en Armenia. Actualmente, el CWR protege 20.000 ha que abarcan desde áreas semidesérticas hasta praderas alpinas y, además, brinda un lugar seguro a una serie de animales en peligro de extinción y raros del Cáucaso Sur y Europa del Este. La tierra para el refugio es arrendada por la FPWC a comunidades de las regiones de Ararat y Vayots Dzor. El arrendamiento dura 25 años, aunque en algunos casos las comunidades han donado tierra para la conservación a perpetuidad. La CWR es el único proyecto de este tipo en todo el Cáucaso Sur. El refugio se estableció como un proyecto de APP ejemplar, en que se entrelazan la participación de la comunidad local, la educación, el ecoturismo y la conservación de la naturaleza. El objetivo general de la CWR es contribuir a la protección eficiente de la biodiversidad en Armenia, por medio de la mejora de la conservación de la flora y fauna en las zonas de amortiguamiento y los corredores de migración de vida silvestre de la reserva, cuya gestión antes era insostenible.

El éxito del modelo ya es visible. La FPWC mantiene una estación permanente de guardaparques, operada por seis funcionarios provenientes de la propia comunidad. Los guardaparques patrullan el área continuamente para prevenir cualquier tipo de actividad ilegal y, también, para monitorear a los animales. Luego, la información se ingresa a una base de datos, a partir del cual se crea un mapa en SIG del área. Esto permite tener una mirada detallada del rango de especies, hábitats sensibles y corredores de vida silvestre importantes. Mientras que en 2010 la vida silvestre en el área era casi inexistente, principalmente debido a la caza ilegal, ahora las cámaras trampa, ubicadas por toda la CWR, muestran un significativo número de animales raros o de la Lista Roja, incluyendo a la cabra bezoar (Capra aegagrus), el oso pardo (Ursus arctos), la víbora de Armenia (Vipera raddei) y el quebrantahuesos (Gypaetus barbatus), al igual que especies comunes como el lince caucásico (Lynx dinnik), el martes, el tejón, el lobo gris, el zorro y la liebre. En el verano de 2013, unas cámaras trampa grabaron a un leopardo persa macho (Panthera pardus saxicolor) dentro de la APP. Este éxito de la CWR le ha permitido a la FPWC planear una expansión de las APPs hacia importantes áreas de conservación en los bordes sur de Armenia (Röttger et al., 2016).

Autor: Vicky Mkrtchyan, Fundación para la Preservación de la Vida Silvestre y los Bienes Culturales

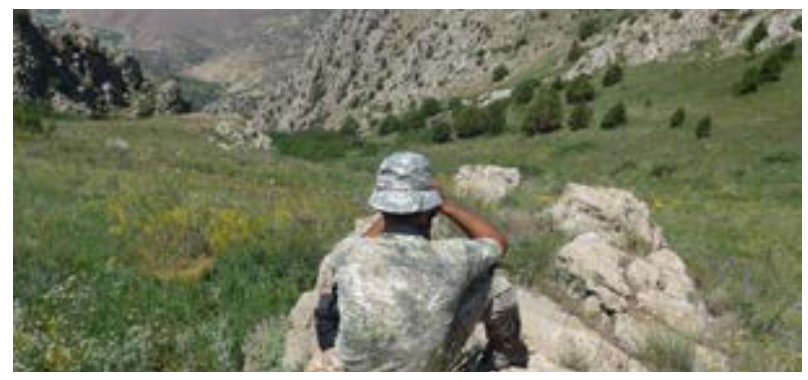

El Caucasus Wildlife Refuge @ Sue Stolton

\section{Principio 1.4: Las APPs pueden ser establecidas a través de una variedad de mecanismos}

Los enfoques para el establecimiento de APPs (Lausche, 2011) incluyen:

1. El propietario acuerda/establece voluntariamente un área protegida formal, conservando la titularidad de las mismas y ejerciendo responsabilidades de gestión conforme a los objetivos de conservación fijados y a la categoría correspondiente de área protegida (ver Caso 6 de Kenia y 10 de Sudáfrica).

2. El propietario cede voluntariamente al gobierno determinados derechos legales de uso de la propiedad privada con el fin de preservar ciertos valores de conservación, manteniendo la propiedad del bien y el derecho a desarrollar otros usos no vinculados a la conservación, pero compatibles con esta (por ejemplo, mantener una vivienda). En ocasiones se ceden ciertos derechos sobre un bien particular a cambio de derechos para utilizar y explotar una propiedad adyacente o de otro tipo, o de incentivos tales como la reducción de impuestos sobre la propiedad para compensar por la pérdida teórica de valor de otro potencial de producción. Los mecanismos para este enfoque incluyen servidumbres (también denominada servidumbre ecológica o ambiental en algunos países), acuerdos de conservación continua (es decir, la restricción está vinculada a la propiedad, no al propietario, y por tanto, permanece en efecto, incluso si hay cambio de dueño) y acuerdos de manejo (ver Caso 1 de Australia, Caso 2 de Brasil y Caso 7 de Nueva Zelanda).

3. Una ONG, entidad de investigación o religiosa recibe fondos de beneficencia o recaba fondos del sector privado o público para adquirir, arrendar o gestionar la tierra donada para la protección y conservación (ver Caso 3 de China y Caso 5 de Alemania).

4. Una ONG, entidad de investigación o religiosa o una organización con fines de lucro compra o dona territorios terrestres o marinos y luego vende esta propiedad a otro propietario privado después de haber establecido un acuerdo de conservación sobre el título (por ejemplo, un fondo rotativo o acuerdo de conservación) (ver Caso 4 de Costa Rica).

5. Una corporación con fines de lucro adquiere o gestiona directamente un área de conservación con el fin de generar ganancias por medio de actividades compatibles con la conservación, como el turismo (ver Caso 8 de Perú).

6. Una corporación con fines de lucro asigna, dona o gestiona directamente un área de conservación, con el objetivo de crearse una buena imagen pública, o bien, en concepto de concesión o compensación por el ejercicio de otras actividades. Las motivaciones pueden traducirse en el interés de obtener un certificado ecológico para un proyecto conexo de urbanización o explotación, o bien, el deseo de hacer una inversión a futuro (ver Caso 9 de Samoa).

7. Una organización con fines de lucro, ONG o entidad de investigación, por medio de un acuerdo contractual con los gobiernos o las comunidades locales, crea un área vedada a extracción marina o lacustre por medio del llamado Acuerdo de Conservación Marina (ACM), y gestiona directamente esta área para la conservación, la investigación o para generar ganancias a partir de actividades compatibles como el turismo (ver Cuadro 1.7 y ACM \& Cl, 2012). 
Estos mecanismos no deben ser vistos o implementados de manera aislada. Al contrario, una buena práctica implica encontrar 'combinaciones de mecanismos óptimas' que maximicen el beneficio de conservación por un esfuerzo o costo mínimo (Young et al., 1996). Además, las condiciones determinadas para el establecimiento de APPs no siempre resultan suficientes para proteger el área en el largo plazo y, por tanto, pueden requerir mecanismos adicionales para la custodia a largo plazo con el fin de asegurar que el área cumpla con la definición de una APP.

\section{Buena práctica 1.4.1: Los mecanismos para establecer una APP no deben menoscabar otros derechos legítimos a tierras o recursos}

Es importante que los propietarios de APPs (o posibles propietarios futuros) se encarguen de la diligencia debida, para garantizar que la adquisición de áreas para el establecimiento de la APP no menoscabe los derechos legales o consuetudinarios de terceros. Confiar en la información manejada por los Estados o registros de tierra suele ser insuficiente $y$, usualmente, se requiere una investigación mayor. Los futuros propietarios deben conocer los posibles derechos de acceso tradicionales y aplicar los principios del Consentimiento Previo, Libre e Informado (FAO, 2017) al tratar con las comunidades locales y sus derechos. También es importante determinar si la APP podría desfavorecer los distintos derechos de acceso a recursos específicos, sitios espirituales o rutas de acceso, y que los propietarios de APPs consulten a las comunidades cuando se planeen intervenciones que pudiesen restringir aquellos derechos. Donde corresponda, los propietarios deben respetar la Declaración de las Naciones Unidas sobre los Derechos de los Pueblos Indígenas (ONU, 2007) y estar informados acerca de las políticas de la UICN, las que pueden ayudar a garantizar las buenas prácticas, incluyendo: WCC 2016 Resolución 30, "Reconocimiento y respeto de los territorios y áreas conservadas por pueblos indígenas y comunidades locales (ICCA) que se superponen con las áreas protegidas", ${ }^{16}$ WWC 2008 Resolución 38 "Reconocimiento y Conservación de los sitios naturales sagrados en áreas protegidas"17 y WWC 2012 Recomendación 147 "Sitios naturales sagrados - Apoyo a los protocolos para su custodia y al derecho consuetudinario frente a las amenazas y desafíos globales". ${ }^{18}$

\section{Buena práctica 1.4.2: La gobernanza privada suele establecerse por medio de la propiedad de la tierra pero existen otros mecanismos posibles}

Las APPs pueden establecerse en tierras arrendadas, siempre que estas tengan como propósito ser de largo plazo y renovables (ver Caso 3 de China y Cuadro 1.7). Los arrendamientos pueden pasar a múltiples propietarios, pero el objetivo de conservación debe permanecer. Por ejemplo, en Tanzania, la Reserva Grumeti se creó por el gobierno en 1994, principalmente, con el fin de proteger la ruta de migración anual de los ñus (Connochaetes). En 2002, la Grumeti Community and Wildlife Conservation Fund, una organización sin fines de lucro, obtuvo el derecho a gestionar y conservar el área de 140.000 ha. Cuatro años más tarde, la compañía de safaris, Singita, ${ }^{19}$ comenzó a hacerse cargo de la gestión de la propiedad a petición del concesionario. La gestión de conservación del área se ha mantenido constante en el tiempo.

\section{Cuadro 1.7 \\ Chumbe Island Coral Park en Zanzíbar, Tanzania: La primera APP marina en el mundo}

A partir de una propuesta de inversión para una APP marina y terrestre presentada por Chumbe Island Coral Park Limited (CHICOP), ${ }^{20}$ en 1993 el Zanzibar Commission for Land and Environment le arrendó a la empresa un área de 2,44 ha para la construcción de un ecolodge en la deshabitada isla de Chumbe por un periodo renovable de 33 años. Entre 1991 y 1994, CHICOP negoció exitosamente con el gobierno semiautónomo de Zanzíbar, Tanzania, para que el arrecife de coral al oeste y el bosque de la isla se registraran como un área marina protegida (AMP), con el manejo de la AMP encomendado a CHICOP. La empresa se estableció específicamente con el propósito de desarrollar y gestionar la AMP de un modo financieramente sostenible, utilizando el ecoturismo para generar ganancias y cubrir todos los costos operativos y las actividades asociadas de conservación, investigación, educación y concientización. Gracias a ello, Chumbe se convirtió en el primer parque marino gestionado en Tanzania, la primera AMP de gestión privada en el mundo y, a la fecha, también en un singular modelo de AMP financieramente autosostenible. Los objetivos de la empresa no tienen fines de lucro, y por más de 20 años han implementado iniciativas de conservación y educación dentro del marco de tres planes de manejo y con la participación de las partes interesadas (1995-2005, 2006-2016 y 2017-2027). Las operaciones del negocio de ecoturismo siguen principios comerciales para la maximización de ingresos y la promoción de la rentabilidad con el objetivo de asegurar el flujo de ingresos para las actividades de la AMP. Constituye ahora un exitoso ejemplo de una AMP orientada a los negocios y gestionada de modo sostenible y eficaz.

Autor: Sibylle Riedmiller, Chumbe Island Coral Park Ltd. Para más información, ver Dodds (2012).

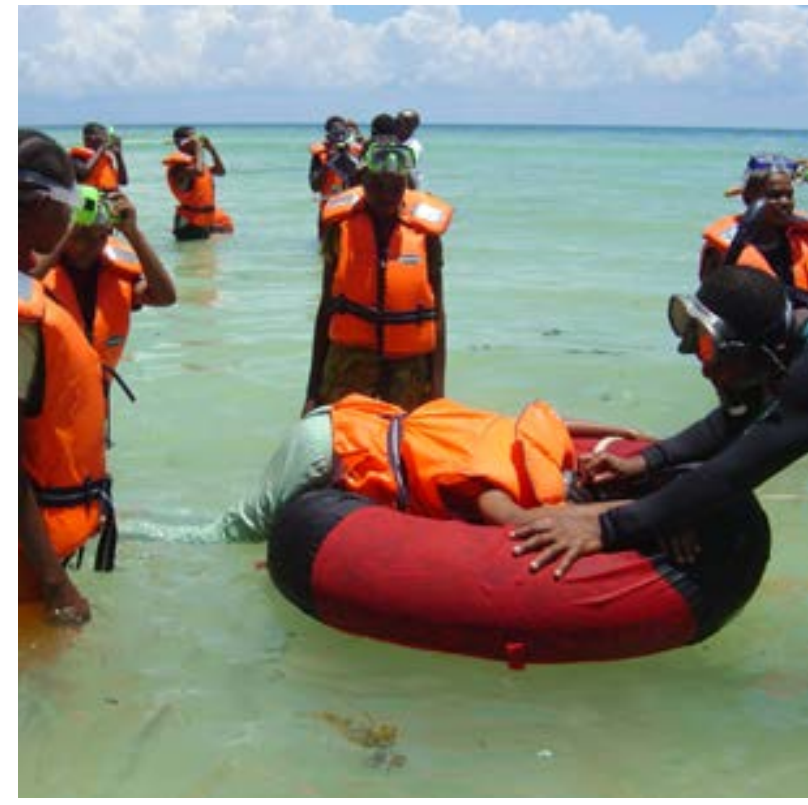

El programa de educación @ C Chumbe Island Coral Park 


\section{Principio 1.5: Todas las APPs deben establecerse con una estrategia a largo plazo y financiamiento sustentable}

Las APPs deben establecerse con una expectativa de resultados de conservación a largo plazo; es probable que los elementos clave incluyan planificación para la conservación, un apoyo financiero sostenible y a largo plazo junto con una sucesión generacional.

Buena práctica 1.5.1: Los mecanismos para el establecimiento de APPs deben garantizar la protección en el largo plazo

Cuando se establece una APP, es esencial que el estatus de conservación de territorios terrestres y marinos se asegure a largo plazo (ver Sección 4), aun cuando no exista ningún instrumento legal. Es importante, entonces, considerar los problemas que puedan surgir a partir de la custodia intergeneracional (Buena práctica 1.5.2). Las generaciones actuales dictan las decisiones de conservación de las generaciones futuras por medio del establecimiento de la APP, o creando servidumbres de conservación 'perpetuas' (Thompson, 2004). Dado que las condiciones, las preferencias y el conocimiento cambian con el paso del tiempo, dichas 'conservaciones intergeneracionales' pueden volverse problemáticas a no ser que los propietarios sucesores mantengan una ética de conservación o que la sociedad esté dispuesta a defender las protecciones legales.

Buena práctica 1.5.2: El establecimiento de una APP debe anticipar los posibles cambios de dueño de la propiedad y establecer reglas para la sucesión

Las APPs están sujetas a sufrir cambios en la gobernanza de la propiedad a lo largo del tiempo. Por ello, es necesario desarrollar un plan de contingencia durante la etapa de su establecimiento (Buena práctica 4.1.4 y Caso 4 de Costa Rica). Por ejemplo, si un land trust de una ONG o un propietario decide crear una APP, puede formar un acuerdo con una ONG de conservación asociada para asumir la responsabilidad de la propiedad en caso de que la ONG/propietario inicial no pueda continuar manteniendo sus propiedades. Los acuerdos de conservación también pueden ser incluidos en escrituras y registros públicos de la propiedad, de modo de garantizar que cualquier acuerdo esté vinculado a la tierra, y no a los propietarios (ver Cuadro 1.8).

Cuando la declaración de un acuerdo de conservación o una servidumbre se realiza por medio del gobierno, una autoridad legal u ONG, deben considerarse, en la planificación y el presupuesto futuros, los recursos para una participación continua con los propietarios actuales y los venideros. Por ejemplo, en Brasil, el Refugio Ecológico Caimán ${ }^{21}$ está buscando establecer una asociación con una ONG para garantizar la gestión de la Reserva Privada a largo plazo, mitigando posibles cambios en las prioridades de negocio en el futuro.

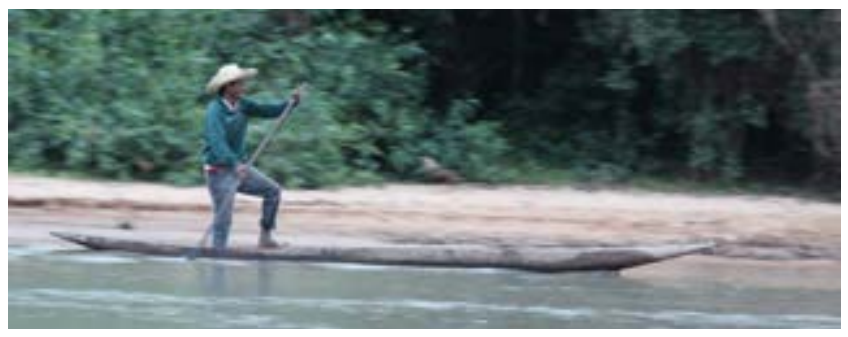

El último residente de la RPPN Sesc Pantanal @ Brent A. Mitchell

Buena práctica 1.5.3: Las APPs creadas como compensación de biodiversidad deben seguir la política de la UICN sobre compensación de biodiversidad

Las compensaciones de biodiversidad pueden contribuir positivamente a los resultados de conservación (ver Cuadro 1.9), como, por ejemplo, el establecimiento de distintas APPs o la restauración de valores de biodiversidad en las APPs. Sin embargo, la Política de la UICN sobre Compensaciones de Biodiversidad (WCC 2016 Res 059)22 también establece que "No obstante, las compensaciones de biodiversidad solo son apropiadas para los proyectos que hayan aplicado rigurosamente la jerarquía de mitigación (evitar, minimizar, restaurar/rehabilitar y compensar)".

\section{Cuadro 1.8 Brasil: Precursores de las APPs}

Brasil fue pionera en América Latina en la creación de reservas privadas, dado que el Código Forestal de 1934 preveía el establecimiento de APPs, entonces llamadas Bosques de Protección. Estas áreas se mantuvieron como propiedad privada y se consideraban legalmente intocables. Con la reforma del Código Forestal de 1965, la categoría Bosques de Protección fue eliminada, pero la nueva ley retuvo la opción de declarar cualquier porción de tierra privada como área de conservación perpetua (Art. $6^{\circ}$, Ley Federal n4 771/1965). Esto requirió la firma de un acuerdo con las autoridades y su registro por medio de una escritura. Esta nueva opción, no obstante, solo se volvió realmente operativa 25 años más tarde, con la aprobación oficial de este decreto y la creación del concepto moderno de Reserva Particular del Patrimonio Natural (RPPN, también por su sigla en portugués) (Mesquita \& Vieira, 2004). Ver Caso 2 de Brasil para más detalles.

Autor: María Cristina Viera Weyland y miembros del CRPPN, Asociación RPPN

\section{Cuadro 1.9 Ingula Nature Reserve South Africa: Una historia de éxito de compensación corporativa}

Una compensación medioambiental fue necesaria para la aprobación de la planta Ingula Pumped Storage Scheme (Maphisa et al., 2017). De este modo, en 2018 se declaró la Ingula Nature Reserve ${ }^{23}$ (una APP perteneciente a una empresa), ubicada en las inmediaciones, con el objetivo principal de conservación de la naturaleza. Este es un ejemplo de cómo un emprendimiento industrial con una compensación adecuada en la formación de una APP puede integrar tanto la conservación como el desarrollo económico, y beneficiar a ambas partes.

Autor: Daniel Marnewick, BirdLife South Africa 


\section{Sección 2: Gestión de un área bajo protección privada}

¿Hacia quién está dirigida esta sección?

Hacia cualquier persona a cargo de la gestión de una APP, ya sea un propietario privado, una ONG u otros. Cabe precisar que, pese a que no todas las buenas prácticas aquí presentadas podrán aplicarse a todos los tipos y tamaños de APPs, estos ejemplos, extraídos de experiencias de todo el mundo, sí ofrecen orientaciones sobre algunos de los aspectos más importantes en la gestión de APPs.

Contar con un buen sistema de gestión es clave para garantizar una conservación efectiva de la naturaleza. Idealmente, este sistema debiese considerar todos los aspectos involucrados en la gestión de un área protegida, desde la identificación de los objetivos, hasta el monitoreo y la adaptación. El grado de practicidad que tenga la implementación de las buenas prácticas presentadas aquí dependerá del tamaño, las necesidades y las condiciones de cada APP.

Se puede encontrar bastante información relativa a las buenas prácticas en la gestión de áreas protegidas, muchas de estas, aplicables a las APPs (ver Cuadro 2.1). Esta sección ofrece una serie de ejemplos sobre cómo distintas APPs de diversos lugares del mundo han implementado estas prácticas.

\section{Cuadro 2.1 \\ Herramientas y orientaciones para la gestión de áreas protegidas}

Existe ya una vasta cantidad de literatura y un gran número de métodos desarrollados en torno a la planificación y gestión de la biodiversidad para la conservación. Tanto la Comisión Mundial de Áreas Protegidas (CMAP) ${ }^{24}$ como el detallado volumen en línea Protected Area Governance and Management (Worboys et al., 2015) proporcionan información sobre buenas prácticas generales que abordan un amplio

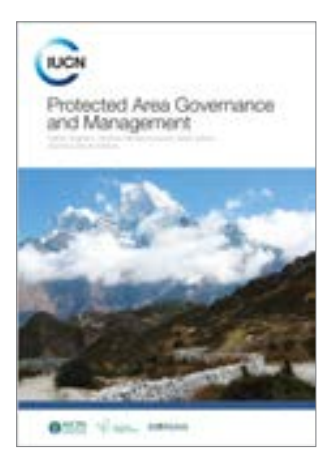

rango de temas asociados a la gestión de áreas protegidas. A través de su Programme on African Protected Areas \& Conservation (PAPACO), la UICN actualmente ofrece una serie de cursos abiertos y en línea (MOOCs, ${ }^{25}$ por su sigla en inglés) sobre conservación y áreas protegidas, además de otra iniciativa organizada en conjunto con la Sociedad Zoológica de Londres y National Geographic. Los cursos están pensados para un número ilimitado de participantes y entregan información relativa a la gestión de áreas protegidas a cualquier persona con acceso a internet.
Principio 2.1: Los actuales y futuros propietarios de una APP deben tener claridad sobre lo que ocurre tanto dentro como alrededor del área antes de desarrollar actividades de gestión

De ser posible, es importante recolectar información geográfica, hidrológica, social, ecológica, cultural, legislativa/política y sobre el patrimonio geológico de la APP y su entorno antes de planificar cualquier actividad de gestión. Este paso de planificación suele denominarse análisis de contexto (CMP, 2013). Hay casos en que los dueños ya cuentan con conocimientos, heredados de generaciones pasadas, sobre el área. Pero existen otros casos, como cuando ONGs/organizaciones con fines de lucro adquieren/arriendan un territorio, donde el acceso a la información es más limitado. Las buenas prácticas descritas a continuación destacan importantes fuentes de información (ver Cuadro 2.3). La mayoría de las áreas debieran poder acceder a ella a través de agencias, organizaciones e investigadores de conservación. A su vez, las alianzas (Buena práctica 2.5.4) también constituyen fuentes clave de información, en las que todos los socios debieran compartir una apreciación común del área.

Buena práctica 2.1.1: El modelo de gestión se puede construir a partir de legislaciones existentes o sobre la base de experiencias y prácticas implementadas por propiedades similares

La gestión debe construirse sobre la base de lo que ya está disponible. Esto se puede traducir en procurar que las acciones sigan las legislaciones del gobierno, como el caso de México (Hora et al., 2018), Brasil (ver Caso 2) y Sudáfrica (ver Caso 10), donde la mayoría de las APPs se manejan bajo el mismo sistema legislativo que las áreas protegidas manejadas por el gobierno (ver Cuadro 2.2); o bien, puede significar adaptar y aplicar planes de manejo desarrollados para propiedades con objetivos similares. Dado que muchas de las APPs son relativamente pequeñas, la conectividad con las zonas aledañas es particularmente importante. Tomarse un tiempo para estudiar el contexto del sitio y su entorno (en términos de conservación de la naturaleza y desde una perspectiva social, cultural y económica) puede implicar el ahorro de recursos al momento de desarrollar un sistema de gestión. En los casos con varias áreas situadas juntas 
dentro de un mismo paisaje, un plan de manejo general puede ser más apropiado que uno individual para cada área (ver Cuadro 2.4). Esto puede significar un uso más eficiente del tiempo, los fondos y los recursos. Por ejemplo, a medida que la agricultura comercial y la producción de turbas se han vuelto menos viables, los Humedales de Avalon en Somerset, Reino Unido, se han ido convirtiendo en un mosaico de áreas protegidas pertenecientes a agencias de gobierno y distintas ONGs de conservación. Las actividades se llevan a cabo de manera cooperativa en todo el paisaje y las acciones de gestión son planificadas en conjunto (Avalon Marshes Landscape Partnership, 2011).

\section{Cuadro 2.2 \\ Buena práctica de gestión y requerimientos legislativos en el contexto de las APPs de Sudáfrica}

La Ley de Áreas Protegidas $(2003)^{26}$ de Sudáfrica exige

a todas las áreas de esas características, incluyendo las APPs, redactar un plan de manejo y presentarlo a las autoridades de conservación más relevantes, y a la vez asignar a una autoridad para la gestión. Tanto las Normas y Estándares para la Gestión de Áreas Protegidas en Sudáfrica (National Gazette No. 41224, 2017) como las Regulaciones para la Administración Apropiada de las Reservas Naturales - desarrolladas en conformidad con la Ley de Áreas Protegidas de Sudáfrica- incluyen requerimientos para la evaluación del manejo de áreas protegidas declaradas en tierras privadas. Las regulaciones exigen que la autoridad asignada para la gestión monitoree y entregue información anual sobre el estatus de la implementación del plan de manejo, mientras que las Normas y Estándares exigen informes anuales sobre el progreso del proyecto en el cumplimiento y la mantención de normas y estándares. Los requerimientos para la entrega de este último informe se cumplen al completar una evaluación relativa a la eficiencia de gestión, para lo cual se utiliza una versión de la Herramienta de Evaluación de la Efectividad de Manejo (METT, por sus siglas en inglés), específicamente desarrollada para Sudáfrica (Buena práctica 2.4.2). Las evaluaciones METT son singularmente útiles para identificar y priorizar actividades de gestión, y de esta forma abordar las deficiencias y mejorar la eficiencia. Las evaluaciones son rápidas y fáciles de realizar. Idealmente, debieran ser completadas por los directores de las áreas, su personal y otras partes interesadas como parte de un proceso de autoevaluación. Estas evaluaciones sirven más para comparar los resultados de una misma área a lo largo del tiempo que para comparar los resultados entre distintas áreas, pues la repetición de evaluaciones revela tendencias de eficiencia y contribuye al manejo adaptativo de las áreas protegidas (Cowan et al., 2010).

Autor: Greg Martindale, Conservation Outcomes
Buena práctica 2.1.2: Incorporar los valores de conservación y el estatus y tendencias de biodiversidad al plan de manejo y sistema de gestión

A la hora de desarrollar un sistema de gestión, es importante obtener información sobre las especies, el estatus del hábitat y las tendencias. Un estudio de línea de base ayuda a determinar qué se debe monitorear y evaluar, y por consiguiente, de qué forma se pueden entender el estado y las tendencias de biodiversidad. A pesar de que pocas áreas - sea cual sea su régimen de gobernanza - cuentan con líneas de base completas, tener algún conocimiento sobre el estatus y las tendencias permite identificar acciones específicas de manejo. Como primer paso, las APPs pueden compilar y evaluar datos existentes y desarrollar, por ejemplo, mapas básicos de hábitats, presencia de especies y conectividad con otros hábitats naturales y seminaturales. Se debe prestar especial atención a las especies o ecosistemas de importancia regional, nacional o global. El Cuadro 2.3 ofrece una lista de fuentes de información global, más adelante en el texto se presentarán fuentes locales y regionales.

Buena práctica 2.1.3: Incorporar en la gestión conocimientos de pueblos indígenas, locales y tradicionales y, cuando corresponda, conocimiento ecológico tradicional

Cuando se desarrollan actividades de gestión, trabajar con y aprender de otros puede ahorrar una cantidad de tiempo y esfuerzo considerable, y además permite construir alianzas locales. Esto fue lo que sucedió en una evaluación ecológica rápida (Sayre et al., 2000), conducida por la Fundación Vida Silvestre en Argentina, en el desarrollo de un nuevo acuerdo para una reserva privada, ocasión en la que se realizaron entrevistas al personal del área, a los residentes vecinos y a las otras partes interesadas. Compartir conocimientos funciona de dos maneras: por una parte, los locales pueden aprender más sobre la presencia de especies de vida silvestre y, a la vez, compartir su visión sobre problemas de conservación, amenazas, entre otros, y por otra, los técnicos a cargo de conducir la encuesta, o los dueños de la propiedad, pueden conocer nueva información o temas que podrían impactar la gestión del sitio. En algunos lugares, el conocimiento ecológico tradicional puede contribuir de manera esencial a la gestión (ver Cuadro 2.4).

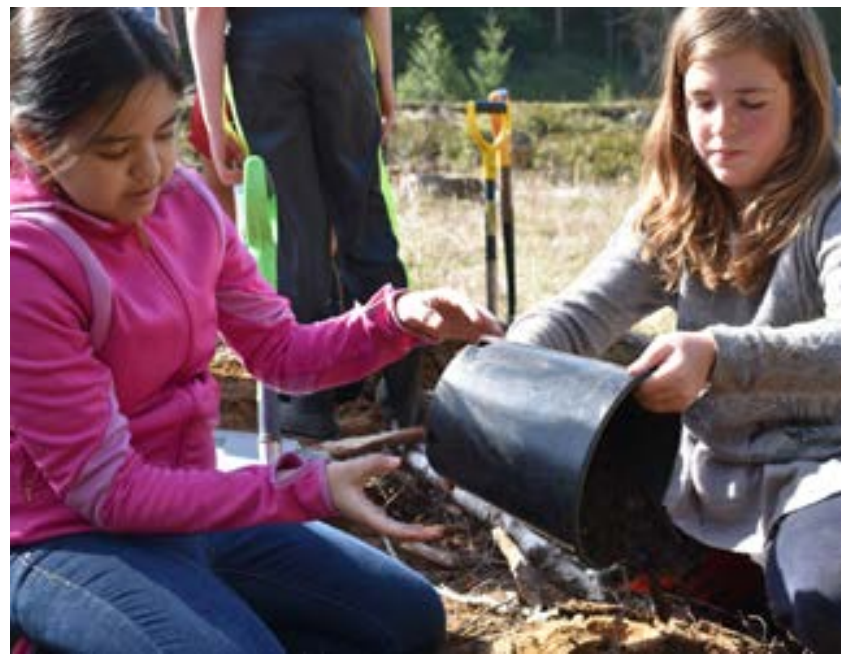

Con la ayuda de mayores y expertos, niños, estudiantes y voluntarios locales han ayudado a la Galiano Conservancy (ver Cuadro 2.11) en Canadá a restaurar un bosque de árboles melíferos nativo (c) Galiano Conservancy Association 
Cuadro 2.3

\section{Fuentes de datos de conservación global para complementar datos nacionales}

Protected Planet ${ }^{27}$ es la fuente más completa de información espacial y de gestión en áreas protegidas a escala mundial.

\section{Global Biodiversity Information Facility (GBIF) ${ }^{28}$ contiene} datos sobre todos los tipos de vida existentes en la Tierra. Es la base de datos de biodiversidad más grande del mundo, y cuenta con registros de más de 1,7 millones de especies, incluyendo desde bacterias hasta ballenas azules. Las bases de datos en la plataforma están organizadas según editorial, país, especies, etc.

La Lista Roja de Especies Amenazadas de UICN ${ }^{29}$ cuenta con la evaluación más completa del estado de conservación de las especies de plantas y animales. Al igual que las bases de datos globales, las Listas Rojas Nacionales ${ }^{30}$ han sido desarrolladas en varios países.

\section{La Base de Datos Mundial sobre las Áreas Clave para} la Biodiversidad ${ }^{31}$ es manejada por BirdLife International en representación de la Alianza de las Áreas Clave para la Biodiversidad (ACB). Esta plataforma almacena datos sobre ACBs globales y regionales, incluyendo las Áreas Importantes para las Aves y la Biodiversidad (IBAs por su sigla en inglés), sitios de la Alianza para la Extensión Cero (AZE por su sigla en inglés), ACBs identificadas mediante perfiles de ecosistemas de hotspots, apoyados por el Critical Ecosystem Partnership Fund, y algunas ACBs. Esta base de datos se va actualizando en la medida en que se revisan las ACBs existentes e identifican las nuevas.

Google Earth ${ }^{32}$ ofrece recursos en línea y acceso a imágenes satelitales, mapas y terrenos, mientras que Earth Engine ${ }^{33}$ cuenta con imágenes globales, incluyendo algunas históricas de más de cuarenta años, que pueden ser usadas para mapear un área y proveer datos de línea de base de hábitats.

Global Forest Watch ${ }^{34}$ puede analizar un área a partir de su mapa base para obtener estadísticas sobre la pérdida de bosques en el transcurso de este milenio. En Perú, la red regional en San Martín utiliza la plataforma Global Forest Watch para monitorear la deforestación en las APPs. Esta red en San Martín forma parte de un grupo de trabajo multisectorial en conjunto con las autoridades regionales, donde se abordan temas relacionados con la gestión de bosques.

Planet.com ${ }^{35}$ con más de 175 satélites en órbita, es capaz de capturar imágenes de cualquier lugar de la Tierra a una resolución de $3 \mathrm{~m}$ y $72 \mathrm{~cm}$.

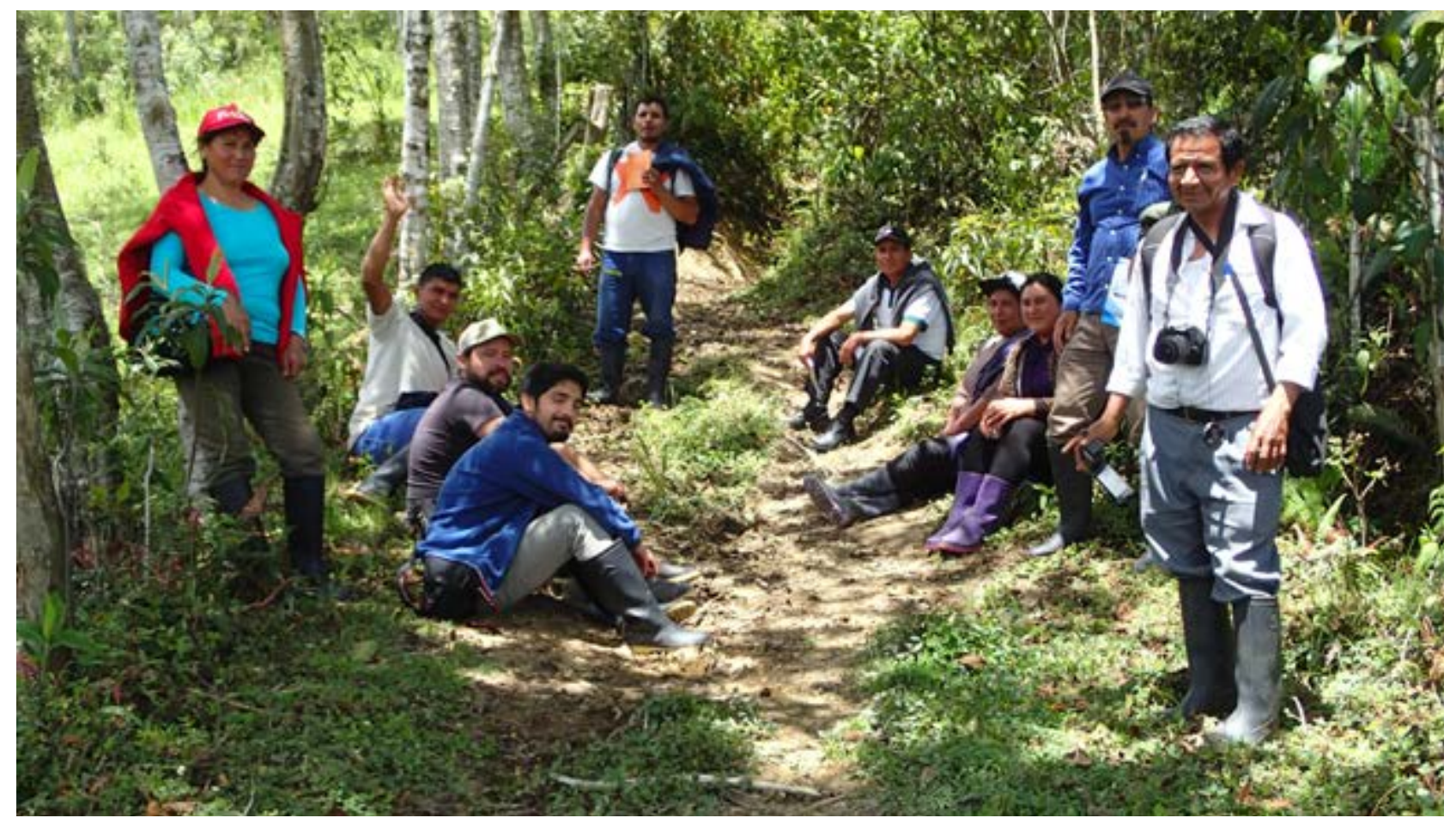

Miembros de la red de APPs RED AMA, en Amazonas, Perú, verificando en terreno alertas de deforestación en la APP Bosque de Palmeras - Molinopampa, sobre la base de información proveniente de Global Forest Watch @ Aaron Groth 


\section{Cuadro 2.4 \\ Conocimiento ecológico tradicional y Bush Heritage Australia}

Para Bush Heritage Australia, ${ }^{36}$ incorporar el conocimiento ecológico tradicional en la gestión de las APPs es un principio operacional fundamental que permite reconocer y respetar los derechos e intereses sobre tierras y aguas de los pueblos originarios. Esto lo implementan apenas la organización es invitada a asociarse con propietarios aborígenes o previo a la adquisición de tierra para la creación de una APP. Luego, continúa a lo largo de toda la gestión de la APP, con el fin de identificar los valores ecológicos, culturales y sociales importantes para las comunidades originarias y, también, para apoyar los sistemas de conocimiento y prácticas tradicionales y su uso. Aquello se logra por medio de reuniones con corporaciones aborígenes y grupos de familias, salidas de campo, evaluaciones al patrimonio cultural y, también, animando a la población originaria a participar en la planificación de conservación y el manejo de tierras. Los valores identificados por los dueños tradicionales se incorporan al Healthy Country Plans y, por cierto, a los planes de manejo de las APPs, por medio de estrategias y acciones específicas. Además, las descripciones de los valores y la selección de indicadores utilizados para monitorear el avance también incorporan el conocimiento cultural.

Los acuerdos de gestión colaborativa entre las organizaciones aborígenes y Bush Heritage se desarrollan para favorecer a aquellos acuerdos de gobernanza que respalden la alianza y expresen el compromiso mutuo de poner el plan en marcha. Un ejemplo es la Naree Station Reserve. ${ }^{37}$ Ubicada al norte de Nueva Gales del Sur, se trata de una propiedad adquirida por la organización y parte del pueblo aborigen budjiti. Los dueños tradicionales estuvieron vinculados con esta APP desde el comienzo y, en los últimos seis años, la participación del pueblo budjiti ha comprendido: su colaboración en el primer bioblitz ecológico (Buena practica 2.5.4), salidas de campo (2 o 3 veces al año), una gran reunión familiar anual entre las generaciones más jóvenes y los mayores - reconocidos por la comunidad como cultores de tradiciones patrimoniales $-y$, desde luego, evaluaciones al patrimonio cultural en torno a las áreas significativas para este pueblo.

Autor: Sarah Eccles, Bush Heritage Australia

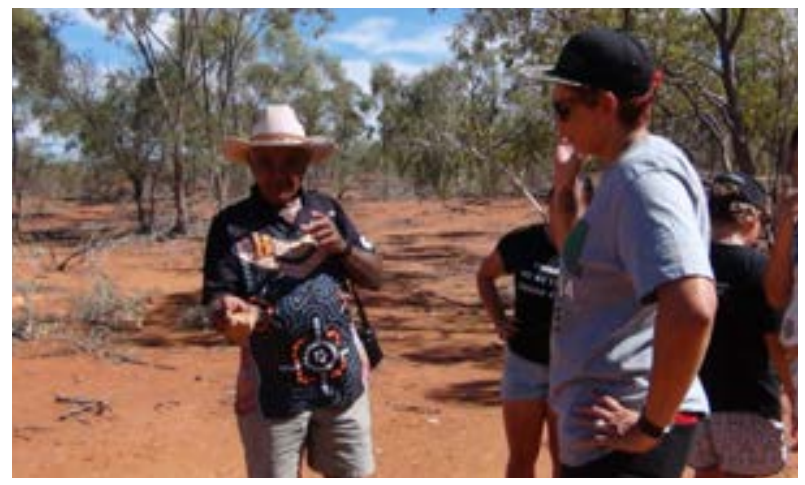

El miembro mayor de la comunidad budjiti, Phil Eulo, intercambiando conocimiento cultural en la Naree Station Reserve de Bush Heritage Australia (c) Sarah Eccles
Buena práctica 2.1.4: Llevar a cabo un buen proceso de consulta con las partes interesadas permite asegurar su participación y contribución en el desarrollo y gestión de la APP

En los planes de manejo es necesario emplear mecanismos que integren tanto el aprendizaje como el conocimiento social y experiencial. Así, resulta importante trabajar con las partes interesadas y los titulares de derechos de modo de lograr un buen entendimiento de la APP existente o futura. Esto permite evitar la puesta en riesgo de derechos de acceso (Buena práctica 1.4.1) y la duplicación de esfuerzos, y a la vez, encontrar soluciones a cualquier desafío de manera colaborativa. También ayuda a los futuros dueños de APPs no provenientes de ese territorio a entender mejor el contexto y, así, garantizar la relevancia de su APP a escala local en términos de resultados sociales, económicos y de conservación. El proceso de consulta, además, puede facilitar la comunicación de metas y objetivos, lo que asegura transparencia y, por tanto, contribuye a aumentar el apoyo y la participación en la APP. La colaboración también aumenta las habilidades y el conocimiento. Pues, por medio del proceso de gestión, los propietarios desarrollan conocimientos sobre conservación, basados en un lugar específico, que pueden resultarles útiles a las redes de APPs, agencias de conservación y a futuros propietarios.

\section{Principio 2.2: Los sistemas de gestión deben enfocarse en el logro de objetivos definidos para la APP}

Los sistemas de gestión suelen presentarse en documentos escritos (por ejemplo, planes de manejo a cinco años y planes operacionales anuales) que ayudan a desarrollar una comprensión y visión común de una APP en particular. También, pueden estar conformados por una serie de planes más pequeños, dirigidos a ámbitos específicos (por ejemplo, planes de turismo, de negocios, de investigación, de patrullaje, de restauración, de monitoreo, entre otros), en lugar de un plan principal, aunque es importante que estos planes estén conectados por medio de una visión general y objetivos acordados. El proceso de planificación no tiene por qué ser complejo o formal, pero sí es importante pensar cuidadosamente en el tipo de gestión que el sitio requiere y, a la vez, registrar exactamente lo que la APP pretende lograr.

Buena práctica 2.2.1: Crear una estrategia (por ejemplo, una visión, misión, objetivos y acciones) como parte del plan de manejo de la APP

Desarrollar y acordar un propósito común permite delimitar las actividades de gestión y facilita la comunicación y la recaudación de fondos (ver Cuadro 2.11). Esto se puede lograr definiendo una visión relevante para el entorno local. Esta visión debe describir el estado deseado por el cual los propietarios trabajan y, usualmente, incluye elementos de conservación, sociales, culturales y económicos (ver Caso 4 de Costa Rica). En algunas ocasiones, esto puede significar la mantención de las condiciones actuales (en cuyo caso, tal vez se requiera poca actividad de gestión). En otros casos, la visión puede describir una APP transformada - por ejemplo - por medio de restauraciones o reintroducciones. 
La declaración de la visión, tal como lo sugiere el nombre, debe ser inspiradora y breve, y la gestión debe enfocarse en alcanzar aquella visión. Se recomienda poner en marcha los otros elementos del sistema de gestión cuando ya se ha establecido y declarado la visión, y no antes.

\section{Buena práctica 2.2.2: Desarrollar planes de actividades basados en objetivos de conservación cuyo progreso pueda ser evaluado}

Worboys y Trzyna (2015) ofrecen una buena introducción al arte de la planificación del manejo. Idealmente, un plan de actividad debe incluir un cronograma, responsabilidades, distribución de recursos (por ejemplo, presupuesto, equipamiento, entre otros), programación, priorización y mapeo (por ejemplo, zonas).

Buena práctica 2.2.3: Realizar una evaluación de riesgos y desarrollar un plan de mitigación, de modo que, cuando surja un problema, exista un plan de acción listo para ser implementado

Aunque este nivel de planificación pueda resultar un tanto agobiante, particularmente para aquellas APPs con poca capacidad de gestión, son precisamente estas las áreas menos preparadas para salir adelante cuando surgen problemas. Crear un plan de mitigación (es decir, el proceso mediante el cual se desarrollan opciones y acciones para aumentar oportunidades y reducir amenazas) debe formar parte del sistema de gestión general y ser conocido por todos aquellos vinculados con el manejo de la APP. La evaluación debe tomar en cuenta los riesgos principales (por ejemplo, posibles amenazas) que podrían poner en peligro los objetivos del sitio, como incendios (ver Cuadro 2.5), caza furtiva, inundaciones, protestas, colapso de financiamiento, etc. Otros tipos de riesgos (por ejemplo, los relacionados con voluntarios, socios que trabajan en el sitio o visitantes) también deberán ser considerados, y es posible que se necesiten pólizas de seguro. Al igual que con los planes de manejo, los dueños de las APPs deben revisar si existen planes similares de carácter local y adaptables a las necesidades de su organización.

\section{Principio 2.3: Los costos totales y los beneficios de la APP deben entenderse como la base de la gestión}

Los costos asociados a la gestión de una APP dependerán de factores como su tamaño, características naturales y el objetivo del área. Mantener el estado actual del territorio también implica solventar gastos como la gestión de incendios, la defensa legal, etc. (Rissman \& Butsic, 2011). Algunos propietarios de APPs las financian por medio de ingresos recaudados (por ejemplo, provenientes de turismo o de la membresía en una $\mathrm{ONG}$ ), mientras que otras lo son a través de fundaciones, subvenciones, etc. (ver Sección 3 sobre incentivos), o bien, mediante una combinación de las anteriores. Cualquiera sea la fuente de fondos, es importante determinar las actividades del plan de manejo y el sistema de gestión de acuerdo con presupuestos reales. Desarrollar un plan de manejo que no puede ser implementado, en definitiva, se traduce en una pérdida de recursos. Trabajar con redes de APPs (ver Sección 8) o con territorios terrestres o marinos de conservación aledaños puede ayudar a repartir la carga de trabajo y los costos financieros (Buena práctica 2.1.1). Además, la gestión de una APP puede requerir otros tipos de recursos, tales como equipos, recursos humanos o técnicos, que deben ser considerados al reestructurar los planes de manejo (Ojidos, 2017). Al igual que los costos, el rango completo de beneficios de las APPs se debe delimitar de forma clara, y deben realizarse actividades para compartir esos beneficios cuando sea factible.

\section{Cuadro 2.5 La mitigación del riesgo de incendio: Un ejemplo en Brasil}

Pese a que forman parte natural de varios ecosistemas, los incendios forestales pueden significar un riesgo importante para los hábitats, la vida silvestre, el personal de las APPs, los visitantes, la infraestructura y las propiedades aledañas. Aun así, muchos propietarios de APPs no cuentan con suficientes recursos para manejar este tipo de riesgo (e.g. Halliday et al., 2012). En las áreas propensas a incendios, el plan de mitigación debe incluir la identificación de aquellas zonas de riesgo donde es probable que el fuego comience y se esparza. Una evaluación precisa de problemas relacionados con incendios forestales y la definición de respuestas frente a estos eventos pueden determinarse por medio de un mapa de zonas de riesgo de incendio. Los datos satelitales juegan una parte importante en la identificación y mapeo de incendios forestales y, también, en el registro de la frecuencia con la que distintos tipos/zonas de vegetación son afectados. Un sistema de información geográfica (SIG) puede ser utilizado para combinar distintos factores causantes de incendios en el mapa. Algunas herramientas útiles en el plan de prevención y mitigación son los datos globales de incendios, provenientes en tiempo casi real de imágenes satelitales y disponibles en el mapa de incendios activos de la NASA, ${ }^{38}$ y la plataforma Global Forest Watch Fires ${ }^{39}$ (GFW Fires).

En Brasil, la compañía de cosméticos Grupo Boticário maneja dos APPs, Salto Morato y Serra do Tombador, por medio de su fundación. Ambos sitios cuentan con varios procedimientos y estándares relacionados con la evaluación y mitigación de riesgos, además de la seguridad del personal empleado. En Serra do Tombador, cada año se desarrolla un mapa de zonas de riesgo de incendios, dada su alta amenaza. Los mapas se realizan tomando en consideración: un análisis integrado de los factores de riesgo que influencian la ignición y propagación (clima, viento y biomasa), además de las condiciones de acceso dentro de la APP, el establecimiento de áreas prioritarias de protección y la determinación de acciones de protección que se llevarán a cabo durante el año. Sumado a ello, debido a que la amenaza existe más allá de los límites de la APP, en 2014, la fundación creó una red regional para monitorear y optimizar las acciones de prevención y animar al gobierno a mejorar su ejecución.

La Federación de Reservas Ecológicas Particulares del Estado de São Paulo (FREPESP ${ }^{40}$ ) formó una asociación entre el gobierno estatal y la policía militar para manejar los brotes de incendios. De este modo, las APPs en el estado pueden realizar planes de protección sabiendo que cuentan con el apoyo de la policía militar y con recursos públicos para luchar contra los incendios y, así, proteger sus reservas.

Autor: Flávio Ojidos, Confederación Nacional de Reservas Privadas del Patrimonio Natural, Brasil 


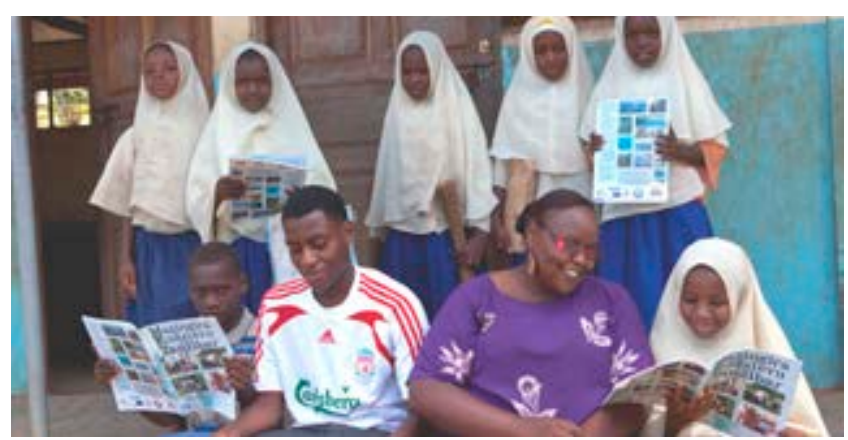

El programa de educación en Chumbe Island Coral Park

\section{Buena práctica 2.3.1: Determinar las actividades de gestión de acuerdo con un presupuesto realista}

Ya realizado el borrador del plan de manejo y sistema de gestión, es importante conocer los costos mínimos de mantención de la APP, de manera de determinar las actividades de acuerdo con un presupuesto realista. También es clave evaluar los riesgos que atentan contra la estabilidad financiera y, por cierto, que los propietarios los entiendan a cabalidad y, luego, planifiquen según estas posibles disrupciones (Buena práctica 2.2.3). Además, resulta útil distinguir entre los costos operacionales (por ejemplo, costos diarios propios de la gestión, como personal, equipamiento, mantención, seguridad y actividades contra la caza furtiva) y los costos de actividades específicas de gestión (por ejemplo, proyectos de restauración o investigaciones particulares). De acuerdo con la fundación del Grupo Boticário en Brasil, este enfoque dual también mejora la eficiencia operacional y las evaluaciones, además de facilitar la planificación de actividades estratégicas. En Chile el Santuario Cañi ${ }^{41}$ es manejado por el Grupo de Guías Cañi (GGC), una asociación local que tardó cinco años en armar un plan de financiamiento para su gestión por medio del ecoturismo. No obstante, el aumento de los impactos ambientales - producido por el incremento de visitantes, los que se multiplicaron por diez entre 2007 y 2017 -, la falta de planificación formal y los limitados recursos humanos y financieros dejaron claro que el GGC necesitaba diseñar un plan de manejo para visitantes basado en su capacidad de gestión (dos personas) y sus recursos financieros reales. (Ver Tourism and Visitor Management in Protected Areas BPG [Leung et al., 2018], para más información sobre planificación de visitas).

\section{Buena práctica 2.3.2: La APP debe brindar beneficios a la comunidad local}

Las APPs, y en particular las APPs con fines de lucro, deben contribuir a la comunidad cuando sea posible, por medio del empleo directo, suministro/abastecimiento local, apoyo a los servicios de la comunidad (por ejemplo, en el área de salud, educación, finanzas o asuntos de seguridad) y, también, por medio de efectos asociados, tales como el aumento de número de visitantes a restaurantes, hoteles y guías turísticas (ver Caso 6 de Kenia). Para evitar expectativas poco realistas, es importante planificar dichas actividades cuidadosamente y evaluar los mercados y clientes futuros con detención. De ser posible, las empresas deben construir sus instalaciones respetando el entorno local, las tradiciones de construcción, etc. (ver Caso 4 de Costa Rica). El turismo basado en las APPs puede servir de catalizador para generar conciencia en torno a la conservación y los temas sociales con los que se enfrentan los visitantes $\mathrm{u}$ otras partes interesadas y, de este modo, puede también facilitar la obtención de apoyo para el desarrollo de infraestructura, salud $u$ otros programas educativos, etc. (ver Cuadro 2.6). Las APPs, además, pueden conformar verdaderas escuelas que incentivan la participación de la comunidad local en el desarrollo de proyectos de infraestructura relacionados con la conservación. Por ejemplo, uno de los refugios dentro del Makuleke Contractual Park ${ }^{42}$ en Sudáfrica es manejado por la empresa Seasons in Africa mediante una concesión a treinta años por parte de la comunidad local, la que es dueña del territorio. Una vez que finalice ese periodo, la propiedad del hotel pasará a la comunidad, habiendo sido capacitada con las habilidades necesarias para gestionarla de manera rentable. Por último, y de suma importancia, cualquier participación de las comunidades locales o pueblos indígenas en la toma de decisiones, junto con la distribución de cualquiera de los costos y beneficios asociados, debe ser equitativa (Franks et al., 2016).

\section{Cuadro 2.6 \\ Apoyando a las comunidades costeras en Indonesia}

Un proyecto de ecoturismo es el que está detrás de la conservación de la isla Nikoi (15 ha) en Indonesia. La gestión está enfocada en la conservación marina, tanto para sustentar el negocio como para restaurar la salud de los arrecifes del área, los que han sido víctimas de la sobrepesca. Nikoi lleva varios años trabajando para conseguir el establecimiento de un área protegida marina. Lograr la aceptación por parte de la comunidad local es un elemento clave para el éxito. Esto permitirá generar conciencia sobre el uso sostenible de los recursos, por una parte, y fortalecer la participación de la población local en el turismo como sustento económico, por otra. En 2010, los fundadores crearon The Island Foundation,43 una fundación que ha establecido siete centros de formación dedicados a la entrega de educación de buena calidad, mediante un currículo innovador que apoya programas de alfabetización y otros de un amplio rango de habilidades. A la fecha, 1.100 profesores, provenientes de 25 escuelas estatales, han sido capacitados y 2.300 niños han participado en los programas. Es más, por medio del resurgimiento de la tradición cultural de las carreras de bote Jong y la limpieza comunitaria de las playas, Nikoi ha sido capaz de suscitar conciencia sobre la salud del ecosistema marino con los pescadores locales, lo que ha generado aún más apoyo en el desarrollo de un área protegida.

Autor: Delphine Malleret-King, The Long Run y Andrew Dixon, Nikoi Island

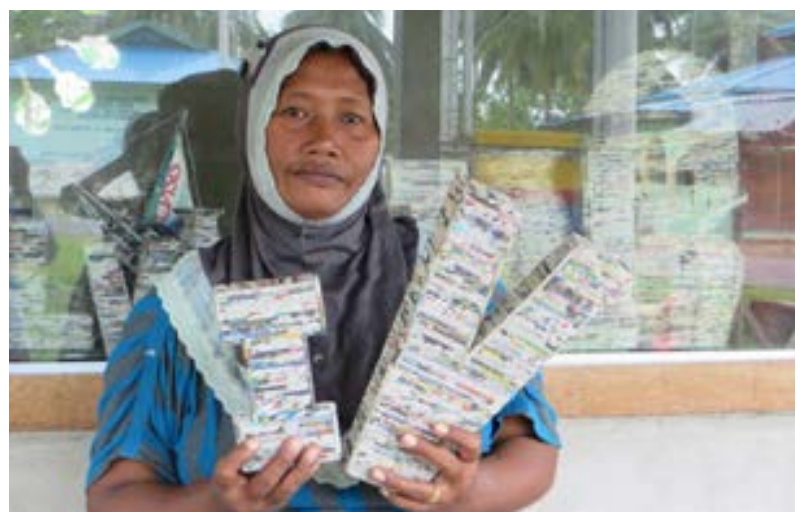

Productos de la Nikoi Island Foundation (c) isla Nikoi, Indonesia 


\section{Cuadro 2.7}

\section{Monitoreo en Haller Park, Mombasa, Kenia}

Ubicado al sur de la planta de cementos Bamburi de Lafarge, sobre la carretera de Mombasa/Malindi, Haller Park ${ }^{44}$ (antes Bamburi Nature Trail) combina una APP con un zoológico. Su historia data de los años setenta, cuando el Dr. René Haller comenzó a experimentar con técnicas para rehabilitar una extensa cantera de piedra caliza. Con el tiempo, lo que alguna vez fue un paisaje baldío ahora conforma un diverso ecosistema de bosques, praderas y humedales. Esta restauración a largo plazo tiene particular importancia para la región. Pues, los bosques costeros de África del Este poseen un alto valor de biodiversidad y han sido clasificados como uno de los 21 hotspots de biodiversidad global; sin embargo, muchos de ellos han sido destruidos y solo quedan unos cuantos terrenos.
Una asociación a largo plazo entre el Fondo Mundial para la Naturaleza (WWF, por su sigla en inglés) y Lafarge se dedicó a revisar diversos temas, entre los cuales incluyeron la elaboración de un sistema de gestión para la rehabilitación de canteras. Debido al largo proceso de restauración, también desarrollaron directrices generales para el monitoreo (Lafarge, 2007), junto con planes de monitoreo específicos para una serie de sitios restaurados, incluyendo a Bamburi. Al personal de Lafarge le interesaba generar un sistema de monitoreo más completo, en parte, para conocer la efectividad de distintos indicadores y, de este modo, poder compartir la información con otros sitios de canteras tropicales. A continuación, la Tabla 4 resume el sistema de monitoreo desarrollado.

Autor: Nigel Dudley, Equilibrium Research

Tabla 4: Borrador del sistema de monitoreo de Bamburi

\begin{tabular}{|c|c|c|c|c|c|}
\hline & Objetivo & Indicador & Método de recolección & Recolector & Notas \\
\hline 1 & \multirow[t]{7}{*}{$\begin{array}{l}\text { Bosque } \\
\text { autosostenible }\end{array}$} & Plantación de árboles & Cantidad plantada por año & $\begin{array}{l}\text { Personal de Lafarge Eco } \\
\text { Systems }\end{array}$ & Ya recolectados \\
\hline 2 & & Biomasa & Biomasa total de árboles & Por decidirse & \\
\hline 3 & & $\begin{array}{l}\text { \% (o número) de especies de } \\
\text { árboles nativos }\end{array}$ & $\begin{array}{l}\text { Datos de plantación pero } \\
\text { también encuestas }\end{array}$ & $\begin{array}{l}\text { Personal de Lafarge Eco } \\
\text { Systems }\end{array}$ & \\
\hline 4 & & Especies invasoras & Enfoque en 1-2 especies & Por decidirse & Por ejemplo, Neem \\
\hline 5 & & \% en rehabilitación & SIG & $\begin{array}{l}\text { Requeriría imágenes } \\
\text { periódicas }\end{array}$ & \\
\hline 6 & & Calidad del agua & & $\begin{array}{l}\text { Personal de Lafarge Eco } \\
\text { Systems }\end{array}$ & Ya recolectados \\
\hline 7 & & Perfil del suelo & $\begin{array}{l}\text { Ya sea profundidad del humus } \\
\text { o cantidad de mil pies }\end{array}$ & $\begin{array}{l}\text { Personal de Lafarge Eco } \\
\text { Systems }\end{array}$ & \\
\hline 8 & \multirow[t]{5}{*}{ Biodiversidad } & Aves & $\begin{array}{l}\text { Tal vez enfoque particular en } \\
\text { aves más raras }\end{array}$ & $\begin{array}{l}\text { Personal de Lafarge, } \\
\text { estudiantes }\end{array}$ & $\begin{array}{l}\text { Por ejemplo, el regreso } \\
\text { de los bucerótidos }\end{array}$ \\
\hline 9 & & Murciélagos & Número de especies & Por decidirse & $\begin{array}{l}\text { Actualmente muestra un } \\
\text { aumento }\end{array}$ \\
\hline 10 & & Varano & Abundancia & Por decidirse & $\begin{array}{l}\text { Aún no queda claro qué } \\
\text { es lo que mostraría }\end{array}$ \\
\hline 11 & & Salud animal & $\begin{array}{l}\text { Condición física, lombriz, } \\
\text { garrapatas, impactos asociados } \\
\text { al pastoreo }\end{array}$ & $\begin{array}{l}\text { Personal de Lafarge ya } \\
\text { recolecta datos }\end{array}$ & $\begin{array}{l}\text { Probablemente sea } \\
\text { más útil para animales } \\
\text { salvajes }\end{array}$ \\
\hline 12 & & Especies raras & Monitoreo de retorno & & \\
\hline 13 & $\begin{array}{l}\text { Paisaje } \\
\text { variable }\end{array}$ & $\begin{array}{l}\% \text { de elementos de agua (u otro } \\
\text { paisaje) }\end{array}$ & SIG & $\begin{array}{l}\text { Requeriría imágenes } \\
\text { periódicas }\end{array}$ & \\
\hline 14 & $\begin{array}{l}\text { Valor } \\
\text { educativo }\end{array}$ & $\begin{array}{l}\text { Visitantes (extranjeros, keniatas, } \\
\text { escuelas) }\end{array}$ & Número por año & $\begin{array}{l}\text { Personal de Lafarge ya } \\
\text { recolecta datos }\end{array}$ & $\begin{array}{l}\text { También es útil recibir } \\
\text { retroalimentación }\end{array}$ \\
\hline 15 & \multirow[t]{2}{*}{$\begin{array}{l}\text { Valores } \\
\text { sociales }\end{array}$} & Baobabs & $\begin{array}{l}\text { Mantención de árboles por } \\
\text { razones culturales }\end{array}$ & $\begin{array}{l}\text { Personal de Lafarge ya } \\
\text { recolecta datos }\end{array}$ & \\
\hline 16 & & $\begin{array}{l}\text { Valor de los productos } \\
\text { provenientes del sitio }\end{array}$ & $\begin{array}{l}\text { Por ejemplo, madera de } \\
\text { construcción, productos } \\
\text { forestales no madereros (PFNM) }\end{array}$ & & $\begin{array}{l}\text { Este indicador no ha } \\
\text { sido desarrollado por } \\
\text { completo }\end{array}$ \\
\hline 17 & $\begin{array}{l}\text { Investigación } \\
\text { científica }\end{array}$ & $\begin{array}{l}\text { Número de estudiantes } \\
\text { trabajando }\end{array}$ & & & Por desarrollarse \\
\hline 18 & $\begin{array}{l}\text { Restauración } \\
\text { rentable }\end{array}$ & $\begin{array}{l}\text { Reducción en costos para } \\
\text { lograr un bosque autosostenible }\end{array}$ & & & Necesitaría metas claras \\
\hline
\end{tabular}




\section{Principio 2.4: La gestión debe ser adaptativa}

Dado que la incertidumbre es algo común en el ámbito de la gestión ecológica, toda buena gestión conlleva la idea de 'aprender en la práctica', lo que significa que las intervenciones realizadas en la gestión pueden tener resultados inesperados (tanto exitosos como fallidos). Esto es particularmente certero ahora que las futuras condiciones ecológicas son inciertas producto del cambio climático (Gross et al., 2016). Los administradores de APPs deben tomar las medidas necesarias para entender de qué modo las acciones de gestión afectarán las metas de conservación, además de recolectar datos relacionados con los resultados de las metas y modificar acciones futuras sobre la base de este aprendizaje. Un manejo adaptativo tiene como objetivo garantizar que los profesionales incorporen la reflexión en sus acciones, con el fin de potenciar el ejercicio de conservación y aprendizaje (Groves \& Game, 2016).

\section{Buena práctica 2.4.1: Aprender de los éxitos y los fracasos y adaptar los sistemas de gestión según corresponda}

Es aconsejable desarrollar un sistema de monitoreo para evaluar los cambios de estatus o tendencias en factores relacionados con los objetivos de la APP (por ejemplo, tendencias poblacionales de especies, condiciones de hábitats, calidad del agua, voluntarios trabajando en el área, número de turistas, visitas educativas, etc.). Los resultados del monitoreo deben retroalimentar la gestión de modo directo. El Cuadro 2.7 muestra un ejemplo de sistema de monitoreo simple, desarrollado para una sola APP en Kenia, en tanto, el Cuadro 2.8 entrega detalles de monitoreo de toda la red de APPs en Australia. Donde sea posible y pertinente, los administradores de APPs deben integrar en el monitoreo a los pueblos indígenas, las comunidades locales, los trabajadores de las empresas (ver Cuadro 2.7), los voluntarios (ver Cuadro 2.10) o grupos más amplios de partes interesadas (por ejemplo, visitantes, huéspedes en APPs basadas en turismo).

\section{Buena práctica 2.4.2: Establecer autoevaluaciones para medir la eficacia de la gestión}

Realizar de modo regular autoevaluaciones relativas a la Efectividad del Manejo de las Áreas Protegidas (PAME, por su sigla en inglés) permite identificar las debilidades e ineficiencias en el manejo de una APP. Existen bastantes orientaciones relacionadas con las herramientas y la implementación de PAME (ver Cuadro 2.9). Un ejemplo es el de la asociación chilena Así Conserva Chile, Asociación de Iniciativas de Conservación en Áreas Privadas y de Pueblos Originarios, ${ }^{49}$ la que desarrolló una herramienta para evaluar la situación actual de las APPs que desean unirse a la asociación. De este modo, adaptaron al contexto chileno la Herramienta de Evaluación de la Efectividad de Manejo, o HEEM (METT, por su sigla en inglés) (Stolton et al., 2007), con el fin de crear un instrumento que reúne seis aspectos fundamentales: gestión, protección, personal, planificación, presupuesto y participación comunitaria. Un rápido cuestionario les permite a los propietarios entender su contexto, establecer prioridades y elaborar un plan de acción. La asociación también utiliza la HEEM como línea de base para medir el progreso de las acciones realizadas. Sudáfrica también desarrolló un sistema de evaluación anual basado en la HEEM (ver Cuadro 2.2) y Colombia cuenta con una metodología para evaluar la eficiencia de la gestión de las APPs pertenecientes a la Asociación Red Colombiana de Reservas Naturales de la Sociedad Civil (RESNATUR), desarrollada y testeada por WWF Colombia (Mayorquín et al., 2010 y ver Cuadro 2.2).

\section{Cuadro 2.8 \\ Bush Heritage Australia da cuenta del impacto por medio de métricas IRIS}

Bush Heritage Australia ${ }^{45}$ entrega los datos recolectados de sus APPs a la Collaborative Australian Protected Area Database (CAPAD, por su sigla en inglés) y, además, monitorea y reporta, en un informe anual, el impacto de conservación de sus APPs. Para ello, la organización utiliza una serie de indicadores estratégicos, adaptados a partir de los Impact Reporting and Investment Standards (IRIS, por su sigla en inglés), ${ }^{46}$ un conjunto de estándares aceptados internacionalmente y establecidos por la Global Impact Investing Network. El uso de Estándares Abiertos para la Práctica de la Conservación ${ }^{47}$ y del software Miradi48 le permite a Bush Heritage Australia planificar, implementar, monitorear y evaluar la gestión de sus APPs a lo largo del tiempo. Luego, Bush Heritage entrega información sobre la producción total junto con los resultados e impacto de todas sus APPs, por medio del uso de los datos derivados del proceso de Estándares Abiertos. Las métricas estandarizadas de IRIS permiten a los donantes/patrocinadores evaluar el rendimiento a una escala organizacional. Así, junto con detallados indicadores financieros y sociales, Bush Heritage realiza un informe anual en relación con las siguientes métricas medioambientales IRIS:

- Superficie de tierras protegidas y gestionadas de manera sostenible por Bush Heritage o sus socios (total de hectáreas bajo protección)

- Porcentaje de tierras con evaluaciones de línea de base de biodiversidad adecuadas (conocimiento sobre qué está siendo protegido)

- Porcentaje de reservas en áreas mal representadas del Sistema Nacional de Reservas y las metas de Aichi sobre la biodiversidad (protección en las áreas que más la necesitan)

- Área de tierras protegidas y manejadas sosteniblemente por Bush Heritage o sus socios (total de hectáreas bajo protección)

- Extensión de la línea fronteriza con el área protegida aledaña (potenciando el impacto positivo por medio del trabajo con otros)

- Superficie de área protegida adyacente (potenciando el impacto positivo por medio del trabajo con otros)

- Cantidad de especies y comunidades amenazadas en reservas o tierras de socios (protección en las áreas que más la necesitan)

- Clasificación anual del estado de las amenazas clave en comparación con la clasificación de línea de base original (resultado de la conservación)

- Clasificación anual del estado de salud de las metas de conservación de alto valor en comparación con la clasificación de línea de base original (impacto de conservación).

Autor: Kate Fitzherbert, Bush Heritage Australia 


\section{Cuadro 2.9 \\ Marco de Efectividad de la Gestión de Áreas Protegidas}

La UICN CMAP define la Efectividad del Manejo de las Áreas Protegidas (PAME) como una herramienta para medir qué tan bien está siendo manejada un área, esto es, el grado en que se están protegiendo los valores naturales y culturales, y logrando las metas y objetivos. El nivel de efectividad del manejo (Hockings et al., 2006) puede medirse por medio de un esquema compuesto por seis elementos que entrega directrices para la realización de evaluaciones (ver Figura 1) y sugerencias sobre las mismas. Para mayor información sobre los sistemas PAME (incluyendo la Herramienta de Evaluación de la Efectividad de Manejo, HEEM o METT por su sigla en inglés) y dónde se han llevado a cabo esas evaluaciones, visite protectedplanet.net (ver Cuadro 7.1).50

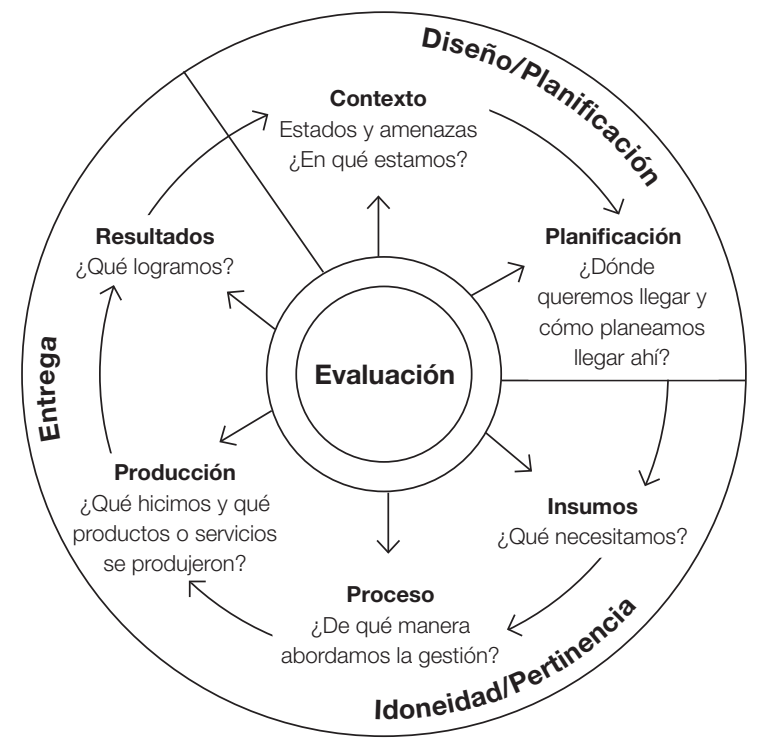

Figura 1: El esquema UICN CMAP PAME

\section{Buena práctica 2.4.3: Complementar la autoevaluación} con evaluaciones de eficacia independientes

Las evaluaciones y certificados externos que miden la eficiencia de la gestión pueden ser particularmente significativos para las APPs por una serie de razones, como: reconocimiento (Buena práctica 1.1.3), acceso a aquella experticia tal vez no disponible en la APP (Buena práctica 2.2.4) y acceso a financiamiento. Existen sistemas de evaluación independientes de carácter internacional, regional y nacional (Buena práctica 1.1.3). La Lista Verde de Áreas Protegidas y Conservadas de la UICN (ver Cuadro 1.1) es un estándar global relativamente nuevo para las áreas protegidas y conservadas bajo todo tipo de gobernanza. Está dirigido a escala nacional y regional, y actualmente varios países están implementando procesos de la Lista Verde. Dos APPs en Kenia, Lewa y OI Pejeta, participaron en una fase piloto de la Lista Verde en 2014 (ver Caso 6 de Kenia). Por su parte, la Land Trust Alliance, ${ }^{51}$ ubicada en los EE. UU. (ver Cuadro 8.2), también ofrece un sistema de certificación con estándares altos para la conservación de tierras. Existen, además, otros sistemas de certificación enfocados en el establecimiento y el mantenimiento de las APPs, como, por ejemplo, la certificación LIFE ${ }^{52}$ en Brasil, orientada hacia los sistemas de gestión medioambiental de un amplia diversidad de empresas. Estas pueden documentar sus contribuciones a la conservación de la biodiversidad, por ejemplo, por medio del establecimiento y la mantención de APPs, y así mejorar su puntaje de evaluación. The Long Run ${ }^{53}$ certifica APPs sostenidas por medio del turismo a través de su estándar Global Ecosphere Retreats $₫$ (ver Cuadro 8.3).

\section{Principio 2.5: La creación de un equipo debe ayudar a desarrollar capacidad de gestión para la APP}

Es común que pequeñas APPs tengan muy poco personal pagado que pueda dedicarse a la gestión a tiempo completo. Sin embargo, se puede construir capacidad de gestión con la ayuda de otras APPs y sus propietarios, vecinos, voluntarios, investigadores o alianzas con otras instituciones. En algunas áreas, la participación de miembros de pueblos originarios y de la comunidad local puede ser de especial importancia (ver Cuadros 2.6 y 2.11).

Buena práctica 2.5.1: Distintas organizaciones pueden realizar distintos tipos de actividades de gestión

Hay veces en que los propietarios pueden decidir hacerse cargo solo de algunos aspectos de la gestión y delegar otros aspectos a socios, por ejemplo, enfocándose en la conservación, pero encomendando las actividades con fines de lucro, como el turismo, a externos (ver Caso 4 de Costa Rica). Un caso es el de las 168 ha de la Reserva Natural de Osununú en Argentina, de la Fundación Temaikèn y reconocidas legalmente por el Sistema de Áreas Protegidas del Gobierno de la Provincia de Misiones. Con el fin de garantizar el cumplimiento de los objetivos de conservación y su zona de amortiguamiento, se implementó un programa de trabajo conjunto (respaldado por acuerdos) con el Parque Provincial aledaño (gestionado por el Gobierno de Misiones). Desde 2010, ambas organizaciones han planificado y ejecutado conjuntamente acciones como: planes de contingencia para incendios, capacitaciones para la interpretación patrimonial, educación medioambiental y difusión (por ejemplo, programas de radio, visitas guiadas para estudiantes, etc.), sumadas a la mantención de accesos. En otros casos, se pueden asignar entidades de gestión específicas, por ejemplo, una ONG, para manejar un sitio (ver Caso 3 de China).

\section{Buena práctica 2.5.2: Promover las redes colaborativas de propietarios de APPs}

Las redes de APPs pueden ayudar a desarrollar la capacidad de los dueños/administradores y aumentar la eficiencia en la gestión (ver Sección 8, Caso 8 de Perú y 9 de Samoa). Este apoyo puede traducirse en compartir equipos (por ejemplo, cámaras trampa) junto con experticia y experiencia (por ejemplo, la realización de presupuestos), o también en temas relacionados con la gestión práctica (por ejemplo, gestión de incendios/técnicas de restauración, ver Cuadro 2.5). 


\section{Buena práctica 2.5.3: Los programas de voluntarios pueden brindar apoyo a las actividades de gestión}

Los voluntarios pueden proporcionar apoyo en la realización de las actividades programadas en los planes/sistemas de gestión de APPs. No obstante, desarrollar y gestionar un programa de voluntarios requiere trabajo y experticia (ver Cuadro 2.10). Las recomendaciones sobre cómo desarrollar este tipo de programa (por ejemplo, How to Set Up a Volunteering Programme ${ }^{54}$ ) pueden servir como punto de partida. Es de suma importancia obtener el permiso de los propietarios de APPs antes de que los voluntarios ingresen a un sitio privado.

En el Reino Unido, el 85\% de las personas que trabajan para la Royal Society for the Protection of Birds ${ }^{55}$ está compuesto por voluntarios, cifra que representa casi un millón de horas de trabajo voluntario al año. Asimismo, en Canadá, el programa de Voluntarios para la Conservación de la Nature Conservancy of Canada ${ }^{56}$ realizó más de 200 eventos de voluntariado en 2017, atrayendo alrededor de 2.750 canadienses que contribuyeron con casi 13.200 horas de actividades dedicadas a la naturaleza. En Sudáfrica, el programa Custodians of Rare and Endangered Wildflowers ${ }^{57}$ trabaja con propietarios privados para generar herbarios de las propiedades y, también, con proyectos de ciencia ciudadana (Ellwood et al., 2017), como la iniciativa 2nd Southern African Bird Atlas Project.

\section{Buena práctica 2.5.4: Desarrollar alianzas/acuerdos de trabajo con colaboradores externos}

Selinske et al. (2015) señalan que la meta principal de los titulares de APPs suele ser aprender a gestionar su propiedad, aunque no siempre lo reconozcan de manera explícita. Dado que muchos de los administradores de APPs cuentan con poca capacitación formal en ecología o biología de la conservación, el desarrollo de alianzas con instituciones educacionales (Shackleton et al., 2009) es a menudo sumamente importante para las APPs. Las alianzas, en general, permiten mejorar los resultados de la gestión y pueden establecerse con universidades, centros de investigación, empresas y pueblos originarios y comunidades locales, gobiernos y organizaciones con y sin fines de lucro (ver Caso 6 de Kenia, 8 de Perú y 9 de Samoa). A su vez, distintos tipos de APPs pueden tener conjuntos de habilidades diferentes pero complementarios. Por ejemplo, las APPs de empresas pueden aportar habilidades de negocio a una asociación, mientras que las ONGs pueden apoyar el trabajo de conservación de una empresa mediante su conocimiento y habilidades, dando credibilidad, ayudando a ahorrar costos y, en ocasiones, garantizando la continuidad (ver Cuadro 2.5).

La búsqueda de alianzas con especialistas en conservación también puede conformar una manera rentable de adquirir habilidades e implementar actividades de conservación, particularmente para las APPs con recursos limitados. Por ejemplo, en Ecuador la Fundación Jocotoco ${ }^{58}$ administra 18.000 ha de reserva, a partir de recomendaciones científicas externas, dado que este resultó ser el método más rentable. Los centros de investigación generan información que puede ser difundida de modo extenso, lo que permite posicionar a las APPs dentro de contextos de conservación más amplios. En Perú, la plataforma Conservamos por Naturaleza ${ }^{59}$ promueve la campaña Dona tu Talento ${ }^{60}$ que busca profesionales de distintas áreas como economía, arquitectura, biología y turismo para que donen tiempo y conocimiento a una APP con el fin de resolver problemas específicos. A la fecha, más de cien profesionales y estudiantes se han unido a la iniciativa.

Las universidades pueden apoyar en la recopilación de datos relevantes para la gestión, mediante actividades de ciencia ciudadana y, de este modo, contribuir también a crear un sentido de custodia y apoyo. Un buen ejemplo de trabajo colaborativo es el que se realiza por medio de un bioblitz (un periodo intenso de catastro de especies, cuyo propósito es registrar a todas las especies vivas dentro de un área designada). El concepto de bioblitz se desarrolló a fines de los años noventa para reunir a científicos, naturalistas y voluntarios con el objetivo de que realizaran un intensivo estudio de campo durante 24 horas. Los bioblitzes se han llevado a cabo en todo el mundo y en todo tipo de áreas de conservación, incluyendo APPs.

\section{Principio 2.6: La información sobre la gestión de la APP debe comunicarse ampliamente}

La comunicación es importante para todas las áreas protegidas, pero particularmente crucial para varios tipos de APPs, tales como aquellas pertenecientes a ONGs conformadas por una gran cantidad de miembros con los que deben comunicarse. Las que ofrecen turismo con fines de lucro también necesitan promocionar sus servicios, a veces en contra de la dura competencia de las actividades vacacionales más típicas. El uso de redes sociales para animar a los visitantes satisfechos a entregar su respaldo es un buen modo de promocionar.

\section{Buena práctica 2.6.1: Desarrollar iniciativas de difusión para informar al público sobre la gestión y los éxitos de las APPs}

Mantener al público (vecinos, grupos de interés, público general, entre otros) informado sobre el estado del área es clave para conseguir apoyo y participación. La comunicación con los pueblos originarios y las comunidades que viven dentro o alrededor de una APP es particularmente importante, como también lo es en el caso de los donantes y funcionarios de gobierno. Esto puede comprender la realización de actualizaciones periódicas sobre avistamientos de vida silvestre, y también de información relacionada con la gestión, proyectos y convocatorias de voluntarios. Internet ofrece una gran cantidad de alternativas sin costo para transmitir un mensaje. Por su parte, la CMAP de la UICN estableció una serie de orientaciones generales (Cohen et al., 2015) en torno a la difusión científica y las relaciones con los medios de comunicación. Por cierto, la comunicación entre los propietarios de APPs también es sustantiva (ver Sección 8 sobre el establecimiento de redes de contacto). La información sobre, por ejemplo, eventos especiales o avistamientos de vida silvestre inusual debe mantenerse actualizada. No obstante, es altamente recomendable decidir cuidadosamente si hacer pública o no información sobre una especie, ya que esto puede aumentar el grado de perturbación, o incluso de caza furtiva de especies de alto valor o de sus nidos, huevos o crías. Conservamos por Naturaleza en Perú es una gran plataforma comunicacional que le permite a los propietarios y a APPs divulgar sus experiencias de conservación por medio de videos e historias. ${ }^{61}$ La plataforma conecta a donantes con campañas específicas, ${ }^{62}$ tales como una APP en busca de fondos para reforestación, supervivencia de hábitats y de especies, etc. 


\section{Cuadro 2.10}

\section{Lecciones aprendidas a partir del trabajo con voluntarios: Namibia, Brasil y Canadá}

Una gran cantidad de voluntarios provenientes de distintos contextos ha visitado Namibia para aportar a la conservación por medio de la N/a'an ku sê Foundation, ${ }^{63}$ desde que esta fue creada en 2006. Las lecciones aprendidas son:

1. Satisfacción laboral: es fundamental que los voluntarios sepan que el trabajo que están realizando es vital para el proyecto y que, además, puedan ver el impacto directo que este tiene en el medioambiente.

2. Entrega de conocimientos: es importante asegurarse de que los voluntarios aprendan sobre las especies del ecosistema y la razón por la que se está realizando ese trabajo en particular, sobre todo cuando se está trabajando con especies que suelen generar confusión (por ejemplo, la hiena manchada, Crocuta crocuta).

3. Sentido de propiedad: es importante que los voluntarios puedan llevarse a casa la experiencia y el conocimiento adquiridos, para que, de este modo, se conviertan en una suerte de embajadores internacionales de la conservación. Los voluntarios son una pieza clave en las iniciativas de difusión de conservación, tanto las públicas como las internacionales.

Más de 500 personas han participado en el programa de voluntariado de la Reserva Natural Salto Morato ${ }^{64}$ en Brasil desde su creación en 1996. El programa fue reformulado recientemente tras una evaluación que recogía sus 20 años de experiencia. Algunas de las lecciones aprendidas son:

1. Expectativas claras: los objetivos del trabajo voluntario deben ser cabalmente comprendidos.

2. Integración con otras actividades de APPs: es muy importante que los voluntarios entiendan cuál es su rol en el logro de objetivos de la APP.

3. Alineamiento: todo el personal de la APP debe tener conciencia del rol de los voluntarios.

4. Medición de resultados: se recomienda que las áreas evalúen la experiencia del voluntario.
5. Seguridad primero: los programas deben considerar la posibilidad de proporcionar un seguro de accidentes a los voluntarios.

6. Atención al cumplimento de la ley: cada país cuenta con un marco legal referido a los trabajadores y a las condiciones de trabajo que las APPs deben conocer. En algunos casos, también existen regulaciones específicas para el trabajo voluntario.

La organización Nature Conservancy of Canada (NCC) ${ }^{65}$ ofrece una variedad de eventos prácticos de voluntarios dentro de áreas prioritarias de conservación en todo el país. Cada evento de voluntariado está diseñado con el fin de garantizar un impacto de conservación significativo. Ya sea cuando el enfoque está centrado en eliminar especies invasoras, realizar inventarios, monitorear especies, mejorar la experiencia de los visitantes por medio de la mantención de caminos y la mejora de señalética, o bien, plantar árboles, arbustos y pastos nativos, los eventos siempre se diseñan con el fin de abordar acciones urgentes, necesarias, beneficiosas y determinadas en los planes de manejo de la NCC.

Año tras año, las encuestas muestran que las dos razones principales que tienen los voluntarios para participar en programas de conservación son:

- Contribuir a la protección de los lugares naturales y de las especies por medio de acciones significativas y estratégicas.

- Relacionarse con personas que comparten visiones similares.

En las palabras de uno de los participantes de una encuesta de voluntarios: "Me impresionó el sentido de comunidad, la concurrencia de personas con la meta común de contribuir al bien mayor de la naturaleza, la vida silvestre y el medioambiente".

Autores: Georgina Hockings y Karl Fester, N/a'an ku sê Foundation, Marion Letícia B. Silva, Fundação Grupo Boticário y Lisa McLaughlin, Nature Conservancy of Canada

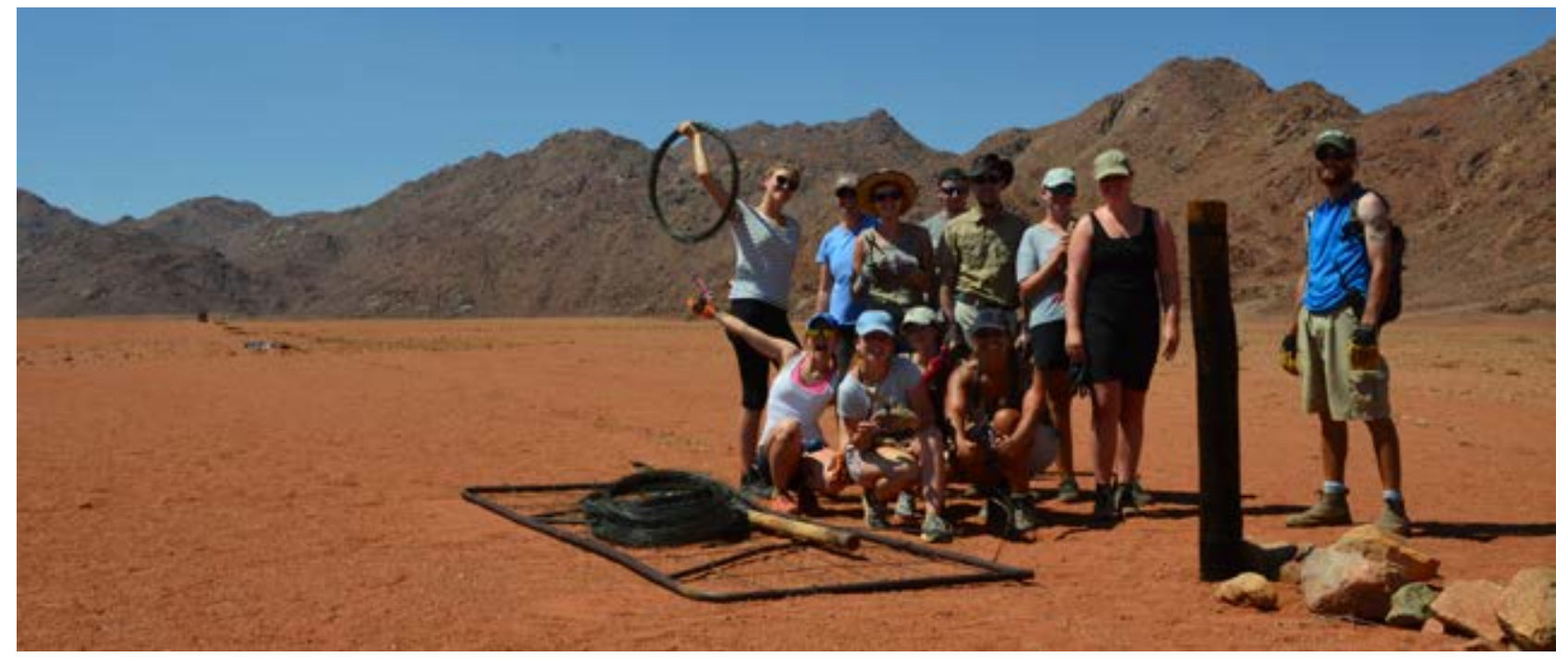

Voluntarios retirando cercado antiguo en Kanaan N/a'an ku se Desert Retreat, Namibia, para abrir rutas migratorias para la vida silvestre. Es importante que los voluntarios vean el impacto de, en este caso, haber retirado tantos metros de cercado (0 Boel Nilsson 


\section{Cuadro 2.11 \\ Creando conciencia comunitaria para la conservación en Canadá}

La Galiano Conservancy Association, ${ }^{66}$ en British Columbia, fue fundada en 1989 como uno de los primeros land trusts canadienses basados en la comunidad, y cuenta con cerca de 185 ha, además de acuerdos de conservación que cubren más de 200 ha, en la isla Galiano de las islas del Golfo del Sur. Galiano posee un ecosistema de selva tropical templada, dominado por el pino Oregón (Pseudotsuga menziesii) y ubicado dentro de la zona biogeoclimática de Coastal Douglas Fir. Los objetivos de la asociación son: la conservación terrestre y marina, custodia y restauración, junto con educación medioambiental y sensibilización pública.

El objetivo de educación y sensibilización se ha alcanzado, principalmente, por medio de programas de instrucción medioambiental para estudiantes de todas las edades, incluyendo estudiantes de primaria, profesores, estudiantes universitarios canadienses e internacionales, grupos comunitarios y público interesado. Sus terrenos funcionan como laboratorios de campo para cursos de restauración ecológica y, también, para muchos proyectos de investigación de posgrado. El evento anual Musical Walkalong for Learning ${ }^{67}$ es una experiencia única que combina música, naturaleza y, por sobre todo, la celebración de la educación medioambiental, en la que músicos tocan para quienes recorren los senderos del bosque o borde costero. A través de este evento, se recaudan fondos para los programas de beca destinados a grupos escolares, como niñas y niños citadinos que, de otro modo, no podrían costear su asistencia a estas iniciativas. Los programas de la Galiano Conservancy Association no solo se basan en la comunidad de la isla y los visitantes para compartir los objetivos de conservación, sino que también constituyen una forma de incentivar a que los propietarios donen terrenos para la conservación (Buena práctica 3.1.1). Tal como declaró uno de ellos: "Entregarle oportunidades a la próxima generación de científicos y tomadores de decisiones para desarrollar una ética de conservación y amor por la naturaleza es algo que apoyo con felicidad".

Autor: Risa Smith, Galiano Conservancy Association

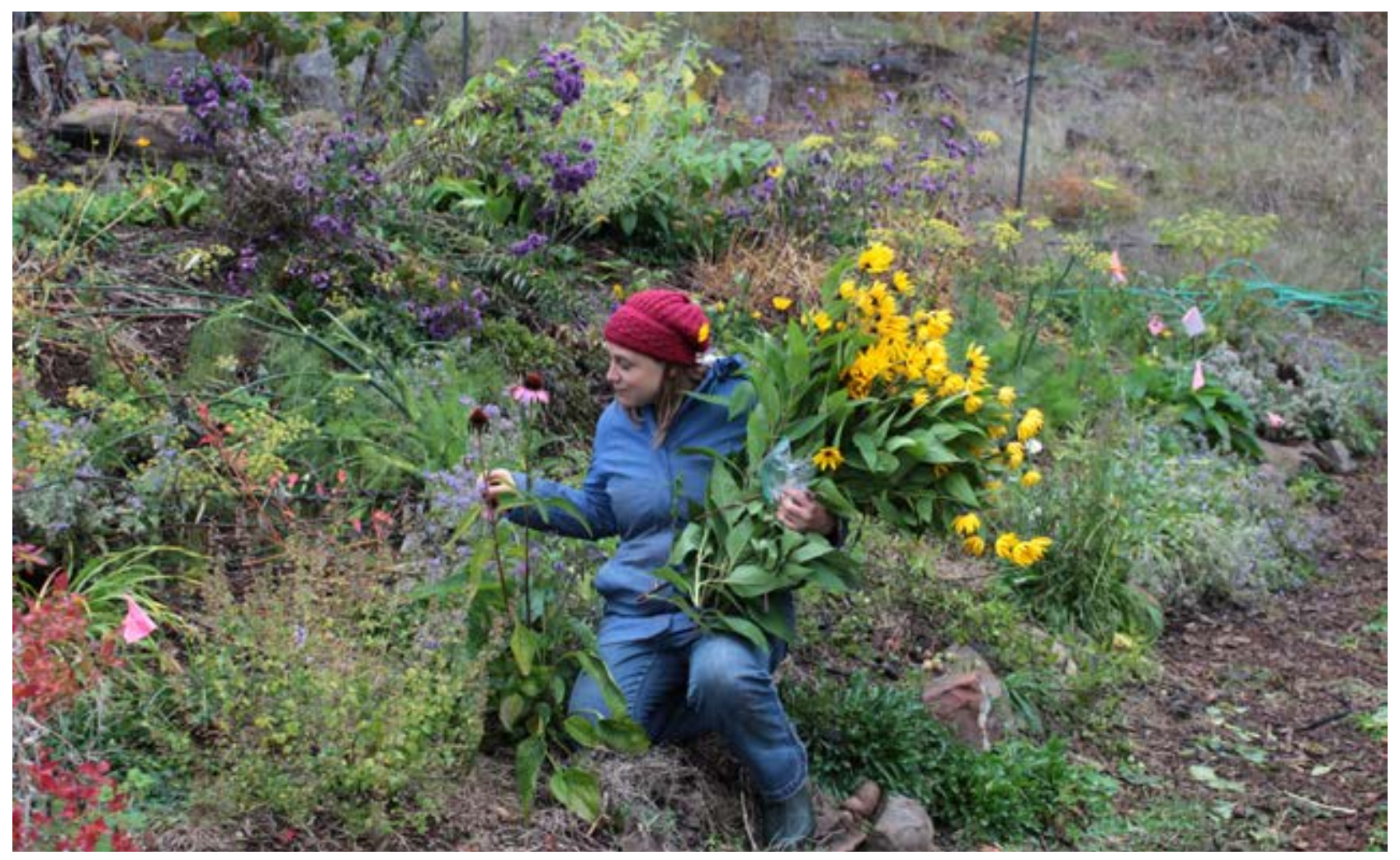

Galiano Conservancy ๑ Galiano Conservancy Association 


\title{
Sección 3: Incentivos para las áreas bajo protección privada
}

\author{
¿Hacia quién está dirigida esta sección? \\ Gran parte de esta sección será de mayor interés para gobiernos y entidades de \\ financiamiento de APPs (por ejemplo, ONGs, fundaciones privadas, etc.) que desarrollan \\ políticas con el fin de incentivar la designación y gestión de APPs.
}

Los incentivos para la creación de APPs comprenden beneficios a propietarios o posibles propietarios (por ejemplo, ONGs, fundaciones, etc.) con el fin de motivarlos a conformar APPs o apoyar su gestión a largo plazo. Existe una serie de incentivos que ha demostrado ser efectiva (ver Cuadro 3.1), incluyendo: el reconocimiento y la construcción de redes, la entrega de apoyo para la gestión y marketing de las APPs e incentivos financieros directos e indirectos (Selinske et al., 2016). Dado que las razones tras el establecimiento de APPs son diversas e incluyen, por ejemplo, motivaciones, creencias y valores, distintos tipos de propietarios requerirán distintos tipos de incentivos.

Esta sección ofrece orientaciones generales sobre el diseño y la implementación de aquellos incentivos más comunes, además de presentar buenas prácticas asociadas a tipos específicos de incentivos y recogidas de distintas partes del mundo a lo largo de varios años. Cabe, sin embargo, advertir que el apartado no pretende ser una revisión exhaustiva de todas las clases de incentivos disponibles para propietarios.

\section{Principio 3.1: Los incentivos para las APPs se deben diseñar, comunicar e implementar con prudencia para asegurar su efectividad}

El diseño de incentivos debe realizarse en paralelo al desarrollo de programas de APPs del gobierno u otras entidades, y debiera continuar en la medida en que el programa evoluciona. Esto implica la consideración de varios factores, tanto en términos de la demanda - qué incentivos resultan más atractivos para los propietarios -, como de la oferta - cuáles son asequibles económicamente, prácticos, justos y sostenibles, y cuáles funcionan dentro del marco legislativo e institucional - (ver Caso 1 de Australia y Caso 10 de Sudáfrica).

Buena práctica 3.1.1: Los incentivos deben vincularse al logro de los resultados de conservación deseados y ser entendidos de manera clara por todas las partes

Los incentivos deben estar relacionados con la gestión y el desempeño de APPs en curso (ver Principio 1.5 y Cuadro 3.2). Deben ofrecer orientaciones claras sobre los criterios de elegibilidad para poder acceder a ellos, y también sobre las sanciones relacionadas con el incumplimiento de un acuerdo. En algunos casos, las razones por las cuales un propietario se decide por la conservación pueden verse reforzadas por una amenaza externa

\section{Cuadro 3.1 Distintos tipos de incentivos para APPs}

Existe una gran variedad de incentivos que incluye:

- Respaldar la ética de conservación, la identidad cultural y el sentido de pertenencia del propietario por medio de la educación y concientización (ver Caso 7 de Nueva Zelanda).

- Reconocer tanto los esfuerzos del propietario como su participación en redes de APPs (ver Caso 4 de Costa Rica, Caso 7 de Nueva Zelanda y 8 de Perú).

- Entregar apoyo para la gestión, lo que puede generar beneficios económicos para los propietarios, ayudar a crear buenas relaciones y facilitar la construcción de lazos, junto con aumentar el aprendizaje y el nivel de concientización.

- Ofrecer mejores oportunidades de marketing y acceso a los mercados de productos verdes.

- Brindar incentivos financieros, incluyendo pagos directos, exenciones tributarias y subsidios verdes (ver Caso 1 de Australia y 10 de Sudáfrica).

- Procurar el cumplimiento de aquellas leyes que afectan a los propietarios (algunos ejemplos: la intervención del gobierno en la supervisión; la protección y el enjuiciamiento de delitos ambientales por parte de los gobiernos de Brasil y México, junto con el Caso 6 de Kenia).

que afecta un área (por ejemplo, desarrollo de infraestructura, minería, etc.), la que se puede frenar cuando esa área alcanza el estatus de APP. También se pueden desarrollar incentivos para animar a propietarios de terrenos aledaños a realizar una gestión más compatible con la conservación y, así, asegurar la conectividad, los corredores de biodiversidad, etc. En los EE. UU., por ejemplo, la American Prairie Reserve ${ }^{68}$ tiene como objetivo crear la reserva natural más grande de los EE. UU. continentales, principalmente por medio de la adquisición de tierras. Esta es una meta ambiciosa que, inevitablemente, deriva en un mosaico de áreas de conservación dentro del territorio más amplio que se tiene como objetivo. Por ello, la American Prairie Reserve desarrolló el Wild Sky Program, ${ }^{69}$ un incentivo que ofrece una prima a aquellos ganaderos dispuestos a que sus tierras sean sitios propicios para la vida silvestre, que favorezcan la generación de corredores migratorios. 


\section{Cuadro 3.2 \\ El primer incentivo fiscal efectivo para la biodiversidad de Sudáfrica}

La Ley de Impuesto sobre la Renta de Sudáfrica alude a un incentivo fiscal específico para la biodiversidad (sección [S] 37D), orientado tanto a generar sostenibilidad financiera para áreas protegidas en tierras privadas o comunales, como a motivar y recompensar el compromiso de los propietarios.

Este incentivo permite que el valor de la tierra de una reserva natural o de un parque nacional se deduzca del impuesto sobre la renta, reduciendo el impuesto a pagar por el propietario, lo que posibilita un mayor flujo de caja para el manejo del sitio. Esta recompensa fiscal es la primera de carácter nacional, y su inclusión, en 2016, en una declaración de impuestos de propietarios de APPs fue un éxito. Esto trajo consigo el primer incentivo fiscal para la conservación de la biodiversidad privada en Sudáfrica.

Los dos beneficios principales de este incentivo fiscal comprenden: 1) el apoyo para la creación de APPs sólidas y 2) la creación de una herramienta innovadora para su sostenibilidad financiera. Los beneficios consisten en: 1) los requisitos de la Ley de Impuesto sobre la Renta están correlacionados con los requerimientos de la Ley de Áreas Protegidas, así, se garantiza que las APPs calificadas como beneficiarias de la deducción de impuestos hayan sido formalmente declaradas como áreas protegidas capaces de dar fe de la seguridad jurídica, la permanencia, la gestión y el compromiso a largo plazo, y 2) S 37D genera un beneficio financiero sustancial y tangible que ayuda a los propietarios a cumplir sus responsabilidades de gestión, fomenta su motivación en el mediano y largo plazo, además de facilitar la eficiencia fiscal necesaria para conseguir el éxito sostenido de aquellas actividades económicas compatibles con las APPs.

Autor: Candice Stevens, BirdLife South Africa

\section{Buena práctica 3.1.2: Diseñar distintos 'grados' de incentivos}

Los criterios de elegibilidad para poder acceder a incentivos pueden tener mayores matices que el simple requisito de contar con el estatus de APP. En otras palabras, es posible establecer distintos grados de incentivos. Por ejemplo, el tamaño de la recompensa puede depender del valor social y de conservación de la APP, como en Australia, donde los incentivos son mayores para las áreas con alta biodiversidad e identificadas como prioritarias para la conservación extendida, o para aquellas que ofrecen beneficios adicionales para la conservación, como seguridad hídrica o creación de empleos. Los incentivos también se pueden utilizar para aumentar el nivel de compromiso, como es el caso de la aplicación de mayores restricciones para el uso del suelo y periodos de protección más largos, como sucede en Sudáfrica (ver Caso 10).

\section{Buena práctica 3.1.3: Ofrecer una combinación de} alternativas de incentivos

Mientras más amplia sea la variedad de incentivos ofrecidos, y más flexible sea el programa de la APP, mayor será el atractivo para los propietarios (Cumming, 2007; Selinske et al., 2017).
Buena práctica 3.1.4: Los incentivos pueden provenir de múltiples fuentes

Los incentivos no tienen por qué ser entregados únicamente por la principal entidad implementadora vinculada a la APP. Organizaciones como ONGs, entidades corporativas u otros programas gubernamentales también pueden asociarse a las APPs y ofrecer incentivos como mentorías sobre gobernanza o capacitación sobre gestión de incendios. En ese caso, la agencia de implementación necesitaría encontrar estos otros socios y facilitar su apoyo. De igual manera, las redes de propietarios pueden apoyarse entre sí, como lo demuestra la Buena práctica 3.5.1 (ver también Sección 8).

\section{Buena práctica 3.1.5: Abordar los desincentivos a los que están expuestos los propietarios cuando establecen o gestionan APPs}

Es importante tratar de comprender las barreras - o desincentivosa las que los propietarios se exponen al crear o gestionar APPs. Algunas de estas barreras pueden abordarse mediante la creación de incentivos 'positivos'. Por ejemplo, si la idea de manejar un área protegida de manera activa le resulta intimidante a un propietario, el apoyo práctico del Estado, una ONG u otras APPs (Principio 2.5) podría servir como motivación. A veces, las barreras pueden ser de tipo financiero, como la insuficiencia de recursos para una gestión a largo plazo, y otras pueden estar relacionadas con aspectos no financieros, como la falta de conocimiento sobre el ecosistema o un acceso limitado a mercados de productos verdes, tales como el turismo ecológico sostenible (ver Leung et al., 2018). Las barreras también pueden ser legales o incluir sanciones fiscales, como un aumento en los impuestos sobre la tierra, una sanción económica por la falta de aprovechamiento productivo de tierras o la pérdida de subsidios disponibles para otros sectores, como las industrias primarias (Smith et al., 2016).

\section{Buena práctica 3.1.6: Trabajar con los propietarios para adaptar y revisar los incentivos}

Los incentivos, desincentivos e incentivos perversos deben tomarse en consideración apenas se comienza a diseñar un programa de APP y, también, en la medida en que este evoluciona. A la vez, es clave escuchar las observaciones de los propietarios y estar abierto a realizar cambios según corresponda. Por ejemplo, el primer incentivo fiscal planteado en Sudáfrica resultó no ser tan efectivo para los propietarios, por lo que fue necesario enmendar esa importante legislación tributaria con el fin de mejorar su eficiencia (ver Caso 10 de Sudáfrica).

\section{Principio 3.2: Los incentivos se deben diseñar para motivar tanto el establecimiento de la APP como su gobernanza y gestión a largo plazo}

Los incentivos para el establecimiento de APPs pueden ser distintos a aquellos que ayudan a garantizar su gestión en el largo plazo (ver Cuadro 3.3). A pesar de que los propietarios pueden optar por incursionar en acuerdos de largo plazo, para proteger su territorios terrestres o marinos a partir de una ética de conservación, su compromiso con el programa puede depender de la experiencia que hayan tenido, por ejemplo, con las agencias de conservación que brindan apoyo o con el tipo de asistencia recibida para la gestión (Selinske et al., 2015). 


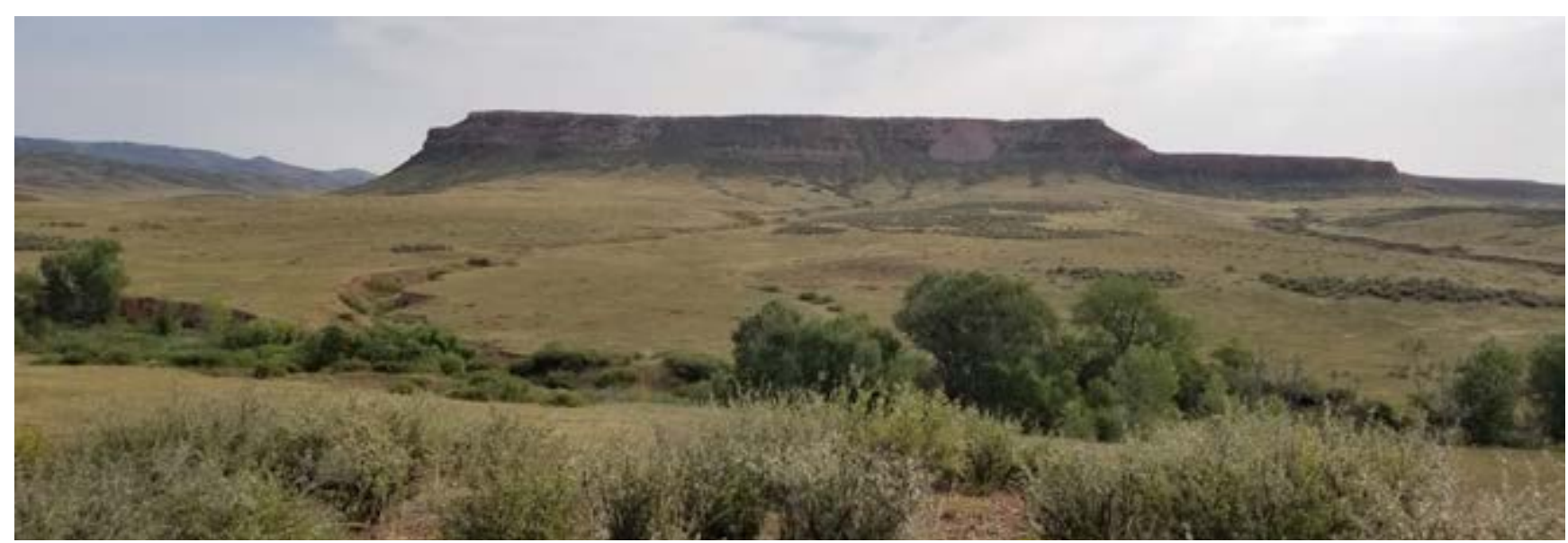

Table Top Conservation Bank @ Ben Guillon

\section{Cuadro 3.3 \\ Table Top Conservation Bank, EE. UU.}

La propiedad Table Top está ubicada en el norte de la cordillera Frontal, en el estado de Colorado, EE. UU., y ha sido reconocida como un área crítica para el hábitat del ratón saltarín de las praderas (Zapus hudsonius preblei). La propiedad le pertenece al Colorado State Land Board (CSLB, por su sigla en inglés), ${ }^{70}$ una agencia pública cuya misión es gestionar las tierras con el fin de, por un lado, generar ingresos razonables y de manera constante para la educación (preescolar y secundaria), y por otro, preservar de manera adecuada este activo patrimonial. Antes el sitio era utilizado para el pastoreo de ganado, lo que impactaba las áreas ribereñas, esenciales para el ratón. La Table Top Conservation Company — sociedad de responsabilidad limitada (SRL) - , una subsidiaria de Conservation Investment Management LLC (CIM) -empresa de asesoría financiera para la conservación - y el CSLB formaron una innovadora asociación público-privada para desarrollar un banco de conservación bajo la Ley de Especies en Peligro de Extinción de los EE. UU. La CIM hoy trabaja con un grupo de consultores líder, junto con inversionistas individuales, y espera poder destinar más de USD 2.000.000 para el desarrollo y la gestión de este banco de conservación -incluyendo la restauración de la zona ribereña-, junto con la implementación de estrategias para alcanzar un equilibrio entre la conservación y las necesidades de los ganaderos. Los inversionistas comparten las ganancias generadas a partir de la venta de créditos de mitigación con el CSLB, a cambio del uso de la tierra y la obligación de protegerla de forma permanente. Esta estructura le permite al CSLB cumplir con su doble misión de generar ingresos y garantizar la conservación a largo plazo sin tener que tomar riesgos financieros significativos ni desarrollar experticia interna sobre el banco de conservación (Colorado State Land Board, 2017).

Autor: Ben Guillon, WRA, Inc.
Buena práctica 3.2.1: Los incentivos dirigidos a motivar el compromiso a largo plazo deben ser sostenibles por un periodo de tiempo similar a la duración de este

Los incentivos ineficaces o provisionales pueden incitar a la creación de APPs 'temporales' que desaparecen cuando los incentivos expiran, incluso cuando el objetivo inicial era la protección permanente. Por el contrario, los fondos dedicados con un plan de inversión a largo plazo, como los fondos de fideicomiso, son herramientas valiosas para el apoyo de APPs (ver Cuadro 3.3). Los incentivos deben ser flexibles y ajustarse a los cambios de las condiciones. En Brasil, por ejemplo, se está desarrollando un proyecto piloto denominado Conservação em Ciclo Contínuo: Como Gerar Recursos com a Natureza e Garantir a Sustentabilidade Financeira de RPPNs, ${ }^{71}$ cuyo objetivo es desarrollar proyectos y acciones para generar recursos financieros, parte de los cuales son asignados para la creación de un fondo de fideicomiso. Este fondo brinda apoyo a la gestión y protección de reservas a largo plazo. En Australia, por ejemplo, la formación de ONGs, por medio del programa David Thomas Challenge ${ }^{72}$ de The Nature Conservancy, exigía la creación de un fondo de fideicomiso para la gestión futura.

\section{Principio 3.3: Identificar y evitar los incentivos perversos}

Los incentivos perversos son aquellos desarrollados con otro objetivo en mente, como estimular la agricultura o la producción de energía, y que pueden tener consecuencias negativas involuntarias para la conservación de la biodiversidad (Gordon et al., 2015). Con el fin de evitar ese tipo de efectos, es necesario considerar de qué modo los incentivos pueden interferir unos con otros en relación con el logro de los resultados de conservación.

\section{Buena práctica 3.3.1: Abordar los subsidios perverso que desincentivan el establecimiento y la gestión de APPs}

Los subsidios que generan incentivos perversos pueden eliminarse ejerciendo presión directamente contra el subsidio, creando un subsidio 'igual pero opuesto' que facilite la conservación (como se ha hecho en Sudáfrica con la creación de incentivos para APPs relacionados con las tasas de impuesto y a la propiedad, y cuyo fin 
es compensar la pérdida de incentivos destinados a la agricultura), o 'reverdecer' el subsidio original (por ejemplo, subsidios agrícolas verdes o ecológicos). Este último enfoque suele ser el más efectivo.

\section{Principio 3.4: El reconocimiento y el apoyo son incentivos clave para las APPs}

Un incentivo importante para los propietarios de APPs es la posibilidad de poder sentirse miembros de una comunidad esforzada por promover la conservación (ver Caso 7 de Nueva Zelanda). Las relaciones entre los propietarios, las ONGs y las autoridades gubernamentales de conservación también son un factor que puede motivar la formación de una APP. Para algunos propietarios, los incentivos no relacionados con las finanzas pueden ser tan significativos - si es que no más - como los financieros (Selinske et al., 2015). No obstante, es importante tener en cuenta que no todos los propietarios de APPs buscan obtener un reconocimiento externo por sus esfuerzos.

Buena práctica 3.4.1: Los propietarios de las APPs deben ser reconocidos e impulsados a sentirse parte de una comunidad de áreas protegidas más amplia

El reconocimiento y la conexión con los pares pueden ser incentivos importantes, particularmente cuando es solo una persona la que establece la APP (ver Caso 9 de Samoa). En Brasil, por ejemplo, el gobierno declaró el 31 de enero como el Día Nacional de las APPs. El propósito de este día es reconocer el esfuerzo de los propietarios por preservar la naturaleza, destacar la relevancia de la inversión privada en el mantenimiento de la biodiversidad y reconocer los esfuerzos públicos de conservación. Cada año se realizan diversos eventos para celebrar esta causa, durante los cuales: suelen crearse nuevas reservas, se anuncian nuevos programas de apoyo y se desencadena una movilización positiva en torno a los temas relacionados con las APPs, lo que termina generando interés mediático. Por su parte, la Red Argentina de Reservas Naturales Privadas realiza una Jornada a Puertas Abiertas, que consiste en una visita grupal a una APP (junto con sus miembros y otros propietarios de APPs), y a través de la cual se busca: informar sobre el modo en que el área se gestiona, intercambiar experiencias y generar una instancia en la que los propietarios de la red puedan compartir. Esta práctica ha tenido como consecuencia reconocimiento, motivación y aprendizaje para todo el grupo. En Perú, aquellos propietarios que reciben la Resolución Ministerial ${ }^{73}$ del gobierno se sienten reconocidos y orgullosos, incluso, cuando esta haya demostrado no agregar valor adicional a los incentivos directos ni tampoco a los beneficios (SERNANP, 2014).

De acuerdo con investigaciones realizadas en Sudáfrica, las relaciones positivas generadas entre los propietarios, las agencias de conservación y las ONGs juegan un rol importante en la promoción del compromiso de los propietarios, particularmente en incentivarlos a mantener los acuerdos de APPs a largo plazo (Selinske et al., 2015). En Nueva Zelanda, los acuerdos de conservación se han vuelto una norma social para los propietarios (ver Caso 7). El hecho de sentirse parte de una comunidad que piensa parecido ayuda a que las personas mantengan sus acuerdos de APPs.

\section{Principio 3.5: La gestión directa y el apoyo técnico para la gestión de una APP son incentivos que favorecen el compromiso a largo plazo}

La gestión directa y el apoyo técnico son clave para motivar a los propietarios, pues combinan los beneficios, provenientes del ahorro tangible de costos, con la promoción de un sentido de pertenencia a una comunidad más amplia. Este tipo de vínculo puede facilitar la construcción de relaciones y aumentar el nivel de conciencia ambiental. El desarrollo colaborativo de los planes de manejo y la entrega de ayuda para abordar temas prácticos y especializados, como la gestión de incendios y el control de especies invasoras, pueden ser útiles (Buena práctica 2.5.4, Caso 8 de Perú y 9 de Samoa). La entrega de apoyo puede relacionarse con la gestión de la biodiversidad, la gobernanza, la obtención de certificados, el manejo de procesos burocráticos y operaciones de gestión, entre otros. Además, tanto las capacitaciones como lo que se puede aprender de los pares pueden ser instancias valiosas.

Para poder elaborar la planificación financiera y establecer provisiones garantes de la protección a largo plazo, es necesario ser capaz de cubrir el costo total asociado a las necesidades de conservación. En aquellos casos en que una organización solo adquiere algunos derechos específicos sobre el uso de suelo de una propiedad (por ejemplo, servidumbres o restricciones), mientras el propietario continúe ocupando y haciendo uso de la tierra, los costos asociados a la conservación podrían ser más bajos que aquellos asociados a una propiedad de pleno dominio. De cualquier modo, es importante contar con las provisiones financieras necesarias para poder monitorear los gastos y costos legales asociados al eventual incumplimiento de un acuerdo de conservación existente.

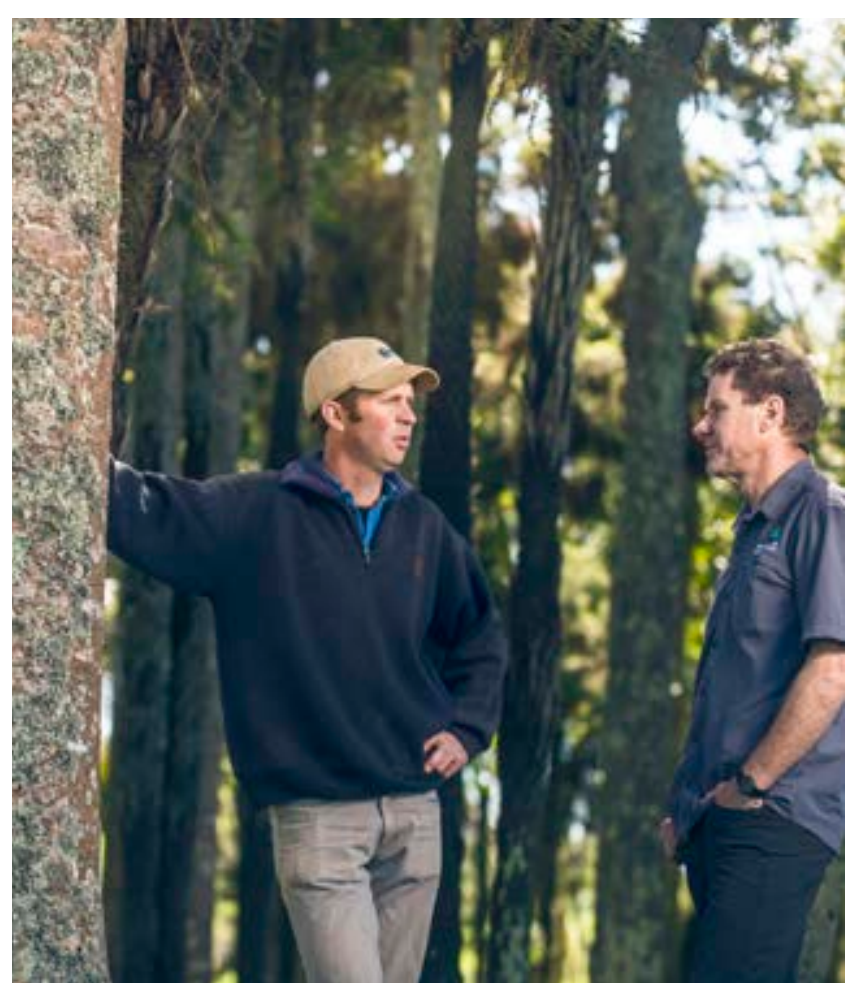

Reunión entre un representante regional del QEll con un contratista de un acuerdo de conservación al lado de un kauri (Agathis australis) en Waikato (C) QEll National Trust 
Buena práctica 3.5.1: El apoyo en la gestión puede provenir de distintos actores

En Nueva Zelanda, por ejemplo, grupos conformados por quienes han firmado acuerdos ofrecen salidas de campo y capacitaciones dictadas por los mismos miembros, los que además trabajan de manera colaborativa en el predio del otro (Buena práctica 8.2.1). En los programas de gestión de biodiversidad sudafricanos, la autoridad de conservación estatal, junto con el propietario, confeccionan los planes de manejo, esto usualmente con el apoyo y la participación de ONGs. En el estado de São Paulo, Brasil, los propietarios de las reservas preparan el plan de protección junto con la policía ambiental, cuya función es apoyar las acciones de protección e inspección.

\section{Principio 3.6: El apoyo en marketing es un incentivo eficaz para APPs con el potencial de generar ingresos}

En algunos casos, la posibilidad de generar ingresos de las APPs es distinta a la que presentan las áreas protegidas por el Estado, por ejemplo, al atraer distintos mercados de ecoturismo. Las APPs suelen estar mejor posicionadas para retener ingresos que las áreas protegidas por el Estado, en las que ingresos, como las tarifas de entrada, son destinados a fondos estatales en lugar de ser retenidos para la gestión del área protegida.

Buena práctica 3.6.1: Diseñar incentivos que aporten reconocimiento y valor de marketing a las APPs que generan ingresos, a partir de su estatus y las prácticas que promueven la biodiversidad

El reconocimiento formal de las APPs puede traducirse en un valor agregado de marketing y, por consiguiente, beneficiar a aquellas áreas que combinan sus actividades con operaciones que generan ingresos (ver Sección 5, que se refiere específicamente a APPs con fines de lucro que generan ingresos como subtipo). De esta manera, este tipo de APPs puede aprovechar el reconocimiento ecológico para mejorar su acceso al mercado, como es el caso de aquellas pertenecientes al sector de ecoturismo (ver Cuadro 8.3).

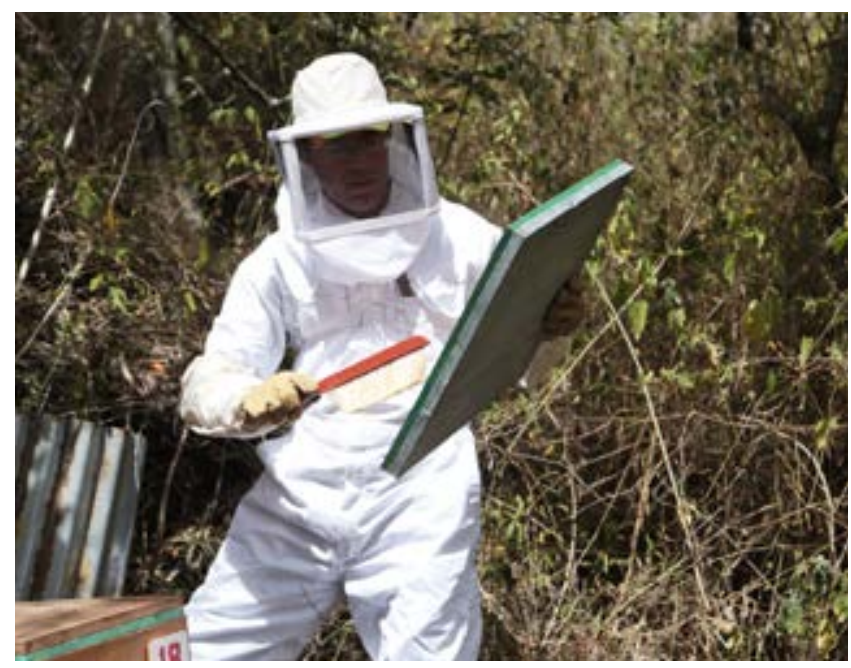

Perico Heredia, dueño de la APP Milpuj-La Heredad en Amazonas, extrayendo miel que luego se venderá en tiendas a lo largo de Perú, gracias a los esfuerzos de marketing realizados por la red de APPs (C) Conservamos por Naturaleza / SPDA

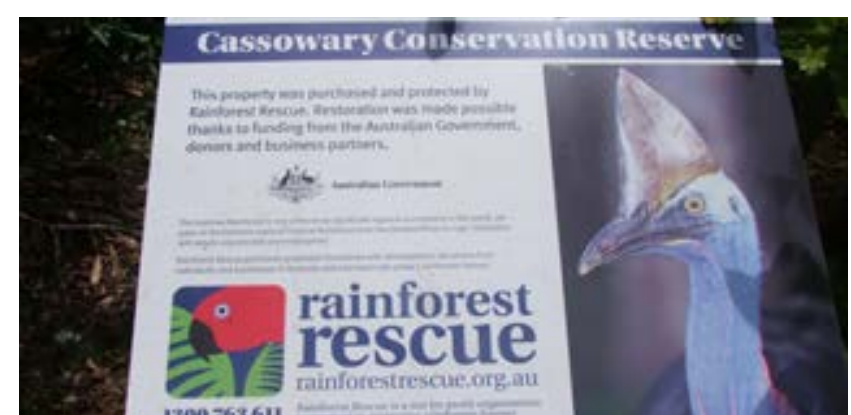

El Gobierno Australiano ha ayudado a financiar diversas APPs,

incluyendo aquellas que protegen el casuario austral (Casuarius casuarius) (C) James Fitzsimons

\section{Principio 3.7: Los incentivos financieros son importantes para el establecimiento y la gestión de las APPs}

Los incentivos financieros incluyen pagos directos, incentivos fiscales y el apalancamiento de fondos de contrapartida. El fin de algunos es motivar el establecimiento de APPs, como para la adquisición de tierras, otros compensan a los propietarios por los costos relacionados con la gestión de la APP u ofrecen beneficios financieros adicionales que exceden de los costos incurridos.

Buena práctica 3.7.1: Buscar oportunidades para apalancar fondos adicionales que complementen la inversión de la APP

El estatus de APP puede otorgar credibilidad a los proyectos en busca de donantes interesados en invertir en conservación. La protección formal de una APP puede hacer que la recaudación de fondos se vuelva más fácil para un propietario, pues el estatus de APP puede brindar credibilidad frente a quienes desean invertir en la conservación. Los fondos apalancados y de contrapartida, provenientes de organizaciones de APPs (como los land trusts), son catalizadores importantes que facilitan el desarrollo de estas. Por ejemplo, el gobierno australiano, como parte del National Reserve System Programme, le otorgó a land trusts privados hasta dos tercios del precio para la adquisición de tierras con valor de conservación alto, y además llenó vacíos en la representatividad del sistema de áreas protegidas desde 1996-2010 (Fitzsimons, 2015). El Plan de Manejo de Aves Acuáticas Norte América, ${ }^{74}$ una fuente de financiamiento trilateral entre Canadá, los EE. UU. y México, también asigna fondos de contrapartida a las APPs.

Buena práctica 3.7.2: Los pagos directos pueden ser utilizados para compensar a los propietarios por los costos reales o los costos de oportunidad

Podría decirse que las dos formas más conocidas de pagos directos para APPs son, por un lado, las compras de servidumbres de conservación y, por el otro, los pagos por servicios ecosistémicos (ver Cuadro 3.4). Los propietarios suelen donar servidumbres de conservación, pero a veces estas son adquiridas por organizaciones públicas o privadas. En los EE. UU., por ejemplo, The Nature Conservancy adquiere servidumbres de conservación cuando el propietario no tiene acceso al beneficio de exención tributaria asociado y, además, se considera que su tierra es de alta prioridad. Otro tipo de servidumbre disponible es el split receipt, una forma de donación a través de la cual el propietario recibe parte del dinero y dona el remanente del valor total. 


\section{Cuadro 3.4 \\ Uso de pagos por servicios ambientales para financiar APPs}

Los pagos por servicios ambientales (PSA) se basan en un modelo donde los beneficiarios - o usuarios - de un servicio ecosistémico, como la regulación de aguas, realizan un pago directo o indirecto al proveedor de ese servicio a cambio de prestación de servicios y mantenimiento (Greiber, 2009). Usualmente, el proveedor es el mismo propietario o la entidad responsable de gestionar la tierra. El comprador es el usuario intermedio, que puede ser público o privado, local, nacional o internacional. La escala del esquema PSA depende del sistema ambiental. Algunos ejemplos comunes de servicios ambientales que forman parte de esquemas PSA son: el almacenamiento de carbono, la cantidad y la calidad del agua. Los esquemas PSA suelen basarse en acuerdos voluntarios.

Existen muchos esquemas PSA que no necesariamente derivan en una APP o benefician a las APPs (por ejemplo, cuando un acuerdo con un propietario resulta en un contrato de protección de tierras de corto plazo). No obstante, los esquemas PSA pueden ser utilizados para realizar pagos directos a los propietarios de APPs. Por ejemplo, algunos estados en Brasil dirigen programas de PSA para APPs, como es el caso de São Paulo. Aquí, a los propietarios se les paga por la conservación de la biodiversidad y la producción de agua. Para esto, se requiere la creación de un plan de acción para la APP y la verificación de la prestación de servicios. Existe otro ejemplo en Fiyi, donde Conservation International se asoció con Fiji Water $^{75}$ para financiar las 16.340 ha de la Sovi Basin Protected Area $^{76}$ mediante un arrendamiento a 99 años con el iTaukei Lands Trust Board y propietarios de la cuenca de Sovi. Con el fin de generar ingresos para los propietarios, la compañía de agua embotellada Fiji Water creó y otorgó un trust fund (o fondo fiduciario). Los intereses acumulados por este trust fund facilitan el pago de las primas de los arrendamientos, compensan las regalías no recaudadas provenientes de la madera, ofrecen oportunidades de desarrollo a las comunidades y permiten implementar el plan de manejo (Keppel et al., 2012).

El programa de PSA de México, implementado por la Comisión Nacional Forestal (CONAFOR), entrega apoyo por un periodo de 5 años para prevenir el cambio en el uso de suelo de zonas boscosas. Las propiedades beneficiadas no son consideradas APPs debido a la corta duración del apoyo, y también porque, pese a que estos acuerdos son renovables, los propietarios deben volver a concursar y competir con muchos otros para permanecer en el programa. Sin embargo, una pequeña parte de este ha evolucionado hacia la permanencia de largo plazo por medio del establecimiento del Fondo para la Biodiversidad, un trust fund de apoyo, también dirigido por la CONAFOR. El fondo ha sido capitalizado para otorgar apoyo utilizando únicamente los intereses y manteniendo el capital, y está orientado a la protección de biodiversidad en estado crítico presente en una serie limitada de propiedades identificadas (privadas y comunales) situadas fuera de las áreas protegidas por el gobierno, lo que lo convierte en un incentivo eficaz para el establecimiento de una cantidad limitada de APPs. Existe una gran cantidad de literatura disponible sobre el PSA (GrêtRegamey et al., 2017; Neugarten et al., 2018). ${ }^{77}$
Buena práctica 3.7.3: Los incentivos financieros deben promover la adicionalidad

Se pueden destinar recursos financieros adicionales a las APPs cuando estas ofrecen servicios ecosistémicos que trascienden el campo de conservación de la biodiversidad, como adaptación y mitigación del cambio climático, o gestión de captación para abastecimiento hídrico. De ser esta una alternativa, el acuerdo inicial de APP o acuerdo de conservación debe ser diseñado para que esto sea viable. Por ejemplo, en Nueva Zelanda, los propietarios que cuentan con acuerdos de conservación pueden beneficiarse directamente del intercambio de bonos de carbono relacionados con la regeneración de bosques, y en algunos casos las captaciones también pueden beneficiarse del ciclo de nutrientes para proteger la calidad del agua dulce de los lagos y ríos.

Buena práctica 3.7.4: Los incentivos fiscales deben desarrollarse conjuntamente entre los departamentos de finanzas de los gobiernos, otras agencias gubernamentales relevantes, ONGs y los propietarios

Los incentivos fiscales se refieren al uso de impuestos y subsidios ofrecidos con el objetivo de cambiar el comportamiento en torno a las APPs. Algunos ejemplos incluyen la exención de impuestos para propietarios de APPs (ver Caso 10 de Sudáfrica y 11 de EE. UU.) o para obtener subsidios para la prestación de servicios ambientales, como en México. La creación de incentivos fiscales, usualmente a cargo de departamentos gubernamentales de medioambiente $\mathrm{u}$ ONGs, necesita desarrollarse junto con otros departamentos gubernamentales relevantes u ONGs. Aquellos que estén negociando incentivos deben demostrarle al gobierno la importancia y el valor de apoyar a esa APP por medio del uso de incentivos fiscales. (Los incentivos pueden traspasar limitaciones fronterizas. Por ejemplo, la organización de beneficencia American Friends [AF] of Canadian Land Trusts ${ }^{78}$ se estableció para permitirles a propietarios estadounidenses con tierras en Canadá la posibilidad de donar propiedades a organizaciones de los EE. UU. y poder acceder a incentivos tributarios, y a cambio la AF transfiere la propiedad al land trust canadiense para su gestión a largo plazo).

\section{Buena práctica 3.7.5: Los incentivos fiscales se deben diseñar de manera de poder aplicarlos a la mayor cantidad de APPs}

Por ejemplo, el diseño de incentivos tributarios a los que solo pueden acceder algunos individuos de alto patrimonio neto y no el resto de propietarios de APPs con un nivel de biodiversidad similar puede ser, en definitiva, un problema. En estos casos, es necesario que existan otros incentivos disponibles para estos propietarios. 


\title{
Sección 4: Garantizando la permanencia de las áreas bajo protección privada
}

\author{
¿Hacia quién está dirigida esta sección? \\ Esta sección está dirigida a quienes desarrollan políticas o incentivos para las APPs \\ (por ejemplo, gobiernos, ONGs, fundaciones privadas, etc.) y a propietarios en proceso \\ de establecimiento o formalización de APPs. Al igual que en otras secciones, el enfoque \\ está puesto sobre aquellas áreas desarrolladas y gestionadas de acuerdo con la \\ definición de APPs de la UICN.
}

La 'conservación de la naturaleza a largo plazo' es un componente central en la definición de área protegida de la UICN. En el caso de las áreas protegidas manejadas por el gobierno, este concepto es parte importante de su establecimiento, debido a políticas y legislaciones relacionadas. Sin embargo, en otros tipos de gobernanza la idea de 'a largo plazo' no siempre es tan clara.

En Áreas bajo protección privada: Mirando al futuro (Stolton et al., 2014) se propone 'propósito de conservación a largo plazo' en lugar de 'conservación a largo plazo' con el fin de abarcar un rango más amplio de situaciones. El informe sugiere que las APPs deben demostrar que su propósito de conservación es 'perpetuo' o, al menos, 'a largo plazo'. La definición de 'largo plazo' presenta dificultades para cualquier área protegida, por lo que incluso aquellas bajo manejo gubernamental pueden no estar seguras en el largo plazo (Mascia et al., 2014). En el caso de las APPs, se entiende que implementar los acuerdos garantes de una protección permanente (acuerdos de conservación, acuerdos de tenencia, entre otros) puede tomar tiempo. De acuerdo con las directrices de la UICN, una APP debe demostrar un compromiso de conservación a perpetuidad o, al menos, de conservación a largo plazo, el que debe perdurar al menos 25 años (Stolton et al., 2014).

\section{Principio 4.1: La gobernanza de una APP debe representar el compromiso de alcanzar la conservación a largo plazo}

\footnotetext{
Si bien este principio es, por definición, un prerrequisito para las áreas protegidas, merece la pena reiterarlo, pues existe la posibilidad de que algunas APPs no cuenten con la misma protección legal que aquellas gestionadas por el Estado (Lausche, 2011; Bingham et al., 2017). En estos casos, el compromiso a largo plazo (junto con otros medios efectivos) se convierte en un componente central para su permanencia. Tanto el registro del compromiso (de conservación a largo plazo) por parte de ONGs ambientales, como las políticas relacionadas con la disposición de tierras para la conservación, sirven para demostrar el compromiso de conservación a largo plazo. Aquellos acuerdos de fideicomiso
}

con donantes de tierras o de financiamiento para la adquisición de tierras también pueden servir como prueba de un compromiso de conservación a largo plazo.

En algunos países, la declaración de una APP implica obligaciones legales para la protección a largo plazo (ver Caso 2 de Brasil), lo que la posiciona en igualdad de condiciones respecto de las áreas gestionadas por el Estado. Cuando este no es el caso, el compromiso a largo plazo puede demostrarse por medio de una o más de las siguientes opciones:

- Demostrar que el estatus de APP trascenderá los cambios de propietario, por medio de servidumbres, acuerdos de conservación, testamentos, cesión de los derechos de desarrollo inmobiliario y otras medidas legales pertinentes.

- Cuando los acuerdos formales asociados a APPs son a corto plazo, el compromiso de conservación a largo plazo puede ser demostrado por medio de pruebas que den fe de este último propósito (por ejemplo, acuerdos renovables u objetivos a largo plazo declarados). La finalización de un acuerdo de duración limitada jamás debe prohibir la continuación de una APP. Es importante establecer alguna forma de monitoreo que corrobore que el compromiso de conservación inicial persista, mientras se establecen las medidas de conservación a largo plazo.

- Prácticas de gestión activas o pasivas, cuyo objetivo sea proteger la integridad de los recursos naturales presentes en la APP, y validadas por gobiernos o unidades locales o regionales de asociaciones nacionales de APPs que cuenten con directrices y un registro nacional.

En el caso de aquellas APPs de pleno dominio de organismos de conservación, la protección puede provenir de una restricción de conservación impuesta sobre terceros (agencia gubernamental u otro tipo de organización no gubernamental), o bien, de una ley específica que asegure el estatus de conservación de manera legal. No obstante, los planes de manejo de un organismo de conservación también pueden servir para documentar su compromiso. 


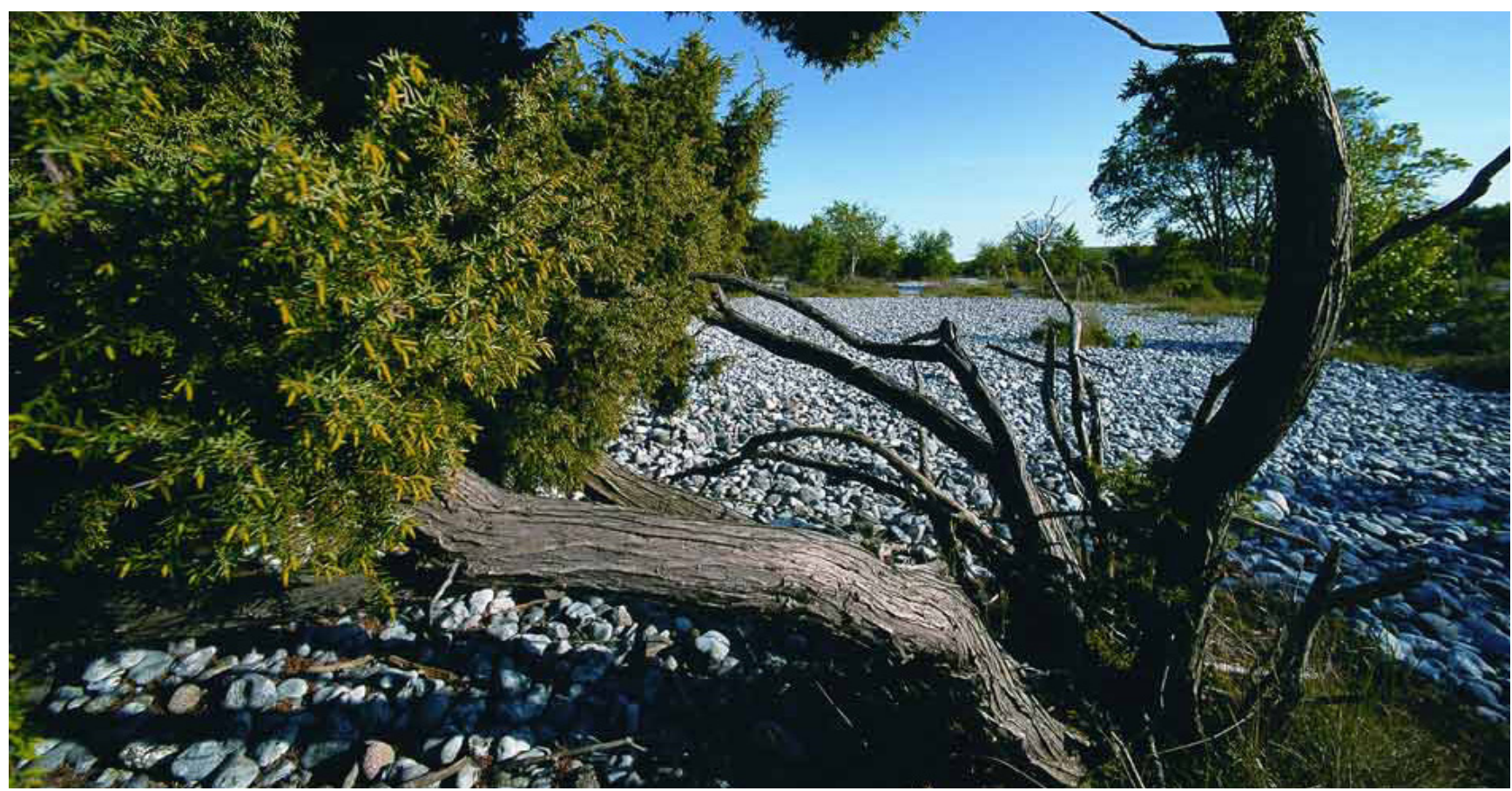

La DBU es dueña de la mayor parte de la red National Natural Heritage en Alemania. Las áreas de pedernales en Rügen solían ser parte de un campo de entrenamiento militar (c) Norbert Rosing

Buena práctica 4.1.1: La mejor forma de garantizar la permanencia es por medio de instrumentos legales que fortalezcan el ejercicio de gobernanza

La conservación a largo plazo de APPs suele lograrse de manera más efectiva cuando existe un instrumento legal vinculado a un agente de conservación institucionalizado, o mediante un estatus legal otorgado por agencias gubernamentales pertinentes (ver Caso 11 de EE. UU.). En Brasil, las APPs se crean a perpetuidad por medio de una ley garante de la conservación de la tierra, incluso si los propietarios o la gobernanza cambian a lo largo del tiempo. En el Reino Unido, las APPs de propiedad del National Trust son inalienables, es decir, la tierra no puede ser ni vendida ni hipotecada contra los deseos del trust sin la realización de un procedimiento parlamentario especial (Crofts et al., 2014). Nueva Zelanda también cuenta con acuerdos similares (ver Caso 7). Otros instrumentos legales apropiados son aquellas provisiones legalmente vinculantes, que forman parte de las escrituras de incorporación de land trusts, y que incluyen prácticas de disposición de tierras para la conservación a instituciones que comparten los mismos valores, además de garantizar la permanencia de los objetivos de conservación ante una falla institucional imprevista de un land trust.

En Alemania, el gobierno federal, por medio de la iniciativa National Natural Heritage, ${ }^{79}$ exime de privatización a aquellas tierras de propiedad federal con un alto valor de conservación, y las transfiere sin costo a los estados (Länder) u organizaciones - o fundaciones - dedicadas a la conservación, con el fin de asegurar que su protección sea permanente y, así, garantizar la conservación de la naturaleza (ver Caso 5 de Alemania). Junto con ser vinculantes para los futuros propietarios, los mecanismos apropiados deben contar con medidas de seguridad que aseguren la permanencia de las APPs (por ejemplo, involucrando a terceros en un acuerdo de conservación, ver Hardy et al., 2017), como sucede en Australia (ver Caso 1). En Kenia, en 2012, la fundación Lewa Wildlife Conservancy (ver Caso 6) adquirió la mayoría de los terrenos sobre los cuales se había establecido este santuario.
Por medio de este acuerdo, el primero de este tipo en el país, la propiedad de las tierras se transfirió de propietarios individuales a institucionales, para así asegurar la existencia y función de Lewa en relación con la conservación, la comunidad y el desarrollo. Otro ejemplo es el de la APP costarricense Lapa Ríos, la cual firmó la primera servidumbre en aplicarse a un negocio privado con el fin de asegurar el futuro de la reserva (ver Caso 4).

Existen distintos tipos de instrumentos privados para la conservación de territorios privados a lo largo del mundo, cada uno de ellos con implicancias legales derivadas de legislaciones nacionales o regionales. El glosario contiene definiciones de algunas de estas herramientas. Chile, por ejemplo, fue pionero en elaborar un instrumento legal para la protección de territorios privados, denominado Derecho Real de Conservación (DRC). Anteriormente, el sistema legal exigía que los acuerdos de conservación (servidumbres) se realizaran solamente entre propiedades adyacentes. Tras su aprobación en 2016, el DRC cambió la ley para permitir la protección de territorios privados en cualquier lugar. Al poco tiempo, Chile estableció el primer DRC entre una iniciativa de conservación privada, la Hacienda el Durazno, y un servicio público, la Corporación Nacional Forestal (CONAF). Este importante avance podría servir como precedente para aquellos países cuyos sistemas de tenencia de tierras se basan en el código civil.

Buena práctica 4.1.2: En caso de no contar con instrumentos legales, los acuerdos deben ser renovables y el compromiso de conservación a perpetuidad

Asegurar la permanencia de una APP es clave para la obtención de beneficios provenientes de la conservación a largo plazo. No obstante, las buenas prácticas en pos de la permanencia de las APPs no deberían limitar el desarrollo de iniciativas de conservación de territorios terrestres o marinos que podrían, en el futuro, ser incorporados formalmente como APPs. En muchos casos, no es posible realizar acuerdos permanentes, o bien, los 


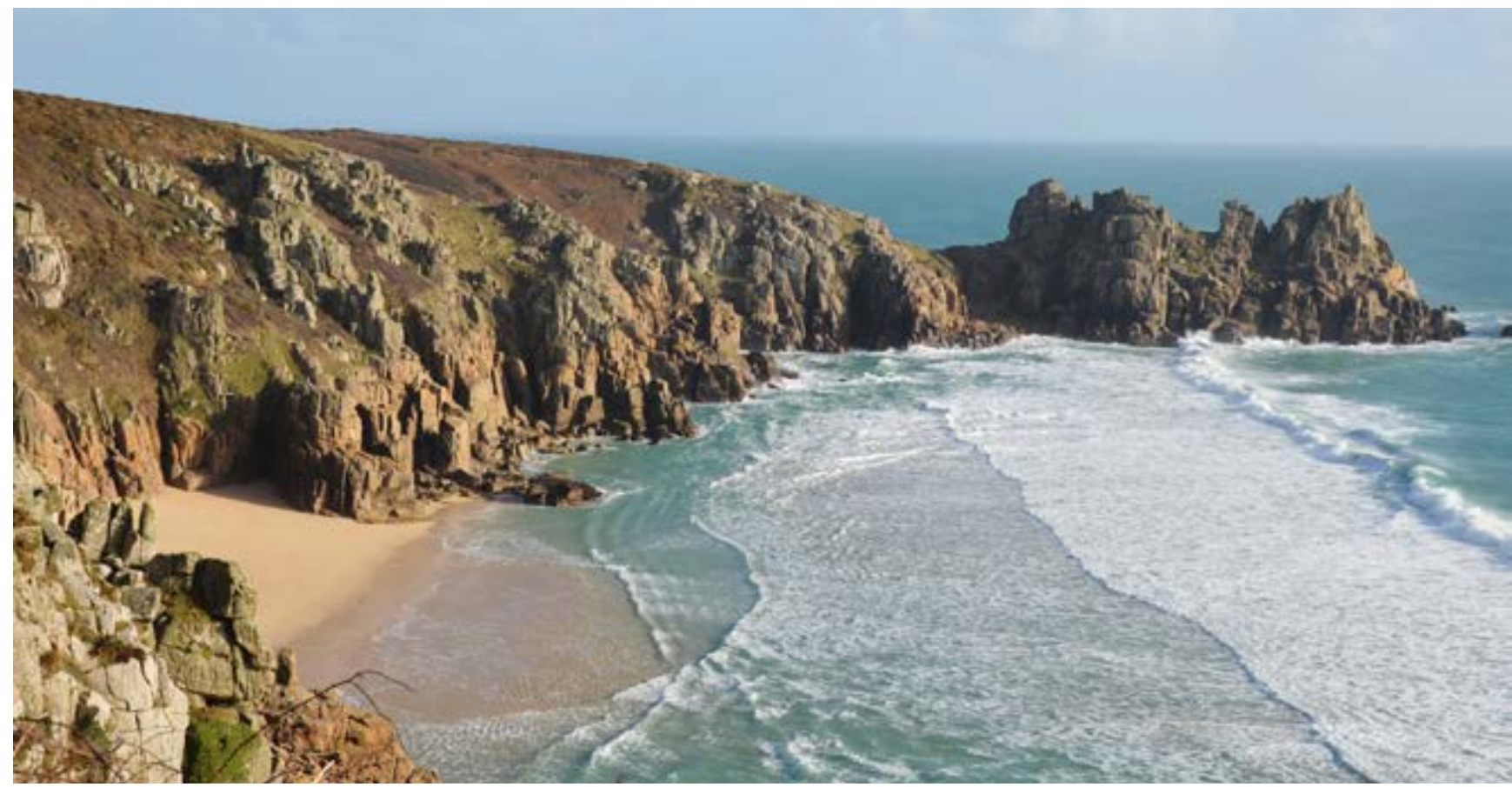

Áreas de propiedad del National Trust del Reino Unido, como partes de la península de Penwith en Cornwall, son algunos de los lugares más protegidos del Reino Unido @ Sue Stolton

propietarios recién comienzan a experimentar la conservación de sus territorios terrestres o marinos, y sus compromisos. Lo ideal es que los acuerdos de conservación de plazo fijo sean renovables y que la intención sea la de renovarlos a perpetuidad (Buena práctica 3.2.1). Sin embargo, en algunos países existen incentivos financieros gubernamentales de corto plazo, por ejemplo, los pagos por servicios ambientales, como lo es el PSA (ver Cuadro 3.4), que terminan convirtiéndose en un punto de partida para prácticas asociadas a la conservación de tierras privadas con el potencial de llegar a convertirse en iniciativas de largo plazo. En otros casos, el financiamiento entregado por las agencias gubernamentales, u ONGs de conservación para proteger el valor ambiental crítico en propiedades privadas, solo puede ser brindado por periodos de tiempo limitados mientras se busca otra solución. En estos escenarios, la finalización de un acuerdo no necesariamente significa que se perderá el estatus de APP si existe un compromiso por encontrar un mecanismo alternativo para la conservación a largo plazo (Stolton et al., 2014).

\section{Buena práctica 4.1.3: En caso de no existir instrumentos legales o estatus disponibles o plausibles, debe generarse algún tipo de prueba transparente de compromiso a largo plazo}

Cuando no se cuenta con instrumentos legales, se recomienda que las áreas que desean ser reconocidas como APPs (ver Principio 7.1) tengan una prueba por escrito de su compromiso a largo plazo, disponible para las partes interesadas, junto con una descripción de cómo ese compromiso será implementado a lo largo del tiempo. Estas pruebas pueden incluir, por ejemplo, planes de manejo a largo plazo. Cualquier proceso llevado a cabo con el fin de modificar estos documentos debe ser transparente, de modo que quede claro si el área debe dejar de ser considerada una APP. La transparencia no siempre significa que la información deba estar disponible para todos, pero esta debe ser entregada ya sea a una institución de conservación reconocida, a una red establecida de APPs, o a una agencia gubernamental pertinente.
Actualmente, varios países presentan dificultades para conseguir documentos legales o formales que demuestren un compromiso de conservación a largo plazo. La práctica de trasparencia es un signo de madurez en una APP y debe ser considerada como objetivo para aquellas que están desarrollándose. Las restricciones que hoy obstaculizan estas buenas prácticas no debieran, por sí mismas, inhibir la expansión de las APPs en aquellos países con el potencial para desarrollar dichos sistemas.

Los agentes de conservación institucionales de carácter nacional o regional pueden ayudar a brindar pruebas que demuestran compromiso y transparencia, sin perder su anonimato (Buena práctica 7.1.4). Es posible que conseguir transparencia sea difícil en aquellas áreas en las que las estructuras de gobernanza centrales o regionales son débiles o se han deteriorado debido a actividades ilícitas. Por ejemplo, durante la compilación de una base de datos de APPs en México (Bezaury-Creel et al., 2012), algunos propietarios privados manifestaron su preocupación ante la posibilidad de que el mal uso de información pudiese derivar en invasiones a sus predios. (En algunas partes de México, se estima que las tierras no trabajadas o utilizadas para la ganadería son 'desperdiciadas' y que, por lo tanto, otros están en su 'derecho' de traspasar la propiedad privada para hacer uso de la tierra). En otros casos, los propietarios discutieron sobre la posibilidad de que las comunidades locales perciban a las APPs como tierras abandonadas o improductivas, a las que se les puede dar un mejor uso con beneficios a corto plazo, sin considerar el amplio espectro de servicios ambientales que la APP puede ofrecer en el largo plazo (Bingham et al., 2017). 


\section{Buena práctica 4.1.4: Deben asegurarse los compromisos de conservación para futuros propietarios}

Los propietarios deben tener en cuenta la sucesión y de qué manera se mantendrá el compromiso de conservación de su APP cuando cambie su propietario. Las APPs, por lo tanto, deben estructurarse de modo que el compromiso de conservación sea obligatorio para todos los futuros propietarios (ver Principio 1.5, Buena práctica 3.2.1 y Caso 1 de Australia). Es fundamental exigir un plan de sucesión claro para la continuación de la APP, uno que incluya aspectos como restricciones al uso de suelo, financiamiento y transferencia de propiedad. En aquellos casos en que los sucesores no estén dispuestos o no sean capaces de mantener el compromiso de conservación, debiera existir una alternativa que permita transferir la APP a una institución de conservación confiable.

En su forma más básica, una iniciativa de conservación individual puede surgir a partir de la intención de un propietario privado e independiente de proteger la tierra por razones espirituales, estéticas, prácticas u otros motivos. Estas iniciativas pueden convertirse en esfuerzos de conservación eficientes que perduran mientras el individuo esté vivo o, incluso, por más tiempo si se convierten en proyectos familiares traspasados de generación en generación. No obstante, cuando no existen instrumentos legales disponibles para lograr la conservación a largo plazo, o cuando se carece de la planificación financiera requerida para la gestión de tierras, estos proyectos se vuelven más propensos al fracaso con el paso de los años. Como estas iniciativas suelen no ser verificables por terceros, la transparencia de su compromiso no siempre es evidente. Si los instrumentos legales no son los apropiados o no están disponibles, se pueden emplear buenas prácticas que van desde el establecimiento de una declaración de conservación verificable (Buena práctica 4.1.3) o mecanismos de financiamiento de largo plazo, como trust funds (o fondos fiduciarios) específicos que puedan cubrir los futuros costos de gestión. También existe la opción de establecer disposiciones jurídicas que permitan transferir la gobernanza o propiedad a una institución de gestión de la conservación (por ejemplo, una ONG o un land trust), en caso de que el propietario de la APP deje la propiedad, o si existe una falta de interés por parte de sus herederos de continuar protegiendo la tierra (ver Caso 4 de Costa Rica).

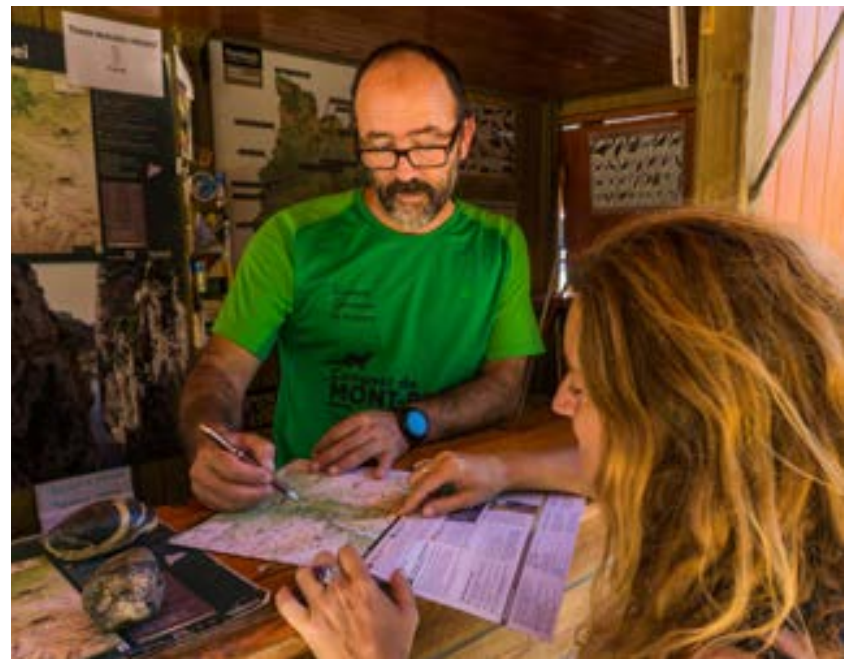

España tiene varias redes de conservación privada bien establecidas. La reserva Desfiladero de Mont-rebei fue adquirida por la Fundació Catalunya-La Pedrera en 1999 @ F Fundació Catalunya-La Pedrera

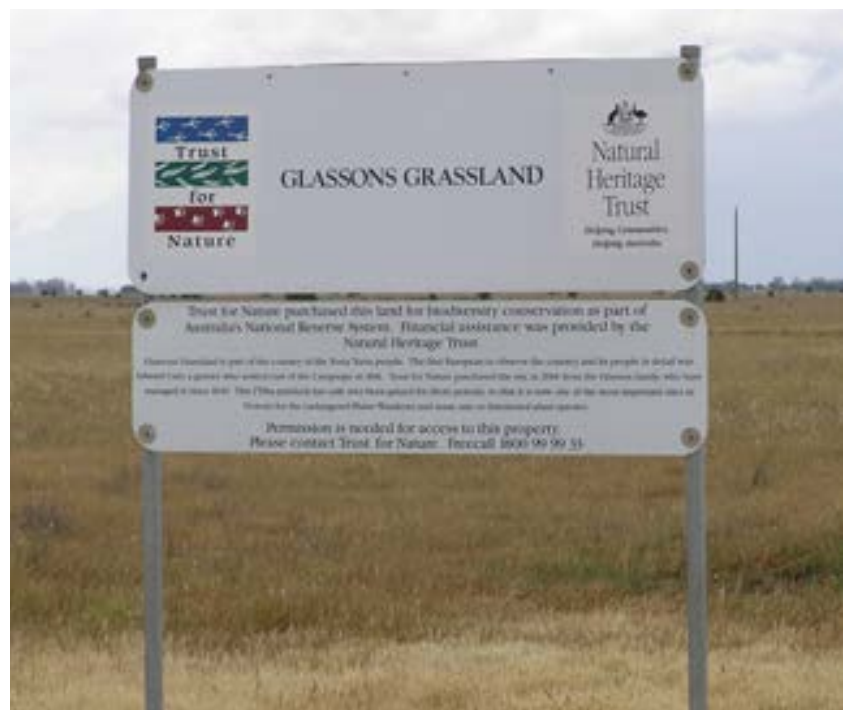

Glassons Grassland, Trust for Nature, Victoria del Norte, Australia (C) James Fitzsimons

Buena práctica 4.1.5: Ser miembro de una red de conservación privada puede ayudar a garantizar la conservación a largo plazo

La organización formal de propietarios comprometidos con la conservación y la gestión de tierras a largo plazo puede favorecer la continuidad de la protección (ver Sección 8).

\section{Buena práctica 4.1.6: Las APPs deben contar con mecanismos que aseguren que el compromiso de conservación no variará con el cambio de liderazgo}

La continuidad de una conservación a largo plazo puede verse afectada en APPs con ciclos de planificación a corto plazo o en casos donde el liderazgo y la propiedad cambien abruptamente (ver Buena práctica 1.5.1). Un ejemplo de esto sucedió en Eslovenia, donde una empresa estableció una APP por motivos filantrópicos, pero luego abandonó su compromiso para disminuir costos. Otra manera de garantizar que el foco esté puesto en la conservación es la implementación de políticas aprobadas por el consejo supervisor, o bien, reservando puestos en consejos donde se toman decisiones para representantes interesados en la conservación, entre otras alternativas.

\section{Buena práctica 4.1.7: Los programas de gobierno que permitan o motiven la conservación privada deben incluir disposiciones para la permanencia}

Existen muchos gobiernos nacionales y regionales que han explorado diversos tipos de esfuerzos colaborativos, ya sea incorporando APPs dentro de sus estrategias de conservación (Buena práctica 1.2.1), o entregando incentivos económicos específicos o fiscales para apoyar las prácticas de conservación en tierras privadas (Buena práctica 4.1.1 y Caso 2 de Brasil).

Las tierras incorporadas a estrategias de conservación gubernamentales han sido integradas a sistemas de protección de la biodiversidad más amplios, por medio de una serie de herramientas, incluyendo acuerdos de conservación legalmente vinculantes y establecidos a perpetuidad entre el gobierno y los propietarios, como en el caso de Nueva Zelanda (Caso 7), donde el acuerdo de conservación se registra junto con la escritura del 
terreno (ver Caso 11 de EE. UU.). En México, los propietarios pueden declarar APPs, voluntariamente, por un periodo de 15 (un mínimo bastante menor a los 25 años recomendados por estas directrices) a 99 años, y estas áreas son luego consideradas equivalentes a un área protegida del gobierno. En ambos casos, las APPs son integradas al sistema nacional de áreas protegidas. En Europa las tierras con fines de conservación obtenidas con la ayuda económica del programa LIFE, ${ }^{80}$ de la Unión Europea, solo pueden acceder a estos fondos si existe un compromiso de conservación a perpetuidad. En Australia, los fondos del gobierno federal asignados a aquellas tierras adquiridas por ONGs, para ser incluidas al Sistema Nacional de Reservas, exigen el establecimiento de un acuerdo de conservación al poco tiempo de la compra (Fitzsimons, 2015).

\section{Principio 4.2: Muchos instrumentos de conservación privada pueden contribuir a la permanencia de la APP}

Tanto la cantidad de APPs como la cantidad de personas y prácticas involucradas están creciendo a escala global. Junto con el desarrollo de diversos tipos de APPs, existe un rango cada vez más amplio de enfoques que pueden contribuir a asegurar la permanencia de los resultados de conservación.

Buena práctica 4.2.1: Las restricciones de conservación que limitan ciertos tipos de uso pueden llegar a convertirse en herramientas de conservación eficientes y, a veces, pueden estar alineadas con la definición de APP

\section{La propiedad sobre territorios terrestres y marinos incluye} diversos tipos de derechos de uso, por ejemplo, para el desarrollo comercial, actividades agrícolas, producción forestal, pesca, caza o recreación. Los acuerdos de conservación establecidos legalmente incluyen diversas clases de instrumentos con la suficiente fuerza legal como para, por un lado, excluir algunos - o la mayoría- de los derechos de uso y, por el otro, permitir el uso de otros derechos (ver Caso 11 de EE. UU.). Los propietarios no siempre tendrán control sobre todos los derechos de tierra o agua conservada al establecer un área. Estas pueden seguir siendo consideradas APPs si cuentan con planes garantes de aquellos derechos que puedan afectar el éxito de conservación y, por consiguiente, de la conservación a largo plazo (ver Cuadro 4.2).

\section{Buena práctica 4.2.2: Deben establecerse} procesos para enfrentar las posibles violaciones a las restricciones de conservación

Es clave contar con un plan de mitigación y acción en caso de que surjan problemas de cumplimiento. Por ejemplo, ese plan debe indicar en qué instancias los organismos fiscalizadores deben negociar el incumplimiento de las obligaciones, o bajo qué circunstancias es necesario tomar acciones legales (incluyendo en el caso de terceros) (Rissman \& Butsic, 2011; Hardy et al., 2017).
Cuadro 4.1

\section{'Comprar-proteger-revender': Una estrategia de conservación de The Nature Conservancy}

El Conservation Buyer Program es una de las estrategias utilizadas por The Nature Conservancy para lograr la conservación a largo plazo, mientras libera recursos financieros para adquirir nuevas APPs, particularmente en los EE. UU. La aplicación de esta estrategia incluye tres pasos básicos: se adquieren tierras en áreas de conservación críticas; se diseñan servidumbres de conservación apropiadas para esa tierra, con el fin de proteger sus características naturales, y se venden tierras a individuos que aceptan los términos de la servidumbre de conservación protectora, por medio de lo cual se consigue la permanencia de la APP (TNC, 2018). Este programa forma parte de un método de conservación más amplio, 'comprarproteger-revender', que incluye el uso de fondos rotatorios y fondos de capital más sustanciales para comprar, proteger y revender tierras privadas con valores de conservación en todo el mundo (Hardy et al., 2018 a,b,c).

Autor: James Fitzsimons, The Nature Conservancy

\section{Cuadro 4.2}

\section{Controlando los derechos, asegurando la conservación: Reserva Karukinka, Chile}

La Reserva Karukinka ${ }^{81}$ (300.000 ha), ubicada en Tierra del Fuego, Chile, le pertenece y es manejada por la Wildlife Conservation Society (WCS, por su sigla en inglés). A pesar de que la reserva es propiedad de la WCS, los derechos de minería de extracción de turba (25\% del terreno está cubierto de turberas) estaban disponibles para quienes quisieran explotar este recurso. Luego de años de investigación y de difundir el valor de conservación global de las turberas entre las distintas partes interesadas, la WCS consiguió que Karukinka fuera declarada Área de Interés Científico por el Gobierno de Chile en 2015. Esto condujo a que Chile, a través del Ministerio de Minería, declarara la investigación científica como prioridad dentro de la Reserva Karukinka, para luego, así, prohibir la minería de turba y proteger el territorio de esta amenaza a perpetuidad (Saavedra et al., 2011; Gobierno de Chile, 2015).

Autor: Melissa Carmody, Wildlife Conservation Society 


\section{Sección 5: Temas relacionados con subtipos específicos de áreas bajo protección privada}

¿Hacia quién está dirigida esta sección?

Esta sección está dirigida principalmente a las APPs gestionadas por empresas y a aquellas que siguen un modelo con fines de lucro, sobre todo, por medio del turismo. También puede resultar de interés para otros subtipos específicos de APPs, tales como centros de investigación o entidades religiosas.

No todas las APPs son dirigidas por personas u ONGs/trusts de conservación. Algunas les pertenecen a - o son gestionadas por - instituciones que no necesariamente están vinculadas con la conservación como, por ejemplo, los centros de investigación, entidades religiosas o empresas con fines de lucro - las compañías mineras o de combustibles fósiles, operadores turísticos, operaciones forestales o agrícolas y, también, empresarios sociales-. Aunque son menos conocidas que las APPs a cargo de individuos u ONGs, esta clase de APPs puede ser igualmente valiosa. Y pese a que están expuestas a ciertos desafíos, también ofrecen importantes oportunidades, como conseguir que nuevos sectores de la sociedad participen en la gestión para la conservación.

Cuando las empresas son propietarias directas de territorios terrestres o marinos, a veces optan por establecer APPs en áreas que no usarán con fines productivos. En algunos países, las empresas son obligadas a contrarrestar el daño derivado de sus operaciones, lo que puede resultar en la adquisición de territorios terrestres o marinos para establecer una APP. Por su parte, algunas instituciones religiosas destinan una porción de sus tierras para el establecimiento de áreas protegidas como un modo concreto de expresar su fe y compromiso con la naturaleza. Los centros de investigación y las universidades (Levitt, 2014), en ciertas ocasiones, también destinan áreas para la protección como parte del mandato de investigación del centro (ver Cuadro 5.1). Las leyes y políticas individuales pueden funcionar como motivación. Por último, se está volviendo cada vez más común el establecimiento de APPs que generan ingresos, por ejemplo, por medio de actividades turísticas que implican visitas de día o estadía nocturna. En un contexto en el que la brecha de financiamiento para las áreas protegidas limita tanto el aumento de la cobertura del área como la mantención de la red existente, las APPs con fines de lucro tienen el potencial de ofrecer un modelo financiero sostenible, cuyas ganancias aseguran la biodiversidad y los resultados de desarrollo a largo plazo. Ampliar el tipo de partes interesadas en estas iniciativas también puede derivar en dinamismo, habilidades nuevas y una nueva manera de pensar en el sector de APPs. No obstante, en todos los casos siempre es necesario contar con sistemas de gestión eficientes y realizar buenas prácticas que permitan tanto generar suficientes ganancias como sostener la conservación y los resultados de desarrollo a largo plazo, además de asegurar que la generación de ganancias no pase a ser más importante que el objetivo de conservación.

Al igual que los otros tipos de APPs aquí mencionados, estos sitios deben cumplir con la definición de APP de la UICN (ver Sección A) e, idealmente, deben ser gestionados de acuerdo con las buenas prácticas presentadas en este volumen. En el caso de aquellos que tengan un objetivo de conservación, pero que no sean APPs, estos podrían ajustarse a la definición aún en desarrollo de 'otras medidas de conservación eficaces basadas en áreas' (ver Apéndice 1).

\section{Principio 5.1: Los subtipos específicos de APPs pueden requerir modos de reconocimiento, apoyo y motivación a medida}

Si bien las APPs dirigidas por grandes ONGs suelen adaptarse bien a las estrategias nacionales y regionales, aquellas a cargo de empresas, universidades $u$ organizaciones religiosas pueden encontrarse un tanto alejadas de la conservación más convencional. Adicionalmente, puede que algunos de estos propietarios/gestores de APPs cuenten con poco conocimiento, experiencia o acceso a información científica relacionada con la conservación. Aun cuando aquí también se aplican los mismos estándares dirigidos al resto de las APPs, es posible que quienes estén a cargo de la gestión necesiten distintos tipos de ayuda e incentivos para construir conocimiento y experiencia. Es por eso que las buenas prácticas abordan tanto las necesidades de la APP como su posición dentro de una comunidad de conservación más amplia en términos de alcance y participación.

Buena práctica 5.1.1: Incentivar a las empresas dueñas/gestoras a registrar sus APPs en la Base de Datos Mundial de Áreas Protegidas (WDPA)

La Sección 7 ofrece orientaciones específicas sobre cómo enlistar y registrar una APP. No obstante, es posible que aquellas entidades que no forman parte de la comunidad de conservación más 


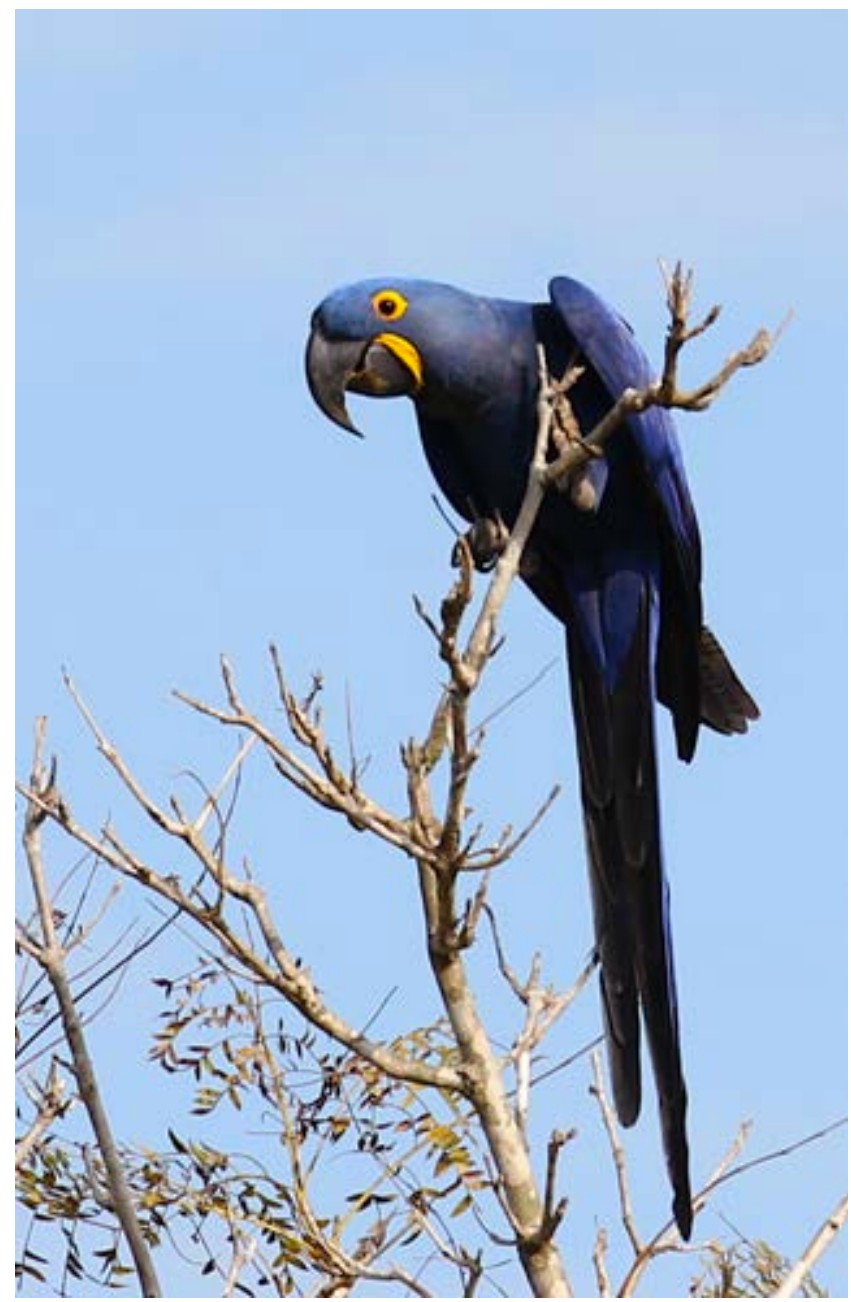

Guacamayo jacinto @ Brent Mitchell

convencional necesiten incentivos o lineamientos específicos que las ayuden en el proceso de registro de sus sitios como parte del patrimonio de áreas protegidas nacional e internacional. En algunos países, a veces se requieren evaluaciones y asesores externos que, por un lado, verifiquen que las áreas sean compatibles con la definición de APP y, por otro, entreguen orientaciones sobre cómo incorporarlas a las listas nacionales de áreas protegidas. Trabajar con ONGs que también gestionan APPs puede servir como punto de partida, así como también con organismos nacionales de la UICN, por ejemplo, los Comités Nacionales y Regionales ${ }^{82}$ (ver Caso 12 del Reino Unido). The Long Run (ver Cuadro 8.3), una entidad que representa a una red de APPs pertenecientes o gestionadas por empresas de turismo, se encarga de entregarle datos a la WDPA (Buena práctica 7.1.4). Tiene, asimismo, la facultad de proponer APPs para que estas sean inscritas - siempre y cuando cumplan con la definición de APP (ver Sección A)—, funciona como punto de contacto para la WDPA y ayuda a sus miembros a recopilar la información requerida. Esta información es posteriormente verificada por un experto local o una entidad de gobierno que confirma la sostenibilidad del sitio y aprueba su registro. Por ejemplo, la Reserva Lapa Ríos, en Costa Rica (ver Caso 4), decidió incorporarse a la lista de la WDPA, reforzando el reconocimiento de su enfoque de conservación. Además, contar con instrumentos legales vinculantes (ver Sección 4) suele garantizar el reconocimiento nacional, al igual que formar parte de una red de APPs (ver Sección 8).
Buena práctica 5.1.2: Explorar alianzas con ONGs, académicos $u$ otros especialistas para maximizar el valor de la APP

No todos los dueños o administradores de APPs poseen la experticia necesaria para gestionar una APP, ni querrán o podrán invertir en personal especializado. Una manera de conseguir ayuda, formal o informalmente, puede ser por medio de ONGs locales, ciudadanos interesados $u$ otros especialistas o académicos a cambio de un lugar donde poder investigar (Buena práctica 2.5.4). Esta ayuda puede consistir en la entrega de recomendaciones para: el diseño de un plan de manejo simple, la realización de inventarios de especies presentes y el monitoreo a largo plazo, entre otros. En algunos casos, puede que los voluntarios incluso estén disponibles para ayudar con áreas de gestión, como la restauración o la remoción de especies invasoras. Estas alianzas no solo fortalecen la capacidad de las APPs, sino que también las ubican dentro de un paisaje de conservación más amplio.

Estos son algunos de los muchos ejemplos existentes en la actualidad:

- $\quad$ En Laikipia, Kenia, los proyectos Lion Landscapes y Living with Lions realizan investigaciones con el objetivo de reducir el conflicto humano-depredador. La Borana Conservancy, ${ }^{83}$ una organización que se sustenta por medio de ganancias provenientes del turismo, se asoció a estas entidades, lo que no solo le permitió fortalecer su gestión para una mejor conservación de los leones, sino también reducir los conflictos humano-depredador con los pastores vecinos.

- El Refúgio Ecológico Caiman ${ }^{84}$ (Buena práctica 1.5.2), ubicado en Brasil, lleva años contribuyendo a la conservación del guacamayo jacinto (Anodorhynchus hyacinthinus), y también ha participado en la conservación del jaguar (Panthera onca), a través del Oncafari Project. Ambos proyectos han hecho de Caiman un verdadero refugio para estas dos especies, aumentando su población, contribuyendo con conocimientos significativos y permitiendo que la iniciativa se haya transformado en una experiencia única de turismo. Del mismo modo, la alianza con el Instituto Nacional Ecológico Ambiental (INEA, por su sigla en portugués), le brinda apoyo a la iniciativa de turismo Sinal do Vale ${ }^{85}$ para llevar un registro del avance de restauración en la mata atlántica en Brasil.

- En las Maldivas, biólogos marinos de dos ONGs basadas en el Reino Unido le brindaron apoyo al centro turístico Six Senses Lamuu ${ }^{86}$ para el desarrollo de una reserva marina.

- La empresa forestal UPM maneja las 1.400 ha del Bosque Griffin, ${ }^{87}$ ubicado al lado del Parque Nacional Repovesi en el sur de Finlandia. El área está a cargo del Aarnikotka Forest Administrative Committee, un comité conformado por representantes de UPM, Metsähallitus Parks and Wildlife (la agencia nacional de áreas protegidas) y el South-Eastern Finland Centre for Economic Development, Transport and the Environment. 


\section{Cuadro 5.1 \\ Entidades de investigación de APPs: Estación Nanya, Australia}

Ubicada al oeste de Nueva Gales del Sur, Australia, la Estación Nanya $^{88}$ fue adquirida por la Universidad de Ballart (hoy conocida como Federation University Australia) en 2004 con fines de conservación, investigación y educación. La propiedad de 40.000 ha fue comprada con fondos provenientes del National Reserve System Program del gobierno de Australia (ver Caso 1 de Australia) y contiene un sistema único de lagos salinos naturales, mallee antiguo (especie de eucalipto con múltiples tallos) y una serie de ecosistemas intactos. Todas las actividades de conservación tienen proyectos de investigación asociados e incluyen:

- Reducir la presión del pastoreo sobre la propiedad mediante el cese del suministro de agua artificial (tanques terrestres), el control de cabras y la destrucción de madrigueras de conejos.

- Regenerar comunidades de flora y fauna en peligro de extinción mediante el uso de cercos de separación alrededor de comunidades en estado crítico.

- Proteger la población del faisán australiano (Leipoa ocellata) por medio del control de depredadores exóticos y el monitoreo de los sitios de nidos.

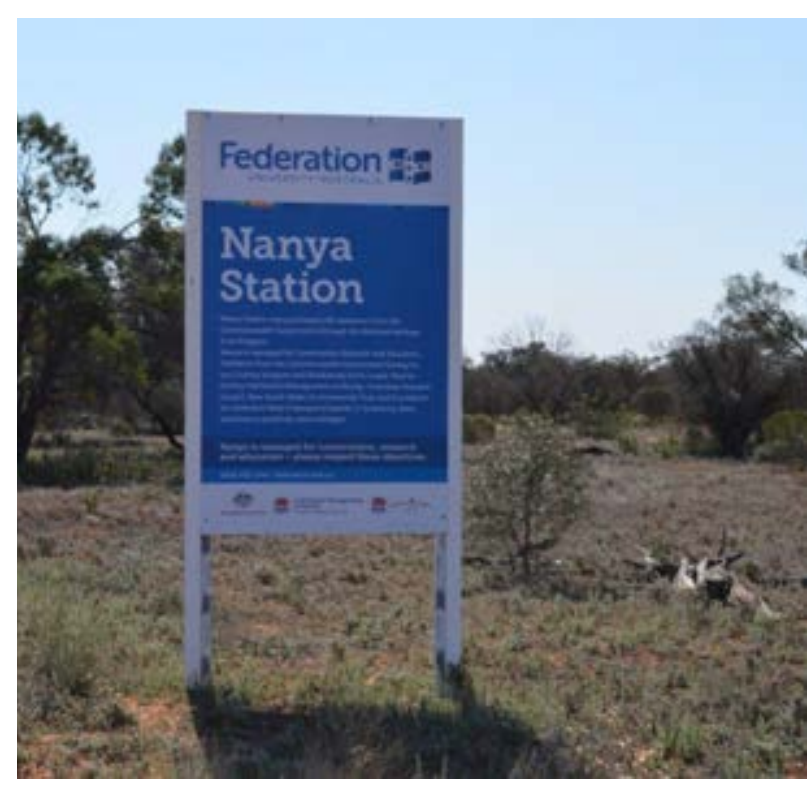

Estación Nanya @ Jamie McDonald

Autor: James Fitzsimons, The Nature Conservancy

\section{Cuadro 5.2 \\ Vino y conservación: Un ejemplo de Australia del Sur}

La propiedad Banrock Station ${ }^{89}$ en Australia del Sur es gestionada por una importante empresa agrícola privada (Accolade Wines Ltd). Además de operar 250 ha de viñas, la compañía lleva más de 25 años comprometida con la restauración de los humedales y las zonas boscosas aledañas, por medio de: la eliminación de presiones del pastoreo de ganado, el control de especies salvajes o de malezas, el restablecimiento de un régimen hidrológico natural, la reintroducción de especies nativas bajo amenaza y la revegetación. Dada sus credenciales ambientales y su designación como sitio Ramsar, el lugar fue seleccionado en 2013 por la agencia ambiental del gobierno estatal para reintroducir la especie Acanthocladium dockeri, una planta que se creía extinta hacía mucho tiempo. Con un promedio de 60.000 visitantes al año, entre una y dos clases en universidades/escuelas y voluntariados (como el grupo International Student Volunteers ${ }^{90}$ ), desde 2005 Banrock Station se ha transformado en un gran ejemplo de trabajo de conservación in situ por parte de una empresa privada interesada en el bien común (Tourenq et al., 2016).

Autor: Banrock Station

\section{Principio 5.2: Las APPs corporativas pueden generar beneficios para las empresas y viceversa}

Al igual que los otros tipos de APPs (ver Sección 1), las razones para establecer APPs corporativas varían, e incluyen:

- Satisfacer el interés personal del director de la empresa.

- Aumentar las credenciales verdes, como en el caso de los productores de vino en Australia del Sur (ver Cuadro 5.2), quienes usan estas credenciales para acceder a mercados de exportación adicionales.

- Dar buen uso a aquellos territorios terrestres o marinos que le pertenecen a la empresa pero que esta ya no utiliza (como sitios de canteras o minas, ver Cuadros 2.7 y 5.3).

- Contar con áreas no aptas para la explotación.

- Poseer áreas particularmente valiosas desde el punto de vista de la conservación (y que posiblemente requieren protección bajo esquemas de certificación).

- Ser áreas bajo restauración.

Aquellas áreas apartadas para ser conservadas en la actualidad, pero cuyo propósito es la explotación futura, no clasificarían como APPs, ya que no podrían demostrar un propósito a largo plazo según se describe en la Sección 4.

La creación de áreas protegidas puede beneficiar a las empresas de distintas maneras, incluyendo:

- Demostrar compromiso con el bien común.

- Desarrollar una imagen más positiva y, con ello, conseguir apoyo de la comunidad. 
- Atraer equipos de trabajo para la gestión de APPs innovadores, que aporten a la empresa habilidades y maneras de pensar nuevas.

- Fortalecer la credibilidad de sus esfuerzos de responsabilidad social empresarial (RSE) y su compromiso con el medioambiente, diferenciándola del resto del mercado, lo que suele reforzarse por medio de la verificación de terceros.

- Proteger aquellos recursos y servicios ecosistémicos de los que la empresa depende para sus operaciones, como la cantidad de agua, calidad del agua, polinizadores y control natural de pestes.

- Brindar oportunidades para generar otras fuentes de ingresos, por ejemplo, por medio de las visitas o la venta de créditos de carbono.

- Crear oportunidades para lograr una mayor integración de la empresa con las comunidades locales, por ejemplo, por medio de la investigación o potenciando las visitas educativas guiadas.

- Ofrecer un espacio para la inspiración o recreación del personal de la empresa, que pueda ser utilizado para una serie de actividades beneficiosas, incluyendo la formación de equipo.

Buena práctica 5.2.1: Tanto las empresas como otros subtipos de APPs pueden hacer uso de fortalezas tales como habilidades administrativas, manejo de recursos, resiliencia financiera y capacidad para la gestión de la conservación

Las APPs administradas por empresas pueden aprovechar aquellas herramientas y habilidades de gestión utilizadas en su negocio principal para potenciar, por ejemplo, la creación de capacidad, las provisiones y las habilidades informáticas, legales y presupuestarias. Además, las APPs pueden beneficiarse del espíritu emprendedor, la efectividad administrativa, la innovación y la toma de riesgos. Si una empresa forma parte de una red de APPs más amplia, de carácter regional o nacional, puede facilitarle la creación de oportunidades que permitan transferir estas habilidades a APPs de otros sectores y a otros tipos de áreas protegidas. Las organizaciones de investigación que gestionan APPs también pueden ser líderes en el ámbito de la gestión de áreas protegidas a escala global. Un ejemplo es la Cedar Creek Ecosystem Science Reserve, ${ }^{91}$ perteneciente a la University of Minnesota (EE. UU.). Operada por la misma, en colaboración con la Minnesota Academy of Science, sus investigadores fueron los primeros en utilizar radio collares para el seguimiento de animales. Llevan alrededor de sesenta años investigando las quemas controladas, y la APP cuenta con una de las comunidades de insectos más estudiadas en el mundo.

\section{Principio 5.3: Las APPs gestionadas por industrias extractivas deben demostrar su contribución a la conservación de la biodiversidad}

Las operaciones de las industrias extractivas, como las de empresas forestales, mineras y de combustibles fósiles son, en definitiva, complejas. Suelen ser propietarias de grandes terrenos no utilizados para la extracción o donde la extracción ya no se realiza (ver Cuadros 2.7 y 5.5). Estos terrenos pueden ser restaurados para la conservación y transformados en importantes APPs para la vida silvestre (especialmente en paisajes culturales), o sitios de patrimonio geológico o de geoturismo.

\section{Cuadro 5.3: \\ Recreando el hábitat tras la extracción de arena y grava: Attenborough Nature Reserve, Reino Unido}

La Attenborough Nature Reserve, ${ }^{92}$ perteneciente a y gestionada por el Nottinghamshire Wildlife Trust, es una APP ubicada sobre una cantera de grava en el valle de Trent, Nottinghamshire, Reino Unido. El sitio estuvo en operación desde 1929 hasta 1966 (cuando se formó la reserva). La compañía CEMEX, sin embargo, continúa extrayendo arena y grava en zonas aledañas. De hecho, las barcazas de la compañía atraviesan la reserva para llegar a la planta de procesamiento. Una vez explotados, los sitios son restaurados como humedales, con una serie de grandes lagos con islotes donde se regeneran zonas de bosques nativos. Estructuras como los carrizales, plataformas de nidos flotantes, pajareras y nidos artificiales promueven el retorno de especies como el avetoro común (Botaurus stellaris), estérnidos, aviones zapadores (Riparia riparia) y búhos. La reserva tiene una superficie de 266 ha que incluyen refugios para la observación de aves o hides, rutas y un centro de interpretación premiado en diversas ocasiones. Sobre uno de los bordes del área corre el río Trent, el que ocasionalmente acarrea agua de inundación y actúa como un corredor de vida silvestre. Esta área recibe una cantidad importante de visitantes que van a observar aves, caminar o correr, lo que ha implicado una cautelosa planificación para poder mantener áreas extensas sin perturbar la vida silvestre. Pese a no tener un origen natural, el área logra sustituir humedales desaparecidos debido a cientos de años de agricultura, y constituye un hábitat importante para las aves acuáticas, especialmente durante el invierno: se han registrado más de 250 especies de aves desde que se creó la reserva (Dudley, 2011).

Autor: Nigel Dudley, Equilibrium Research

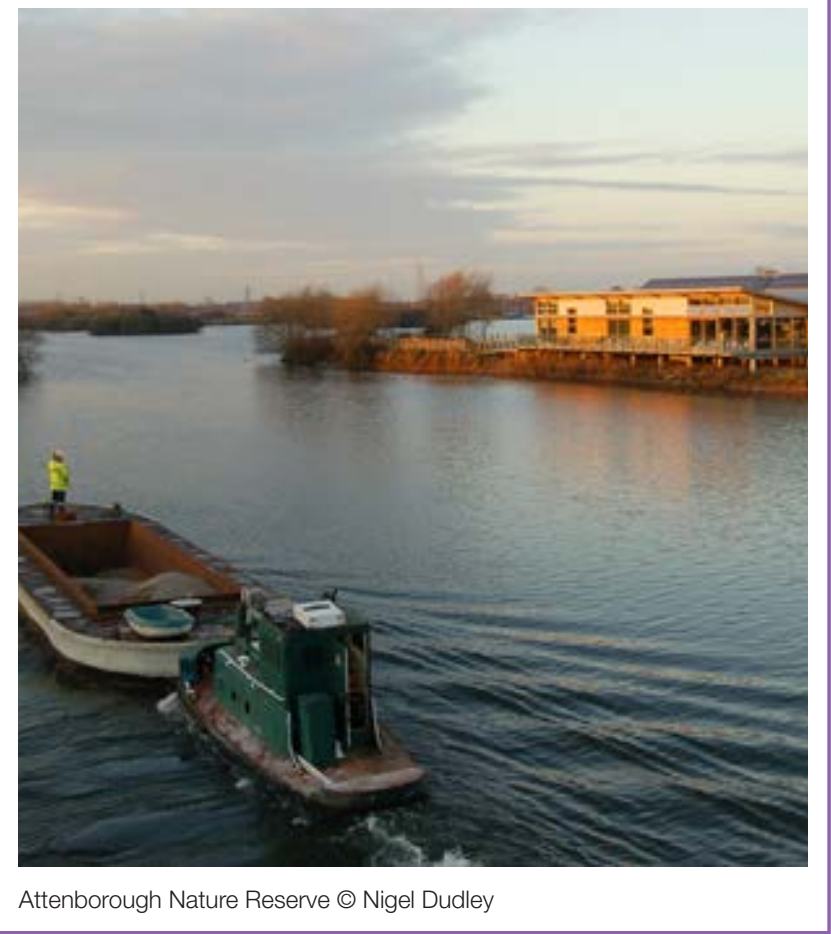




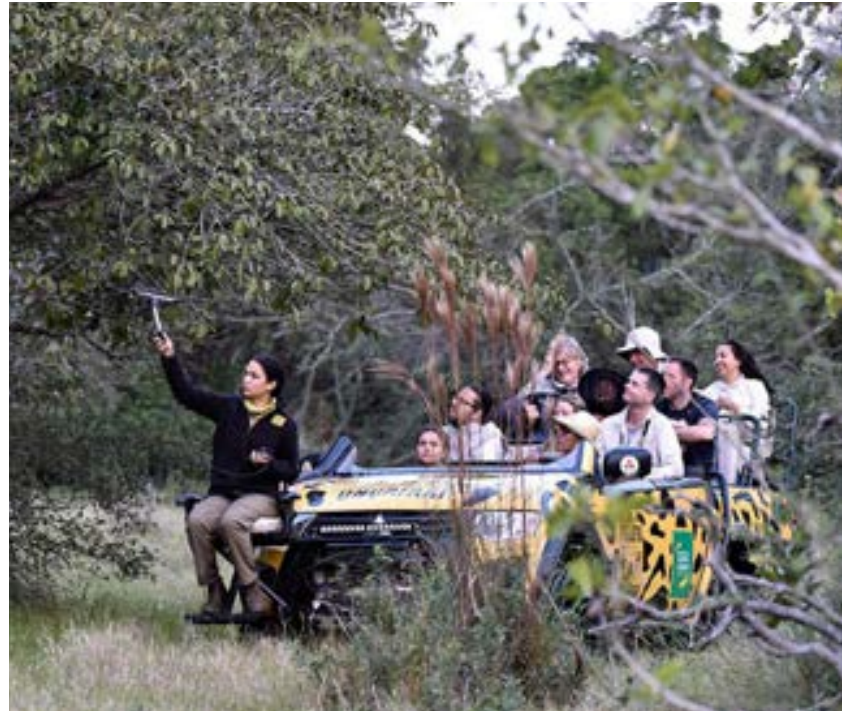

C Project Oncafari

Buena práctica 5.3.1: Una APP gestionada como parte de una operación extractiva debe estar separada de dicha operación

Las APPs vinculadas a operaciones extractivas (es decir, con un tipo de gestión no enfocada en la conservación), como la minería o la actividad forestal, deben tener claridad sobre los márgenes entre el uso de suelo para la extracción y aquel destinado a la conservación. Esto significa que, dentro de los límites de la APP, no pueden coexistir usos incompatibles. Por ejemplo, la primera APP del Sistema Nacional de Áreas Protegidas (SNAP), Esteros y Algarrobales del Río Uruguay (EARU), ${ }^{93}$ clasificada por el Forest Stewardship Council (FSC) como un Bosque de Alto Valor de Conservación, le pertenece a la empresa forestal UPM-Forestal Oriental, la que también la gestiona. Incorporada al sistema nacional en 2015 , las 1.550 ha de paisaje protegido incluyen estuarios, algarrobos (Ceratonia siliqua) y bosques nativos, y forman parte de un sitio Ramsar más extenso.

\section{Principio 5.4: Las APPs establecidas por compañías o empresas con fines de lucro deben asegurarse de alcanzar sus resultados específicos de conservación}

Las empresas con fines de lucro pueden proporcionar un modelo financiero sostenible para las APPs, lo que podría garantizar su longevidad. En el caso del turismo sostenible basado en la naturaleza, por ejemplo, existe una conexión intrínseca entre las ganancias de la empresa y la conservación, en la que las ganancias dependen de la conservación y la conservación suele depender de las ganancias (ver Caso 4 de Costa Rica). Es por ello que, en el caso de este tipo de actividad turística, y aún más cuando se trata de usos de suelo menos compatibles, es de suma importancia abordar la tensión que pueda surgir entre un requerimiento de ganancias a corto plazo y un resultado de conservación. Asimismo, contar con la capacidad de amortiguar los resultados de conservación durante una recesión económica o ante colapsos repentinos del mercado es clave, ya que estos reducen las ganancias de las APPs (por ejemplo, las grandes recesiones turísticas provocadas por factores económicos globales, problemas de seguridad, brotes de enfermedades, etc.).
Buena práctica 5.4.1: Las APPs creadas bajo un modelo de negocios con fines de lucro deben desarrollar modelos financieros resilientes que garanticen resultados de conservación sostenibles

Todas las APPs deben construir modelos de negocio que incorporen aquellos costos de gestión asociados a la conservación de la naturaleza (ver Principio 2.3), lo cual concierne, especialmente, a aquellos emprendimientos con fines de lucro. El apoyo directo proveniente de las operaciones comerciales de actividades de conservación debe ser visto como una estrategia de reinversión prudente. Puede ser útil destinar una parte fija de los ingresos - o ganancias - a actividades de conservación, pues esto permite asegurar un presupuesto predecible para actividades clave. Hay muchos mecanismos de financiamiento directo, incluyendo tasas de conservación por pernoctación en el caso del turismo. Por ejemplo, los visitantes que se alojan en el Segera Retreat, ${ }^{94}$ en Kenia, pagan una tasa por noche y por persona, la que está destinada al apoyo de la conservación. Existen, naturalmente, factores externos que pueden afectar la rentabilidad de las operaciones, poniendo en riesgo las actividades de conservación. Por ello, diversificar las fuentes de ingreso, a lo largo del tiempo, es una estrategia efectiva y útil. En el caso del turismo, puede ser ventajoso pensar en desarrollar productos que permitan expandir los mercados. Cuando la empresa está dirigida a turistas internacionales, y el negocio es significativamente estacional, la creación de paquetes especiales de temporada baja para turistas locales puede ayudar a reducir los problemas de flujo de caja. También es posible considerar productos compatibles que no sean de carácter turístico. Por ejemplo, Tahi, ${ }^{95}$ en Nueva Zelanda, desarrolló una marca sostenible única de miel de manuka con el fin de fortalecer la viabilidad financiera de su APP. Otra buena práctica involucra crear un fondo de reserva que ayude a garantizar la gestión continua de las APPs, en el caso de que la fuente principa de financiamiento colapse (ver Cuadro 5.4). Por último, establecer un vehículo sin fines de lucro para recaudar fondos externos destinados a actividades específicas o con el fin de crear una reserva también puede ser de utilidad. En Namibia, Wolwedans ${ }^{96}$ estableció la Wolwedans Foundation, ${ }^{97}$ la que le permite a las APPs

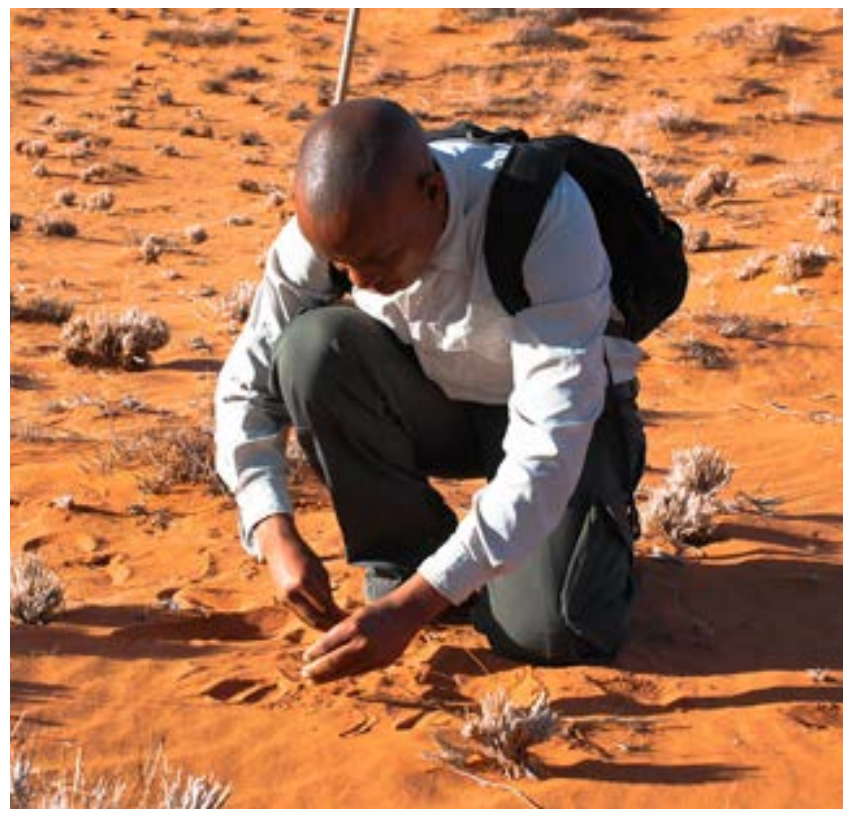

(C) Wolwedans, NamibRand Nature Reserve, Namibia 


\section{Cuadro 5.4 \\ Creando seguridad financiera a largo plazo para la gestión de la Borana Conservancy, Kenia}

Borana, ${ }^{98}$ ubicada en Laikipia, Kenia, es una iniciativa que forma parte de uno de los mayores paisajes de rinocerontes negros en el país (ver Caso 6 de Kenia). La entidad creó una APP sin fines de lucro de 14.000 ha con un claro propósito de conservación. Con el paso del tiempo, ha ido diversificando sus canales de ingresos con el objetivo de aumentar su capacidad y sustentar los costos de funcionamiento derivados de la conservación. Las principales fuentes de ingresos son el turismo y un emprendimiento de ganadería sostenible. Recientemente, Borana estableció una granja de permacultura que abastece las operaciones turísticas, lo que ha mejorado la experiencia de los huéspedes y creado oportunidades para la educación. Como una entidad sin fines de lucro, Borana busca fondos de donantes para apoyar la conservación de rinocerontes y los programas de difusión, y así brindar educación y atención médica y propulsar emprendimientos microempresariales que aseguren el apoyo continuo de la comunidad, en general. Para reducir el nivel de vulnerabilidad de las actividades de conservación ante una posible recesión del sector turismo, Borana estableció una reserva financiera por medio de la venta de acciones dentro de la entidad de conservación. De esta manera, los accionistas se comprometen a sustentar los costos de la gestión en proporción a su participación accionaria. Finalmente, se utilizó el capital obtenido a través de la participación de los accionistas para establecer un fondo de dotación para amortiguar los costos asociados a la conservación ante cualquier caída repentina en los rendimientos comerciales.

Autores: Delphine Malleret King, The Long Run, y Michael Dyer, Borana

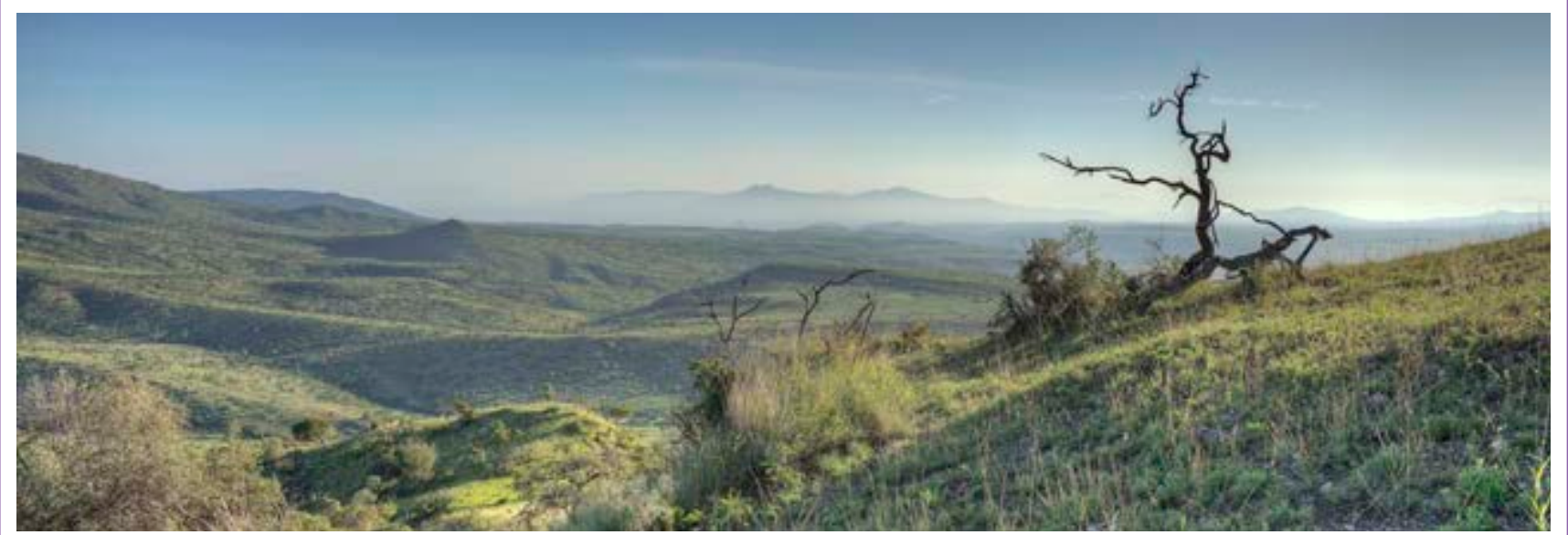

(C) Borana Conservancy, Kenia

recaudar fondos de donantes internacionales para la conservación de la NamibRand Nature Reserve (ver Cuadro 8.4).

\section{Buena práctica 5.4.2: Cualquier tensión inherente que surja entre las ganancias y la conservación debe ser abordada por medio de objetivos bien articulados}

Las operaciones de la empresa no deben incidir negativamente en las actividades de conservación o los valores de la APP, ni tampoco minimizar las posibles consideraciones sociales o económicas (ver Caso 4 de Costa Rica y Caso 6 de Kenia). Para garantizar esto, es clave que las empresas tengan claridad sobre los efectos de sus actividades y cómo mitigarlos. También es importante contar con objetivos de conservación bien articulados (ver Principio 1.2), que se alineen con la definición de APP (ver Principio 1.1) y que refuercen sus elementos comerciales, pero sin ser determinados por ellos. De no ser bien gestionado, el turismo puede tener efectos negativos sobre el medioambiente. Por ejemplo, los visitantes pueden afectar el comportamiento de los animales (patrones de caza de depredadores, sitios de caza), degradar el hábitat (pisotear la vegetación o los corales) e, incluso, impactar el negocio mismo. La aplicación de marcos de gestión basados en estándares existentes sirve para asegurar que los objetivos de conservación se cumplan. Estos pueden ser utilizados para establecer indicadores y estándares en el manejo de visitantes y definir posibles límites de uso para los mismos, de ser necesario. Herramientas como estas pueden ayudar a identificar vulnerabilidades del sistema, por una parte, y a tomar las precauciones necesarias para minimizar los impactos sobre los hábitats y la vida silvestre, por otra parte (ver Cuadro 3.4 en Leung et al., 2018). Por ejemplo, los códigos de conducta para las visitas guiadas pueden incluir restricciones como la distancia mínima desde la que está permitido observar la vida silvestre, el número máximo de automóviles que pueden estar simultáneamente dentro de un área, la obligación de mantenerse en los senderos y, posiblemente, pueden definir zonas de acceso restringido en aquellos sectores claves para la anidación o reproducción. En Mara Conservancies, ${ }^{99}$ en Kenia, un área compuesta de tierras arrendadas a dueños de la comunidad y gestionada por operadores turísticos, el número de camas disponibles para pernoctar (es decir, de visitantes) es limitado. La regla general es de una persona-cama por cada 350 acres (un poco más de 140 ha). Esta medida está integrada a la regla de conservación, cuyo fin es evitar la puesta en peligro de los objetivos de conservación por medio de metas de ganancias de corto plazo. Los procesos de certificación y acreditación, como el reconocimiento de The Long Run GERß (ver Cuadro 8.3), pueden ayudar a las empresas a asegurar un equilibrio óptimo entre los resultados de ganancias, conservación y sociales. 


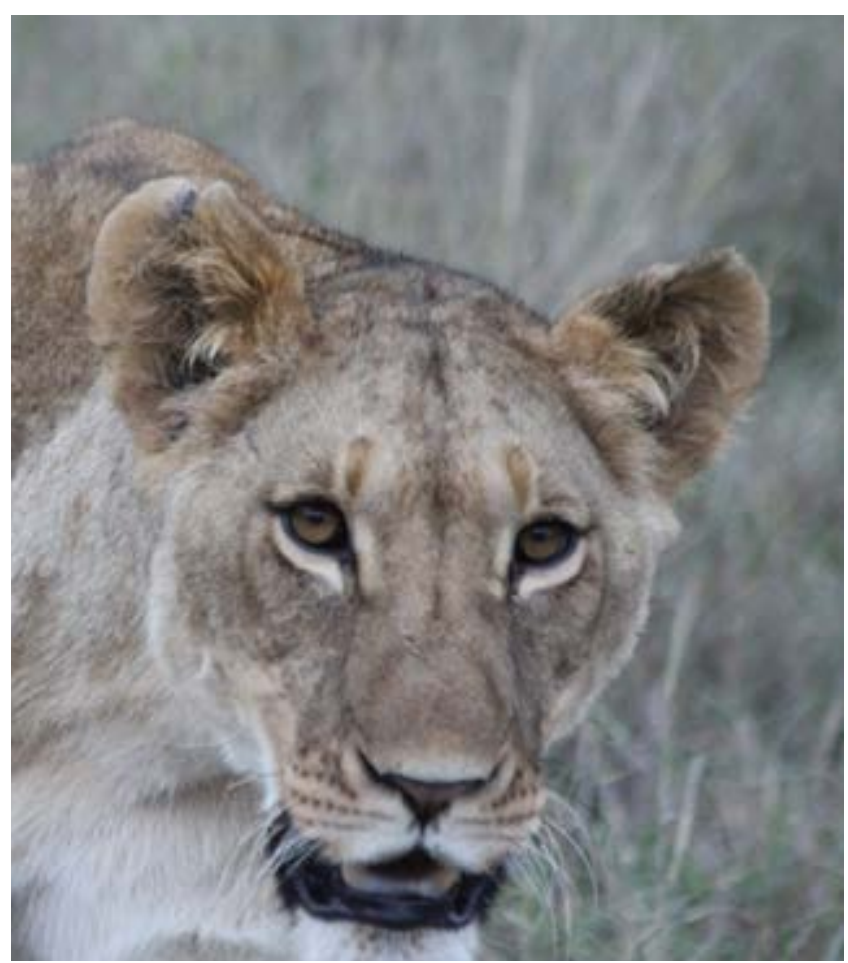

León, Ol Pejeta Conservancy @ C Brent A. Mitchell

Buena práctica 5.4.3: Incentivar a los vecinos y a otras partes interesadas a adoptar usos de suelo compatibles con la conservación a través del conocimiento y las lecciones aprendidas

El éxito de las APPs basadas en actividades de turismo, al igual que el de otras APPs, puede ser significativamente susceptible al tipo de uso de suelo que las rodea. En muchos casos, la degradación ambiental, la fragmentación de la tierra y el uso insostenible pueden afectar a las poblaciones y hábitats de vida silvestre y disminuir el valor turístico. Asegurar una actitud colaborativa y difundir información y conocimiento sobre la conservación, podría aumentar la cobertura del área protegida y mejorar el patrimonio natural de la empresa (ver Caso 6 de Kenia). Por ejemplo, después de haber demostrado que el valor del turismo basado en la conservación es competitivo respecto de la agricultura en el Maasai Mara, Kenia, Cottars 1920s Camp ${ }^{100}$ ofreció su apoyo para el desarrollo de la Olderkesi Conservancy, ${ }^{101}$ un área de 2.670 ha basada en la comunidad que protege el desplazamiento de vida silvestre, mejora la experiencia para los visitantes y genera ingresos para la comunidad Olderkesi. La Grootbos Private Reserve ${ }^{102}$ demostró el valor ambiental y económico del sistema floral South África Flynbos, y convenció a los vecinos para que cambiaran el uso ganadero de sus tierras a un uso para la conservación. Como resultado, las 121 ha para la conservación con las que comenzaron en 1991 aumentaron a 19.000 ha al 2015 y fueron inscritas formalmente como parte de la Walker Bay Fynbos Conservancy. ${ }^{103}$ Por último, las APPs pueden ayudar a crear conciencia y a difundir información entre el público. Por ejemplo, el Refúgio Ecológico Caiman ${ }^{104}$ en Brasil respaldó la creación de la ONG SOS Pantanal, ${ }^{105}$ la que ha sido fundamental para generar conciencia entre las partes interesadas públicas, investigadoras y gubernamentales sobre el pantanal y sus desafíos. Esto derivó en la creación de la Carta Caiman para el Pantanal y el reconocimiento del mismo como un bioma esencial.

\section{Principio 5.5: Las entidades religiosas pueden aportar a la conservación por medio del desarrollo de APPs en su propia tierra}

Las APPs pertenecientes a organizaciones religiosas pueden incluir áreas alrededor de edificios sagrados (por ejemplo, templos, monasterios), tierras pertenecientes y gestionadas por autoridades religiosas y sitios naturales sagrados conectados con la fe, que pueden ser puntos de peregrinaje. Muchos sitios naturales poseen un alto valor de conservación (Dudley et al., 2010) y las tierras religiosas también protegen ecosistemas fragmentados importantes. Cuando la conexión entre la conservación y la fe es demasiado cercana, existe la posibilidad de que esta pueda generar un desincentivo importante ante la venta de tierras con valor natural. Las áreas establecidas a partir de creencias religiosas son importantes, pues transmiten un mensaje a personas que, de otro modo, no se enterarían de la ética tras las iniciativas conservacionistas convencionales.

Buena práctica 5.5.1: Alentar a los grupos religiosos a integrar sus objetivos espirituales más amplios con la conservación basada en sitios específicos

La mayoría de los grupos religiosos más importantes del mundo declaran de manera explícita la conexión entre sus sistemas de creencias y sus objetivos de conservación, usualmente a través de referencias a sus textos sagrados (Palmer \& Finlay, 2003). Muchos de estos grupos son propietarios de tierras arrendadas para la conservación (ver Cuadro 5.5.) o gestionadas de manera activa por ellos. En Brasil, por ejemplo, el Instituto Soka ${ }^{106}$ se hace cargo de una APP perteneciente a una entidad budista, enfocada en la restauración y en acciones de educación ambiental, incluyendo la distribución de plántulas a más de 87.000 personas en 35 comunidades de la Amazonía brasileña.

\section{Buena práctica 5.5.2: Apoyar a los grupos religiosos por medio de alianzas activas y asesorías}

Pese a que existen muchos grupos religiosos comprometidos con la conservación, puede que en la práctica tengan poca experiencia en el ámbito de la gestión. El apoyo por parte de la comunidad conservacionista puede fortalecer los lazos con la conservación, por medio de mecanismos como la incorporación a comités de asesoría. En Europa, el grupo A Rocha ${ }^{107}$ trabaja con iglesias para desarrollar reservas naturales en los mismos patios de estas y en otras de sus propiedades. Estos sitios, por ejemplo, pueden servir de soporte a ejemplares extremadamente viejos de tejo común o tejo negro (Taxus baccata) que han desparecido del resto del paisaje. Del mismo modo, muchas iglesias en el Reino Unido gestionan todos o parte de los patios de sus edificios como reservas naturales (como es el caso de la alianza con el Norfolk Wildlife Trust ${ }^{108}$ ) y alientan a los parroquianos a involucrarse de manera directa en la gestión, monitoreo y otras actividades que suelen involucrar trabajo con la organización Caring for God's Acre, ${ }^{109}$ la que asesora a administradores de cementerios sobre la gestión de sitios para la conservación de la naturaleza. 


\section{Cuadro 5.5 \\ Trabajando con donaciones religiosas para el establecimiento de APPs: Jabal Moussa, Líbano}

Bordeado por el río Abraham o Adonis, conocido por su mitología, la zona montañosa Jabal Moussa, ubicada en la cordillera del Líbano, fue descrita en 1861 por el historiador francés Ernest Renan en Mission de Phénicie como la zona más 'salvaje' y 'excepcional' de la región. De propiedad del Patriarcado Maronita (Católico Romano) y una serie de fondos de fideicomiso eclesiásticos, el área estuvo protegida por siglos y, además, mantuvo una relación simbiótica con pueblos aledaños que desarrollaban actividades de tipo forestal, de carbón, pastoreo y agricultura. No obstante, hacia fines del siglo $X X$, algunas presiones provenientes de la creciente actividad inmobiliaria, la construcción de caminos y diversos modos de caza furtiva (tala de árboles, explotación de canteras, caza de animales) comenzaron a amenazar este santuario tan rico en biodiversidad animal y vegetal.

En 2007, luego de que intentaran abrir un camino en el corazón de la montaña, cerca del famoso Camino Romano y de las inscripciones que puso el emperador Adriano en el bosque para proteger al cedro, un grupo de amantes de la naturaleza y algunos simpatizantes citadinos formaron la ONG Asociación para la Protección de Jabal Moussa (APJM, por su sigla en inglés) ${ }^{110}$ con el fin de conservar el patrimonio cultural y natural del área. Sin embargo, en ese entonces la legislación libanesa no reconocía las reservas naturales ubicadas dentro de tierras privadas, por lo que la APJM logró negociar y financiar un contrato de arrendamiento de 10 años con fondos de fideicomiso eclesiásticos para arrendar grandes terrenos de la montaña. La asociación acudió a numerosas organizaciones y convenciones internacionales para convencer al gobierno libanés sobre la importancia de convertir el sitio en una reserva de la biosfera de la UNESCO en 2008, un área importante para la conservación de las aves (según los

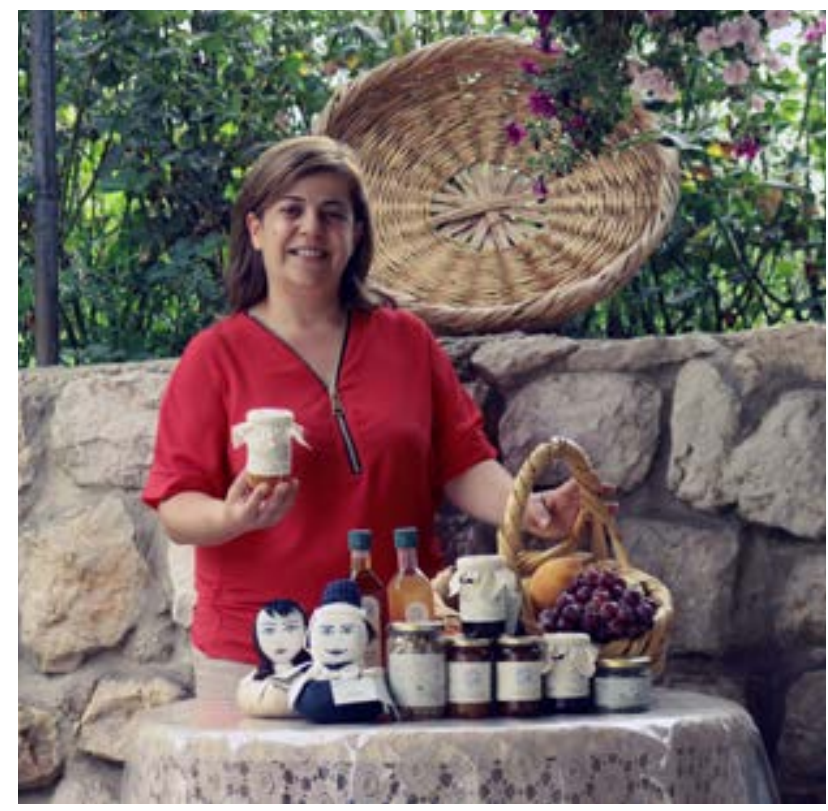

Productos comestibles y artesanales, Jabal Moussa @ Association for the Protection of Jabal Moussa criterios internacionales de BirdLife) en 2009, miembro de UICN ese mismo año y un área de importancia para las plantas y un área clave para la biodiversidad (Buena práctica 1.3.1).

En la actualidad, la reserva Jabal Moussa es conocida local y regionalmente por ser un destino ecoturístico que ofrece diversos paquetes para el senderismo guiado por jóvenes locales, hospedaje operado por habitantes de la zona y una serie de productos artesanales y comestibles hechos por mujeres locales en una cocina-taller central financiada con fondos de la APJM. Estos productos se venden en las entradas de la reserva y, cada vez más, en diversos puntos de venta del Líbano (las especialidades más reconocidas son la miel y el tomillo). Después de haber registrado menos de mil visitas en sus inicios, la reserva albergó a 22.000 ecoturistas en 2017. Las actividades socioeconómicas también incluyen la apicultura y viveros de árboles nativos, las que contribuyen a la conservación.

A diez años del inicio de este emocionante emprendimiento, los arqueólogos internacionales están documentando restos que van desde la Edad del Bronce cananea (2500 años antes de Cristo) a la Edad Media egipcia, los botánicos están estudiando el número creciente de especies endémicas y la APJM se encuentra negociando un contrato de arrendamiento renovable de 50 años para propiedades de la iglesia, mientras fortalece sus lazos con los habitantes de la zona con el fin de permitirle a la mayor cantidad posible participar de la conservación a largo plazo. Esta APP se está convirtiendo, cada vez más, en un área protegida para la naturaleza, la cultura, sus habitantes y visitantes internacionales.

Autor: Pierre Doumet, Asociación para la Protección de Jabal Moussa

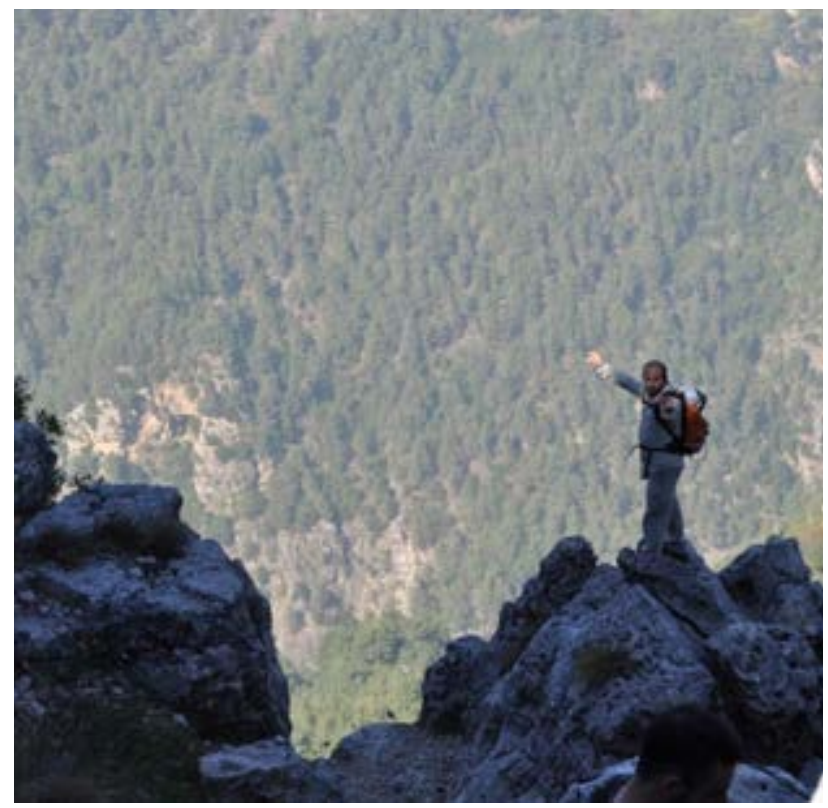

Guía local Jabal Moussa @ Association for the Protection of Jabal Moussa 


\section{Sección 6: Coordinación}

con los sistemas nacionales de áreas protegidas

\section{¿Hacia quién está dirigida esta sección?}

Esta sección está dirigida hacia quienes están a cargo de desarrollar redes nacionales de APPs (por ejemplo, gobiernos, ONGs, etc.), gobiernos subregionales, otras entidades encargadas de crear APPs y propietarios que ya han establecido o están considerando establecer una APP.

Es importante que las APPs sean reconocidas por su contribución al sistema nacional de áreas protegidas (Buena práctica 1.2.1), tanto por su valor propio como por la diversidad que aportan (en términos de gestión, gobernanza, de las partes interesadas y los valores ecológicos). Las APPs son vitales y, pese a que su contribución a los esfuerzos nacionales e internacionales de conservación es aún poco valorada, deben ser reconocidas y alentadas.

Los gobiernos y el sector de conservación muestran cada vez más interés en incorporar a las APPs en los sistemas nacionales de áreas protegidas. Esto, tanto para cumplir con los objetivos de conservación internacionales, como para realizar una planificación de conservación más completa. Para muchos países, la idea de integrar la gobernanza de áreas protegidas que no forman parte del Estado a los sistemas nacionales es relativamente nueva. No obstante, la experiencia recopilada en las últimas dos décadas sobre áreas protegidas manejadas por comunidades indígenas o locales ha demostrado que es necesario incluir todo tipo de gobernanza. En algunos casos, las APPs han sido establecidas independientemente del sistema nacional, mientras que en otros son los gobiernos y las ONGs las que promueven su establecimiento con el fin de llenar vacíos significativos dentro de la cobertura de conservación (Buena práctica 1.2.1). La diversidad de propietarios de APPs y de sus objetivos puede presentar desafíos en términos de coordinación de un sistema nacional de áreas protegidas, pero también puede resultar ser una fortaleza.

Uno de los prerrequisitos para una incorporación exitosa de APPs a los sistemas nacionales es que exista una relación de confianza y seguridad entre las entidades coordinadoras nacionales (usualmente estatales) y los propietarios/administradores de las APPs. Esta relación debe basarse en una visión compartida sobre la definición de APP (ver Sección 1) y la manera en que se gestiona (ver Sección 2), financia (Sección 3) y protege para garantizar su permanencia en el futuro (Sección 4). Tanto los administradores de los sistemas nacionales de áreas protegidas como los propietarios de las APPs deben tener claridad en torno a los beneficios y las obligaciones que derivan de la incorporación a los sistemas nacionales de áreas protegidas.

\section{Principio 6.1: La conservación se beneficia cuando las APPs se coordinan con otros tipos de áreas privadas dentro de un sistema nacional de áreas protegidas}

La coordinación de APPs como parte de un sistema nacional de áreas protegidas puede generar una serie de beneficios de conservación para las áreas protegidas por el gobierno, las APPs y otros tipos de áreas protegidas. Estos beneficios pueden consistir en una priorización más eficiente para la expansión de redes de áreas protegidas, una mayor comprensión de los corredores protegidos y una gestión más coordinada de todo el paisaje.

Buena práctica 6.1.1: La incorporación de APPs a los sistemas nacionales solo debe realizarse con el consentimiento de los propietarios

El Congreso Mundial de la Naturaleza 2016 de la UICN aprobó la resolución que apoya a las APPs (ver Cuadro 1.5) y llama a los miembros de la UICN a "que incluyan aquellas áreas bajo protección privada que cumplan con los estándares sobre áreas protegidas de la UICN en sus informes sobre cobertura de áreas protegidas y a que entreguen otros tipos de información relacionada, incluyendo a la Base de Datos Mundial sobre Áreas Protegidas y al CDB, en colaboración y acuerdo con los propietarios de dichas áreas" (IUCN, 2016a). La incorporación de APPs a los sistemas nacionales solo debe realizarse con el consentimiento de los propietarios (ver Clements et al., 2018), por ejemplo, por medio de un proceso colaborativo como el desarrollado en el Reino Unido para informar sobre APPs (ver Caso 12).

Buena práctica 6.1.2: La afiliación a los sistemas nacionales no debe imponer obligaciones legales o de gestión adicionales que excedan las condiciones existentes de las APPs

Cuando las APPs se incorporan o afilian a sistemas nacionales después de su establecimiento, es importante que esto no implique la imposición inadvertida de obligaciones legales o administrativas adicionales que vayan más allá de las condiciones propias de APPs. 


\section{Principio 6.2: Las APPs pueden complementar otros tipos de gobernanza de áreas protegidas para desarrollar sistemas nacionales eficaces de áreas protegidas}

Las APPs pueden brindar múltiples beneficios a los sistemas nacionales al aumentar tanto el área total bajo protección como la representación de tipos de hábitats; además de mejorar la conectividad o amortiguar otros tipos de áreas protegidas y proteger los servicios ecosistémicos (Fitzsimons \& Wescott, 2008a,b). Asimismo, las APPs pueden resultar ser el mecanismo más eficiente para asegurar ecosistemas o especies particulares presentes de manera predominante o exclusiva en tierras privadas. Por ejemplo, en Kenia la mitad de los rinocerontes negros de África del Este que están en peligro de extinción (Diceros bicornis michaeli) se encuentra en APPs (Leménager et al., 2014 y ver Caso 6). No obstante, los sistemas nacionales deben reconocer tanto a aquellas APPs con valores naturales altamente priorizados como también a aquellas consideradas potencialmente menos valiosas (ver Principio 1.2).

\section{Buena práctica 6.2.1: El reconocimiento de APPs} por parte del gobierno es un primer paso importante en su incorporación a los sistemas nacionales

El reconocimiento gubernamental puede suceder en distintos niveles, incluyendo: APPs individuales, grupos de APPs bajo una misma organización (por ejemplo, ONGs locales, nacionales o regionales, grupos de investigación, negocios o religiosos) o un mecanismo de APP (por ejemplo, acuerdo de conservación o servidumbre) por parte de una autoridad de área protegida (por ejemplo, gobierno local) (ver Principio 1.3). Idealmente, la definición sobre qué constituye una APP en términos jurisdiccionales relevantes se explicita por medio de un documento de políticas públicas $u$ orientaciones garantes de trasparencia y, a la vez, alineadas con la definición de APP de la UICN (ver Sección A). Este reconocimiento también se otorga en un nivel geográfico, donde las APPs reconocidas formalmente pueden ser incorporadas a mapas de sistemas - con el consentimiento de los propietarios - , para así contribuir cabalmente a la planificación de la conservación local, nacional y regional. Por ejemplo, la Australia's Strategy for the National Reserve System 2009-2030 reconoce claramente la importancia de los distintos tipos de gobernanza de áreas protegidas en el logro de los objetivos de un sistema de reservas extenso, adecuado y representativo en Australia (NRMMC, 2009 y ver Caso 1 de Australia). En Perú, los mapas oficiales de la agencia gubernamental SERNANP incluyen todas las APPs existentes junto con las áreas protegidas nacionales y regionales.

Buena práctica 6.2.2: El reconocimiento y el apoyo brindados a las APPs puede manifestarse a distintas escalas (nacional, regional, local)

El apoyo para las APPs puede manifestarse en distintos niveles jurisdiccionales. Por ejemplo, en Australia, a pesar de que el reconocimiento nacional puede ser importante para el inventario del país, es posible que se requiera legislación de carácter estatal para proteger legalmente el sitio y que las autoridades locales puedan ofrecer incentivos financieros. En Argentina, un país federal, no existe una ley de áreas protegidas a escala nacional

\section{Cuadro 6.1 \\ Creando conexiones: El Northeast Biological Corridor en Belice}

Recientemente, Belice aseguró un importante corredor de conectividad, uno de los tres identificados como clave para la conservación de la biodiversidad por medio de la planificación nacional. El North East Corridor conecta un área protegida por el gobierno, Freshwater Creek Forest Reserve, con dos APPs: la Shipstern Conservation \& Management Area y la Fireburn Reserve. Parte del terreno entre los sitios le pertenece a Balam Jungle Estate, una organización de gestión de madera. Actualmente, se está negociando un trust entre los administradores de las reservas de la ONG y la compañía, con la aprobación del gobierno. La compañía está honrando el acuerdo anterior de apartar una porción de su terreno para la conservación y, como recompensa, espera poder asegurar una tasa de impuestos favorable para sus tenencias de tierra. Desde el punto de vista del gobierno de Belice, un factor clave en la designación del corredor fue la provisión de servicios ambientales para comunidades y tierras agrícolas aledañas, desde el bosque hasta los humedales dentro del NE Corridor. Además de custodiar la seguridad hídrica, la mantención de la conectividad entre nudos forestales importantes apoya la supervivencia a largo plazo de un amplio rango de especies, como el vulnerable pecarí barbiblanco (Tayassu pecari) y el jaguar (Panthera onca). El NE Corridor de Belice permite la expansión del exitoso programa de reproducción para especies en peligro de extinción - como el mono aullador negro guatemalteco (Alouatta pigra) y, prontamente, el mono araña de Geoffroy (Ateles geoffroyi) utilizando animales rehabilitados del tráfico ilegal de vida silvestre (Mitchell et al., 2017).

Autor: Paul Walker, Wildtracks Conservation y Wildlife Rehabilitation Centre, Belice

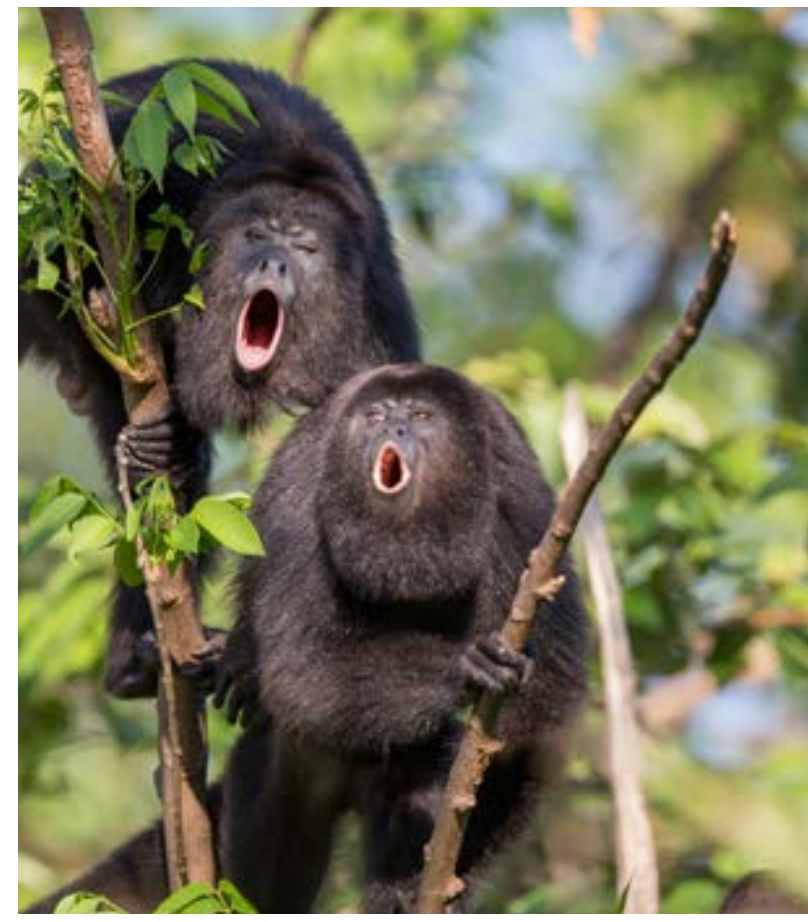

Mono aullador negro guatemalteco @ E. Gissis/Wildtracks 


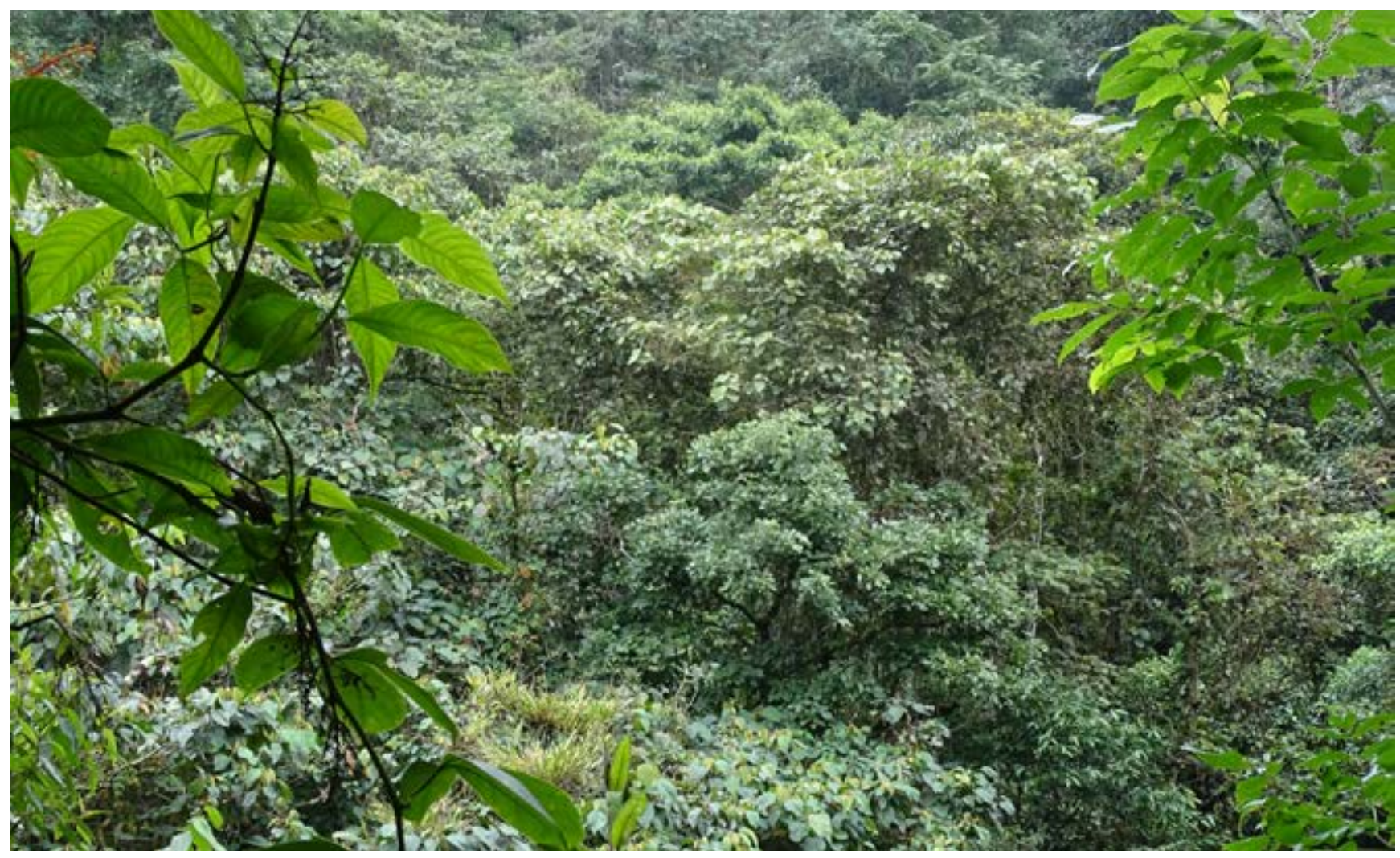

Reserva Natural Kasaguadua, Colombia @ Sue Stolton

(aunque se propuso una), sino que estas son tratadas a escala subnacional. De las 23 provincias del país, 12 incluyen APPs en sus leyes de áreas protegidas. La ley en Misiones, por ejemplo, pide un compromiso de 20 años, además de establecer orientaciones para los planes de manejo. En otros países pueden existir diferentes jurisdicciones nacionales y subnacionales importantes para el reconocimiento de APPs. En Colombia, muchas APPs son reconocidas por el Sistema Nacional de Áreas Protegidas (SINAP); no obstante, una gran cantidad de áreas protegidas municipales no lo son. Más de 80 municipios han establecido sistemas de áreas de protección (Sistema Nacional de Áreas Protegidas SIMAP,111 a nivel municipal, y Sistema Local de Áreas Protegidas SILAP, ${ }^{112}$ a nivel local). Debido a la ausencia de orientaciones centrales, estos sistemas varían, pero las reservas privadas son un componente importante de muchos de los sistemas de conservación local. Tanto el SIMAP como el SILAP tienen el potencial de establecer vínculos entre los planes de zonificación territorial municipal (que designan áreas de conservación municipal y protección ambiental), la planificación departamental y los sistemas subnacionales de áreas protegidas.

\section{Buena práctica 6.2.3: El sistema nacional de áreas protegidas debiese coordinar estrategias para incorporar a las APPs}

Las estrategias de incorporación de APPs a los sistemas nacionales de áreas protegidas pueden ser impulsadas por el gobierno - como en Australia (ver Caso 1) y Sudáfrica (ver Caso 10) -, por el sector privado u ONGs (ver Caso 4 de Costa Rica), o mediante un enfoque híbrido que cuente con iniciativas de ambos sectores (ver Caso 12 del Reino Unido). Independientemente del enfoque, ser capaz de garantizar una relación de confianza y beneficios mutuos, articulados de manera transparente, posiblemente resulte en un mayor éxito a largo plazo. Brasil, Colombia y Perú113 están entre los pocos países de Latinoamérica que han incluido a las APPs en sus sistemas oficiales de áreas protegidas. En Colombia, en algunos casos, la coordinación entre APPs y el Sistema Nacional de Áreas Protegidas (SNAP) está a cargo de la Asociación Red Colombiana de Reservas Naturales de la Sociedad Civil. ${ }^{114}$ Muchas de estas ONGs son locales y también las principales administradoras de recursos para la implementación de planes de manejo para reservas privadas.

\section{Buena práctica 6.2.4: La coordinación entre las} APPs y los sistemas nacionales ofrece numerosos beneficios para la conservación que debieran ser promovidos ante las agencias y los administradores de todos los tipos de gobernanza de áreas protegidas

Los beneficios de integrarse al sistema nacional incluyen: una mayor capacidad para lograr objetivos globales de conservación y su implementación in situ a escala nacional y regional (tales como representación, conectividad y servicios ecosistémicos); un posicionamiento más eficiente de futuras áreas protegidas de diversos tipos de gobernanza, lo que beneficia a los propietarios existentes al aumentar la viabilidad de su patrimonio de conservación; el potencial para desarrollar una gestión coordinada de amenazas o procesos ecológicos en tierras públicas y privadas; la posibilidad de una conservación de especies en peligro de extinción -y, de ser necesario, una reintroduccióncoordinada, y el aumento del número de participantes en áreas protegidas y sistemas nacionales por medio de la incorporación de propietarios comprometidos. Finalmente, una mayor comprensión de la ubicación, el patrimonio y las direcciones de los tipos de gobernanza deriva en una planificación de conservación más informada. 


\section{Cuadro 6.2}

\section{Colaboración entre tipos de gobernanza de áreas protegidas para salvar al cocodrilo del Orinoco en Colombia}

La conservación del cocodrilo del Orinoco (Crocodylus

intermedius) es un ejemplo de coordinación entre APPs y el sistema nacional para beneficiar una especie en serio peligro de extinción. La Fundación Palmarito Casanare ${ }^{115}$ es una ONG que desde 2011 trabaja en la conservación de una de las especies en mayor peligro de extinción en el mundo. Las estimaciones indican que existen menos de 2.000 cocodrilos en el área de distribución total de la especie, la región de Los Llanos, ubicada entre Colombia y Venezuela. Desde 2008, Palmarito ha apoyado a más de 20 APPs, que en conjunto cubren cerca de 76.000 ha. Gracias a un plan de conservación a escala de paisaje, la Fundación Palmarito ha reintroducido 102 cocodrilos criados en cautiverio en diferentes ubicaciones dentro de su área de distribución histórica, incluyendo el Parque Nacional Natural El Tuparro (41 cocodrilos), la APP La Aurora (32) y el río Cravo Norte (29), que en el futuro se convertirá en un área protegida ${ }^{116}$ (Balaguera-Reina et al., 2017).

Autor: Rafael Antelo, Fundación Palmarito Casanare

Buena práctica 6.2.5: La incorporación oficial de las APPs a los sistemas nacionales de áreas protegidas debe incluir reconocimiento y apoyo

La incorporación de una APP al sistema nacional puede abarcar desde el reconocimiento formal de su aporte a la conservación de la biodiversidad hasta mejores incentivos financieros para su protección y gestión (ver Sección 3). No obstante, es importante tomar en cuenta que no todos los propietarios de APPs desean incorporar sus tierras a los sistemas nacionales. Esta reticencia puede deberse a la aprensión de que los gobiernos terminen declarando - ante organismos internacionales - el estado de APPs ya existentes en lugar de invertir en nuevas áreas protegidas (estatales) en otras partes, lo cual es visto por algunos como una manera que tienen los gobiernos de cumplir con las obligaciones internacionales sin tener que tomar decisiones difíciles (Fitzsimons \& Wescott, 2007). Es de suma importancia que los coordinadores de las redes nacionales les comuniquen a los propietarios de APPs si es que sus propiedades serán contabilizadas para el cumplimiento de objetivos. También existe la posibilidad de que algunos propietarios deseen reconocimiento sin querer que sus propiedades sean contabilizadas como parte de los objetivos gubernamentales (ver Clements et al., 2018 y Sección 7).

\section{Buena práctica 6.2.6: Si una APP no desea ser} reconocida como parte de un sistema de gobierno, existen otros mecanismos alternativos para alcanzar 'reconocimiento'

Para aquellos casos en que un propietario de APP no está interesado en obtener reconocimiento nacional, debiese existir una alternativa que pueda, por un lado, otorgarle legitimidad como APP y, por otro, entregarle información sobre cómo recibir apoyo de parte de otros actores de conservación para mejorar sus resultados. La Sección 7 presenta una discusión más detallada sobre las alternativas para reportarse ante organismos internacionales (y, por consiguiente, para conseguir reconocimiento tácito) sin contar con el reconocimiento formal del gobierno, aunque esto continúa siendo un ámbito que requiere mayor claridad (Clements et al., 2018).

Buena práctica 6.2.7: La creación de un sistema nacional de áreas protegidas que incorpore diversos tipos de gobernanza requiere de una coordinación activa y exhaustiva con todos los administradores de áreas protegidas

Alcanzar la coordinación de un sistema nacional de áreas protegidas implica mucho más que simplemente compilar una lista. La construcción de un espacio de comunicación y discusión para generar un sistema coordinado puede significar la conformación de foros anuales, talleres estratégicos y mesas de trabajo para discutir problemas comunes y resolver barreras con el fin de mejorar la coordinación. En algunos países, las conferencias nacionales para la conservación de tierras privadas (por ejemplo, US Land Trust Alliance Rally; Australia National Private Land Conference; Confederação Nacional de Reservas Privadas de Patrimônio Natural, CNRPPN) ayudan a identificar los problemas en común, junto con fortalecer el sector de APPs. La conferencia del International Land Conservation Network es un nuevo foro internacional cuyo fin es robustecer el sector. Los comités nacionales de la UICN pueden jugar un papel importante en el desarrollo de vínculos sustanciosos entre las APPs y los gobiernos (ver Caso 12 del Reino Unido). En algunas ocasiones resulta más beneficioso aplicar un método más formal. Por ejemplo, en Kenia, un directorio, constituido formalmente, se reúne varias veces al año con representantes de todos los tipos de gobernanza de áreas protegidas para discutir diversos temas. Esto incluye reunir a las iniciativas de conservación y otorgarles un espacio directo para que participen en la creación de políticas de gobierno, por ejemplo, en el desarrollo de leyes para las iniciativas de conservación.

Buena práctica 6.2.8: Los representantes de APPs debieran participar en el desarrollo de estrategias y planes nacionales de áreas protegidas

Para mejorar la efectividad tanto de la conservación a escala de paisaje (o jurisdiccional), como de los planes de áreas protegidas y su implementación, las autoridades de gobernanza de APPs debieran formar parte del proceso de planificación estratégica desde el comienzo. Una manera lógica de lograr esto es contar con la presencia de redes de APPs u ONGs en los comités de áreas protegidas. Por ejemplo, por ley, la Belize Association of Privately Protected Areas (BAPPA) cuenta con un puesto en el National Protected Areas Advisory Council. 


\section{Sección 7: Registro de las áreas bajo protección privada}

\section{¿Hacia quién está dirigida esta sección?}

Esta sección está dirigida tanto hacia las agencias de gobierno encargadas de entregar información sobre las áreas protegidas a escala nacional, como también hacia los propietarios. Ambos grupos tienen la opción de registrar APPs.

El registro nacional de áreas protegidas es un elemento clave en los acuerdos internacionales, pues permite a los países demostrar un avance en relación con las metas acordadas, como las del Convenio sobre la Diversidad Biológica ${ }^{117}$ (CDB) y algunas de las incluidas dentro de los Objetivos de Desarrollo Sostenible 14 y $15^{118}$ (ver Caso 10 de Sudáfrica). En términos globales, estas metas son monitoreadas mediante indicadores derivados, en gran parte, de la Base de Datos Mundial de Áreas Protegidas (WDPA, por su sigla en inglés), la que compila datos provenientes de gobiernos nacionales y otras fuentes.

Casi todos los gobiernos nacionales del mundo entregan información sobre sus áreas protegidas a la WDPA (ver Cuadro 7.1), hoy, sin embargo, solo 28 gobiernos entregan información sobre sus APPs (UNEP-WCMC \& UICN, 2018). Algunos gobiernos no reconocen a las APPs dentro de sus sistemas nacionales y algunos propietarios no desean que se entregue información sobre sus APPs (Buenas prácticas 6.2 .5 y 6.2.6). No obstante, informar sobre las APPs a la WDPA puede servir para obtener un mayor reconocimiento de su importancia y, a la vez, destacar la posición de las APPs individuales como parte de una comunidad global de iniciativas de conservación privada y su función en los sistemas de áreas protegidas. Al informar a la WDPA, los propietarios participan de una producción de conocimiento que incide en la planificación, colaboración y ambición internacional. A nivel nacional, una mayor visibilidad de las APPs puede facilitar un desarrollo de redes de conservación más coordinado y promover un apoyo mayor por parte de los gobiernos.

\section{Principio 7.1: Las APPs deberían ser registradas en la Base de Datos Mundial de Áreas Protegidas (WDPA)}

Las APPs representan una oportunidad importante de fortalecer la conservación de la biodiversidad y los servicios ecosistémicos nacionales e internacionales. Para que estos múltiples beneficios se mantengan en el tiempo, las APPs deben ser reconocidas, apoyadas e incentivadas. Un aspecto clave es asegurar que las APPs estén mapeadas y documentadas para que su magnitud y contribuciones sean comprendidas. Las APPs con una documentación adecuada pueden beneficiarse de ejercicios de planificación, tanto para iniciativas de conservación como para otro tipo de planificación de uso de suelo. Por ejemplo, el gobierno de México ${ }^{19}$ ha avanzado significativamente en el registro de áreas protegidas de todos los tipos de gobernanza descritos por la UICN en la WDPA.

\section{Cuadro 7.1 \\ Base de Datos Mundial de Áreas \\ Protegidas y Base de Datos Global para la Eficacia en el Manejo de Áreas Protegidas}

Protected Planet ${ }^{120}$ es una iniciativa del Centro de Monitoreo de la Conservación Mundial del Programa de las Naciones Unidas para el Medio Ambiente (UNEP-WCMC, por su sigla en inglés) en colaboración con la UICN y ONU Medio Ambiente. Incluye a la WDPA y la Base de Datos Global para la Eficacia en el Manejo de Áreas Protegidas (GD-PAME, por su sigla en inglés). El UNEP-WCMC es manejado por medio del CDB para recopilar datos de todas las áreas protegidas de los países, y contiene la base de datos global de áreas protegidas más completa. Para poder ser incorporadas a la WDPA, las APPs deben cumplir con la definición de área protegida de la UICN. Al momento de entregar información sobre un área protegida a la WDPA, se deben entregar los siguientes datos:

- Límites espaciales del área protegida en formato SIG (por ejemplo, shapefile)

- Información descriptiva en el formato del esquema de la WDPA

- Un acuerdo firmado de contribuidor de datos (DCA, por su sigla en inglés)

- Información sobre la fuente.

El Manual de la WDPA detalla con mayor profundidad estos puntos. ${ }^{121}$ Tanto la entrega de datos como la solicitud de información adicional deben enviarse a protectedareas@ unep-wcmc.org

Buena práctica 7.1.1: Los gobiernos, propietarios privados o terceros pueden proporcionar datos sobre las APPs a la WDPA y la GD-PAME

La WDPA puede dividirse en datos que han sido proporcionados o verificados por gobiernos ('Verificados por el Estado') y datos que han sido entregados por proveedores de datos no gubernamentales y verificados por expertos no gubernamentales ('Verificado por un experto') (Buena práctica 7.1.5). Por consiguiente, las APPs pueden ser registradas en la WDPA y la GD-PAME por el gobierno, propietarios o terceros (por ejemplo, ONGs o redes interesadas) (ver Bingham et al., 2017; Caso 2 


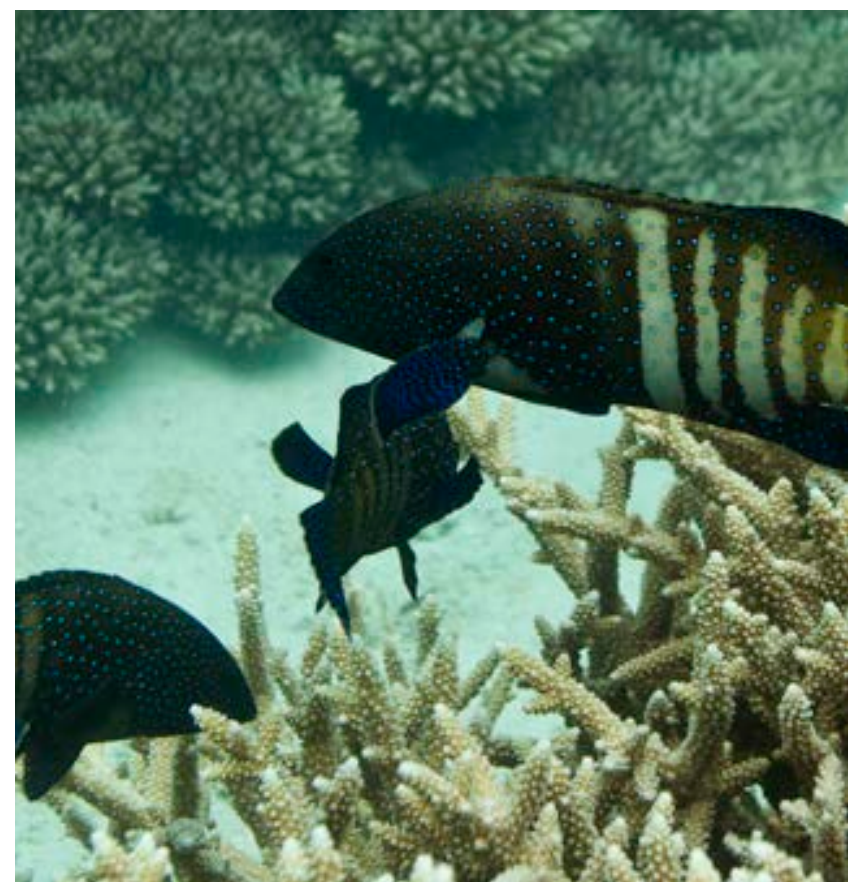

Chumbe Island Coral Park Limited llevó a cabo una negociación exitosa con el gobierno semiautónomo de Zanzibar, Tanzania, para que la isla fuera registrada como una MPA (ver Cuadro 1.7) (C) Chumbe Island Coral Park

de Brasil, Caso 12 del Reino Unido y Buena práctica 5.1.1). Las APPs no reconocidas gubernamentalmente pueden registrarse de igual modo en la WDPA, y permanecer fácilmente distinguibles de aquellas que sí lo son. Esto significa que los usuarios de la WDPA pueden seleccionar fácilmente información sobre áreas protegidas reconocidas por el gobierno, u otras áreas verificadas, dependiendo de lo que necesiten (Bingham et al., 2017).

\section{Buena práctica 7.1.2: Los gobiernos deben informar sobre las APPs solo si tienen un acuerdo con los propietarios privados}

Se alienta a los gobiernos a que informen sobre todas las áreas en sus países que cumplan con la definición de área protegida de la UICN, incluidas las APPs. Al entregar información sobre las APPs, es importante que los gobiernos solo lo hagan bajo acuerdo con las partes interesadas relevantes (por ejemplo, el individuo u organización responsable de la APP) (Buenas prácticas 6.1.1., 6.2.6 y Caso de Australia). Cuando se firman acuerdos que implican el uso compartido de datos (por ejemplo, acuerdos de conservación), es importante que los propietarios conozcan bien cómo se utilizarán los datos y que estén de acuerdo con ello. Los gobiernos deben revisar los datos de las APPs ya registradas en la WDPA y buscar acuerdos con los propietarios que no han aceptado compartir información sobre su sitio. Si los propietarios no están de acuerdo, los gobiernos deben levantar una solicitud ante el UNEP-WCMC para que este elimine los datos de la WDPA. Establecer un vínculo con las redes nacionales de propietarios privados existentes o en vías de desarrollo puede ser una manera eficiente de facilitar las discusiones en torno a la entrega de información a la WDPA (ver Sección 8) (Clements et al., 2018).
Buena práctica 7.1.3: Los datos de las APPs deben ser estandarizados por parte de la entidad informante

En la mayoría de los casos, los gobiernos informan al UNEP-WCMC por medio de un solo punto focal. En aquellas situaciones en las que el punto focal del gobierno tiene la misión de recolectar datos de jurisdicciones múltiples, cada una de esas jurisdicciones deberá entregar información sobre las APPs de manera estandarizada. La realización de pruebas con proveedores de datos específicos puede ayudar a desarrollar sistemas efectivos que faciliten este proceso (ver Caso 12 del Reino Unido). Esto significa que todas las jurisdicciones deben entender de igual manera la definición de APP y, a la vez, contar con procesos consistentes para asegurar la aprobación de los propietarios antes de compartir los datos (ver Sección 6). Esto también se aplica en los casos minoritarios en los que el proceso de información al UNEP-WCMC se realiza a partir de más de un punto focal. Por ejemplo, la Collaborative Australian Protected Area Database (CAPAD), ${ }^{121}$ por medio de la cual el gobierno australiano informa a la WDPA, está conformada, principalmente, a partir de bases de datos manejadas por gobiernos estatales o territoriales. Bajo la Australia's Strategy for the National Reserve System 2009-2030 (Commonwealth of Australia, 2010), todos los gobiernos subnacionales dentro del país han acordado aplicar un estándar común para las áreas protegidas, incluyendo alinearse con la definición de área protegida de la UICN, lo que ha permitido establecer un estándar compartido para la entrega de información a la CAPAD. Los gobiernos que recolectan datos de este modo deben asegurarse de que las orientaciones sobre la entrega de información de APPs sean parte de las recomendaciones ofrecidas a autoridades de gobiernos subnacionales y a otros aliados de ONGs.

Buena práctica 7.1.4: Si el gobierno no puede o no está dispuesto a entregar información sobre las APPs, se debe asignar a otra autoridad para que lo haga

En aquellos casos en que el gobierno nacional no cuente con recursos para entregar información sobre las APPs (por ejemplo, cuando no existe una base de datos centralizada de áreas protegidas), se recomienda que el gobierno nombre a otra autoridad competente para la entrega de información a la WDPA y la GD-PAME (ver Caso 12 del Reino Unido). Los datos entregados por este medio se consideran 'Verificados por el Estado' cuando la autoridad ha sido designada de manera oficial y por escrito por parte del gobierno. En el caso de las APPs, las redes nacionales de propietarios privados o las ONGs grandes que poseen tierras pueden ejercer un papel importante en informar en representación del gobierno. Por ejemplo, el gobierno de Bahamas nombró a la ONG Bahamas National Trust como la encargada de la entrega de datos nacionales a la WDPA. Los datos entregados por el Bahamas National Trust son clasificados como 'Verificados por el Estado' dentro de la base de datos.

Buena práctica 7.1.5: Los propietarios de APPs deben considerar si informar de manera directa, por medio del gobierno nacional o terceros, y conocer las opciones que existen para la verificación de datos

Los proveedores de datos no gubernamentales pueden elegir informar directamente al UNEP-WCMC o hacerlo a través del gobierno nacional. Si eligen hacerlo de manera directa, el UNEPWCMC se encargará de que los datos sean verificados ya sea por 
el gobierno nacional o expertos no gubernamentales relevantes. Es el proveedor quien decide qué camino de verificación tomar. Ambas opciones presentan ventajas, y los propietarios deben considerar cuidadosamente cuál de las opciones es la que más le conviene a su APP. La verificación realizada por expertos puede ser la más apropiada en aquellos casos donde la APP no ha sido reconocida por el gobierno nacional, mientras que la verificación estatal puede funcionar como un avance hacia un mayor apoyo hacia las APPs a escala nacional. Pese a que los propietarios podrían preferir entregar información de manera individual, es importante que tomen en cuenta la posibilidad de hacerlo por medio de terceros no gubernamentales. Por ejemplo, las redes nacionales de propietarios pueden jugar un papel clave en la entrega de un conjunto de datos más extenso (ver Sección 8). La recolección de datos a nivel nacional por parte de redes organizadas, y la posterior entrega de datos a la WDPA, puede ser una forma efectiva de generar el reconocimiento de APPs de otros grupos de interés. Este tipo de redes puede ser particularmente eficiente cuando cuentan con la participación de individuos con las capacidades y habilidades para brindar apoyo a otros que deseen entregar información (por ejemplo, habilidades SIG). Es también posible que las redes nacionales estén mejor posicionadas que los individuos para recaudar los fondos necesarios para la revisión y el desarrollo sistemático de mapas, además de conseguir apoyo externo donde se necesite.

\section{Buena práctica 7.1.6: La entrega de datos de APPs por medio de terceros debe realizarse únicamente si se cuenta con la aprobación de los propietarios privados}

Al igual que con los proveedores de datos gubernamentales, los proveedores de datos no gubernamentales deben garantizar que cuentan con el consentimiento de todos los propietarios relevantes antes de entregar datos. En particular, los propietarios deben considerar si la ubicación y los límites de su APP son de carácter sensible (por ejemplo, debido a la presencia de recursos valiosos) antes de decidir contribuir a la WDPA (Buena práctica 7.1.7). Las organizaciones que están considerando la examinación de APPs a escala nacional pueden revisar el proyecto Putting Nature on the Map, que se encargó de generar mapas de las APPs en el Reino Unido (ver Caso 12). El proyecto contó con la colaboración del Comité Nacional del Reino Unido de UICN, el gobierno del Reino Unido y las ONGs propietarias de tierras, lo que permitió un acuerdo entre múltiples partes interesadas sobre el alcance de las APPs en el país (Crofts et al., 2014; Bingham et al., 2017).

\section{Buena práctica 7.1.7: Se deben conocer las opciones disponibles para restringir el acceso a datos sensibles}

Es posible aplicar restricciones en aquellos casos donde el proveedor estime que los datos son sensibles. Esta puede ser una alternativa útil para las APPs en las que se manejan especies o recursos naturales especialmente vulnerables. Los datos son útiles incluso cuando se han aplicado restricciones, porque el UNEP-WCMC puede utilizarlos para informar las estadísticas nacionales e internacionales sin compartirlos. Existen dos niveles de restricciones:
1. Los datos están disponibles para todos los usuarios, y para todos los usos, excepto para el uso de -o en representación de - una entidad comercial.

2. Los datos están disponibles exclusivamente para el UNEP-WCMC, ONU Medio Ambiente, y no se comparten de otra manera.

\section{Buena práctica 7.1.8: Los proveedores de datos deben estar al tanto de los principios involucrados en el proceso de verificación de datos}

Los datos proporcionados por proveedores de datos no gubernamentales pueden ser sometidos a un proceso de verificación por parte del Estado o de expertos. La verificación del Estado es llevada a cabo por medio de los puntos focales de la WDPA dentro de las agencias estatales. Para la verificación de APPs realizada por expertos, la WDPA depende del apoyo voluntario de los miembros de la Comisión Mundial de Áreas Protegidas (WCPA, por su sigla en inglés) de la UICN. En estos casos, a los miembros de la WCPA se les pide asistencia sobre la base de su experticia en APPs y su conocimiento del país o región en cuestión. El principal propósito tras el proceso de verificación es confirmar que las áreas en cuestión cumplan con la definición de APP y, por consiguiente, sean aptas para ser incorporadas a la WDPA. Tanto a los verificadores del Estado como a los externos se les incentiva establecer vínculos con otros expertos locales y partes interesadas para asegurarse de que entiendan el contexto local en su totalidad.

Desde 2018, el UNEP-WCMC ha implementando una política de entrega anual de datos resumidos a los gobiernos. Este resumen incluirá detalles sobre el número y superficie de áreas protegidas y verificadas por expertos dentro de su país. 


\title{
Sección 8: El rol de las redes de áreas bajo protección privada
}

\author{
¿Hacia quién está dirigida esta sección? \\ Esta sección está dirigida hacia los dueños y terratenientes que gestionan o están \\ dispuestos a gestionar su propia APP, los organizadores/administradores de redes y hacia \\ aquellos representantes de ONGs que apoyan estrategias biológicas de conservación.
}

Las redes de APPs suelen estar conformadas por propietarios y profesionales del área, y a veces cuentan con el apoyo de organizaciones privadas y ONGs. Juegan un papel importante en dar voz a las APPs, sin embargo, su alcance, escala y fuerza varían considerablemente. Las asociaciones de land trusts y las coaliciones de propietarios de conservación, por ejemplo, son un fenómeno de conservación de tierras institucionalizadas de gran alcance, y están creciendo en muchos países. En los Estados Unidos, la Land Trust Alliance ${ }^{123}$ opera desde 1982 y representa a más de 1.000 land trusts miembros a escala nacional. En Europa también se está desarrollando una red similar. ${ }^{124}$ La Australian Land Conservation Alliance ${ }^{125}$ acaba de ampliar su cobertura para incluir, además de ONGs que mantienen acuerdos de conservación, un rango más amplio de ONGs y land trusts interesados en la conservación de tierras privadas. Hay muchos países que cuentan con redes de APPs, como Costa Rica, Chile, Argentina y Brasil. En algunos casos, existen redes locales (estatales o regionales) que luego se reúnen en foros nacionales. Por ejemplo, en la Amazonía peruana (ver Caso 8), las múltiples redes regionales se reúnen en el Encuentro Amazónico de Conservación Voluntaria y Comunal (Amazonía que Late), y se está desarrollando una Red Amazónica de Conservación Voluntaria.

Las redes de APPs suelen ser diseñadas para fortalecer las capacidades de sus miembros en ámbitos como financiamiento, gestión y protección legal de tierras (Ruseva et al., 2016). En algunos países, también cumplen la función de registrar las APPs (ver Secciones 6 y 7). En la mayoría de los casos, las redes organizan encuentros donde sus miembros comparten experiencias y desafíos, y han sido clave en el empoderamiento de los propietarios, al ayudarlos a desarrollar sus capacidades y a asegurar mejores condiciones para ellos por parte del gobierno. Las redes pueden contribuir al éxito de las APPs ya sea difundiendo mensajes y resultados, o facilitando el diálogo entre propietarios y gobiernos. Las redes de APPs, además, pueden abarcar redes de tenencia múltiple específicamente establecidas para lograr la conectividad del paisaje (e.g. Crosthwaite et al., 2013).

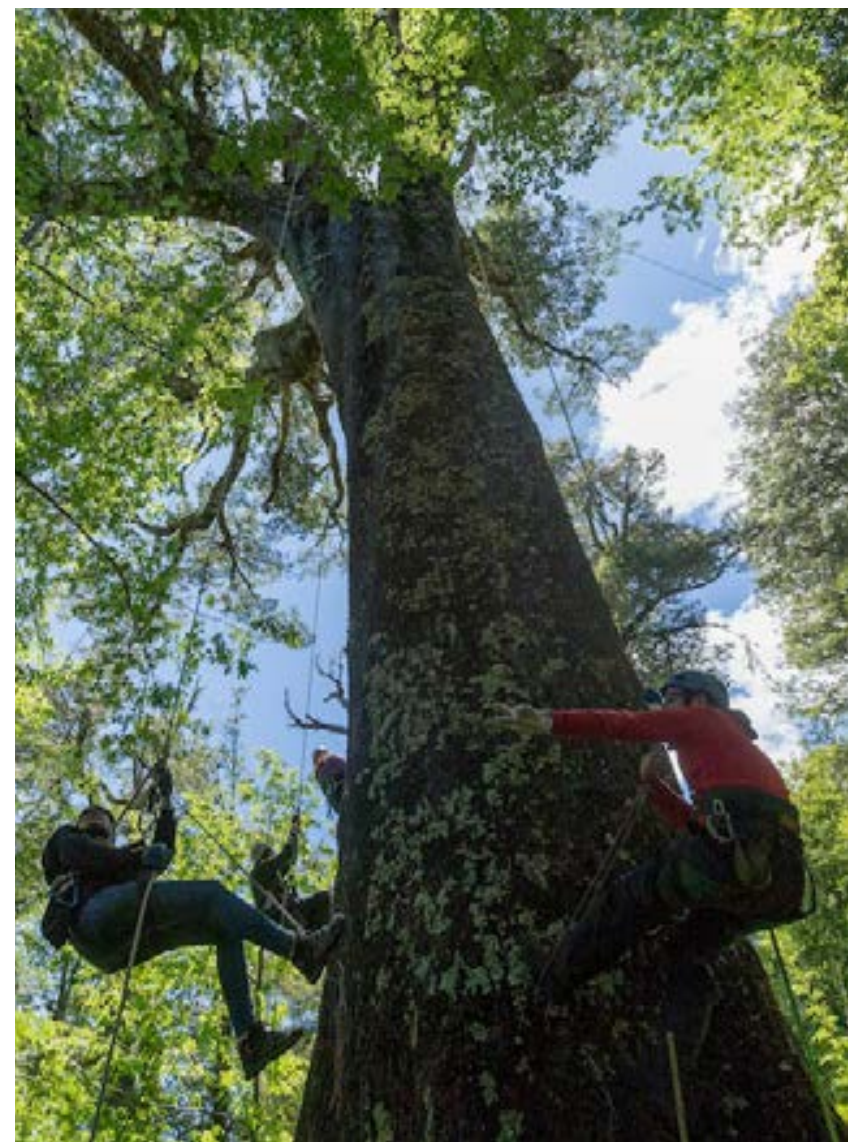

Bosque Pehuén, Chile @ Juan Pablo Miranda

\section{Principio 8.1: Las redes pueden ser mecanismos eficaces para representar los intereses y las preocupaciones de los propietarios}

Al igual que una asociación comercial, las redes de APPs pueden crear una plataforma para comunicar necesidades y hacer presión de manera colectiva, con el fin de reducir las barreras y crear incentivos para el establecimiento y la gestión de APPs. 
Buena práctica 8.1.1: Las redes de APPs nacionales y regionales deben cumplir la función de representar, explicar y defender los intereses de los propietarios en público y en privado

Las redes de APPs pueden crear mensajes y contenidos transparentes y consistentes, a partir de estrategias de comunicación y apoyo, desarrolladas colectivamente (Buena práctica 2.6.1.). Una forma de maximizar las fortalezas de los miembros individuales es, por ejemplo, seleccionando voceros con buenas habilidades comunicativas. También deben generar publicidad positiva que muestre su compromiso con la gestión de APPs. En Perú, un buen ejemplo es Karina Pinasco, dueña de una APP en San Martín, que también dirige una concesión de conservación por medio de su ONG Amazónicos por la Amazonia. ${ }^{126}$ Por años, Karina ha sido la voz de cientos de propietarios de la región, llegando tanto a los medios de comunicación como al gobierno, tanto a los donantes como a los inversionistas (Buena práctica 1.3.2).

\section{Buena práctica 8.1.2: Las redes pueden promover} de forma eficiente el apoyo a las APPs

Los incentivos fiscales y económicos suelen surgir a partir de decisiones gubernamentales o legislativas (ver Sección 3). Las redes de APPs pueden ayudar a conseguir apoyo público para la conservación de la biodiversidad y los servicios ambientales, y también a solicitar financiamiento estatal, de ONGs o agencias de donantes bilaterales, etc. En São Paulo, Brasil, el trabajo de promoción y defensa de la red de propietarios de APPs $^{127}$ fue un factor determinante para la creación de los programas Pago de Servicios Ambientales y Plan de Protección, además de muchas otras estructuras de apoyo para los propietarios de APPs. Estos programas incentivan a los propietarios a crear APPs, liberándolos de la responsabilidad de pagar impuestos que el gobierno federal les cobra a los propietarios regulares. Además, otorgan a los propietarios de APPs la posibilidad de acceder al Fondo Nacional del Medio Ambiente (FNMA) y de tener prioridad en la obtención de préstamos para créditos agrícolas (Monteferri \& Coll, 2009).

\section{Cuadro 8.1 \\ Land Trust Alliance, EE. UU.}

Fundada en 1982, la red de APPs Land Trust Alliance (LTA) es la más grande y antigua del mundo. ${ }^{128}$ La LTA es una organización nacional de conservación de tierras que representa a más de 1.000 land trusts miembros, además de contar con el apoyo de más de cinco millones de miembros nacionales. La red ofrece materiales educativos, promulga estándares y convoca a profesionales del área (la conferencia Land Trust Rally atrae a 1.800 personas cada año). Cabe destacar que la LTA aboga por la obtención de financiamiento para la conservación y por los incentivos tributarios para las APPs. También otorga acreditación ${ }^{129}$ por medio de un programa independiente (ver Cuadro 8.2), junto con llevar a cabo un censo cada cinco años, el que ofrece una visión panorámica sobre el crecimiento del movimiento (Bernstein \& Mitchell, 2005).

Autor: Brent Mitchell, QLF

\section{Principio 8.2: Las redes pueden entregar estructuras de apoyo para los propietarios de APPs}

Las redes se benefician de las economías de escala, ya que permiten desarrollar la capacidad técnica y la asistencia legal que la mayoría de los miembros no puede pagar de manera individual (Principio 2.5). La entrega de este tipo de servicios permite asegurar consistencia en todo el sistema de APPs de facto en un país y alienta a los propietarios a establecer APPs. Por ejemplo, por medio del apoyo a propietarios individuales, la Red Argentina de Reservas Naturales Privadas ${ }^{130}$ ha aumentado el número de APPs en la provincia de Misiones en un $30 \%$ en un periodo de tres años.

Buena práctica 8.2.1: Las redes de APPs permiten centralizar una serie de servicios técnicos y legales para los miembros gracias al trabajo de personal dedicado, experticia externa y apoyo de pares

\section{Estos servicios pueden incluir:}

- Capacitar y asesorar a los propietarios de APPs respecto de temas administrativos, legales y técnicos (ver Caso 8 de Perú).

- Aliviar el peso de la burocracia sobre los propietarios/gestores de APPs (tanto para aquellas ya existentes como para las que se están estableciendo), informando sobre qué organizaciones pueden ayudar, otorgando a los propietarios acceso a financiamiento y ayudando a completar documentos, etc.

- Proporcionar amparo cuando surgen problemas, como defensa legal, asistencia, contacto con los medios de comunicación.

- Facilitar la entrega de información sobre APPs individuales a agencias públicas (ver Sección 7), mediante el desarrollo de formatos estandarizados (Buena práctica 8.3.1) y la generación de capacidad.

- Preparar orientaciones y evaluaciones para la gestión y planes de trabajo estratégicos y anuales de sus miembros, incluyendo monitoreo, evaluación de la efectividad del manejo de las áreas (ver Principio 2.4) y auditorías de la red.

- Ayudar a los propietarios con problemas técnicos como gestión de incendios, control de especies invasoras, etc. Contar con acceso a especialistas que ayuden a los propietarios y a las organizaciones puede ser ventajoso.

- Desarrollar manuales y orientaciones para las APPs relacionados con los planes de negocio, land trusts, ecoturismo, esquemas de pago por servicios ecosistémicos, marketing y productos sostenibles.

- Facilitar las capacitaciones, apoyo e intercambio de información entre pares (ver Caso 2 de Brazil y Caso 8 de Perú).

- Desarrollar proyectos conjuntos entre varias APPs o redes de APPs (ver Caso 6 de Kenia y Caso 8 de Perú).

La participación en redes de APPs, o tierras para la conservación, en términos más generales, puede derivar en una serie de beneficios relacionados con el apoyo social y de gestión. Por ejemplo, en las redes de reservas de tenencia múltiple del sur de Australia, se registró que más de la mitad (55\%) de los gestores de tierras de conservación - públicas y privadas - mantenía contacto de manera regular con otros gestores pertenecientes a sus redes, un poco menos de la mitad (48\%) indicó que había alterado su régimen de gestión tras haber participado en la red, en tanto, un 
54\% sugirió que las decisiones de gestión tomadas en su terreno fueron influenciadas por acciones realizadas en otros sitios de su red (Fitzsimons \& Wescott, 2007).

\section{Principio 8.3: Las redes pueden incidir en el monitoreo y la verificación de APPs}

Las redes pueden ayudar a identificar, verificar y monitorear los objetivos de conservación de las APPs (Principio 2.4).

Buena práctica 8.3.1: En caso de que el gobierno requiera estándares para las APPs, las redes pueden ayudar a establecer y certificar cumplimiento

Las redes pueden ayudar a desarrollar formatos para identificar los valores de conservación (Buena práctica 1.1.3), además de monitorear y evaluar (Buena práctica 2.4.1) protocolos que pueden ser seguidos tanto por propietarios como especialistas de redes (ver Cuadro 8.1). Por ejemplo, en Colombia, ${ }^{131}$ es común que las redes brinden apoyo en el monitoreo y que resuman información de verificación de las APPs.

\section{Cuadro 8.2 \\ Acreditación de land trusts}

Como una manera de anticiparse a las regulaciones estatales, la Land Trust Alliance creó un programa de certificación voluntario en los EE. UU., junto con una comisión para administrarlo. La Comisión ${ }^{132}$ desarrolló estándares específicos y un sistema de documentación riguroso para que los grupos reciban acreditación del land trust. El sistema de acreditación se basa en 65 indicadores organizados en cuatro temas: gobernanza, finanzas, transacciones y custodia. La Comisión funciona como un programa independiente de la Land Trust Alliance. Ya en febrero de 2018, había 398 land trusts acreditados en 46 de los estados y territorios de los EE. UU.

Autor: Brent Mitchell, QLF

\section{Principio 8.4: Las redes pueden jugar un papel importante en la promoción de productos de APPs}

Las APPs individuales suelen desarrollar comercio de pequeña escala para la generación de servicios y productos sostenibles. Las redes pueden facilitar el proceso de marketing de estos productos y conectar a las APPs con proveedores y mercados.

Buena práctica 8.4.1: Las redes pueden entregar orientaciones para el desarrollo de productos y servicios, además de centralizar su promoción

Los productos y servicios de marketing pueden crear espacios para mostrar los resultados y productos de las APPs (ver Cuadro 8.3). Sin embargo, también pueden generar competencia entre los miembros si los procesos no son claros. Cuando una iniciativa es exitosa, las lecciones aprendidas se deben registrar y acompañar de indicaciones claras sobre cómo replicar aquel éxito. Las redes pueden desarrollar marcas centralizadas o sistemas de certificación para sus productos. No obstante, antes de desarrollar marcas o certificados individuales, deben promover y apoyar los sistemas de certificación y estándares disponibles nacional o internacionalmente. Para el turismo, los estándares deben basarse en criterios de carácter internacional, como el Global Sustainable Tourism Council's Destination Criteria. ${ }^{133}$ En Perú (ver Caso 8) la red de APPs publicó una guía sobre servicios de turismo ofrecidos por sus miembros. Por su parte, la Red Argentina de Reservas Naturales Privadas (RARNAP) creó un folleto con APPs que ofrecen ecoturismo, promovido en redes sociales durante temporadas altas. Las redes pueden promocionar a las APPs siempre y cuando la información haya sido entregada por los propietarios, por lo que es importante que los miembros estén comprometidos y participen en actividades grupales en caso de ser posible y pertinente.

\section{Principio 8.5: Las redes de APPs deben procurar que las estructuras y la gobernanza coincidan con su misión y objetivos}

El diseño de redes y gobernanza debe ser proporcional y adecuado para alcanzar los objetivos esperados, tomando en cuenta, por ejemplo, la cantidad de miembros, el alcance geográfico y la complejidad de las tareas.

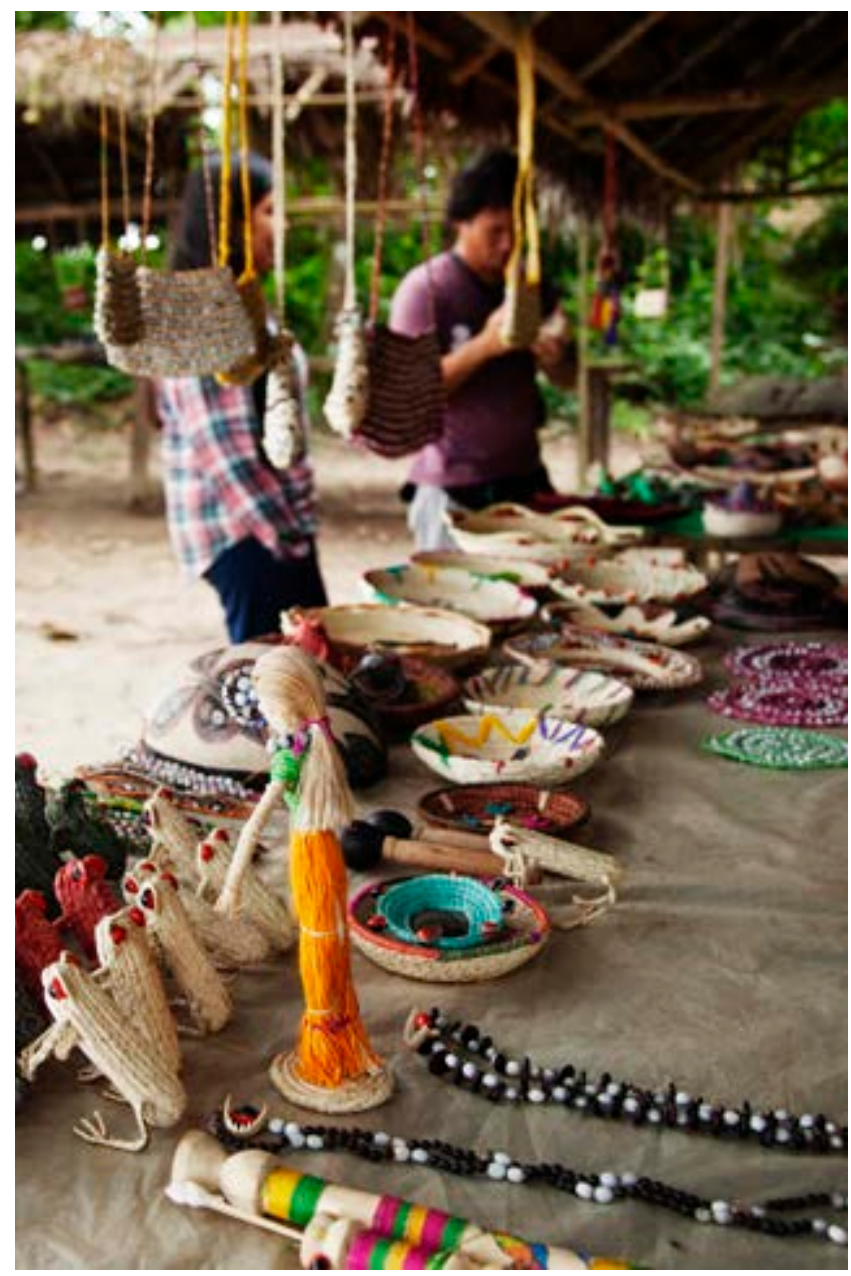

Productos artesanales vendidos en la APP Paraíso Natural Iwirati en Loreto, Perú (C) Conservamos por Naturaleza / SPDA 


\section{Cuadro 8.3 \\ The Long Run: Apoyo a las APPs orientadas al turismo}

The Long Run ${ }^{134}$ es una de las pocas redes globales de negocios turísticos que apoya a cabalidad a las APPs. Esta ONG, ubicada en el Reino Unido, reúne a propietarios/gestores de APPs sustentadas en el turismo basado en la naturaleza y cuyo compromiso es potenciar las actividades comerciales como vehículo para la conservación y el empoderamiento social. El objetivo de The Long Run es "conservar los ecosistemas a nivel global y utilizarlos de manera sostenible para el desarrollo económico por medio de un enfoque holístico" que reúne las cuatro 'c' (4C): conservación, comunidad, cultura y comercio.

La organización se estableció con el fin de incentivar a las APPs basadas en turismo a expandir su impacto social y de conservación de manera continua. The Long Run reúne a sus miembros para que aprendan de sus pares, compartan sus experiencias y tengan la oportunidad de innovar, además de ofrecer asistencia técnica in situ y remotamente. Al reunir a las personas, facilitar la planificación estratégica, junto con documentar y difundir conocimiento, The Long Run promueve el intercambio de conocimientos, acelera el aprendizaje, además de ofrecer el apoyo moral de una comunidad con ideas afines. Fortalece la voz colectiva de las APPs basadas en turismo y expone buenas prácticas mediante la difusión para, así, inspirar a otros a participar. Con el propósito de comparar el rendimiento de sus miembros, The Long Run desarrolló el estándar Global Ecosphere Retreats $®(G E R)$, que reconoce la necesidad de adoptar un enfoque equilibrado en torno a las 4C para conseguir un cambio positivo. El estándar ofrece un punto de referencia y un marco estratégico para, por un lado, incorporar las consideraciones sociales y de biodiversidad en todos los niveles de las operaciones comerciales y, por el otro, adoptar modelos financieros resilientes que permitan sustentar los resultados de conservación en el largo plazo. Sus miembros se comprometen a alcanzar, con el apoyo de The Long Run, los requerimientos estándar en un periodo de cinco años, contados desde su afiliación a la red. Una vez logrados, los miembros son reconocidos como centros de excelencia de APPs basadas en turismo. Los miembros de The Long Run pretenden proteger a más de 8 millones de hectáreas e impactar positivamente la vida de dos millones de personas para el año 2020 (World Tourism Organization, 2016).

Autor: Delphine Malleret-King, The Long Run

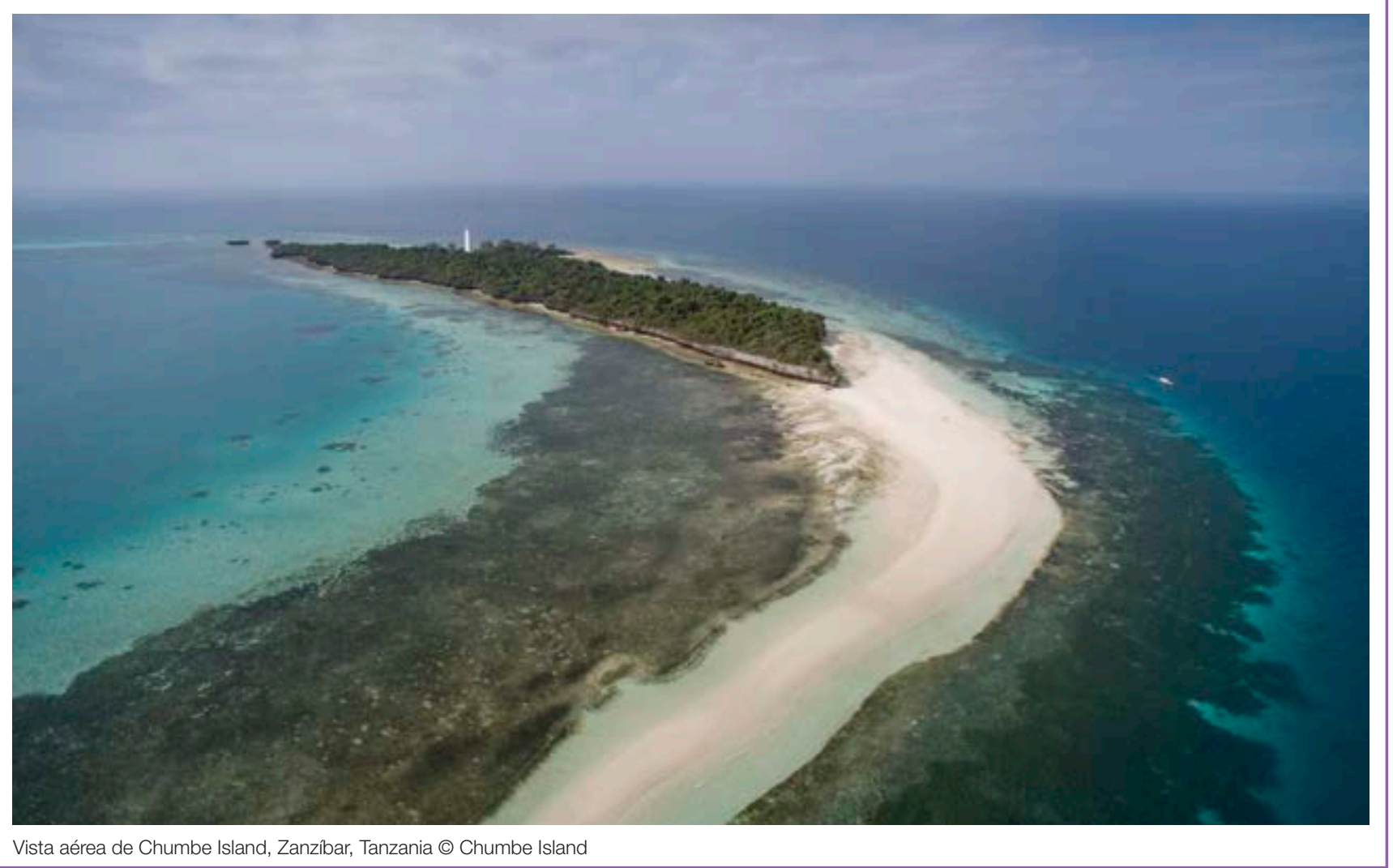


Buena práctica 8.5.1: Desarrollar una declaración de propósitos y objetivos y definir aspectos geográficos para establecer la red (es decir, local, regional, nacional)

A pesar de que los propósitos y objetivos pueden cambiar en cualquier momento, la red debe tener claridad sobre sus parámetros. Las redes pueden establecerse internacional, continental, nacional, subnacional o localmente. Por ejemplo, las redes continentales, como la Red Latinoamericana de Reservas Naturales Voluntarias, tienen un enfoque mayoritariamente regional, mientras que muchos países pertenecientes a esta misma red participan, a la vez, en sus propias redes nacionales -e incluso locales - de APPs, que son la base de las actividades cotidianas. Todas ellas son funcionales, pero es importante tener una idea clara sobre el alcance y los propósitos de cada tipo. Las redes locales suelen reunir propietarios con problemas y objetivos en común, de manera que sea más fácil fijar los objetivos, la gobernanza y la gestión de la red, además de planificar y llevar a cabo las actividades. Recientemente, se formó la red International Land Conservation Network. ${ }^{135}$ Modelada a partir de la Land Trust Alliance de EE. UU., esta red internacional busca empoderar a una comunidad de conservación global, y funciona bajo el alero del Lincoln Institute of Land Policy. ${ }^{136}$

\section{Buena práctica 8.5.2: Institucionalizar las redes para que no dependan de un solo individuo}

Es importante considerar quién establece la red. No obstante, el liderazgo, y con él la dirección organizacional, están sujetos a cambios. Se recomienda depender de los miembros de la red, en lugar de personas externas, y que los roles se vayan intercambiando, para que el liderazgo sea distribuido y compartido. Una fórmula utilizada en Colombia es el programa de APPs llamado Herederos de la Naturaleza, que alienta a los propietarios a involucrar a sus hijos en sus propios espacios de coordinación.

\section{Buena práctica 8.5.3: Si bien las redes pueden} comenzar de manera informal, convertirse en organizaciones formales puede fortalecerlas

Es importante ir revisando los objetivos y propósitos en la medida en que la red evoluciona, ya que las redes suelen responder a necesidades específicas mientras van surgiendo. Se recomienda desarrollar un plan estratégico y un plan anual, ya que estos ayudan a construir una visión, definir prioridades y a establecer actividades acordes al presupuesto. A pesar de que las redes informales pueden ser efectivas en el corto plazo, las redes formalizadas tienen una mayor probabilidad de persistir en el tiempo y de ser más inclusivas (ver Caso 9 de Samoa).

Las opciones varían, dependiendo de si la red es una organización con o sin fines de lucro. Muchas comienzan con un simple acuerdo de buena fe, bajo un memorando de entendimiento (MOU, por su sigla en inglés) o un documento similar. A menudo, estas redes suelen constituirse bajo alguna forma de entidad legal (por ejemplo, fundación, ONG, etc.), a medida que se van desarrollando. Existen distintos modelos para establecer redes: registradas por el gobierno, definidas de forma privada bajo alguna modalidad jurídica del código civil, definida de forma privada bajo un MOU, etc. Esta modalidad jurídica es independiente del éxito de una red. Cada una ha probado ser válida y exitosa cuando los objetivos son claros y la gobernanza bien definida.

Buena práctica 8.5.4: Las redes deben definir los derechos, los deberes y las responsabilidades de la membresía

Las redes deben definir de manera clara la forma en que los miembros colaborarán. Por ejemplo, el propósito de la Greater Sossusvlei Namib Landscape Association, ${ }^{137}$ que reúne un millón de hectáreas en Namibia, es promover y aumentar el nivel de colaboración y cooperación entre sus miembros y, en los casos en que sea relevante y exista acuerdo, armonizar su planificación, gestión y desarrollo a nivel de paisaje. Esto se consigue mediante una visión, objetivos y principios comunes, incluidos en una Constitución y en un Plan de Cogestión y Desarrollo firmados. A veces las redes establecen distintos niveles de membresía, incluyendo a los no-propietarios y partes interesadas, como las ONGs, que pueden tener responsabilidades y derechos distintos. Es muy importante mantener un directorio de miembros y la membresía debería, idealmente, ser información pública.

Buena práctica 8.5.5: Idealmente, las redes deben ser organizaciones independientes con el fin de minimizar la influencia indebida y resguardar la objetividad

Las redes deben ser entendidas como una iniciativa de los propietarios, de modo de evitar que las partes interesadas no se confundan con los intereses que las redes representan cuando surgen problemas u oportunidades. No obstante, las organizaciones existentes pueden servir de incubadoras de redes. Por ejemplo, el Lincoln Institute of Land Policy ${ }^{138}$ cumplió esta función con la Land Trust Alliance en EE. UU., y ahora lo hace con el International Land Conservation Network. El apoyo de este tipo de organizaciones suele ser temporal.

\section{Principio 8.6: Las redes de APPs, como cualquier organización, deben encontrar maneras de apoyar y sustentar sus actividades}

Las redes necesitan tener un presupuesto para operar. Es de suma importancia que los miembros tengan claridad sobre sus obligaciones financieras desde el comienzo y que, además, exista transparencia sobre el uso de recursos externos.

Buena práctica 8.6.1: Las redes pueden establecer programas para generar ingresos, aunque en algunos países estos deben establecerse como entidades independientes y con fines de lucro

Algunas redes de APPs crean empresas para vender los productos de sus APPs basadas en turismo o actividades sostenibles (Buena práctica 3.6.1). En otros casos, los miembros pagan cuotas, aunque estas suelen no ser suficientes para cubrir los costos relacionados con el manejo de la red. 


\section{Cuadro 8.4 \\ La NamibRand Nature Reserve, Namibia: Una asociación de propietarios}

Ubicada al suroeste de Namibia, la NamibRand Nature Reserve ${ }^{139}$ está conformada por 17 granjas, sobrepastoreadas por

ganado, que fueron rehabilitadas y transformadas en un área de conservación contigua. La reserva cubre más de 200.000 ha y su objetivo es gestionar el importante ecosistema Pro-Namib, para mejorar la conservación del paisaje y la biodiversidad. El terreno le pertenece a diez empresas o individuos diferentes que han conservado sus escrituras individuales y, a la vez, firmado acuerdos de asociación y comprometido sus propiedades para que estas formen parte de una única asociación de conservación $\sin$ fines de lucro. Los propietarios son los directores de esta asociación y los responsables de garantizar que la gobernanza general y el personal sean designados para implementar los planes de gestión y el manejo diario de la reserva. Esta es autosuficiente en términos financieros y todos los gastos operacionales y de capital se cubren con las tarifas de ingreso pagadas por los visitantes de los establecimientos dentro de la reserva. La designación de áreas silvestres y otras limitantes, como no permitir más de 25 camas por lugar, ayudan a asegurar la sostenibilidad ambiental aún más. La NamibRand Nature Reserve es percibida por el gobierno como un aliado ambiental importante, ya que el área constituye una zona de amortiguamiento para el Namib-Naukluft National Park (Odendaal \& Shaw, 2010) que colinda con la reserva.

Autor: Nils Odendaal, NamibRand Nature Reserve

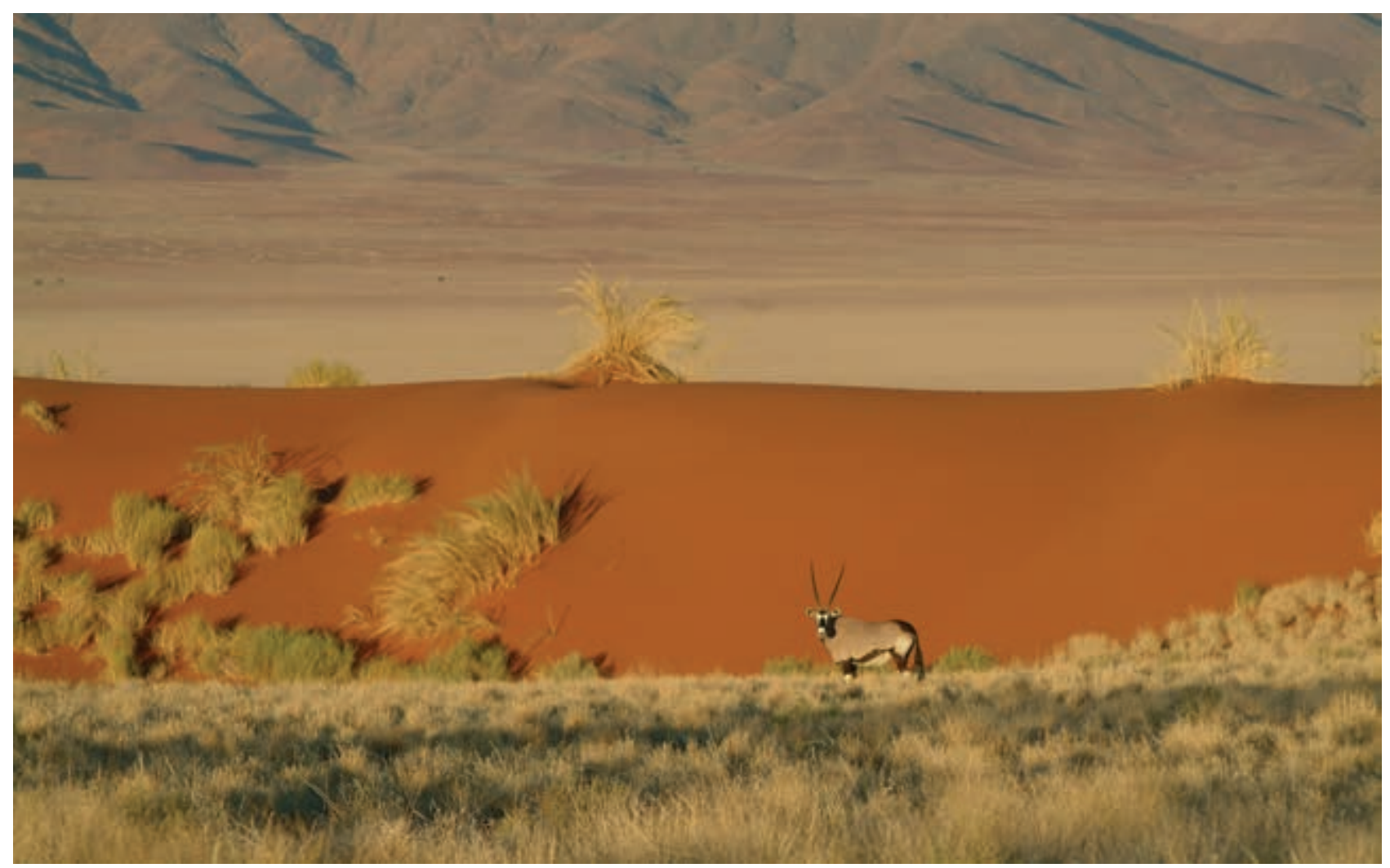

(c) Wolwedans, NamibRand Nature Reserve, Namibia 


\section{Perspectivas}

futuras:

Oportunidades para

concretar el potencial

de las áreas bajo

protección privada
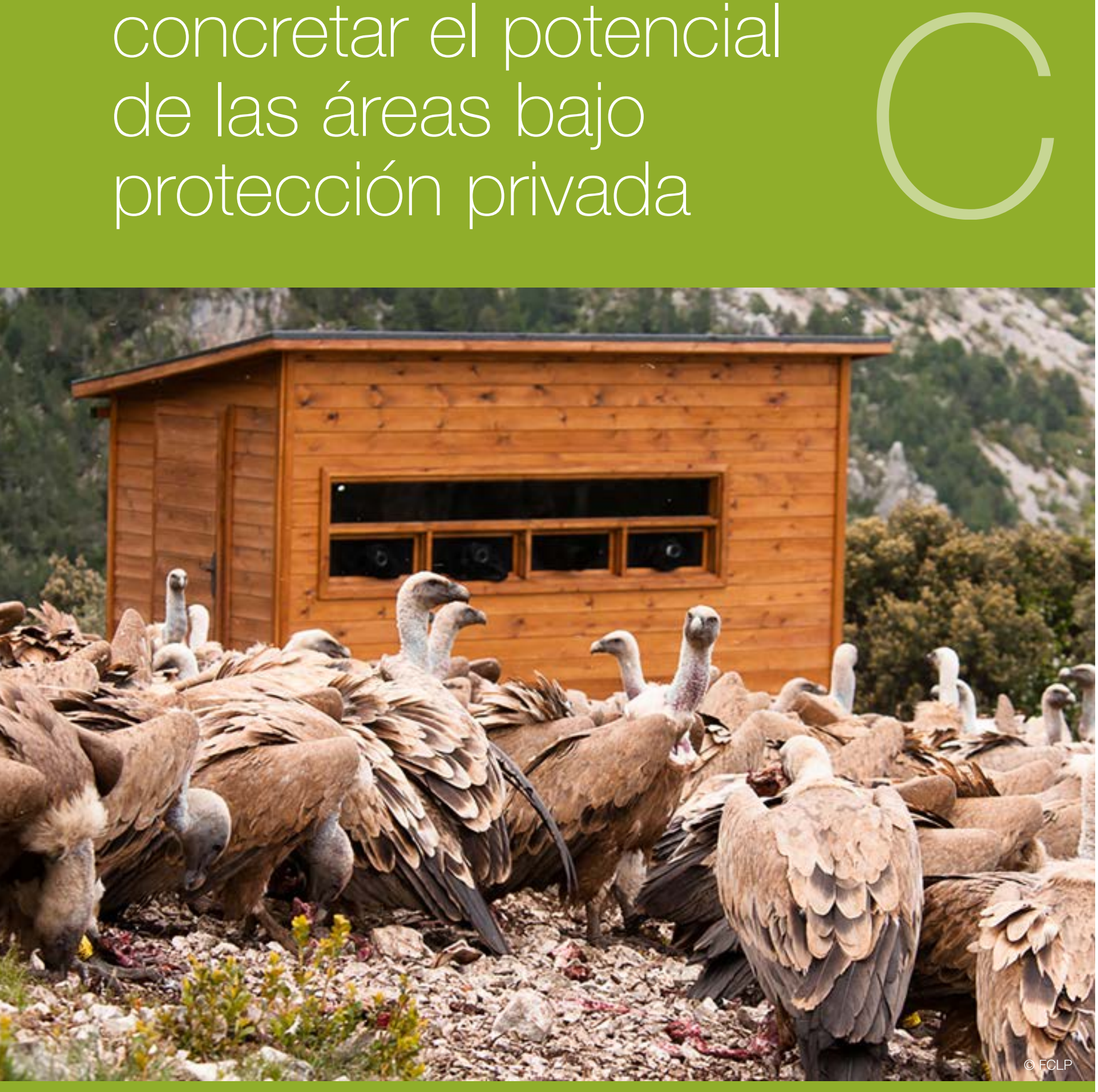
En general, la atención que está recibiendo la gobernanza de áreas privadas es un fenómeno relativamente reciente. Hasta hace dos décadas, era común presumir que las áreas protegidas eran una responsabilidad estatal. Este pensamiento persiste en varias partes del mundo, a pesar de que los primeros land trusts privados son tan antiguos como los primeros parques nacionales. La conservación privada de recursos naturales data de mucho antes. Pero a medida que crece la apreciación de distintos tipos de áreas protegidas, junto con el reconocimiento de los beneficios asociados a la diversidad en los tipos de gobernanza, también aumentan las probabilidades de éxito para la conservación de la biodiversidad.

\section{La necesidad de tipos diversos de gobernanza}

La diversidad biológica sostiene el funcionamiento ecosistémico y la provisión de aquellos servicios ecosistémicos esenciales para el bienestar de los seres humanos (CDB, 2010). La diversidad en los tipos de gobernanza de áreas protegidas es la base de nuestros sistemas de conservación de la biodiversidad in situ. Los distintos tipos de áreas protegidas presentan diferentes fortalezas y desafíos que afectan su nivel de efectividad en términos de la conservación de la naturaleza a largo plazo. Por ejemplo, las áreas protegidas estatales suelen no ser susceptibles a los cambios de propietario, mientras que las APPs sí lo pueden ser. Por otra parte, al ser privadas, las APPs pueden ser menos vulnerables a los cambios políticos que las áreas manejadas por el gobierno. Por consiguiente, la diversidad en los tipos de gobernanza le entrega resiliencia a cualquier sistema de área protegida (Leménager et al., 2014).

Las APPs también contribuyen a generar una ciudadanía colaborativa. Al ser una acción privada y voluntaria, el establecimiento y la gestión de APPs permiten a los individuos participar en la conservación. Esto es una realidad tanto para quienes son propietarios individuales o a escala familiar, como para quienes son miembros de una ONG, un director, ejecutivo o, incluso, empleados de una empresa que posea una APP. Desde grandes áreas silvestres hasta pequeños terrenos que albergan especies en extinción, las APPs posibilitan que personas de diversos ámbitos puedan involucrarse de manera directa.

\section{Recursos privados en pro de un beneficio público}

La UICN adoptó el término áreas bajo protección privada para reflejar que las APPs ofrecen muchos beneficios públicos, a pesar de ser establecidas y gestionadas por entidades privadas. Estos beneficios pueden incluir: conservación de biodiversidad in situ, conservación del hábitat, restauración y conectividad, funciones ecosistémicas como abastecimiento de agua, conservación del patrimonio geográfico, oportunidades de investigación, vínculos religiosos, desarrollo personal y, usualmente, acceso público.

Las APPs suelen ofrecer beneficios públicos a un menor costo que las agencias públicas a cargo de la gestión de áreas protegidas. Al ser gestionadas con recursos privados, las APPs reducen los costos públicos asociados a la compra y la gestión

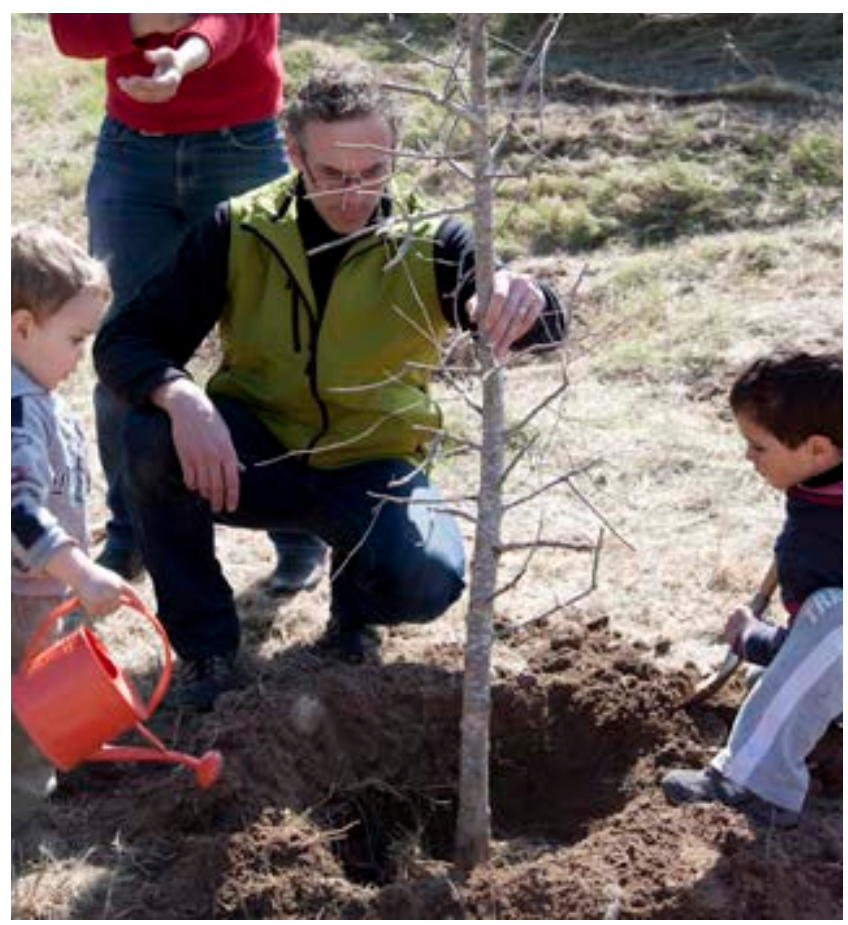

Plantación de árboles en Món Sant Benet @ Fundació Catalunya La Pedrera

de territorios terrestres y marítimos estatales, y, por tanto, de quienes pagan impuestos. Los países pueden maximizar estos beneficios incentivando y apoyando a las APPs.

\section{El futuro de las APPs}

Al igual que con todas las áreas protegidas, aún existen muchos desafíos para lograr que las APPs cumplan a cabalidad con su promesa y el ideal establecido por la UICN en sus directrices (Dudley, 2008). El informe Áreas bajo protección privada: Mirando al futuro, de la CMAP de la UICN, destacó estos desafíos e incluyó ocho recomendaciones generales para el desarrollo de las APPs, incluyendo la creación de estas orientaciones (Stolton et al., 2014). Todavía queda mucho por aprender sobre el sector de APPs a nivel mundial para identificar qué funciona y qué no. Y así como necesitamos que el proceso de registro de las APPs mejore, también necesitamos sistemas que identifiquen las áreas en las que los sitios no funcionan bien (Mascia \& Pailler, 2011).

Ante un escenario en que la sociedad enfrenta las mayores crisis ambientales de nuestro tiempo, como el cambio climático y el colapso de la biodiversidad, junto con otros tipos de áreas protegidas y conservadas, las APPs ofrecen soluciones naturales duraderas (Lopoukhine et al., 2012). 

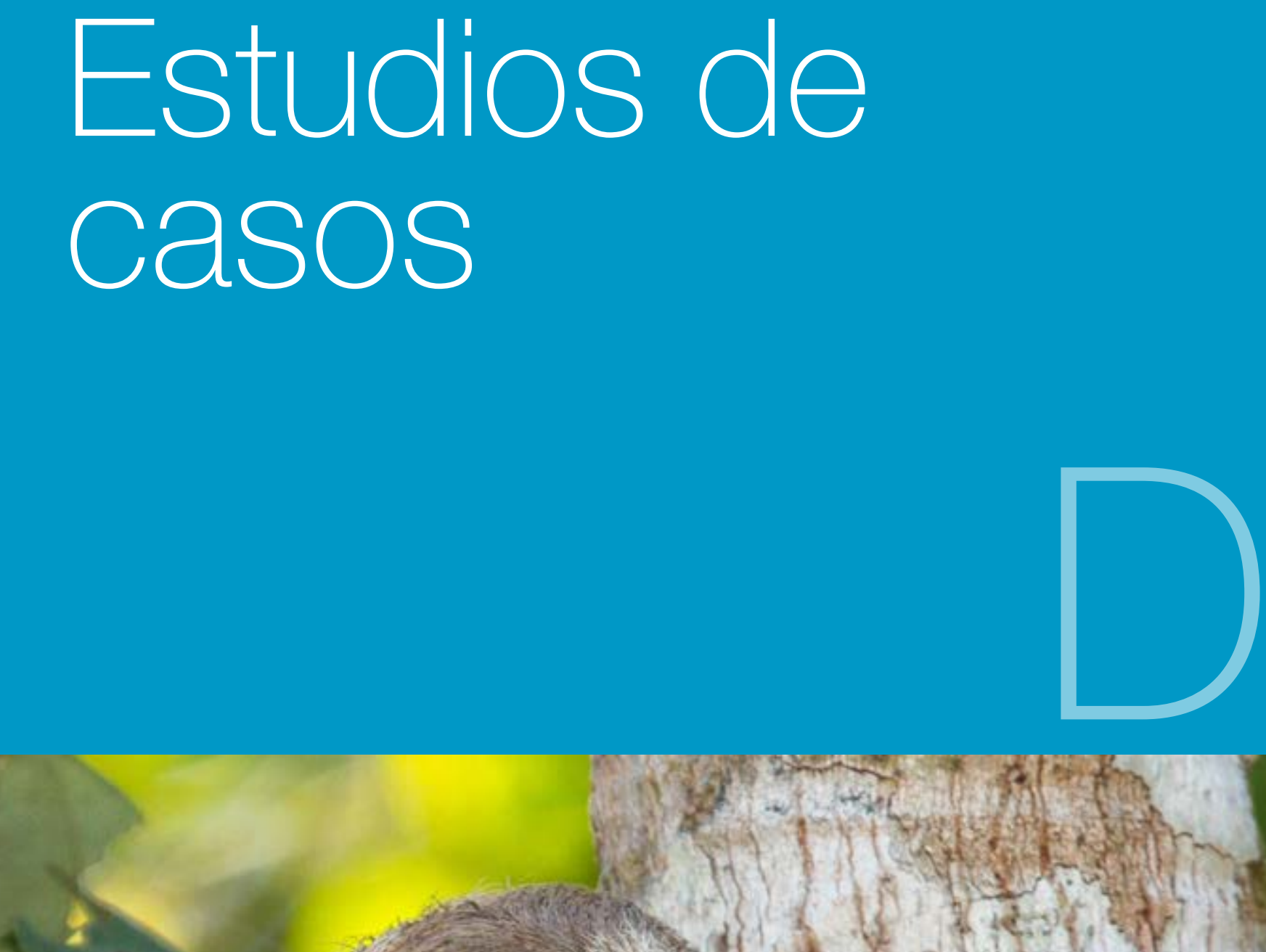
$+2$

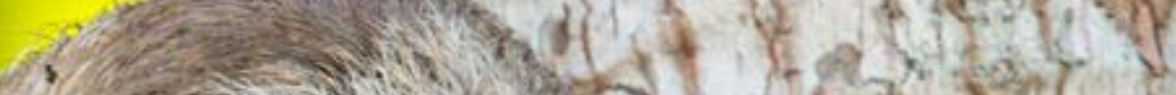

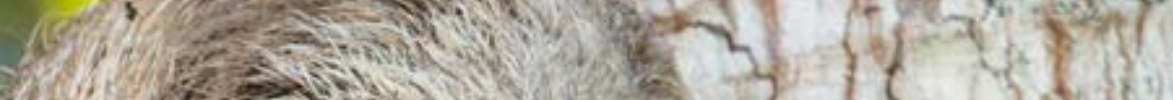

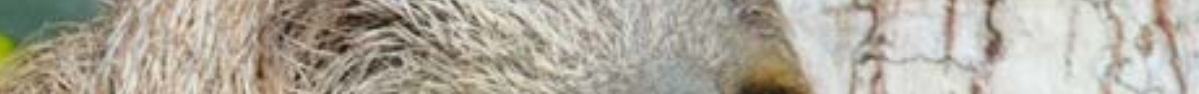

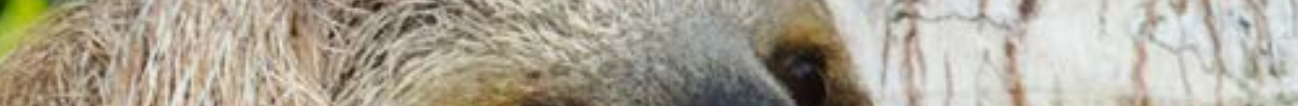

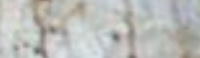
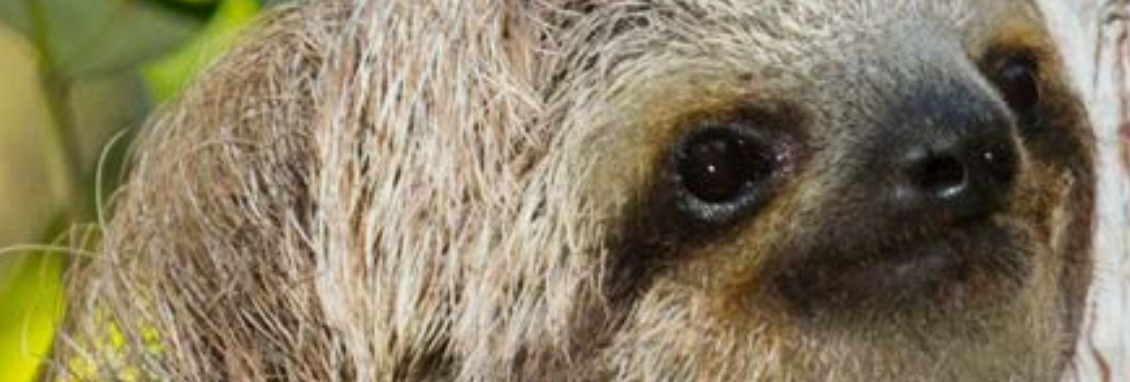

A.t. W.

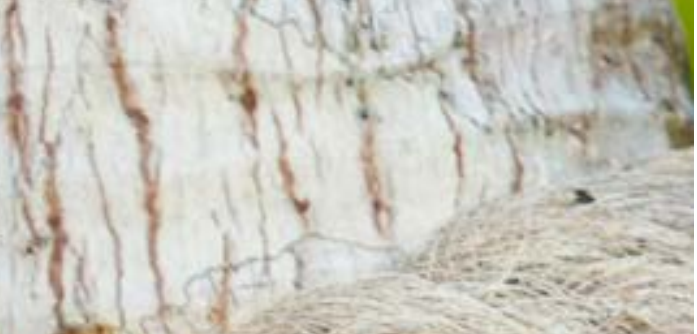

irons

as low

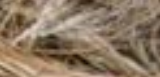

s.
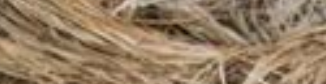

95

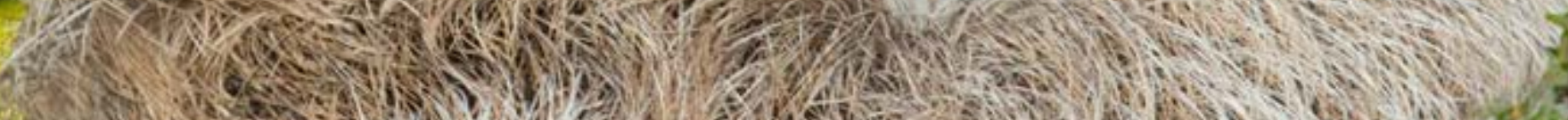
(196. (1) 3. MSE 
Esta última sección presenta 12 estudios de casos de diversas partes del mundo, seleccionados para ilustrar el alcance de las buenas prácticas presentadas en este documento. El foco de cada uno de ellos se muestra en la Tabla 1 y se reitera en el párrafo inicial de cada estudio. Alentamos a todos quienes estén interesados en las APPs a leer la totalidad de los casos, pues juntos representan la diversidad de las APPs que existen a nivel global.

\section{Estudio de caso 1 El Sistema Nacional de Reservas de Áreas Protegidas Públicas, Privadas e Indígenas de Australia}

\author{
James A. Fitzsimons, The Nature Conservancy y \\ Universidad de Deakin
}

El grado en que las APPs se integran a las redes nacionales de áreas protegidas varía a lo largo del mundo, e incluso dentro de cada país. Australia es un ejemplo en el que las APPs son consideradas parte importante del sistema nacional (ver Parte B, Sección 6), donde se ha hecho un esfuerzo concreto por incentivar la inclusión. No obstante, sigue siendo necesario integrar una variedad más amplia de distintos tipos de APPs.

\section{Contexto}

Australia es una nación federal responsable de la gestión de tierras, incluyendo áreas protegidas públicas, las que se encuentran principalmente en sus seis estados y dos territorios continentales. Hasta mediados de la década de los noventa, cada estado y territorio estaba a cargo de desarrollar sus propias áreas protegidas - sobre todo de tierras públicas - y había poca coordinación en términos de enfoque. Tras la ratificación del Convenio sobre la Diversidad Biológica (CDB), el gobierno nacional australiano, junto con los estados y los territorios, acordaron trabajar conjuntamente para crear un Sistema Nacional de Reservas (NRS, por su sigla en inglés), basado en la ciencia y en los principios de integralidad, idoneidad y representatividad (CAR, por sus siglas en inglés).

El objetivo era garantizar que se resguardarán, en áreas protegidas, muestras representativas de ecosistemas en cada una de las más de 80 biorregiones de Australia.

No obstante, se llegó a la conclusión de que esto no se lograría simplemente aumentando el patrimonio público de áreas

protegidas, sino que sería necesario incentivar la incorporación de acuerdos de protección para las tierras privadas e indígenas con el propósito de mejorar el sistema. Además de reconocer estas áreas en las políticas públicas (e.g. JANIS, 1997; NRMMC, 2005, 2009), el gobierno australiano entregó fondos mediante dos programas: el Programa del Sistema Nacional de Reservas (NRSP, por su sigla en inglés), que aportaba con hasta dos tercios del precio de compra para la adquisición estratégica de tierras privadas por parte de las ONGs y gobiernos estatales, y el Programa de Áreas Protegidas Indígenas, que se instauró para facilitar la incorporación de este tipo de tenencias al sistema de reservas. Uno de los criterios clave para la adquisición de tierras bajo el NRSP era que el terreno tuviera el potencial de mejorar la representación del sistema de reserva (con un enfoque en las regiones y ecosistemas biogeográficos subrepresentados).

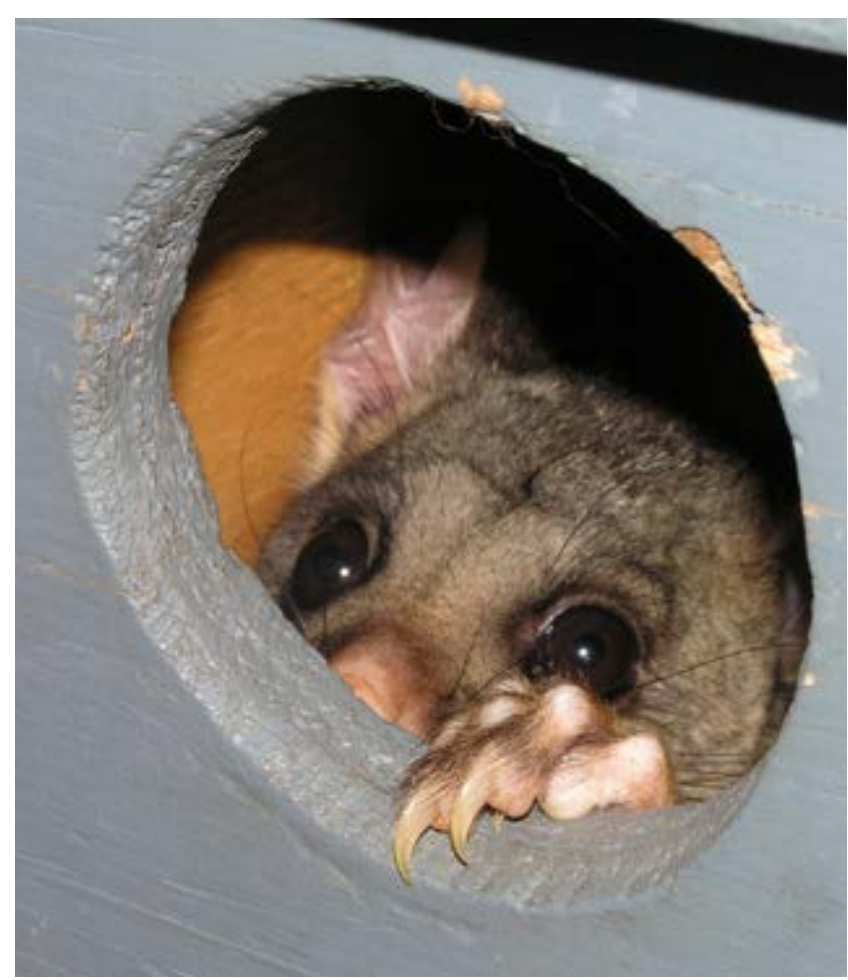

Una zarigüeya australiana (Trichosurus vulpécula) en un nido en Creighton Hills, un área protegida mediante un acuerdo de conservación

\section{La incorporación de las APPs al Sistema Nacional de Reservas}

Entre 1996 y 2013, el NRSP del gobierno australiano proporcionaba hasta dos tercios del precio de compra por terrenos privados adquiridos por los gobiernos estatales, land trusts o grupos comunitarios para ser convertidos en áreas protegidas estatales o APPs, respectivamente. El acuerdo de financiamiento entre el gobierno australiano y el comprador de la tierra dice expresamente que la tierra está siendo comprada para ser incluida en el NRS (Fitzsimons, 2006). El tercio restante del precio de compra debía ser obtenido de otra fuente, y en el caso de los land trusts, estos fondos provenían primordialmente de entidades filantrópicas, que solían interesarse debido al apalancamiento propio de este modelo (Humann, 2012). Las tierras privadas adquiridas por medio del NRSP requerían de acuerdos vinculantes al título de la propiedad que pudieran mantenerse a perpetuidad, aun en casos de cambio de propietario, o de acuerdos a 99 años donde se especificara que este era el tiempo mínimo para calificar (NRMMC, 2005; Fitzsimons, 2006). 


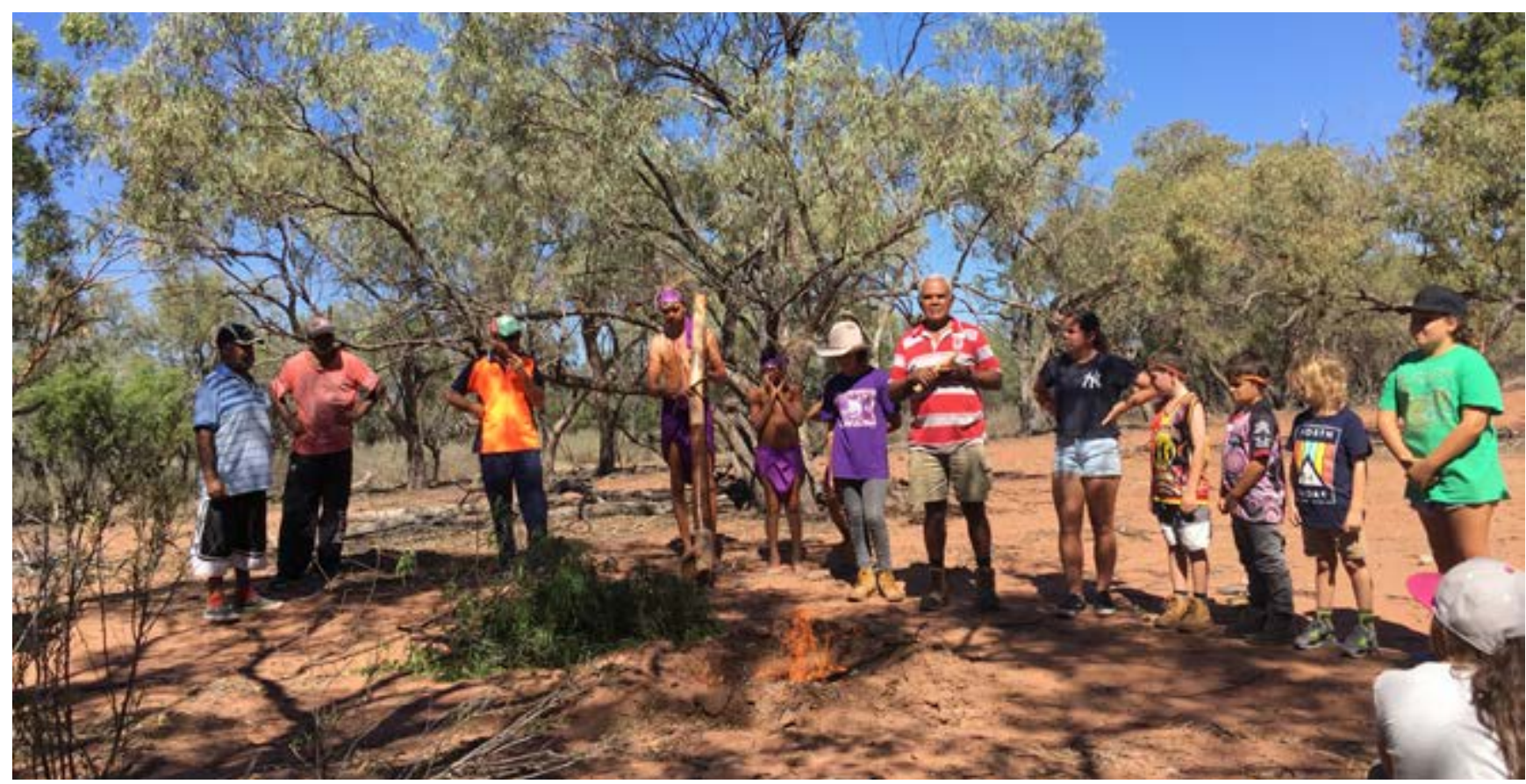

Sahumerio ceremonial, para repatriar artefactos budjiti a la Naree Station Reserve de Bush Heritage Australia, Nueva Gales del Sur, abril de 2018 ๑ Sarah Eccles

La incorporación de APPs al NRS australiano ha resultado en el aumento de la representación de biorregiones y ecosistemas (Taylor et al., 2014). Antes de realizar cualquier compra, se les recomendaba a los land trusts hablar con el gobierno sobre las posibles adquisiciones, con el fin de asegurar que la propiedad tuviera posibilidades reales de obtener financiamiento antes de postular.

En el estado de Tasmania, el gobierno australiano desembolsó AUD 30 millones (aproximadamente USD 22 millones) por una iniciativa cuyo objetivo era que se firmaran acuerdos de conservación para tierras privadas, nuevamente enfocándose en los ecosistemas subrepresentados. Se les ofrecía a los propietarios un pago por adelantado y asistencia en la gestión de conservación de los bosques en sus propiedades, dejando claro que estaban contribuyendo de manera formal al NRS (Buena práctica 7.1.2) (Gilligan \& Syneca Consulting Pty Ltd, 2007).

\section{Desafíos}

La mayoría de los acuerdos de conservación no han sido establecidos con el propósito explícito de contribuir o ser incorporados al NRS, y pocos propietarios han autorizado de manera clara la inclusión de sus propiedades al sistema. Sin embargo, algunos estados australianos han incorporado todos los acuerdos de conservación a la base de datos Collaborative Australian Protected Areas Database (Fitzsimons, 2015) - una representación de facto del NRS - sin haber solicitado una autorización explícita para incluirlos en el NRS (Buena práctica 7.1.2). El desafío, entonces, será resolver esta situación para poder cumplir con la resolución de la UICN, que dicta que los propietarios de APPs deben autorizar su incorporación a las bases de datos nacionales e internacionales.

\section{Resumen}

- El aporte de orientaciones sobre ciencias y políticas permitió guiar las prioridades para la futura expansión de áreas protegidas, incluyendo a las APPs establecidas por medio del NRSP (Buena práctica 1.2.1).

- La existencia de un presupuesto dedicado a la adquisición de tierras durante varios años fortaleció la confianza en el proceso de adquisición de tierras, el que usualmente tomaba varios años de negociaciones (Principio 1.4. y Buena práctica 1.2.1).

- Las APPs nuevas solían ser financiadas solo si cumplían con las metas nacionales, cuya misión era aumentar los niveles de representación de biorregiones o ecosistemas subrepresentados (Buena práctica 1.2.1).

- La mayoría de los acuerdos de conservación establecidos por medio de programas de conservación, aun cuando clasifican como APPs, no han sido establecidos de manera explícita para ser incluidos en los sistemas nacionales de áreas protegidas. Se necesita seguir trabajando para conseguir el apoyo formal de los propietarios y poder incorporarlas a esta red (Buenas prácticas 6.1.1 y 6.2.7).

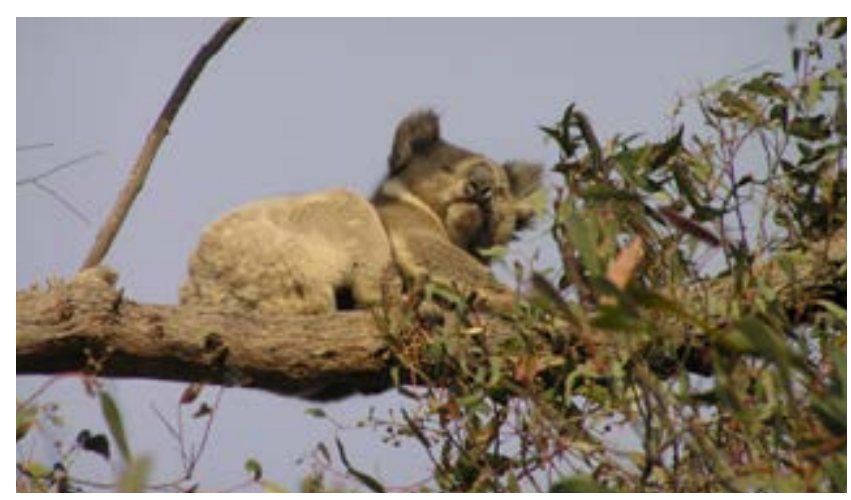

Un koala (Phascolarctos cinereus) en Creighton Hills $\odot$ James Fitzsimons 


\section{Estudio de caso 2 Reservas Privadas del Patrimonio Natural de Brasil: La iniciativa privada como política pública}

Renata Bomfim, RPPN Reluz, Beto Mesquita, consultor independiente, Flávio Ojidos, Confederación Nacional de Reservas Particulares del Patrimonio Natural (CNRPPN) y Maria

Cristina Weyland Viera, Asociación de RPPNs y Otras Reservas Privadas de Mina Gerais

En Brasil, las APPs son reconocidas por ley a perpetuidad; una vez declaradas como tal, su estatus no puede ser revocado, ni por el propietario ni por el gobierno (Buena práctica 4.1.1). La protección permanente es el principal beneficio para el propietario. El sistema también cuenta con una sólida red en desarrollo que entrega apoyo técnico y entre pares (Principio 8.2).

\section{Contexto}

En Brasil existe un sistema de conservación de tierras bien establecido y cada vez mayor, denominado Reserva Particular del Patrimonio Natural (RPPN, por su sigla en portugués) (Pellin \& Lima Ranieri, 2016). Las RPPNs son protegidas a perpetuidad y creadas por iniciativa de los propietarios (De Vasconcellos Pegas \& Castley, 2015). Las actividades permitidas en estas áreas incluyen investigación científica, así como turismo, recreación y educación, siempre y cuando estas no sean incompatibles con la protección de recursos en un área. Este tipo de área protegida surgió en 1990 y, por ley federal, forma parte del sistema nacional de áreas protegidas desde el año 2000. Este es un antecedente significativo, ya que otorga protección permanente, lo que significa que ni siquiera el gobierno puede cambiar el uso de suelo, salvo en casos excepcionales. Estas áreas protegidas continúan siendo de propiedad privada. Pueden ser vendidas o transferidas, pero el certificado de área protegida se mantiene y transfiere al nuevo propietario.

\section{Llenando los vacíos en una red de áreas protegidas}

Hay alrededor de 1.500 APPs en Brasil, que equivalen a 772.000 ha. Si bien esta superficie no es significativa cuando se la compara con los más de 76 millones de ha de áreas protegidas federales, las RPPN suelen estar bien ubicadas para proteger áreas de alta biodiversidad. Además, en términos de gestión, las RPPNs tienen la capacidad de ser mejor manejadas que sus contrapartes gubernamentales. A modo de ejemplo, actualmente existe solo un administrador por cada 45.000 ha de áreas protegidas federales.

Suponiendo un mínimo de un administrador por RPPN, el promedio es de uno por cada 550 ha. Aunque estos son solo promedios de este inmenso país, esta métrica entrega cierto sentido de la escala. Una evaluación reciente sobre la efectividad en el manejo en el estado de Mato Gross do Sul reveló que las RPPNs efectivamente son mejor gestionadas que las del gobierno, aunque ambas deben mejorar (Pellin \& Lima Ranieri, 2016).

Las RPPNs pueden ser certificadas por cualquier nivel de administración gubernamental, ya sea federal, estatal o municipal, pero no reciben muchos incentivos financieros por parte del gobierno que las reconoce. Sí clasifican para recibir beneficios fiscales en el

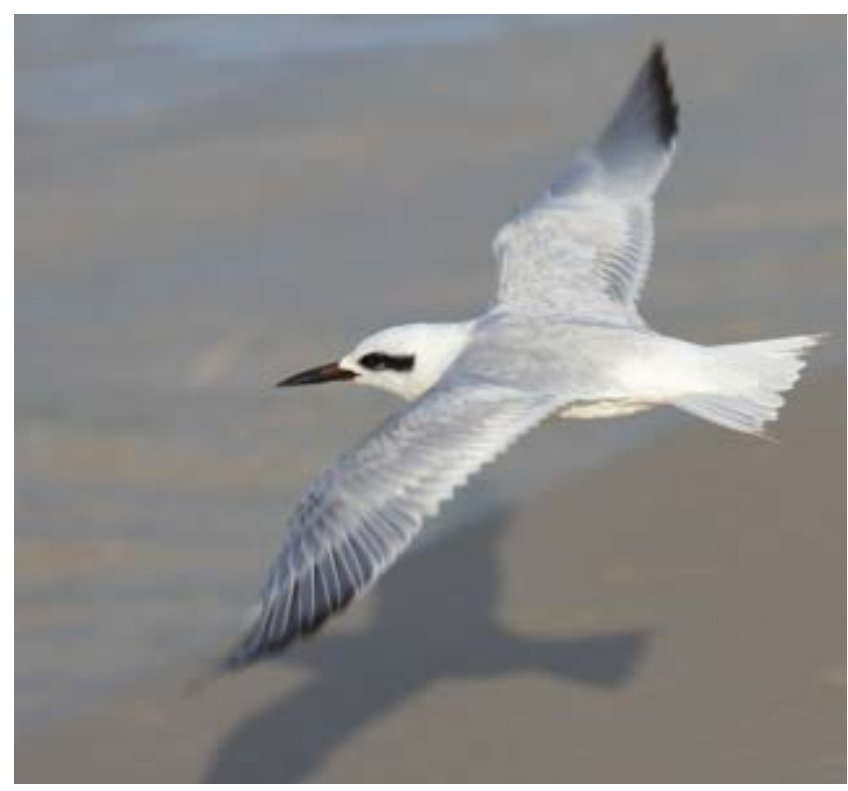

Harrán coroniblanco (Sterna trudeaui) en el RPPN Costau do Santinho (C) Brent A. Mitchell

impuesto a la propiedad, pero a diferencia de los EE. UU. (ver Caso 11), este no es un catalizador importante - excepto en el caso del bioma Pantanal, donde se encuentran las RPPNs más grandes-. Por ello, se apoyan entre sí por medio de una red nacional que entrega recomendaciones sobre cómo obtener sostenibilidad financiera. Por ejemplo, en los estados de São Paulo y Paraná, las asociaciones de propietarios de RPPNs lucharon exitosamente por la creación de un esquema de Pago por Servicios Ambientales. Actualmente, uno de los líderes de la red está trabajando en la creación de una guía sobre esta materia, y las habilidades de gestión dentro de la red están creciendo. Desde el punto de vista del sistema nacional, el gobierno observa una mayor capacidad de conversación y niveles más bajos de inversión directa.

Las RPPNs no están distribuidas uniformemente a lo largo del país. Hay relativamente pocas APPs en el humedal Pantanal, pero en promedio son bastante grandes. Por el contrario, aunque hoy existen APPs en todos los estados brasileros, la mayor cantidad de RPPNs individuales se encuentra ubicada en el bioma mata atlántica, pero en promedio son mucho más pequeñas en tamaño.

Las RPPNs recibieron atención internacional por primera vez mediante la reintroducción del tití león dorado (Leontopithecus rosalia), proveniente de programas de cría en cautividad en zoológicos de todo el mundo, y para quienes las APPs aportaron los hábitats adecuados. La mata atlántica es un hotspot de biodiversidad que concentra dos tercios de la población del país, por lo que solo $16 \%$ del bosque original persiste, y más de un $80 \%$ le pertenece a propietarios privados. Es por ello que es complejo crear nuevas áreas protegidas públicas en esa zona. Este es un excelente ejemplo de cómo las APPs pueden abordar la fragmentación del hábitat y proporcionar conectividad en áreas donde otros enfoques son menos efectivos. 


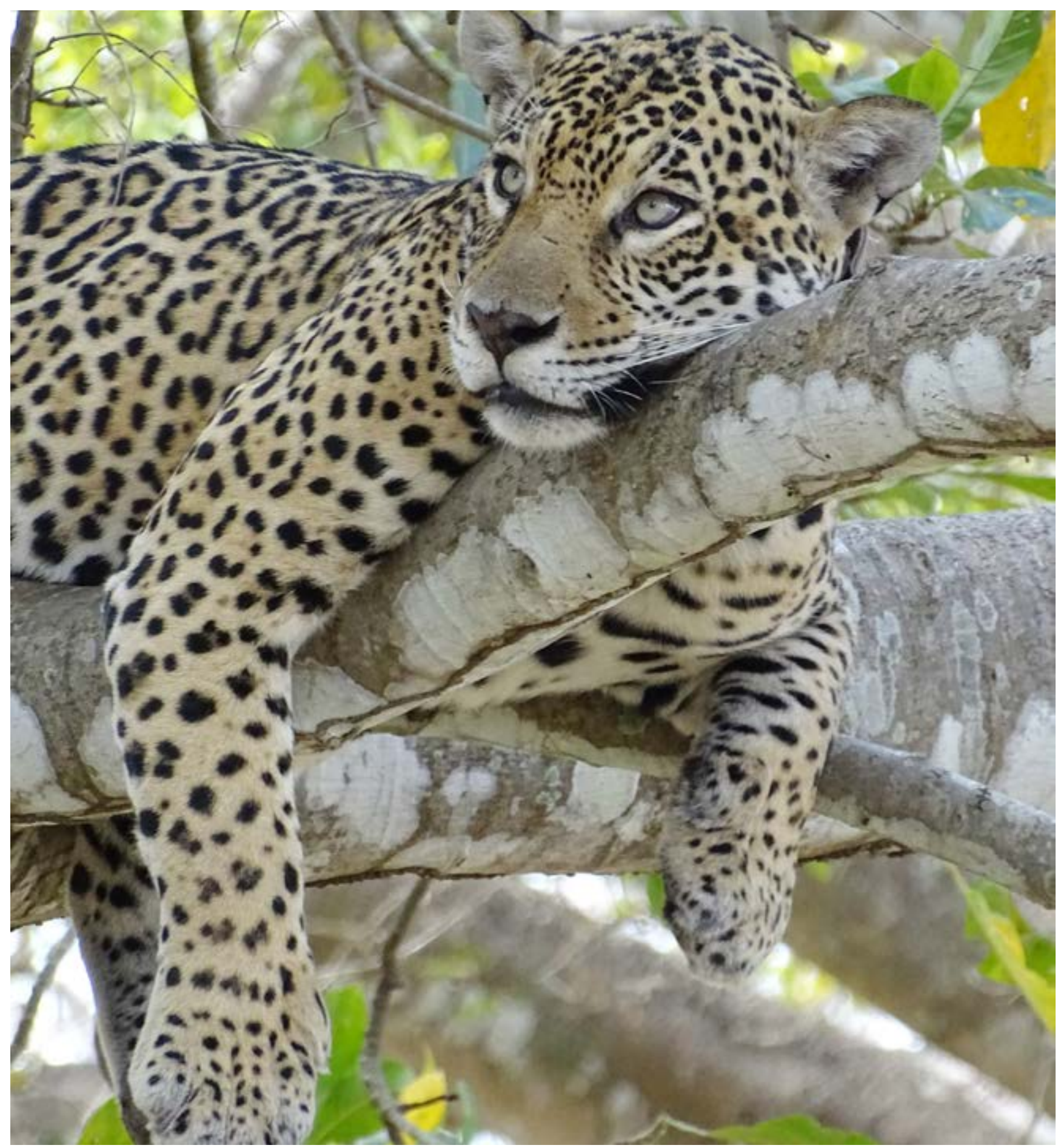

Jaguar (Panthera onca) ๑ Projeto Onçafari

\section{Resumen}

- Las RPPNs son protegidas a perpetuidad; no se puede modificar su estatus de área protegida, ni siquiera por el gobierno (salvo en casos de implementación de servicios públicos donde no existe ninguna otra alternativa local) (Buena práctica 4.1.1).

- Las RPPNs juegan un papel desproporcionadamente grande en la conservación, pues suelen estar ubicadas en biomas subrepresentados en áreas protegidas públicas, y ofrecer conectividad a través de mosaicos de áreas con distintos tipos de gobernanza (Principio 6.2).
- Las redes de RPPNs estatales y federales están comprometidas a entregar apoyo técnico y entre pares a los propietarios individuales (Buena práctica 8.2.1).

- La red nacional mantiene una base de datos, y las RPPNs se consideran parte del sistema nacional de áreas protegidas. Actualmente, una comisión especial trabaja para aumentar el nivel de registros de RPPNs en la Base de Datos de Áreas Protegidas (Buena práctica 7.1.1). 


\section{Estudio de caso 3 Land Trust Reserve de China}

\section{Jin Tong, The Nature Conservancy, China}

Tradicionalmente, todas las tierras en China le pertenecen al 'pueblo' y no existen las tierras 'de propiedad privada' como tal. Desde 2008, una serie de políticas para la reforma de la tenencia de bosques, que pretende separar la propiedad de tierras de los derechos de gestión establecidos por contrato, ha abierto la puerta para que individuos y organizaciones privadas puedan tener derechos de gestión sin cambiar el propietario de las tierras. En el intertanto, ha habido un llamado a diversificar las fuentes de financiamiento para la conservación, con el fin de incorporar inversiones de capital social. El rápido crecimiento de la economía china y el aumento de la filantropía doméstica también permiten que los ciudadanos privados puedan apoyar la conservación financieramente. Estos factores han resultado en la creación de un nuevo modelo de conservación privada en China en esta última década, incorporando fondos y gestión privados al sistema de áreas protegidas. Se trata de una adaptación de los land trusts clásicos de los EE. UU., razón por la cual su nombre es Land Trust Reserve. Este caso ofrece un ejemplo de establecimiento de APPs (ver Parte $B$, Sección 1) en un país donde, hasta hace poco, esa opción no era posible.

\section{Contexto}

Actualmente, más del $15 \%$ de las tierras de China ha sido designado como área protegida, dentro del cual 2.750 reservas naturales cuentan con los niveles más altos de protección legal. Sin embargo, siguen existiendo muchos vacíos de conservación en el sistema de áreas protegidas existente en China. Hoy, la mayoría de las reservas locales o provinciales del sistema son, en esencia, parques que solo existen en papel, pero que, en muchos casos, presentan carencias en términos de fondos, en materia de aplicación de la ley y personal de gestión, además de enfrentar frecuentes conflictos asociados al desarrollo económico local. Por ejemplo, casi la mitad (46\%) del hábitat de los osos panda (Ailuropoda melanoleuca) no ha sido cubierto por reservas naturales.

Laohegou solía ser uno de estos vacíos de conservación. Ubicado en el condado de Pingwu, provincia de Sichuan, Laohegou es un corredor clave para los osos panda que conecta dos de las reservas nacionales de osos pandas. Abarca cerca de 11.000 ha de bosque primario, incluyendo una finca forestal estatal y bosques colectivos en los alrededores, y tiene una población estimada de 10 osos panda. La tala comercial está prohibida gracias al programa de protección de bosques, pero solo un número limitado de actividades de conservación - por ejemplo, prevención de incendios - han sido llevadas a cabo y las prácticas insostenibles de extracción de recursos naturales en áreas aledañas incluían la caza, la pesca y la recolección de productos forestales no madereros.

En 2011, el programa The Nature Conservancy (TNC) China comenzó a colaborar con el gobierno local para explorar el establecimiento de la primera reserva land trust, siguiendo el modelo de los land trusts de los EE. UU. TNC China desarrolló una nueva entidad, la Sichuan Nature Conservation Foundation (SNCF) (la que luego pasó a llamarse Paradise Foundation ${ }^{140}$ ), con

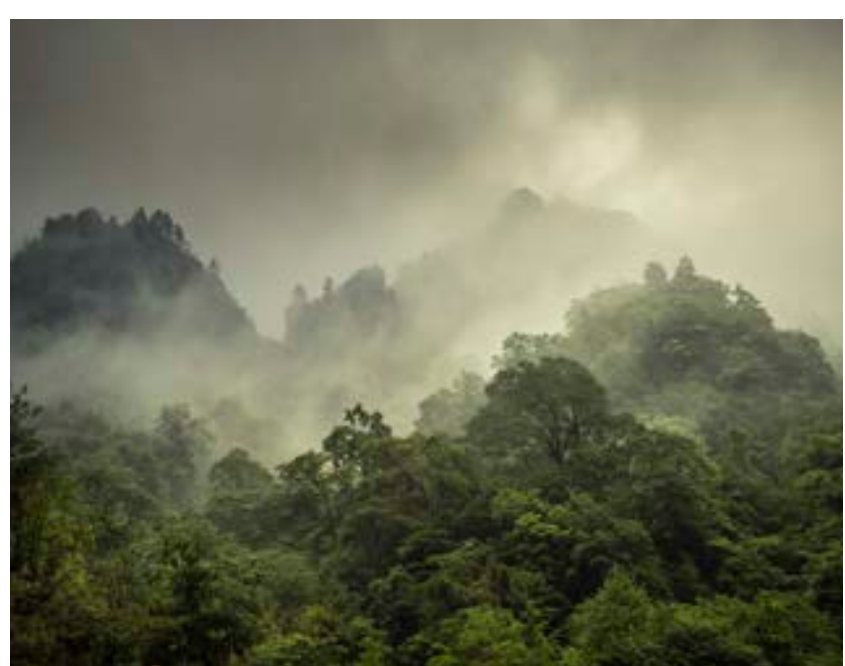

Laohegou Nature Reserve @ TNC

el apoyo de 22 importantes empresarios chinos. Un año después, la SNCF firmó el primer contrato de arrendamiento de conservación de la nación, el que le permite gestionar un terreno de bosque de 11.000 ha por los próximos 50 años (Buena práctica 1.4.2). Con el fin de consolidar aún más las salvaguardas legales de protección, Laohegou fue declarada oficialmente reserva natural a nivel de condado, en septiembre de 2013, con la SNCF como su financiadora y dueña de los derechos para su gestión bajo la supervisión del gobierno local (Buena práctica 1.1.1). La SNFC invirtió cerca de USD 3,3 millones para el establecimiento de reservas en los tres primeros años y sus costos operacionales han sido aproximadamente USD 500.000 desde entonces (Stolton et al., 2014).

Para manejar la reserva, la SNCF patrocinó la creación de una ONG local, Laohegou Nature Conservation Center (LNCC), la que ha contratado a exempleados de las fincas forestales estatales y a residentes de la zona para la gestión diaria y ha recibido apoyo técnico de TNC China (Buena práctica 2.5.1). Dirigidos por TNC China y un grupo de científicos provenientes de los mejores centros de investigación, Laohegou, ha conducido estudios de línea de base, a partir del cual desarrolló su plan de manejo utilizando el marco de Estándares Abiertos (Buena práctica 2.5.4). Este incluye un control estricto de entradas y salidas dentro de la reserva, para evitar los disturbios de origen humano, y un sistema de patrullaje y de aplicación de la ley realizado en conjunto con la Policía Forestal para detectar y lidiar con actividades ilegales. Desde mediados de 2014 se comenzó a implementar un sistema de monitoreo ecológico simple - pero confiable - que utiliza cámaras trampa para ayudar a evaluar la efectividad de la conservación (Buena práctica 2.4.1).

Además de la conservación, Laohegou está experimentado mecanismos pilotos para aumentar las ganancias en las comunidades aledañas (Buena práctica 2.3.2) y para que el financiamiento de la custodia de la reserva sea sostenible (Buena práctica 3.2.1). Se estableció un área de expansión con el fin de incluir comunidades de los alrededores y, además, se desarrolló un plan maestro para guiar el desarrollo de esta zona de una manera ecológica. La SNCF ayudó a montar un sistema para conectar 


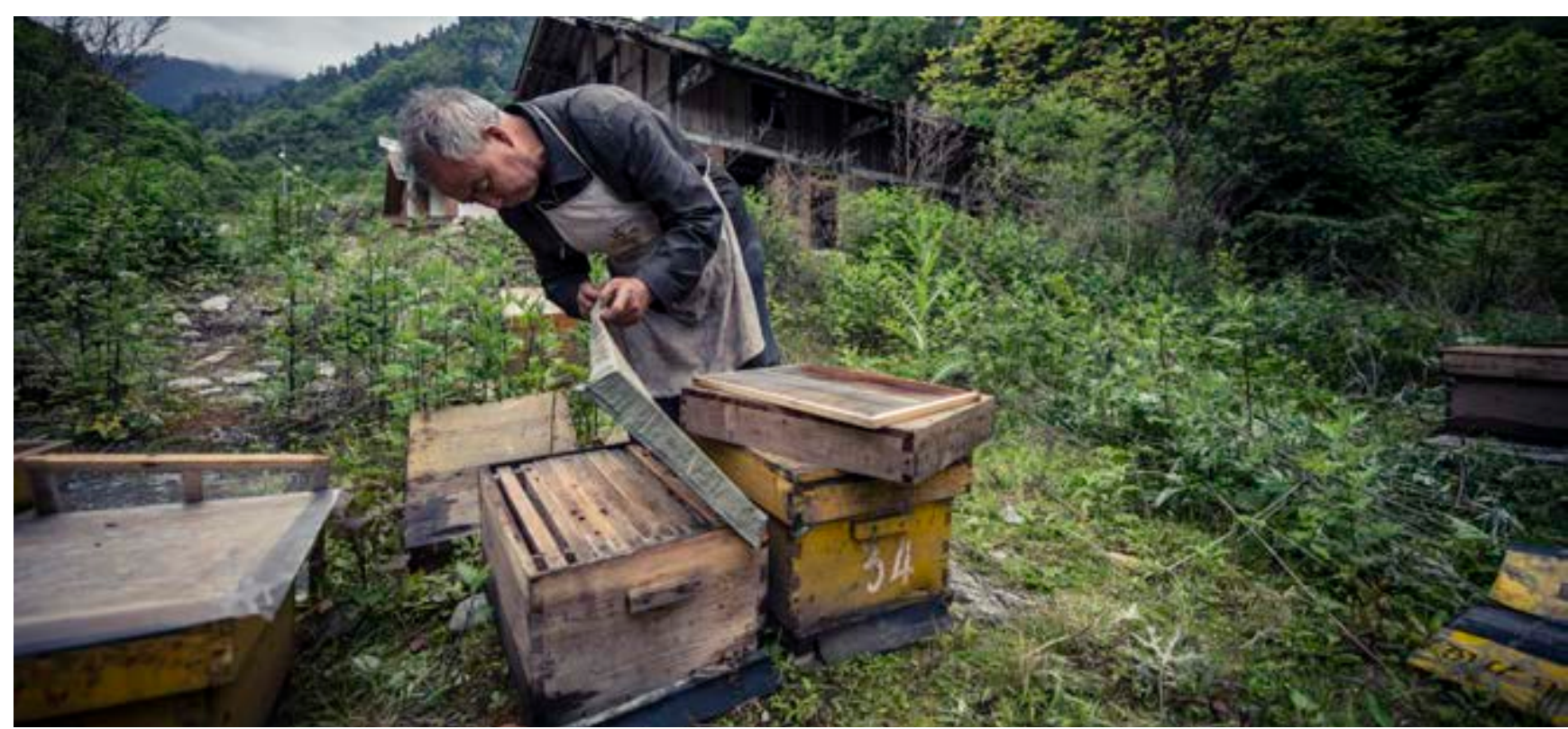

Apicultura en la Laohegou Nature Reserve @ N Nick Hall

los productos agrícolas ecológicos de las comunidades con mercados externos con el fin de venderlos a precios más altos. Las ganancias de las ventas aumentan el ingreso de la comunidad y reducen la presión proveniente de aquellos residentes locales que quieren cazar o buscar alimentos dentro de la reserva. En 2015, la SNFC fundó una empresa social para producir y vender aguamiel proveniente de la apicultura de la reserva. Las ganancias de este negocio contribuirán a financiar las operaciones de la reserva.

Ha habido cambios muy positivos desde el establecimiento de la Laohegou Land Trust Reserve. Equipada con los fondos adecuados, personal calificado y un plan de manejo sensato, la APP ha eliminado casi todas las actividades humanas destructivas, y la población de osos pandas ha aumentado a 13 (según el último catastro de población nacional) y los peces endémicos han regresado a los ríos. Mientras tanto, más de un tercio de los hogares dentro del área de expansión ha podido duplicar sus ingresos por medio de la agricultura ecológica. El modelo de land trust ha sido reconocido ampliamente por distintas agencias de gobierno, organizaciones de conservación y empresas, y ha demostrado que puede ser un suplemento efectivo para el sistema de áreas protegidas manejado por el gobierno.

Más allá de la experiencia en Laohegou, TNC China y sus aliados están explorando otros modelos para demostrar la flexibilidad de este enfoque. Por ejemplo, modelos en los que organizaciones de la sociedad civil asuman las responsabilidades de la gestión de manera parcial o total de una reserva cuya gestión es deficiente. "Hemos estado probando este modelo localizado de land trust para expandir la capacidad de la sociedad de proteger y gestionar de manera sostenible los territorios terrestres y marinos más importantes de China, a la vez que ofrecemos soluciones de formas de vida sostenible para las comunidades locales y creamos un mecanismo que permite financiar la gestión de la reserva a largo plazo mediante contribuciones privadas. Creemos que este modelo podría convertirse en un suplemento significativo para el actual sistema de áreas protegidas de China", dijo el director científico de TNC China, Dr. Jin Tong. Tomando prestada la idea del movimiento de land trusts de los EE. UU., 23 ONGs y fundaciones ambientales domésticas e internacionales lanzaron la asociación China Civic
Protected Areas Alliance en noviembre de 2017, con el objetivo de catalizar el 'movimiento chino de land trusts', aportando con una plataforma para comunicaciones, financiamiento, estándares, políticas y creación de capacidad (Ver Parte B, Sección 8). La visión a largo plazo de esta alianza es poder proteger de manera colaborativa el $1 \%$ del territorio terrestre por medio del apoyo de organizaciones cívicas y privadas y de individuos.

\section{Resumen}

- El establecimiento de la SNCF fue fundamental para el modelo del Land Trust Reserve. Ha funcionado como un canal de financiamiento a través del cual se reciben recursos provenientes de la filantropía que apoyan el establecimiento y la gestión de las reservas, y como una entidad adecuada para la firma de arrendamientos o acuerdos de conservación que permiten poseer los derechos de gestión sobre la tierra (Buena práctica 8.2.1).

- El equipo de gestión dirigido por la comunidad local de Laohegou es clave para asegurar la custodia a largo plazo de la reserva (Buena práctica 2.5.6).

- La idea de 'área de expansión' en torno a las áreas protegidas conecta la conservación dentro de la reserva con el desarrollo ecológico comunitario que ocurre alrededor de la reserva (Buena práctica 2.3.2).

- Un plan de financiamiento sostenible y diversificado para financiar la custodia de la tierra es vital para la estabilidad a largo plazo del modelo de APP (Principios 2.3 y 3.2). 


\section{Estudio de caso 4 APP y turismo: Un ejemplo in situ en Lapa Ríos, Costa Rica}

Delphine King, The Long Run, y Karen Lewis, Lapa Ríos

Lapa Ríos es una iniciativa de turismo de conservación líder en Costa Rica. Este proyecto refleja la fuerza que puede alcanzar un negocio turístico como medio para la conservación, además de revelar: la importancia de tener objetivos de conservación bien articulados y, a la vez, capaces de permear el aspecto más lucrativo de la iniciativa (Principio 5.4), la relevancia de la colaboración (Buena práctica 5.1.2) en distintos niveles, y la utilidad de un enfoque como el que ofrece el marco de las cuatro 'c' (4C) (Cuadro 8.3) que integra conservación, comunidad, cultura y comercio- para fortalecer los impactos de conservación del negocio y, así, garantizar resultados de biodiversidad proyectados en el futuro (Principio 1.5).

\section{Contexto}

La Reserva Lapa Ríos ${ }^{141}$ se ubica cerca del punto donde el golfo Dulce y el océano Pacífico se unen, en la península de Osa en Costa Rica. Los bosques de esta península presentan los niveles más altos de biodiversidad y la mayor densidad de carbono del mundo (Taylor et al., 2015). En la década de los noventa, cuando el crecimiento de la población humana estaba en alza y las prácticas de negocios extractivos insostenibles amenazaban este lugar, John y Karen Lewis compraron 420 ha de tierra, extendidos desde el océano hasta la espina dorsal de la Osa. Ellos querían demostrar que, "Sin importar cómo la corten, mantener una selva tropical en pie es más valioso que cortarla". Su meta era proteger las más de 300 ha de bosque primario, regenerar 80 ha de secciones de pastizales, "proporcionarles a las comunidades locales modos de vida sostenible y mejorar el nivel de concientización en torno a la conservación y la gestión sostenible del medioambiente" (Karen Lewis, fundadora).

Mediante un enfoque que conecta la conservación, la comunidad, la cultura y el comercio (4C) lograron hacer exactamente eso. El bosque se ha recuperado significativamente, y cuentan con un frondoso bosque secundario que cubre todas las zonas que antes estaban degradadas. El área alberga 400 especies de aves, 500 especies de árboles, cuatro especies de monos y jaguares, tapires y perezosos, entre otros (Toft \& Larsen, 2010). Este caso demuestra que el ecoturismo puede ser un catalizador competitivo para la conservación. El éxito logrado se debe a la creatividad, la persistencia, los valores y la estrategia tras el trabajo colaborativo de esta iniciativa.

\section{El turismo responsable como una oportunidad para conservar la península de Osa}

Al comprar la tierra, los dueños se propusieron crear un hotel y una reserva para proteger la selva tropical aledaña. Luego, se dieron cuenta de que era necesario encontrar catalizadores económicos distintos a los que ya existían, tanto para proporcionar opciones de modos de vida sostenibles para las comunidades locales, como en términos de apoyo financiero para sustentar la reserva. La ubicación y la rica biodiversidad de Lapa Ríos ofrecían una coyuntura única para el turismo.

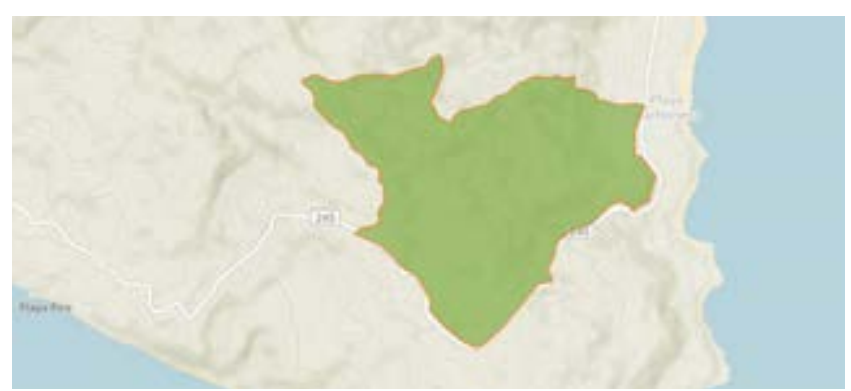

Lapa Ríos se incorporó a la WDPA tras haber sido verificada por expertos de la Comisión Mundial de Áreas Protegidas de la UICN @ Protected Planet, UNEP-WCMC
Desde un comienzo, las metas integraron objetivos de conservación, comunitarios, culturales y comerciales, combinación que permitió transformar la conservación en parte del ADN del negocio (Buena práctica 5.4.2). En esa misma línea, junto con el objetivo de conservación, Lapa Ríos se propuso desarrollar el turismo a partir de buenas prácticas de gestión ambiental. Así, sus cabañas y edificaciones están inspiradas en la cultura indígena de la zona y los materiales renovables que esta utiliza, el agua se calienta mediante energía solar y se promueve la comida local (ver Buena práctica 2.3.2). El diseño abierto de las instalaciones permite que el aire circule y, por lo mismo, se puede prescindir de aire acondicionado. Esto, además, ofrece a los huéspedes la oportunidad de estar inmersos en la vida silvestre, separados de esta solo por una mampara. Las experiencias de los visitantes giran en torno a la naturaleza y las prácticas de bajo impacto que ofrece el hotel. El Plan Maestro de Sostenibilidad de 2010 estableció un marco para el desarrollo de nuevas iniciativas para el negocio. A lo largo de los años, la operación ha sido capaz de invertir más de USD 1 millón en la conservación de la reserva.

\section{Acceso inclusivo}

Con el fin de lograr un éxito a largo plazo, fue importante crear una empresa de turismo inclusiva (Buena práctica 2.3.2), por lo que Lapa Ríos se enfocó en:

- Ofrecer empleo y oportunidades de negocios preferenciales a los residentes de la península de Osa.

- Crear capacidad de construcción básica por medio de capacitaciones in situ.

- Otorgar educación ambiental continua para los empleados, miembros de la comunidad y visitantes.

Los 55 empleados de Lapa Ríos provienen de la región (Buena práctica 2.5.6), y la mayoría de los alimentos se consiguen localmente. Los dueños se dedican de manera activa a su equipo, capacitándolos continuamente y estimulando el ambiente de trabajo. Como resultado, la tasa de rotación de empleados es baja (2-4 anualmente) y más de 10 miembros trabajan ahí hace más de 20 años. El personal forma parte de todas las iniciativas comunitarias de Lapa Ríos. Por lo mismo, los empleados no solo disponen 


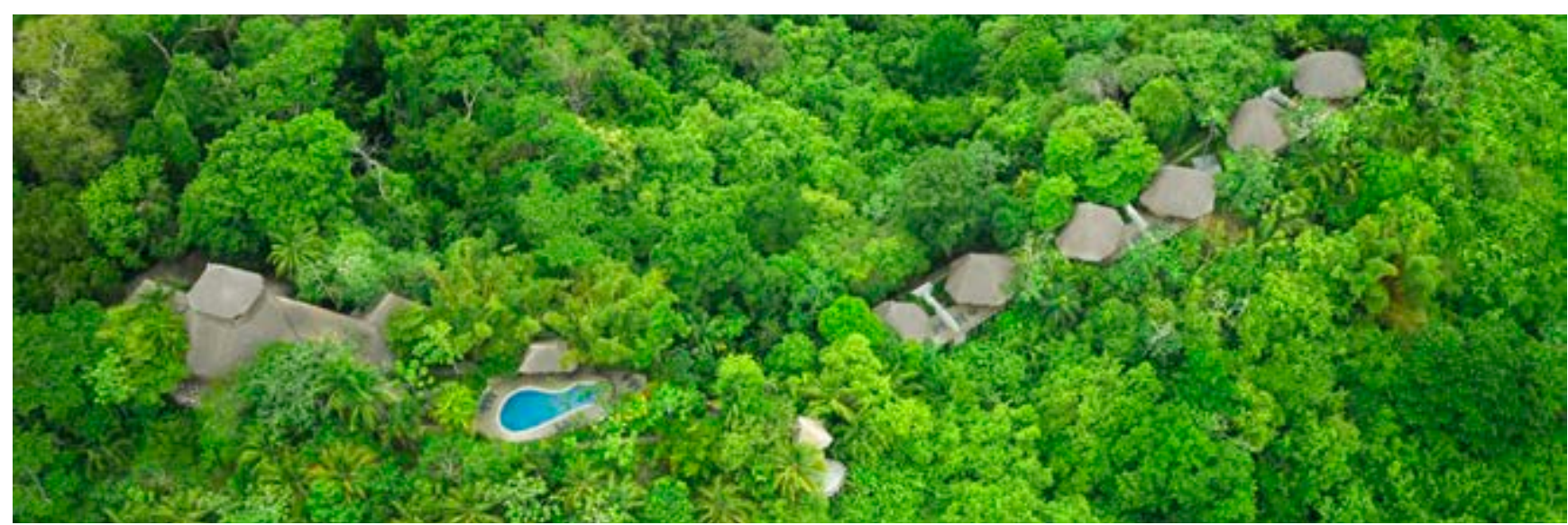

๑) Lapa Ríos, península de Osa, Costa Rica

de tiempo para apoyar los proyectos que cada uno elija, sino que además son considerados líderes de la comunidad. Esto ha fortalecido la relevancia de las acciones comunitarias de Lapa Ríos y el compromiso del personal con los objetivos de conservación de la reserva. Tanto la inversión en educación como la instalación de capacidades se han ido concretando a través de distintos medios, por ejemplo, en el desarrollo de infraestructura escolar, en la implementación de educación ambiental y la creación de una escuela de guías en 2017. En 1991, Lapa Ríos construyó la primera escuela primaria de la zona y, desde entonces, sus esfuerzos han alcanzado a más de 600 niños y han derivado en 13 nuevas escuelas para la península.

La reserva ofrece - para los locales y los huéspedes - diversas oportunidades, por medio de las cuales se puede experimentar, aprender y proteger la naturaleza. Un ejemplo es el programa Caminatas Familiares, que consiste en caminatas guiadas para los miembros del personal y sus familias, con el fin de que exploren su bosque, flora y fauna con interpretación guiada. Además, mediante la ruta Ramas, Cerdos y Basura, aprenden sobre cómo reducir los desechos y el consumo de agua y energía. Durante el almuerzo, el personal y sus familias analizan en conjunto su experiencia y la importancia que tiene para sus vidas. Como resultado, los empleados se sienten orgullosos de lo que hacen y sus hijos se convierten en defensores de la conservación a temprana edad.

\section{Abordando los desafíos}

La colaboración ha sido particularmente importante para asegurar e futuro de Lapa Ríos (Buena práctica 5.4.2). Conscientes del desafío que significa proteger la biodiversidad de Lapa Ríos más allá de sus límites, los dueños convocaron en 1999 la conferencia Ecolodge Owners' Dilemma, que congregó a ONGs de conservación, abogados ambientalistas y expertos en turismo. La reunión tenía como objetivo compartir ideas sobre "Cómo los propietarios pueden proteger la tierra y a las personas que apoyan su negocio de turismo cuando ellos ya no están a cargo" (Principio 4.1). Se exploraron diversas soluciones durante el evento, y las respuestas más aparentes fueron asegurar la tierra en términos legales y solo venderla a compradores con conciencia ambiental y social. En esta oportunidad, los dueños de Lapa Ríos conocieron las opciones que brindan los acuerdos de conservación/servidumbres para restringir el desarrollo y la división de tierras, dos situaciones que ponían en peligro la capacidad de la reserva de continuar funcionando como un catalizador económico en la región y, también, como un ejemplo de negocio de conservación. En aquella época, existía una opción de servidumbre en el sistema legal de Costa Rica, pero no había sido puesta a prueba en el contexto de tierras privadas. Tras el evento, los Lewis se reunieron con posibles compradores, algunos de los cuales compartían su visión, pues la mayoría estaba enfocada en sus resultados netos. Si bien sabían que no todos los compradores buscaban esto, los dueños firmaron una servidumbre en 2013 para "facilitar el proceso de venta y eliminar la necesidad de negociar la conservación frente a la expansión o el desarrollo de infraestructura". Esta se convirtió en la primera servidumbre aplicada a un negocio privado en Costa Rica (Buena práctica 4.1.1).

Otro resultado del taller fue la incorporación a Lapa Ríos de Cayuga Sustainable Hospitality, una empresa de gestión que se alineaba cabalmente con la visión de los Lewis. El aporte de Cayuga incluye gestión profesional, mejoramiento de habilidades, satisfacción de los huéspedes, conectividad comunitaria y economías de escala. Esto les permitió a los dueños poder alejarse del manejo diario del hotel e hizo posible que los elementos de conservación y comunitarios siguieran siendo el eje del negocio, hasta poder encontrar a un comprador apropiado. Haber pasado por los procesos de reconocimiento GER® de The Long Run y de la certificación de turismo de Costa Rica les garantizó a los dueños el cumplimento continuo de sus requerimientos (Buena práctica 1.1.3).

\section{Resumen}

- El éxito económico de la operación de ecoturismo Lapa Ríos es fundamental para la sostenibilidad de la APP (Buena práctica 5.4.1).

- Para reducir la tensión entre las ganancias y la conservación, fue útil que el negocio estableciera metas claras que integraran conservación, comercio y consideraciones comunitarias y culturales (Buena práctica 5.4.2).

- La inclusión comunitaria es importante para asegurar los resultados de biodiversidad a futuro (Buenas prácticas 2.3.2 y 2.5.6).

- La colaboración entre APPs aporta habilidades, apoya su defensa y promoción, amplifica los impactos y ofrece soluciones a problemáticas específicas (Buena práctica 2.5.4).

- Haber asegurado la tierra por medio de una servidumbre de conservación a perpetuidad les ha brindado calma a los dueños y permitió que el proceso de venta fuera directo (Buena práctica 4.1.1). 


\section{Estudio de caso 5 La National Natural Heritage: Contribuyendo al compromiso privado en la conservación de la naturaleza en Alemania}

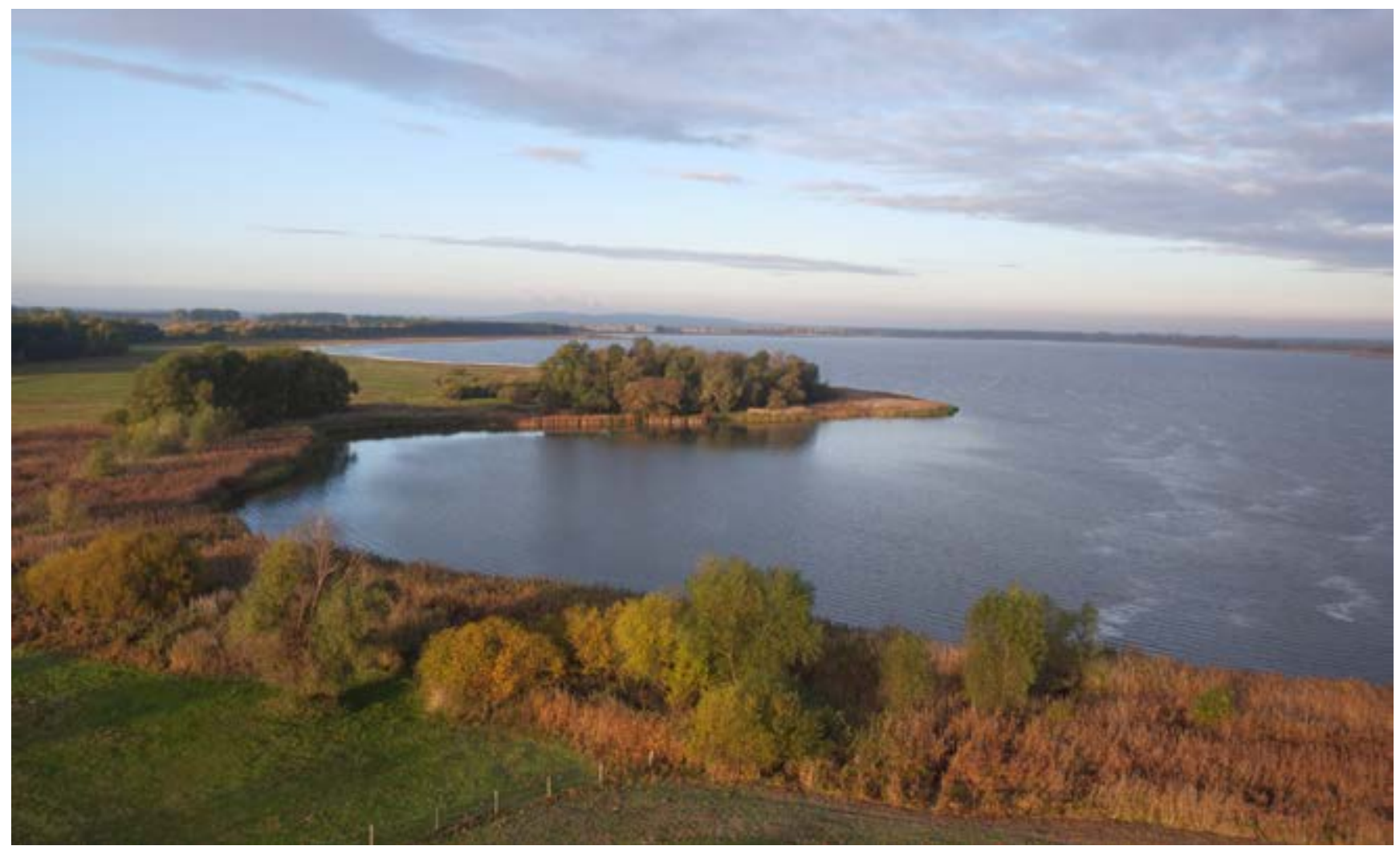

El lago Guelp es manejado por NABU-Stiftung Nationales Naturerbe, el socio alemán de BirdLife International @ Thomas Stephan / Bundesamt für Naturschutz

Gisela Stolpe, BfN Vilm, Karin Reiter, BfN Bonn y Tilmann Disselhoff, NABU

En 2005, Alemania puso en marcha un proyecto nacional para transferir grandes terrenos de tierra de propiedad federal a los estados federales (Länder), ONGs de conservación y fundaciones, con el fin de proteger estos territorios para la conservación de la naturaleza a perpetuidad. Esta transferencia de tierras a gran escala, denominada National Natural Heritage (NNH), ha potenciado considerablemente el papel de las ONGs y las fundaciones ambientales como gestoras de tierra para la conservación en Alemania. Este estudio de caso ilustra una serie de buenas prácticas, particularmente de la Sección 2, relacionada con mecanismos para asegurar y monitorear la calidad, efectividad y coherencia de los enfoques de conservación.

\section{Contexto}

Con el término de la Guerra Fría y la reunificación de Alemania en la década de los noventa, muchos sitios militares, minas de lignito y zonas ubicadas a lo largo del límite interior alemán, entre el este y el oeste (Cinturón Verde), quedaron sin uso. Gracias a la ausencia de usos de suelo agrícola u otros usos intensos, esta área adquirió un alto valor de conservación con muchas especies raras o amenazadas. Es más, diversos usos de suelo, como, por ejemplo, el uso para ejercicios militares, habían trastornado el hábitat (armas de fuego, huellas de tanques, etc.), lo que permitió que nuevas especies amenazadas colonizaran estos sitios. Por consiguiente, el gobierno federal de Alemania decidió crear un proyecto para la transferencia gratuita de tierras estatales con alto valor natural de conservación a los estados federales, ONGs de conservación y fundaciones (Buena práctica 1.2.1). Este enfoque, llamado National Nature Heritage ${ }^{142}(\mathrm{NNH})$, marcó una nueva pauta, pues, por ley, las tierras de posesión federal deben ser privatizadas cuando no existen más usos que conferirle.

Entre 2005 y 2013 , el gobierno transfirió sin costo alguno cerca de 156.000 ha de tierras federales (120.000 ha de las cuales le pertenecían al ejército) para la conservación de la naturaleza (BMUB, 2017). El programa fue renovado en un acuerdo de coalición en 2018 y se espera que logre reunir un total de 186.000 ha de tierra para la conservación. El uso de una serie estratégica de criterios de selección, junto con otras medidas descritas a continuación, ha ayudado a aumentar la integridad de las áreas protegidas existentes, a conservar los sitios con alto valor de conservación y contribuir al establecimiento de corredores silvestres a lo largo de Alemania.

La entidad que posee más sitios NNH es la Fundación Federal Alemana para el Medioambiente (DBU, por su sigla en inglés). La DBU fue formada por el gobierno alemán en 1990 con fondos provenientes de la privatización de una empresa de acero estatal. Actualmente, la DBU es dueña de alrededor de 70.000 ha de tierras $\mathrm{NNH}$. Las ONGs de conservación y fundaciones son propietarias de 25.000 ha, mientras que 28.000 han sido transferidas a los estados federales y 33.000 ha siguen siendo de propiedad federal y 
están bajo la supervisión del Ministerio Federal de Medioambiente. Todas estas áreas son gestionadas de acuerdo con estrictos requerimientos de conservación. Los propietarios de sitios NNH firman contratos que los comprometen a cumplir con los objetivos del proyecto, para implementar las medidas de gestión adecuadas y establecer procedimientos de entrega de información regulares (ver a continuación).

\section{Objetivos, gestión y monitoreo}

El principal objetivo de los sitios NNH es descontinuar de manera gradual cualquier uso comercial de bosques, dependiendo del estado de cada uno. Si bien la gestión activa de bosques naturales (casi) termina inmediatamente a partir de la fecha de transferencia, existen otros hábitats de bosque en los que está permitida la gestión de 'conversión' de corto o mediano plazo para ayudar a restablecer comunidades de vegetación natural. Esto sirve de apoyo para lograr las metas establecidas en torno a las áreas silvestres en la Estrategia de Biodiversidad de Alemania (que consiste en alcanzar un 2\% de las áreas silvestres grandes y un $5 \%$ de las áreas de bosques sin uso forestal, respectivamente, al año 2020). Algunos tipos de bosque desarrollados con valores de conservación particulares, debido a prácticas de gestión tradicionales preexistentes (como pastizales de madera, bosques de encinos y encinos-carpes o bosques de vástagos), requieren de gestión continua. Además, es necesario mantener algunas medidas de seguridad para proteger a los visitantes.

A pesar de que los procesos y las dinámicas naturales son parte de la visión de conservación a largo plazo para todos los bosques, los hábitats de humedales y aguas dulces requieren de cuidado activo de modo permanente, en tanto, los hábitats valiosos 'hechos por el hombre' (por ejemplo, pastizales, matorrales, etc.) requieren de usos de suelo adecuados (por ejemplo, pastoreo extensivo), con el fin de preservar su valor de conservación. Debido a que algunos sitios NNH han sido impactados o parcialmente degradados o contaminados por usos de suelo anteriores, las medidas de restauración o preservación suelen ser necesarias para poder conservarlos, o para que el proceso de transformación a hábitats de mayor valor sea más rápido.

Los propietarios de sitios NNH deben desarrollar una visión para cada sitio (Buena práctica 2.2.1), entregar información anualmente y llevar a cabo planes de manejo para grandes sitios NNH con la asesoría del Ministerio de Medio Ambiente y la Agencia Federal para la Conservación de la Naturaleza (Buena práctica 2.5.4 y Principio 3.5). El monitoreo está incluido en los planes de manejo con el objetivo de evaluar el éxito de las medidas de gestión y permitir ajustes en la gestión del sitio de ser necesario (Buena práctica 2.2.2 y Principio 2.4). Actualmente, se está desarrollando una metodología 'modular' de monitoreo para permitirles a los propietarios de sitios $\mathrm{NNH}$ elegir entre protocolos de monitoreo básicos o más detallados para distintos tipos de hábitats naturales y hechos por el hombre, además de distintos grupos de especies. En muchos de los sitios NNH (particularmente en aquellos que son propiedad de ONGs de conservación), el monitoreo del sitio cuenta con el apoyo de voluntarios (Buena práctica 2.5.3).

\section{Resumen}

- Se ha aprovechado una ventana de oportunidad para transferir tierras de propiedad federal gratuitamente a los estados federales (Länder), ONGs de conservación y fundaciones, lo que ha derivado en la conservación efectiva de áreas en Alemania, dentro de las cuales algunas pueden ser consideradas APPs (Buena práctica 1.2.1).

- Las tierras transferidas son conservadas a perpetuidad, por medio de contratos y servidumbres (para ONGs de conservación y fundaciones) (Buena práctica 4.1.1).

- El gobierno provee directrices detalladas y vinculantes a los nuevos propietarios respecto de la gestión de conservación de la naturaleza (Buena práctica 2.1.1).

- El gobierno sigue teniendo un papel importante en la gobernanza de los sitios, ya que los propietarios deben entregar información sobre los sitios NNH anualmente (Buena práctica 2.4.1).

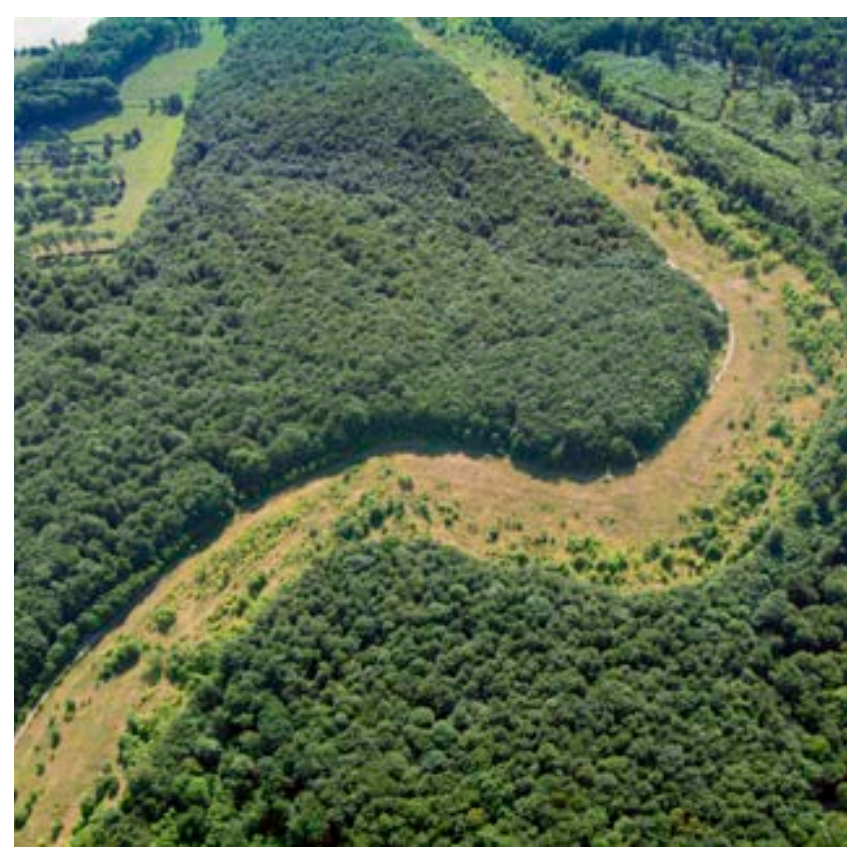

Cerca de 6.000 ha de la red National Natural Heritage pertenecen al Cinturón Verde a lo largo de la exfrontera interalemana @ Klaus Leidorf 


\section{Estudio de caso 6 Un modelo exitoso de gestión de conservación de la vida silvestre: Lewa Wildlife Conservancy, Kenia}

Tuqa Jirmo, Lewa Wildlife Conservancy

Lo que comenzó siendo un santuario de rinocerontes de 2.000 ha en 1984 se ha convertido en un modelo ejemplar de protección de vida silvestre y un catalizador para la conservación y el desarrollo de la comunidad en África del Este. La iniciativa Lewa Wildlife Conservancy funciona como un modelo para la conservación de vida silvestre y su hábitat, mediante la protección y la gestión de las especies, la iniciación y el apoyo de programas de conservación, de desarrollo comunitario y de educación sobre el valor de la vida salvaje. Lewa Conservancy es un buen ejemplo de las orientaciones expuestas en la Parte B, Sección 2 y, específicamente, de una APP que ha podido cumplir con los estándares de la Lista Verde de Áreas Protegidas y Conservadas de la UICN (Cuadro 1.1).

\section{Contexto}

La familia Craig llegó a Lewa Downs en la década de los veinte, donde operó un rancho de ganado por más de 50 años.

Tres décadas más tarde, a comienzos de los años ochenta, una mujer llamada Anna Merz se acercó a la familia con una petición: horrorizada por la disminución de la población de rinocerontes negros (Diceros bicornis) en África, Anna quería establecer un santuario para proteger a los últimos miembros de esta especie en extinción. Esto llevó a que la familia Craig destinara las 16.000 ha de rancho a la creación de la Lewa Wildlife Conservancy, a la que luego se le agregaron 3.000 ha provenientes de granjeros aledaños y 5.500 ha del bosque nacional.

Actualmente, la iniciativa alberga a más del 12\% de la población silvestre mundial de cebras de Grévy (Equus grevyi) en peligro de extinción, más del $12 \%$ de los rinocerontes negros de Kenia en peligro crítico de extinción y más del $14 \%$ de los rinocerontes blancos (Ceratotherium simum), además de otras 70 especies de mamíferos de gran tamaño, nativos de África del Este, y más de 440 especies de aves. En 2013, Lewa recibió reconocimiento mundial, al ser incluida como parte del Sitio de Patrimonio Mundial Monte Kenia y fue seleccionada por la UICN como uno de los sitios pioneros de la Lista Verde, la que reconoce a las organizaciones ejemplares en gestión de áreas protegidas (ver Cuadro 1.1). Desde sus inicios como santuario del rinoceronte negro, Lewa ha crecido y desarrollado, a la par, su práctica de conservación. Hoy, no solo protege especies en peligro de extinción, sino que también trasplanta animales para repoblar nuevas áreas de conservación y parques nacionales estatales, además de compartir sus buenas prácticas en sitios de conservación comunitarios y privados a lo largo de Kenia. Los límites de Lewa cuentan con corredores bien establecidos que llegan al Parque Nacional Monte Kenia y a los grandes pastizales de Kenia del Norte, lo que posibilita el desplazamiento de la fauna silvestre en los paisajes circundantes. Lewa trabaja con sus vecinos para incentivar la gestión colectiva de los ecosistemas. Un ejemplo claro, y un primer paso clave, es el

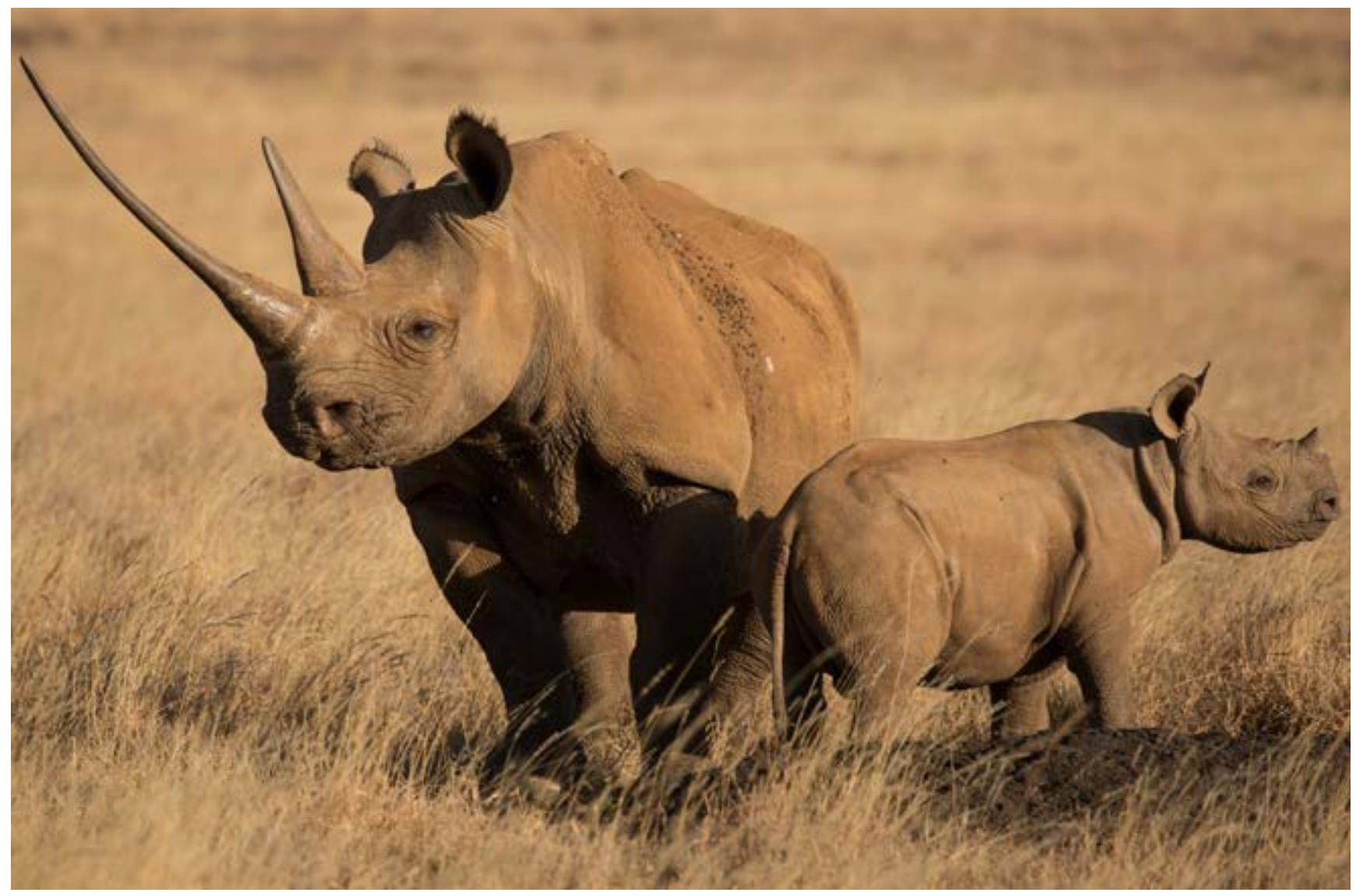

Rinoceronte negro (c) Lewa Wildlife Conservancy 
acuerdo establecido para eliminar los cercos fronterizos entre Lewa y la Borana Conservancy (ver Cuadro 5.4), ubicada al oeste del sitio. Esto permitió aumentar la superficie para el desplazamiento de la fauna silvestre a más de 37.000 ha.

Lewa apoya el ecoturismo comunitario y las iniciativas de turismo cultural, y es un destino ideal para quienes buscan buenas prácticas relacionadas con el turismo sostenible, la gestión de especies en peligro de extinción y la conservación y turismo basados en la comunidad.

\section{Cómo enfrentar problemáticas medioambientales y de conservación a partir del ejemplo de Lewa}

La drástica caída de poblaciones de fauna silvestre en Kenia ha conminado a mejorar la gestión del santuario y a trabajar para asegurar el paisaje para las personas y la fauna silvestre. Esto ha significado: distribuir los recursos de manera efectiva (Buena práctica 2.3.1); promover la rendición de cuentas y la transparencia; incorporar la participación comunitaria en los esfuerzos de conservación (Buena práctica 2.1.3); construir alianzas con agentes relevantes, y promover los valores de las áreas protegidas (Buenas prácticas 2.5 .2 y 2.5.5).

El Programa de Desarrollo Comunitario de Lewa se ha convertido en un ejemplo de conservación que genera beneficios directos e indirectos para las comunidades locales por medio de servicios de salud, educación, agua y el desarrollo de empresas, entre otros (Buena práctica 2.3.2). Actualmente, Lewa brinda apoyo a 21 escuelas, administra 4 clínicas y 13 esquemas de abastecimiento de agua comunitarios, además de apoyar un programa de educación para adultos, un esquema de microcréditos para mujeres y programas de extensión agrícola. Por medio de esta amplia gama de proyectos de desarrollo comunitario, Lewa está impulsando una agenda para abordar las necesidades de las comunidades aledañas al santuario, contribuyendo directamente a mejorar las posibilidades de subsistencia de los habitantes. Además, reconoce que la participación de sus vecinos en la conservación y el uso sostenible de recursos es crucial para la viabilidad a largo plazo de esta importante área de conservación (Buena práctica 2.1.3). El trabajo comunitario de Lewa derivó en la formación del Northern Rangelands Trust, ${ }^{143}$ una entidad que reúne 33 sitios de conservación comunitarios, cuyo mandato es desarrollar comunidades resilientes, transformar vidas, garantizar la paz y conservar los recursos naturales del norte de Kenia y más allá. Además, Lewa ha formado alianzas con el Kenya Wildlife Service (KWS), y se ha asociado con bosques comunitarios, ranchos vecinos y socios de conservación con una visión similar, todos los cuales son parte fundamental del enfoque y éxito de Lewa (Buena práctica 2.5.2).
Lewa tiene un enfoque riguroso frente a la investigación y el monitoreo. La iniciativa cuenta con personal bien calificado y experimentado que realiza investigación aplicada relacionada con zonas de pastoreo, carnívoros, ungulados, rinocerontes, elefantes, insectos y aves. A su vez, tiene una unidad veterinaria completa, a cargo de la autoridad veterinaria del KWS en conexión permanente (Buena práctica 2.5.5). Las operaciones de seguridad contra la caza furtiva combinan tecnología de monitoreo de vanguardia con la participación y el compromiso de las comunidades vecinas. Las fuerzas de seguridad de Lewa no solo protegen a la vida silvestre dentro del santuario, sino que también a los habitantes y vida silvestre que lo rodean. Los miembros del equipo de anticaza furtiva también forman parte de los reservistas de la policía nacional, y cuentan con un mandato del gobierno de Kenia que les permite responder e investigar casos de inseguridad dentro del santuario y de las comunidades colindantes (Buena práctica 2.5.5). Como declara el director general de Lewa Wildlife Conservancy, Mike Watson: "A lo largo de los años, la conservación se ha mantenido como la mejor manera de custodiar un presente y un futuro que beneficie tanto a las personas como a la vida silvestre. Por medio de la conservación, las especies en peligro de extinción bajo nuestra protección tienen un futuro, y las personas que dependen de este paisaje pueden aportar un valor directo a la vida silvestre".

\section{Resumen}

- El Programa de Desarrollo Comunitario de Lewa está diseñado para crear una relación de colaboración cercana con las comunidades locales y disminuir la presión de la comunidad sobre los recursos naturales (Buena práctica 2.1.3).

- Lewa optimiza la efectividad de su gestión organizacional mediante la implementación continua de planes de manejo, buenas prácticas y planificación organizacional estratégica (Buena práctica 2.2.3), basados en los cambiantes desafíos de conservación y de subsistencia de la comunidad, además de diversificar los canales de generación de ingreso (Buena práctica 2.3.1).

- Las alianzas con sectores relevantes del gobierno nacional y de los condados, las iniciativas de conservación privadas y comunitarias, las entidades de conservación locales e internacionales, junto con las instituciones comunitarias y académicas, incluyen un catastro de vida silvestre conjunto, supervisión de enfermedades y gestión de laboratorios de diagnóstico, entre otros. Lewa también gestiona dos bosques del gobierno junto con el Kenya Forest Service y asociaciones de bosques comunitarias (Buenas práctica 2.5.5). 


\section{Estudio de caso 7 Conservación de tierras privadas en Nueva Zelanda como un movimiento social}

Mike Jebson, QEll National Trust

El modelo del Queen Elizabeth II National Trust (QEII) ha demostrado ser una fórmula exitosa de conservación colaborativa de tierras privadas en Nueva Zelanda, gracias a haber apoyado y desarrollado las aspiraciones de los propietarios privados de crear un legado. El modelo ejemplifica muy bien el Principio 3.4 (Parte B, Sección 3), que plantea que el reconocimiento y el apoyo son fuertes incentivos para las APPs. El éxito del QEll también es atribuible a varios aspectos relacionados con buenas prácticas asociadas a las APPs, incluyendo la permanencia (Buenas prácticas 4.1.1 y 4.1.7), marcos legales e institucionales robustos (Buena práctica 1.1.1) y el reconocimiento de los logros de los propietarios.

\section{Contexto}

En los últimos 40 años, la conservación de tierras privadas ha pasado de ser un concepto no probado y solamente promovido por unos pocos agricultores preocupados por el impacto de los subsidios estatales de producción agrícola sobre el patrimonio natural de Nueva Zelanda, a un movimiento de APPs realmente exitoso. El movimiento ha sido adoptado por varios propietarios de granjas y otras tierras rurales, a pesar de los limitados incentivos financieros a su disposición.

El movimiento ha sido liderado por el Queen Elizabeth II National Trust (QEII), una entidad prácticamente independiente del gobierno y con sus propias leyes (Queen Elizabeth the Second National Trust Act 1977), pero con el apoyo financiero del gobierno de Nueva Zelanda. Como parte del acuerdo de financiamiento con el gobierno, el QEll busca asegurar los acuerdos de conservación para cumplir con las necesidades nacionales de protección de la biodiversidad en tierras privadas, o bien, para incorporar corredores o paisajes protegidos. Esta ha sido una práctica que se ha aplicado durante muchos años como parte de la estrategia de biodiversidad de Nueva Zelanda (Buena práctica 1.2.1). La ley Queen Elizabeth the Second National Trust Act 1977 ha establecido un marco legal e institucional robusto para apoyar los acuerdos de conservación como parte del sistema de áreas protegidas de Nueva Zelanda, con el fin de complementar las tierras públicas de conservación (Buena práctica 1.1.1). No obstante, los acuerdos de conservación no son percibidos como instrumentos regulatorios del gobierno u ONGs ambientales para reforzar el cumplimiento de los propietarios, sino como una herramienta para formar alianzas, cuyo fin es apoyar las futuras ambiciones de los propietarios rurales para las tierras que desean proteger.

Al brindar apoyo a los propietarios para la protección de sus preciadas tierras, el QEll ha asegurado un promedio de dos acuerdos por semana (de un tamaño promedio de 40 ha) en los últimos 40 años en todas las islas principales de Nueva Zelanda. Actualmente, esta red de APPs bajo la administración perpetua del QEll cuenta con más de 4.450 acuerdos de conservación (180.000 ha), y está creciendo a una tasa anual de 110 nuevos acuerdos de conservación (que promedian 3.800 ha), lo que no parece desacelerarse. Una vez registrados en el título de tierra privada, los acuerdos de

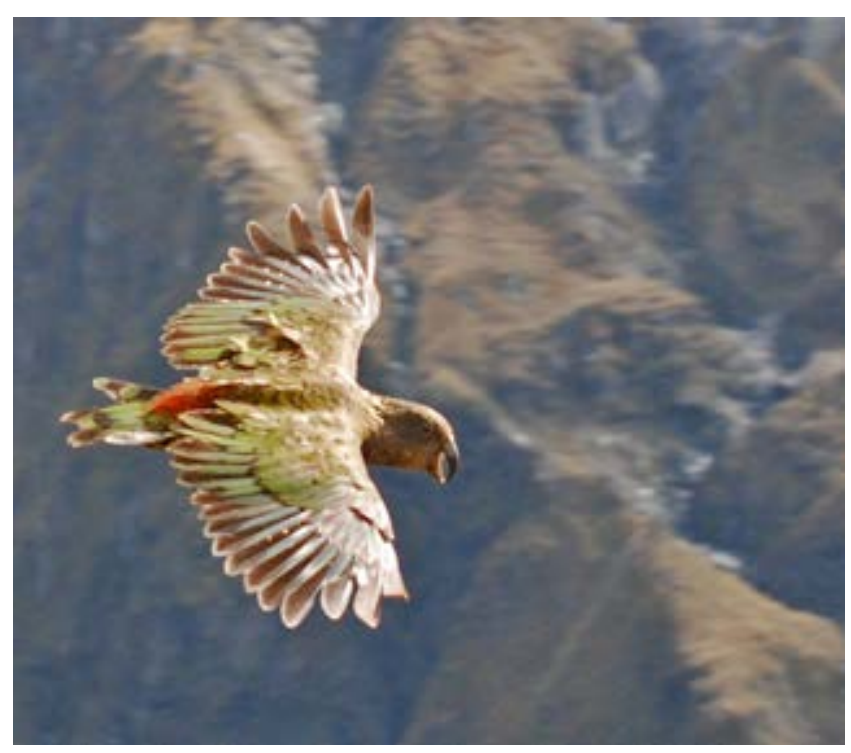

Un kea (Nestor notabilis), un loro alpino nativo, volando sobre Mahu Whenua, el acuerdo de conservación más grande ( 53.000 ha) del QEll en Otago central $\odot$ Bill Wallace, National Trust

conservación del QEll ofrecen permanencia al proteger las áreas como 'espacios abiertos' para propósitos de conservación a perpetuidad (Buena práctica 4.1.1).

Los acuerdos de conservación QEll ofrecen protección legal sólida ante: interferencia gubernamental o ministerial; minería; excavaciones; obras de petróleo y gas; silvicultura comercial; construcción de viviendas; o cualquier otro tipo de uso comercial o de desarrollo que no sea afín. Los acuerdos de conservación sobre las tierras de cultivo también son retirados del uso de la granja, con la excepción de un número pequeño de casos, donde el pastoreo ligero sigue siendo compatible con el patrimonio natural y los objetivos de protección del paisaje. Si bien son poco comunes, y solo se recurre a ellas como última opción, las demandas por incumplimiento de acuerdos llevadas a corte han demostrado la solidez legal de esta iniciativa. En general, las acciones relacionadas con el cumplimiento de los acuerdos han sido bien recibidas por otros propietarios de acuerdos de conservación, pues confían en la protección que estos les entregan.

Todos los acuerdos de conservación registrados son monitoreados regularmente (cada dos años, aproximadamente), y el costo del monitoreo es absorbido por el QEll. Las visitas de monitoreo están destinadas, principalmente, a entregarles a los propietarios recomendaciones para la custodia con el fin de asistir en la gestión, e inspirar a nuevos propietarios que han adquirido tierras bajo un acuerdo de conservación (Buena práctica 8.2.1).

Todos los titulares de acuerdos de conservación se convierten en miembros vitalicios del QEII National Trust, además, son invitados a eventos regionales de acuerdos de conservación, reciben letreros que permiten reconocer su área protegida, son reconocidos en la revista del QEII, Open Space, y reciben asesoría sobre la custodia de sus acuerdos de conservación como parte del monitoreo 


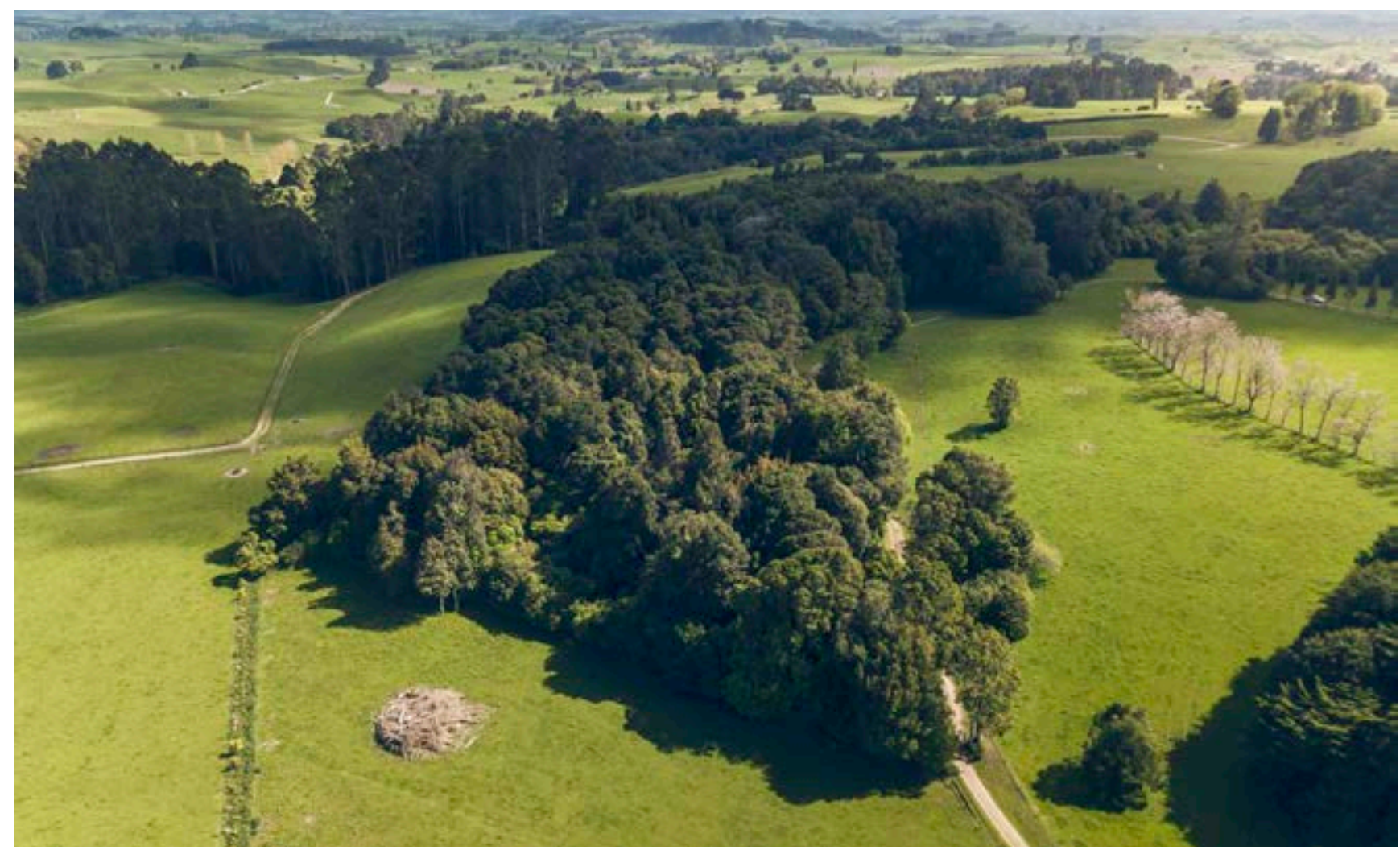

El Stephenson Block en Waikato, el primer bloque de arbustos protegido legalmente del QEll, se ubica en la granja de Gordon y Celia Stephenson, participantes líderes en el establecimiento del QEIl y la conservación de tierras privadas en Nueva Zelanda @ QEII National Trust.

(Buena práctica 8.2.1). Gracias a la buena relación de trabajo con el personal regional del QEll y al orgullo por lo logrado, estos titulares de acuerdos de conservación suelen alentar a sus vecinos a que también protejan las áreas naturales adyacentes, lo que deriva en grupos de acuerdos de conservación que permiten proteger los atributos naturales y los hábitats a una mayor escala.

\section{Responsabilidad social para la conservación}

El modelo del QEIl aborda la mayoría de los elementos de buenas prácticas de las APPs, pero en el escenario internacional resulta algo inusitado debido a la ausencia de incentivos financieros significativos (como beneficios fiscales o subsidios) para impulsar su éxito. Además, el modelo del QEll requiere que los propietarios cubran parte del costo para asegurar la protección legal sobre sus tierras, son a la vez responsables de la mayoría de los costos del cuidado y la gestión constante de la tierra (a excepción de los costos del monitoreo realizado cada dos años, los que corren por cuenta del QEII). La mayoría de los titulares de acuerdos de conservación en Nueva Zelanda cuentan con áreas protegidas especiales dentro de sus terrenos, porque creen que 'hacerlo es lo correcto' y, con razón, están orgullosos y son reconocidos por lo que han creado gracias a los acuerdos del QEIl (Buena práctica 3.4.1). Más que sobre incentivos financieros, el modelo del QEII está construido a partir del orgullo de estos propietarios y la idea de dejar un legado.

Para los agricultores líderes de Nueva Zelanda, el establecimiento de acuerdos de conservación se traduce en una responsabilidad social necesaria para proteger sus áreas de bosque nativo, humedales naturales y otros sitios importantes del patrimonio natural como parte de una buena práctica agrícola y planificación. A la fecha, cerca del $20 \%$ de las granjas de oveja y vacuno en Nueva Zelanda cuenta con un acuerdo de conservación del QEII que protege áreas naturales dentro de sus granjas, y esta cifra crece continuamente. También muchos individuos con conciencia ambiental han comprado tierras ricas en patrimonio natural con el fin de gestionarlas y protegerlas con un propósito de conservación. Estos propietarios terminan trabajando con el QEIl para asegurar sus tierras e inversión con acuerdos de conservación que les provean de protección permanente.

\section{Resumen}

- El establecimiento del QEll fue propulsado por un grupo de agricultores visionarios. Estas raíces rurales les han dado a muchos de los propietarios la confianza para trabajar en conjunto con el QEII, en instancias en que pudieron no haber estado preparados para trabajar con representantes del gobierno central o local (Buenas prácticas 8.5.6 y 4.1.5). Este modelo ha contado con el apoyo bipartito constante de los gobiernos desde que fue concebido hace cuarenta años.

- Todos los acuerdos de conservación tienen un propósito y un objetivo acordados, y establecen los términos y condiciones que pueden adaptarse para encajar con la situación particular de cada uno de los propietarios (Buena práctica 1.2.1).

- Los acuerdos de conservación ofrecen protección robusta y duradera (Buenas prácticas 4.1.1 y 4.1.7).

- Los representantes regionales del QEll que trabajan con los propietarios rurales son conservacionistas de campo que viven en sus comunidades locales (Buena práctica 8.2.1).

- Quienes más luchan por la protección de los acuerdos de conservación en el QEll son a veces quienes ya cuentan con sus propios acuerdos de conservación (Buena práctica 8.1.2). 


\section{Estudio de caso 8 Redes de conservación privada en Perú}

\section{Christel Scheske y Bruno Monteferri, Sociedad Peruana de Derecho Ambiental}

En Perú las APPs reciben un apoyo limitado de parte del gobierno, y no existen organizaciones nacionales que abarquen todas las APPs del país. Como consecuencia, se han formado diversas redes regionales con la ayuda de ONGs como la Sociedad Peruana de Derecho Ambiental (SPDA) o Amazónicos por la Amazonía (AMPA). Es decir, a pesar de la falta de una red nacional oficial de APPS, iniciativas lideradas por ONGs han logrado conectar a las APPS a nivel nacional.

En la última década, se ha aprendido bastante sobre las fortalezas, debilidades y desafíos de estas redes, aspectos que se exploran tanto aquí como en los principios y buenas prácticas de la Parte $B$, Sección 8.

\section{Contexto}

En Perú, el marco legal para las APPs se estableció entre fines de los años noventa y comienzos del 2000. Esto dio lugar a una serie de mecanismos, mediante los cuales los ciudadanos podían establecer compromisos de conservación de tierras reconocidas oficialmente, incluyendo: áreas de conservación privada - establecidas en tierras privadas o de propiedad comunitaria-, concesiones de conservación o ecoturismo para tierras públicas y acuerdos de conservación.

Actualmente, existen cinco redes de APPs en el país (ver Tabla 5). En muchos casos, estas redes incorporan algunas, o bien, la totalidad de herramientas legales que posibilitan la existencia de iniciativas de conservación. Esto les permite a sus miembros tomar distintos rumbos según sus necesidades: en la Amazonía, por ejemplo, algunas APPs le pertenecen a empresarios urbanos que saben cómo financiar la conservación de manera sostenible por medio del ecoturismo, mientras que otras son áreas extensas, manejadas por comunidades locales dependientes de la agricultura y la ganadería para su subsistencia y de la conservación de bosques para el abastecimiento de agua. En el primer caso, los administradores de las APPs suelen ser los mismos por varios años, mientras que, en el segundo, las comunidades que gestionan APPs dependen de consejos elegidos democráticamente que cambian cada cierto tiempo, lo que se puede traducir en una falta de continuidad administrativa, tanto internamente como en relación con la red. Ambos grupos tienen distintos puntos de vista, prioridades y necesidades, pero es la heterogeneidad de los miembros la que brinda diversidad y representatividad a la red, lo que permite generar diálogo y aprendizaje entre los distintos actores de conservación.

Las redes han mejorado la efectividad de las APPs de diversos modos. Por ejemplo, la Red de Conservación Voluntaria de Amazonas recibió dos pequeñas subvenciones en 2017 y 2018, lo que le permitió contar, por primera vez, con fondos autónomos para la implementación de actividades priorizadas por sus miembros, tales como capacitación en servicios de ecoturismo. Además, esta red está creando circuitos turísticos que incluyen a varias de las APPs asociadas, las que luego se promocionan

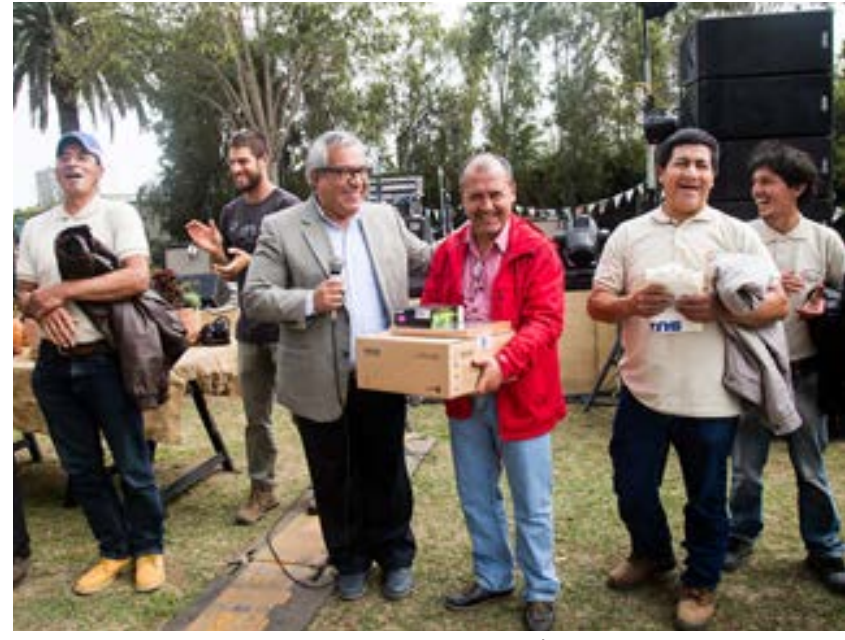

Pedro Gamboa, Director del Servicio Nacional de Áreas Naturales Protegidas, les agradece a los miembros de la RED AMA, la red de APP de Amazona, por sus esfuerzos de conservación privada @ Conservamos por Naturaleza / SPDA

conjuntamente. En San Martín, un subgrupo de miembros formó una cooperativa para la venta de productos forestales no madereros, provenientes de sus APPs. En muchos de los casos (por ejemplo, las áreas de conservación Milpuj La Heredad y Bosque Berlín en la Amazonía), la combinación de visibilidad pública y participación en las redes motivó a los administradores a retomar su vínculo con la conservación con nuevos aires, crear proyectos inéditos, actuar como líderes locales y ampliar sus esfuerzos.

\section{Desafíos}

A pesar de que existen diversas guías de buenas prácticas para la conservación (como se señala en la Parte B, Sección 2), en Perú muy pocos gestores de APPs las utilizan. Tanto la barrera idiomática como la brecha en la investigación/implementación constituyen problemas comunes en el ámbito de la conservación (Knight et al., 2008). Frente a este escenario, las redes de APPs no solo ofrecen un espacio donde compartir conocimientos (Buena práctica 2.5.2), sino que también asisten a las ONGs y a otros actores en la creación de capacidad, ya que permiten abordar el grupo de miembros en su totalidad (Buena práctica 8.2.1). En el caso de la red amazónica, por ejemplo, la SPDA ha proporcionado una serie de talleres sobre herramientas legales para enfrentar amenazas, además de consultorías realizadas por miembros de la red San Martín, capacitados por AMPA para el diseño y gestión de proyectos. Adicionalmente, la SPDA contrató a un coordinador para trabajar directamente con la red regional. En Loreto, en tanto, la SPDA y AMPA han apoyado la red regional con asistencia financiera para que esta pueda contar con oficinas donde realizar reuniones regulares. Asimismo, pese a que las redes peruanas tienen dificultades para conseguir fondos y cuentan con un acceso limitado a subvenciones y programas de becas nacionales o internacionales, las redes San Martín, Amazonas y Madre de Dios han podido obtener fondos para proyectos pequeños gracias a aquellas ONGs que apoyan el diseño de proyectos y la postulación a subvenciones. 
Tabla 5: Resumen de las redes de APP en Perú (junio de 2018)

\begin{tabular}{|c|c|c|c|c|c|}
\hline & Amazonas & Madre de Dios & San Martín & Loreto & Ucayali \\
\hline Nombre de la red & $\begin{array}{l}\text { Red de Conservación } \\
\text { Voluntaria de } \\
\text { Amazonas (RED AMA) }\end{array}$ & $\begin{array}{l}\text { Red de Conservación } \\
\text { de la Biodiversidad de } \\
\text { Madre de Dios }\end{array}$ & $\begin{array}{l}\text { Red de Conservación } \\
\text { Voluntaria y Comunal } \\
\text { de San Martín }\end{array}$ & $\begin{array}{l}\text { Red Amazónica de } \\
\text { Conservación Loreto } \\
\text { (RACOL) }\end{array}$ & $\begin{array}{l}\text { Asociación de } \\
\text { Concesionarios } \\
\text { Conservacionistas } \\
\text { de la Biodiversidad } \\
\text { BioRed Ucayali }\end{array}$ \\
\hline $\begin{array}{l}\text { Número de APPs } \\
\text { miembro }\end{array}$ & 14 & 16 & 34 & 23 & 13 \\
\hline $\begin{array}{l}\text { Número total } \\
\text { de hectáreas } \\
\text { protegidas }\end{array}$ & $125.316,96$ & 6.543 & 700.000 & $5.431,74$ & $110.125,73$ \\
\hline $\begin{array}{l}\text { Tipos de APPs } \\
\text { representadas }\end{array}$ & $\begin{array}{l}\text { Áreas de } \\
\text { conservación privadas }\end{array}$ & $\begin{array}{l}\text { Áreas de conservación } \\
\text { privadas, concesiones } \\
\text { de ecoturismo y } \\
\text { concesiones de } \\
\text { conservación }\end{array}$ & $\begin{array}{l}\text { Áreas de conservación } \\
\text { privadas y concesiones } \\
\text { de conservación }\end{array}$ & $\begin{array}{l}\text { Áreas de conservación } \\
\text { privadas y concesiones } \\
\text { de conservación }\end{array}$ & $\begin{array}{l}\text { Concesiones de } \\
\text { conservación y } \\
\text { concesiones de } \\
\text { ecoturismo }\end{array}$ \\
\hline Activas actualmente & Sí & No & Sí & Sí & Sí \\
\hline $\begin{array}{l}\text { Constituida } \\
\text { formalmente }\end{array}$ & Sí & No & No & Sí & Sí \\
\hline $\begin{array}{l}\text { Cuenta con } \\
\text { presupuesto propio }\end{array}$ & Sí & No & No & No & No \\
\hline $\begin{array}{l}\text { Presencia sitio web/ } \\
\text { en línea }\end{array}$ & Redes sociales & Ninguna & Redes sociales & Redes sociales & Redes sociales \\
\hline
\end{tabular}

En general, a pesar de sus múltiples desafíos, las redes han demostrado que pueden funcionar como un espacio importante para el diálogo y la colaboración, además de ser las encargadas de abogar por la conservación ante las autoridades regionales y otros grupos de intereses. Los miembros de APPs suelen quejarse sobre la lentitud o falta de acción por parte de las autoridades en torno a crímenes ambientales, como la tala ilegal, que afectan a las APPs, las experiencias en San Martín, Amazonas y Loreto han demostrado que las autoridades reaccionan más rápidamente

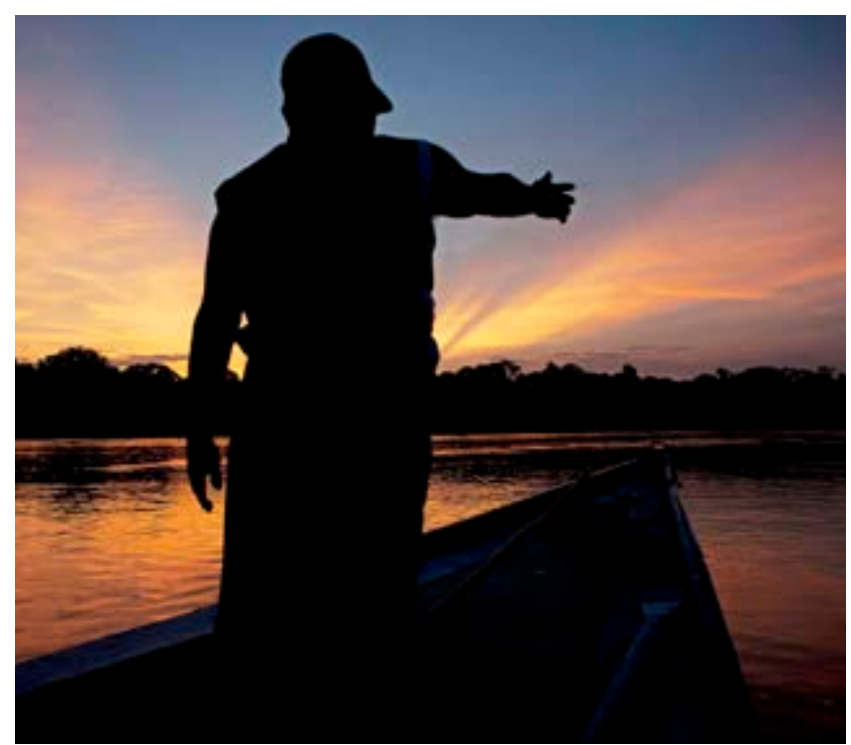

La APP Bahuaja, ubicada al lado de la Reserva Nacional Tambopata y el río Tambopata, genera un corredor de paisaje para la biodiversidad amazónica (C) Conservamos por Naturaleza / SPDA cuando son presionadas por las redes de APPs. Es por esto que fortalecerlas y ayudarlas a garantizar su independencia y sostenibilidad a largo plazo debe ser una prioridad tanto para el gobierno como para las ONGs que trabajan en conservación.

\section{Resumen}

- Las redes constituyen un impulso importante para los gestores de APPs, pues no solo brindan un sentido de reconocimiento, sino también de pertenencia a una comunidad que comparte ideas afines (Buena práctica 8.1.2).

- Las redes de APPs ofrecen plataformas para la acción política proambiental. En Perú, muchas de las autoridades ambientales regionales sufren de corrupción, ineficiencia y falta de recursos, lo que genera un escenario propicio para crímenes ambientales cometidos abiertamente y que luego quedan impunes (Buena práctica 8.1.1).

- Las redes de APPs ofrecen instancias significativas para compartir conocimientos (Buena práctica 8.2.1).

- Las redes ofrecen oportunidades para proyectos conjuntos y financiamiento si se constituyen formalmente como organizaciones sin fines de lucro o entidades similares (Buena práctica 8.2.1)

- Las redes proporcionan plataformas que permiten realizar negocios conjuntos (Buena práctica 8.4.1).

- Contar con la participación de una ONG más grande suele ser un elemento importante para el funcionamiento de las redes (Buena práctica 2.5.4).

Especial agradecimiento a: José Vargas, Martín Vásquez, Fernando Arévalo y Karina Pinasco por sus contribuciones a este estudio de caso. 


\section{Estudio de caso 9 Malololelei Recreation Reserve: Una colaboración exitosa en Samoa}

Moeumu Uili, Ministerio de Recursos Naturales y Medio Ambiente

En 2010, Bluebird Lumber and Hardware Ltd (BBL) compró un terreno de 12 ha, perteneciente a la Iglesia Católica por medio del Church's Land Board. En aquel entonces, el bosque estaba en muy malas condiciones. Producto de la tala, se había destruido más de la mitad de los árboles, que luego fueron reemplazados por árboles de caucho y tulipaneros africanos (Spathodea campanulata).

Frente a ello, el dueño de BBL, Tuiaopo Faamausili Andrew Ah Liki, comenzó a plantar árboles nativos y frutales. Desde su adquisición, el propietario de la reserva se ha encargado de aprovechar cada oportunidad para colaborar con otros actores, alineando sus esfuerzos de gestión con los terrenos vecinos - todos de la Iglesia Católica, salvo unas pocas áreas residenciales privadaspara asegurar, de este modo, los mejores resultados para la biodiversidad (Buenas prácticas, 2.5.2 y 2.5.4).

\section{Contexto}

Ubicada a $7 \mathrm{~km}$ de la capital de Samoa, Apia, Malololelei es una pequeña comunidad en altura, emplazada en la isla central de Upolu, específicamente en una zona edificada recientemente y donde nuevos residentes compran propiedades en busca de sitios más templados. En su punto más alto (600 m aproximadamente), el terreno es bastante plano, y está rodeado por valles tanto al este como al oeste y por dos arroyos que corren hacia la costa.

La reserva se encarga de proteger a las aves nativas, incluyendo algunas especies en peligro de extinción. Además, alberga zonas boscosas, protegidas de los fuertes vientos provenientes de la temporada de ciclones, los que, de otro modo, destruirían los bosques nativos en la parte alta de la isla. Las motivaciones del propietario incluyen: "aumentar la resiliencia de la Malololelei Reserve mediante la gestión sostenible del sitio [y] garantizar el apoyo a nuestra vida silvestre y biodiversidad, por medio de la colaboración con nuestros socios. Respaldamos aquellos esfuerzos de Samoa que buscan aumentar el número de tierras protegidas para la preservación de nuestras especies raras y endémicas, además de nuestros ecosistemas".

\section{Desafíos}

Cuando el terreno fue adquirido su degradación era evidente. Había abundantes áreas abiertas y campos agrícolas. Las especies de plantas predominantes eran invasoras, como también lo eran las especies exóticas como ratas. Existen dos especies de aves endémicas altamente amenazadas en la reserva -el mielero mao (Gymnomyza samoensis) y la paloma manumea (Didunculus strigirostris) - , cuyos nidos, según catastros en curso, corren el riesgo de ser depredados por ratas.

\section{Las alianzas como soluciones}

El éxito de la Malololelei Recreation Reserve se debe, sobre todo, a la colaboración con diversos grupos. Previo a su establecimiento, el actual propietario, Faamausili, participó en el catastro Central Savaii Uplands Biodiversity Rapid Assessment (BIORAP) de 2012, debido

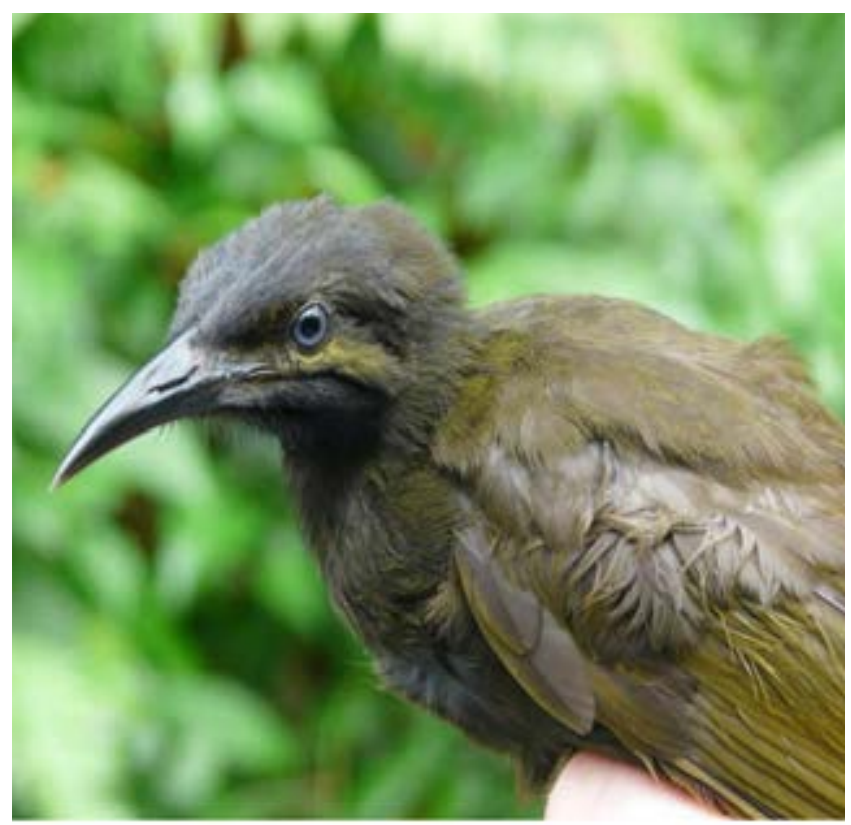

Un mielero mao (Gymnomyza samoensis) macho capturado y soltado durante la realización de un estudio en el pueblo de Magiagi en 2008 @ Rebecca Stirnnemann

a la conexión familiar que tenía con las tierras evaluadas. Este proceso posibilitó la participación de los propietarios, despertando su interés por una biodiversidad sostenible y motivándolos a difundir, dentro de la comunidad local, los conocimientos y beneficios provenientes de la evaluación. Los logros de la BIORAP (2012) contribuyeron a que BBL decidiera apartar las 12 ha de tierras privadas en Malalololei para la conservación de vida silvestre y biodiversidad.

La Malololelei Reserve fue establecida como una reserva nacional en 2015, durante la conmemoración del Día de la Biodiversidad, y con la colaboración de su Ministerio de Recursos Naturales y Medioambiente (MNRE, por su sigla en inglés) y la BBL. Este reconocimiento se debió a que la reserva alberga al mielero mao y la paloma de manumea. Desde el establecimiento del sitio, el MNRE ha trabajado conjuntamente con BBL, bajo un memorando de entendimiento firmado por ambas partes en 2015. Al año siguiente se realizaron evaluaciones de biodiversidad para reunir información para generar una línea de base del sitio. Los resultados mostraron la presencia de estas dos especies de aves, las que ahora forman parte de la Lista Roja de Especies Amenazadas de la UICN. Producto de las múltiples inquietudes sobre el estado crítico de estas especies y la presencia de ratas, una gran cantidad de colaboradores se interesaron en encontrar una solución de modo colaborativo. Por medio de esta alianza, se desarrolló un proyecto con el fin de controlar las pestes invasoras en el área, además de brindar más protección a la vida silvestre, incluyendo las especies de aves.

En septiembre de 2017, se dio inicio al Malololelei Pest Management Project con el apoyo financiero del Zoológico de Auckland y el New Zealand Public Development Conservation 


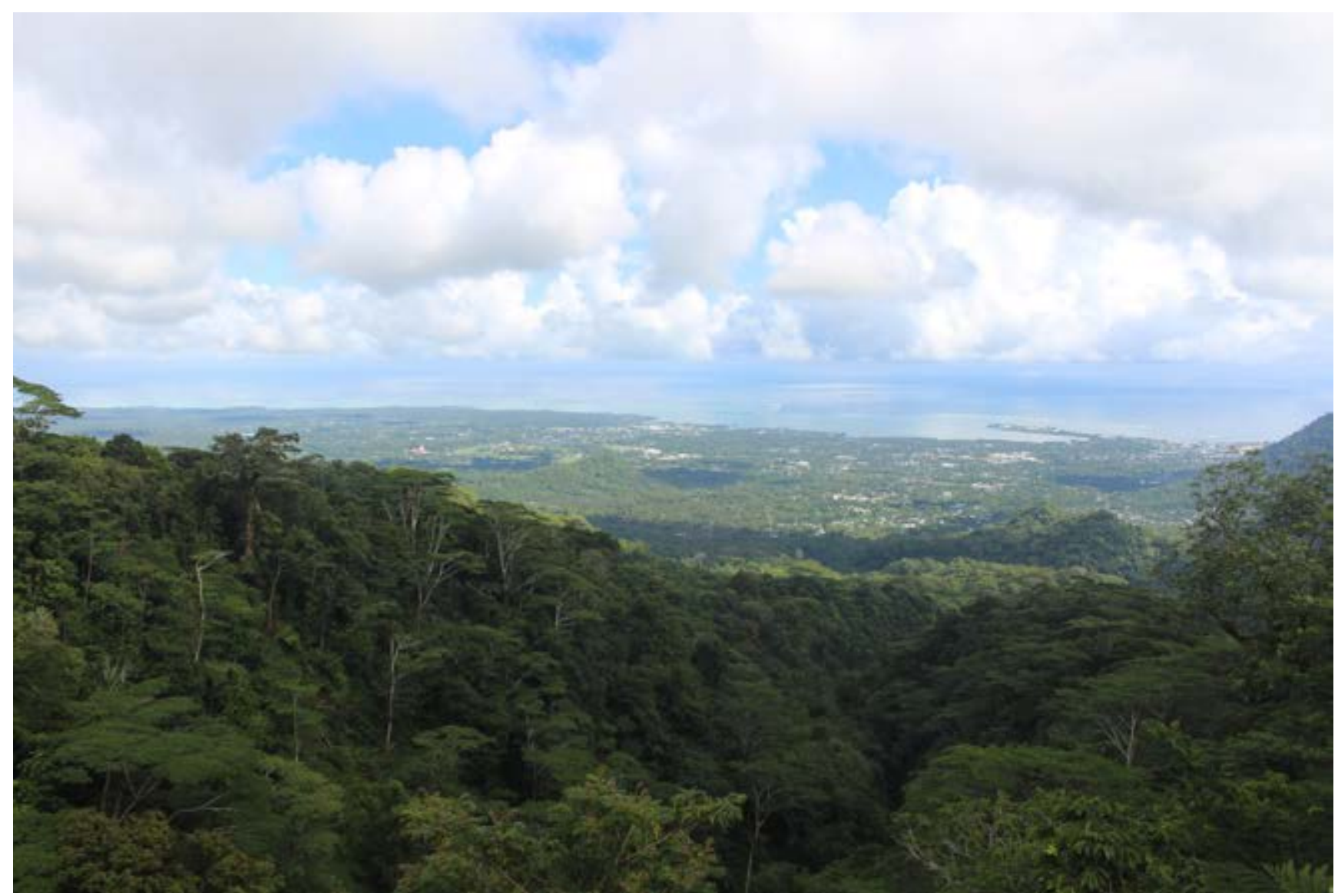

Vista al noroeste de Apia desde el mirador de la Malololelei Recreation Reserve @ Moeumu Uili

Trust Fund, y la asistencia técnica de PelGar International, Samoa Conservation Society y BBL. Actualmente, el MNRE dirige y gestiona la implementación de este proyecto, el que se espera continúe por los próximos dos años, dependiendo de la disponibilidad de fondos.

BBL está interesado en seguir trabajando desde cerca con un grupo importante de socios y partes interesadas. Esto incluye al Catholic Church Land Board (Principio 5.5), el MNRE, ONGs como la Samoa Conservation Society, organizaciones y agencias donantes regionales con el fin de que apoyen y ayuden a mejorar la gestión de la reserva.

El director ejecutivo del MNRE ha mostrado un interés similar y ha dicho que, "El Gobierno de Samoa, por medio del Ministerio de Recursos Naturales y Medioambiente, aprecia el gran apoyo y esfuerzo de nuestros aliados clave para conservar y proteger la biodiversidad nativa, mediante alianzas con el gobierno. Es nuestra misión asegurar la participación de todos nuestros interesados tanto en la gestión sostenible de nuestro paisaje crítico, como la preservación de nuestros recursos terrestres y marinos. Y, por ello, aplaudimos la contribución de nuestros propietarios de tierras privadas, como BBL, por permitir alcanzar esta meta para Samoa".

\section{Resumen}

- Participar y apreciar el apoyo de la comunidad para el desarrollo sostenible de áreas protegidas (Buena práctica 2.1.4).

- Incluir a los distintos grupos de la sociedad, garantizando que haya paridad de género al momento de promover temas sobre la conservación de la biodiversidad: la diversidad de voces deriva en decisiones más resilientes y efectivas (Buena práctica 2.5.4).

- No es necesario dejar de actuar por carecer de fondos. De ser posible, es preferible actuar primero y, luego, recibir fondos para abordar aquello que resulte más relevante (Buena práctica 3.7.1).

- Es mejor comenzar con algo pequeño y con el tiempo construir algo más extenso: las áreas protegidas pueden estar conformadas por varios sitios pequeños que juntos forman una red bien gestionada y de mayor tamaño (Buenas prácticas 8.2.1 y 8.5.3).

- Ofrecer oportunidades a las comunidades y los propietarios locales para que lideren acciones de conservación (Principio 1.3). Los gobiernos, agencias donantes y los expertos pueden ofrecer apoyo y asesoría para sustentar los esfuerzos. 


\section{Estudio de caso 10 Establecer APPs: Lecciones aprendidas de Sudáfrica}

Candice Stevens, BirdLife Sudáfrica

Uno de los 17 países megadiversos en el mundo, Sudáfrica tiene una población de cerca de 60 millones de habitantes y hoy enfrenta una serie de necesidades y oportunidades de desarrollo inmobiliario. Sus múltiples ecosistemas respaldan la salud y el bienestar de su gente, además de su economía. El National Development Plan 2030 del gobierno de Sudáfrica reconoce la "necesidad de proteger el ambiente natural en todos sus ámbitos" (Gobierno de Sudáfrica, 2015a), y en el National Biodiversity Strategy and Action Plan (Gobierno de Sudáfrica, 2015b), estableció que la expansión de áreas protegidas conforma una herramienta clave para alcanzar aquel objetivo. El National Protected Area Expansion Strategy (Gobierno de Sudáfrica, 2010) indica que, para poder cumplir con los objetivos de las políticas nacionales e internacionales - como la Meta 11 de Aichi para la diversidad biológica-, se requiere la expansión de las áreas protegidas en tierras estatales, privadas y comunales. El siguiente estudio de caso examina cómo las APPs sudafricanas se establecen de acuerdo con los principios presentados en la Parte $B$, Sección 3, de estas Directrices y examina la forma en que tanto buenas prácticas para la gestión como incentivos innovadores fueron incorporados a este proceso.

\section{Contexto}

Sudáfrica cuenta con legislación nacional para la declaración formal de áreas protegidas en tierras estatales o privadas, la que exige el consentimiento del propietario y no establece diferencias relacionadas con el estado legal, los derechos y las responsabilidades asociadas al tipo de propietario. Las áreas protegidas en territorio privado son, ante todo, áreas protegidas, y son un claro ejemplo de reconocimiento fiable y oficial de APPs (Buena práctica 1.1.1) en el país. Actualmente, $35 \%$ del patrimonio de áreas protegidas terrestres en Sudáfrica es de propiedad privada, mientras que un $5 \%$ le pertenece a comunidades (ver Figura 2).

En Sudáfrica, un área protegida se define como un territorio terrestre o marino, delimitado geográficamente, protegido por el Protected Areas Act y principalmente gestionado para la conservación de la biodiversidad (SANBI, 2016). Las estrategias para la expansión de áreas protegidas se determinan mediante una planificación espacial detallada, tanto a escala nacional como

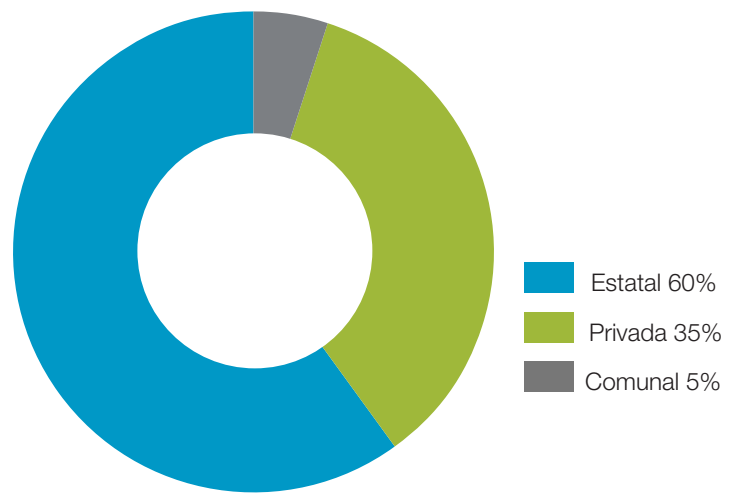

Figura 2: Propiedad de áreas protegidas en Sudáfrica (\%)

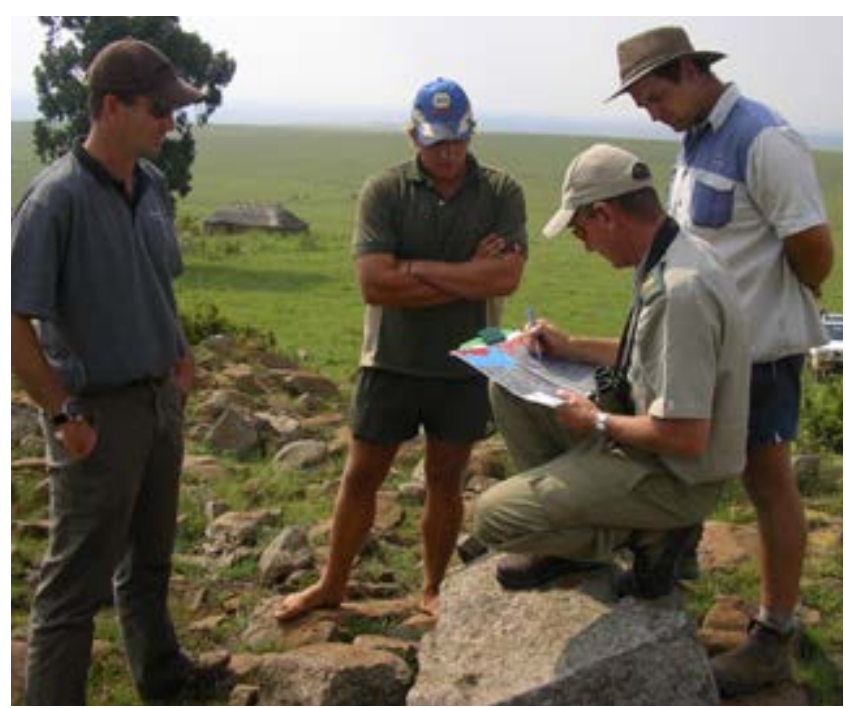

Los propietarios de la APP Sneeuwberg Protected Environment están a cargo de su administración y de formular e implementar el plan de manejo (c) BirdLife South Africa

local (Buena práctica 1.2.1). Los exhaustivos marcos políticos y legislativos del país ilustran la diferencia entre áreas protegidas y áreas de conservación. Las áreas protegidas tienen como objetivo principal la conservación, pero no así las áreas de conservación (SANBI, 2016). Las áreas protegidas y de conservación sudafricanas se reconocen y reportan de manera separada, y ejemplifican claramente la diferencia entre una APP y otros tipos de medidas de conservación efectivas (ver Apéndice 1 y Mitchell et al., 2018).

\section{Expansión de las áreas protegidas mediante la custodia de tierras privadas y comunales}

La National Biodiversity Stewardship Initiative es la principal herramienta para la expansión de áreas protegidas en tierras privadas y comunales. Por medio de esta, se pretende conseguir terrenos en áreas prioritarias de biodiversidad a través del establecimiento de acuerdos con propietarios privados y comunales, a cargo de autoridades de conservación que cuentan con el apoyo de ONGs de conservación (SANBI, 2015). Los acuerdos de biodiversidad establecen una jerarquía que va desde áreas protegidas declaradas formalmente - según se definió anteriormente-, con una duración de 30 a 99 años o a perpetuidad, a acuerdos no vinculantes (ver Figura 3 y Buena práctica 3.1.2). Esta jerarquía muestra la variedad de mecanismos legales que se pueden utilizar para establecer un APP. Particularmente, los crecientes niveles de protección legal y permanencia corresponden con los crecientes niveles de restricciones en el manejo del uso de la tierra y, también, en el aumento de los beneficios e incentivos para los propietarios, como los incentivos fiscales a la biodiversidad (ver Cuadro 3.2).

A la hora de declarar sus terrenos como áreas protegidas, la custodia de la biodiversidad permite a los propietarios de tierras privadas o comunales seleccionar entre tres tipos principales de 


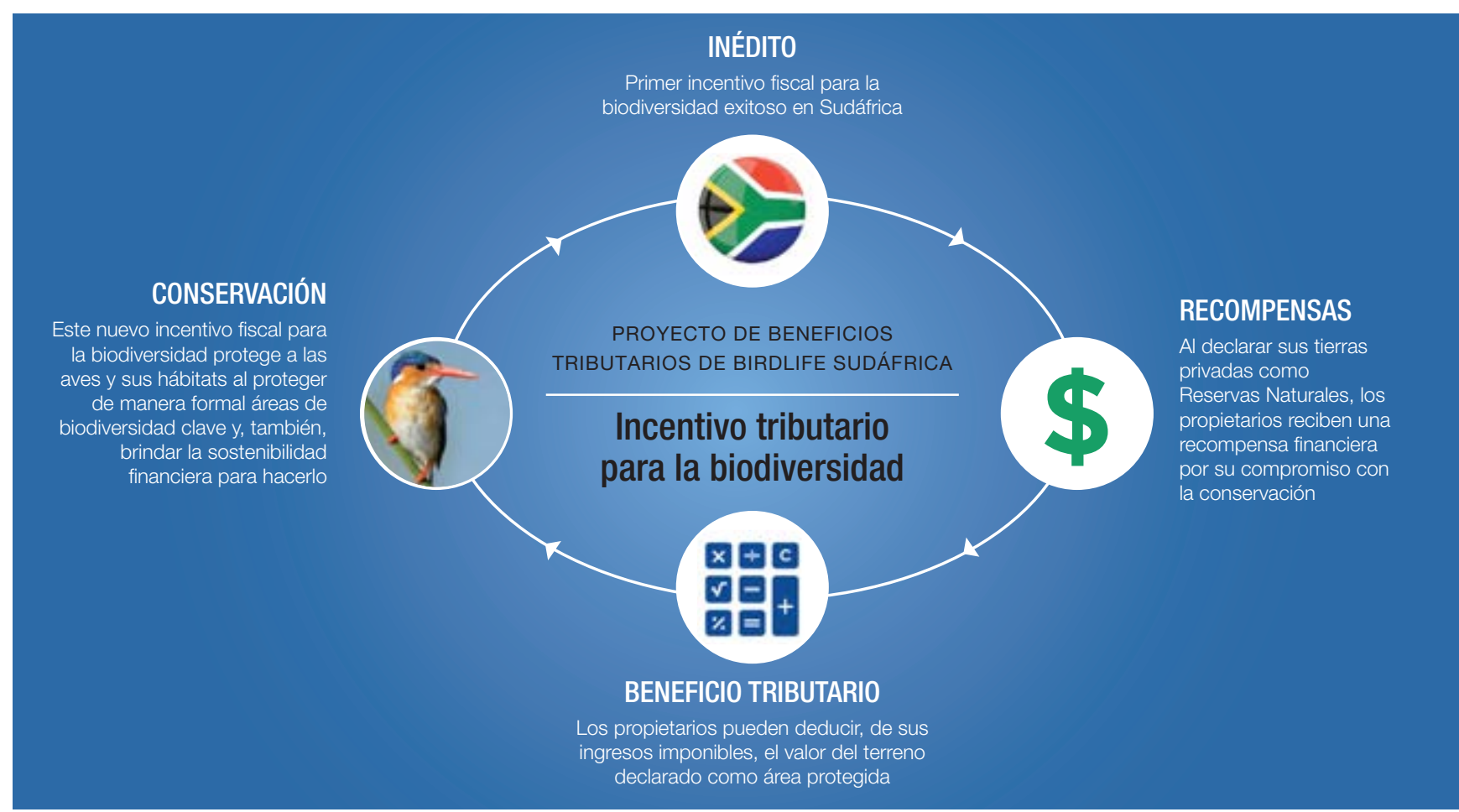

Figura 3: Jerarquía de los acuerdos de custodia de la biodiversidad. La custodia de la biodiversidad representa la detallada estructura institucional y el marco de implementación práctica de Sudáfrica que permite el establecimiento de APPs.

APPs: Parques Nacionales (conocidos como Contract National Parks, o parques nacionales establecidos por medio de un contrato), Reservas Naturales y Ambientes Protegidos. De acuerdo con la legislación, cada uno de estos tipos de APP exige la realización de planes y auditorías (Buena práctica 2.1.1).

Tanto los Contract National Parks como las Reservas Nacionales constituyen áreas geográficas con un alto valor de biodiversidad e infraestructura ecológica, cuyo objetivo principal es la conservación de la biodiversidad (Buena práctica 1.2.1). Los Parques Nacionales están sujetos a Parques Nacionales Sudafricanos (SANParks, por su sigla en inglés), la entidad responsable de gestionar los parques nacionales suscritos al Protected Areas Act y partícipes de procesos de declaración de áreas protegidas en tierras privadas o comunales, homólogos al enfoque de custodia de la biodiversidad. Las buenas prácticas en Sudáfrica determinan que el plazo de declaración de estos acuerdos requiere un mínimo de 99 años, o debe ser a perpetuidad. Los acuerdos involucran regulaciones más estrictas para la gestión, incluyendo la prohibición de usos de suelo insostenibles, como las actividades extractivas. Esta categoría de APPs también ofrece acceso a un incentivo tributario específico para la biodiversidad por medio del Income Tax Act (ver Cuadro 3.2). Las Reservas Naturales también requieren la aprobación obligatoria de la escritura mediante la ley de propiedad, asegurando el estatus del área protegida de la tierra, independientemente de los futuros cambios de propietario.

Existen distintos tipos de propiedades privadas que se pueden declarar como Ambientes Protegidos. Estas APPs se enfocan en áreas más grandes con valor de biodiversidad y funcionamiento ecológico a escala de paisaje y, dado que es un poco más flexible, cuenta con menos restricciones de gestión, lo que permite la conservación de la biodiversidad en paisajes productivos. Las buenas prácticas estipulan que los Ambientes Protegidos se declaran por un mínimo de 30 y hasta 99 años, o a perpetuidad.
La gestión del área se lleva a cabo junto con las partes interesadas, y su implementación está a cargo de los propietarios, quienes cuentan con el apoyo de autoridades y ONGs de conservación (ver Cuadro 2.2).

\section{Resumen}

Tanto la comunidad de práctica en materia de custodia de la biodiversidad, como los marcos políticos y legislativos de Sudáfrica, son las estructuras institucionales que apoyan el establecimiento de APPs sólidas en el país, y han sido clave para su éxito. Las principales lecciones aprendidas mediante el enfoque de custodia de la biodiversidad de Sudáfrica incluyen:

- En Sudáfrica, la legislación nacional reconoce a las áreas protegidas, establecidas ya sea en tierras estatales, privadas o comunales, como tal, y la entrega de información debe realizarse acorde a ello (Buena práctica 1.1.1 y 7.1.2).

- El objetivo principal del establecimiento de APPs en Sudáfrica es la conservación de la naturaleza mediante el compromiso voluntario y a largo plazo de los propietarios (Buenas prácticas 1.2.1, 3.1.1 y 3.2.1).

- El enfoque de custodia de la biodiversidad es el más exitoso para el establecimiento de APPs en el país, pues brinda un marco institucional y una comunidad de práctica (Buenas prácticas 3.4.1 y 3.7.4).

- Las APPs requieren planes de manejo detallados que se auditan anualmente (Buenas prácticas 2.1.1 y 2.4.2).

- Las APPs sudafricanas tienen acceso a innovadores instrumentos financieros para la conservación por medio del primer incentivo tributario para la biodiversidad efectivo, el que está dirigido a la sostenibilidad financiera (Buenas prácticas 3.1.1, 3.1.2 y 3.2.1). 


\section{Estudio de caso 11 Essex County Greenbelt: Un land trust estadounidense 'típico'}

Brent Mitchell, Presidente, Grupo de Especialistas en Áreas Bajo Protección Privada y Gestión de la Naturaleza de la Comisión Mundial de Áreas Protegidas (CMAP) de la UICN y Ed Becker, Essex County Greenbelt Association

En los Estados Unidos, organizaciones especializadas llamadas land trusts suelen ser las encargadas de establecer, monitorear $y$, a veces, gestionar APPS. La permanencia de estas entidades se garantiza por medio de instrumentos legales que forman parte del sistema de tenencia de la tierra (Buena práctica 4.1.1), y los incentivos provienen mayoritariamente de la cesión voluntaria de los derechos de desarrollo y la reducción de impuestos inmobiliarios, a la renta y otros tipos de impuestos relacionados con el valor de esos derechos (Buena práctica 3.7.4).

\section{Contexto}

El nombre de la Essex County Greenbelt Association ('Greenbelt') proviene de una jurisdicción ubicada al norte y al este de la ciudad de Boston, Massachusetts, y representa un primer esfuerzo por proteger los bosques y campos que aún quedan dentro de un área metropolitana en expansión. Desde 1961, este land trust privado ha protegido a más de 7.000 ha a lo largo de la región. La forma en que aquellas zonas se transformaron en áreas protegidas ejemplifica la manera en que Greenbelt funciona y se asemeja a otros land trusts del país.

Greenbelt ha apoyado la conservación de aproximadamente 1.600 ha de tierras privadas, que luego han pasado a pertenecer a o ser gestionadas por otras ONGs, gobiernos municipales o agencias de conservación estatales. Las 5.500 ha restantes siguen a cargo de la organización de dos modos distintos. Un poco menos de la mitad de las tierras -362 en total - se encuentran en reservas 'privadas' de pleno dominio. Esto significa que son de total propiedad de la ONG, una organización 'privada' con un propósito público ('privada' va en comillas porque Greenbelt mantiene el acceso público a todas ellas). La mayoría de estas propiedades cumpliría con la definición de APP de la UICN, dado que su objetivo principal es la conservación, junto con la recreación, educación, etc. Se espera que Greenbelt sea propietaria, proteja y gestione estas áreas a perpetuidad. Un ejemplo de esto es la Allyn Cox Reservation, la que fue donada a Greenbelt en 1974 y hoy es la sede principal de la ONG. Esta porción de 12 ha de costa en altura y pantanos salobres es un destino popular donde realizar caminatas, observación de vida silvestre y eventos al aire libre.

Otras 2.800 ha son protegidas por servidumbres de conservación Las servidumbres, o restricciones como se denominan en Massachusetts, restringen los usos permitidos de la propiedad, pero la mantienen bajo propiedad privada. En EE. UU. las servidumbres usualmente se describen por medio de la analogía 'bundle of sticks' (manojo de varillas), la que se refiere a la propiedad real (Buena práctica 4.2.1) y a los distintos elementos que componen el derecho a la propiedad. Las servidumbres a la propiedad se suelen referir tan solo a una porción de los derechos que un propietario puede tener: por ejemplo, derechos minerales, de acceso y de edificación, entre otros. Las servidumbres de conservación abordan los derechos que rara vez han sido transferidos anteriormente - si es que acaso alguna vez lo fueron -, como el poder para prevenir o prohibir ciertas actividades

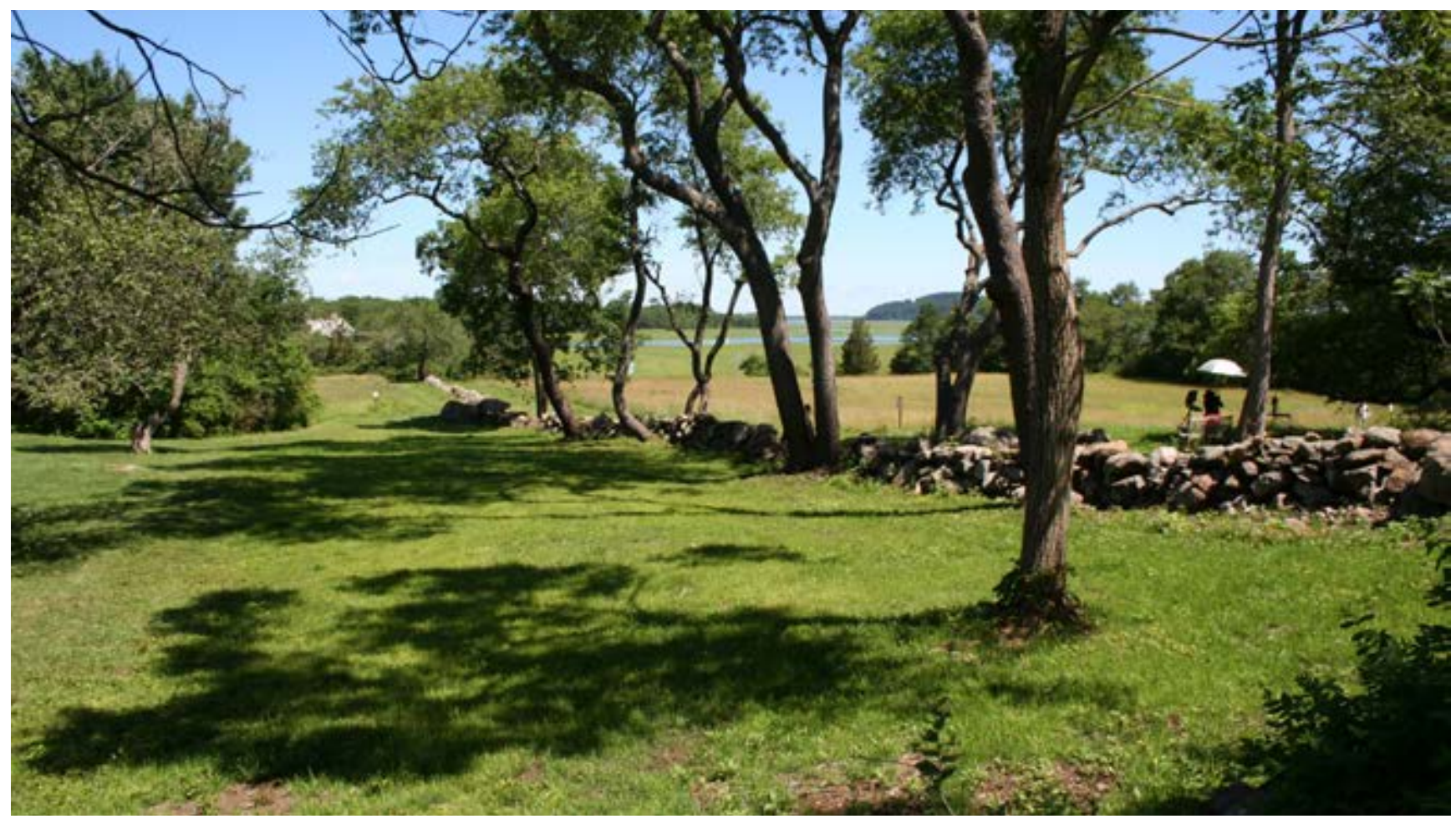

(C) Essex County Greenbelt Association 


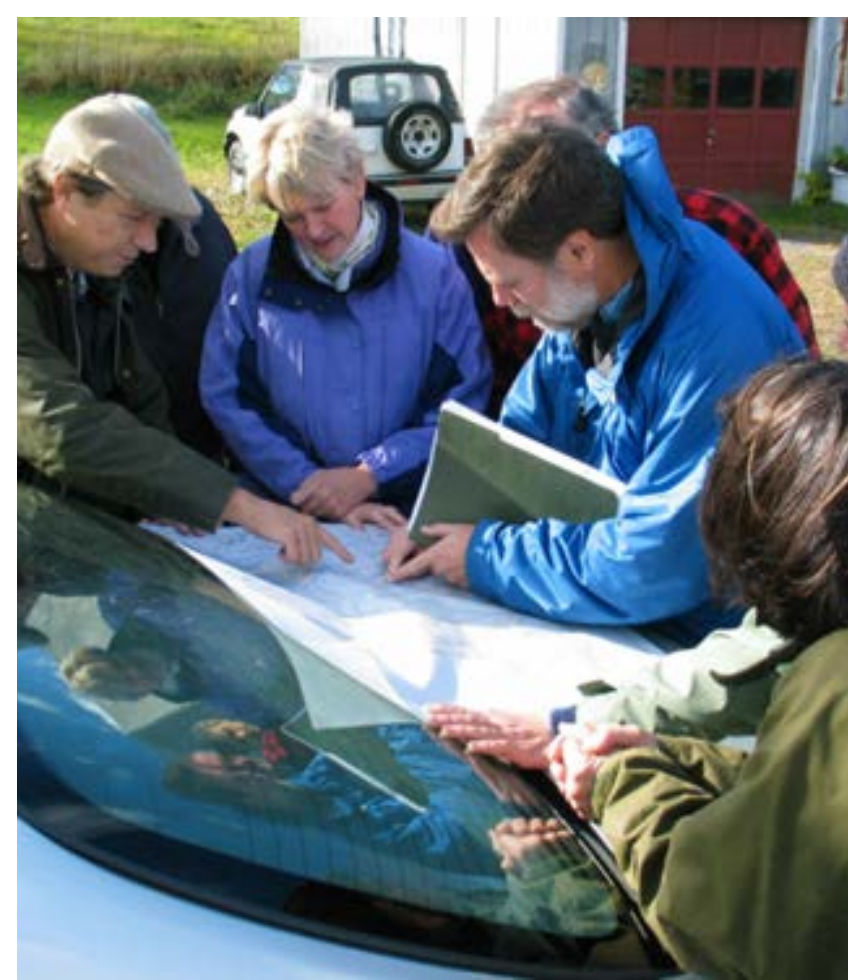

Equipo de evaluación de propiedades @ Essex County Greenbelt Association

en la propiedad, por lo que las servidumbres que otorgaban estos poderes se llamaban 'servidumbres negativas'. (Aunque no todas las servidumbres cumplen con todos los criterios de APPs, muchas sí lo hacen).

Tradicionalmente, la ley en los Estados Unidos se había resistido a las restricciones a perpetuidad sobre el uso del suelo (es decir, restricciones permanentes o efectivas a perpetuidad) y esta ampliación del concepto de servidumbre requirió que se realizaran modificaciones legales a la common law (derecho consuetudinario), las que se materializaron en la Uniform Conservation Easement Act, adoptada por la National Conference of Uniform State Laws en 1981. Esta ley dispuso que las servidumbres de conservación serían a perpetuidad y vinculantes para todos los propietarios posteriores (Buena práctica 4.1.7). También eliminó el requerimiento de la common law según el cual la entidad a la que se le otorga la servidumbre posee otras tierras adyacentes o cercanas al terreno restringido. Si bien las servidumbres de conservación 'quitan' ciertos derechos para siempre, y quedan registradas en la escritura, los derechos no pueden desaparecer de la nada, sino que deben ser de propiedad de otra entidad. He ahí la función de Greenbelt y de otros land trusts del tipo. Greenbelt tiene restricciones sobre 222 propiedades, en las cuales deben monitorear el cumplimiento y, de ser necesario, hacer cumplir los términos de la servidumbre.

Dado que las servidumbres de conservación disminuyen el valor inmobiliario de una propiedad en términos teóricos, los beneficios para el propietario pueden acumularse mediante la reducción de los impuestos a la propiedad y la renta. Los donantes de reservas de pleno dominio, al igual que los donantes que apoyan las operaciones de land trusts, también pueden acceder a los beneficios tributarios a la renta. Estos incentivos pueden ser eficaces (ver Principio 3.7).

\section{Las APPs a lo largo de los EE. UU.}

Greenbelt es uno de los más de 1.300 land trusts del país (Land Trust Alliance, 2015). Aunque así lo indica el título de este estudio de caso, realmente no existe un tipo único de land trust. Por ejemplo, Greenbelt cuenta con 14 empleados permanentes, mientras que otros land trusts, como The Nature Conservancy, son organizaciones mucho más grandes. La mayoría, sin embargo, suele ser más pequeña que Greenbelt. Es más, algunos ni siquiera tienen personal remunerado. Gran parte de estas organizaciones ha adoptado los Estándares y Prácticas promulgados por Land Trust Alliance, y más de 400 land trusts han sido certificados por haber cumplido con los altos estándares establecidos por Land Trust Accreditation Commission.

Sin duda, existen muchos otros tipos de APPs en los EE. UU. Algunos han surgido a partir de iniciativas individuales y, de hecho, todos los subtipos de APPs están representados. Cabe destacar las áreas de investigación académicas permanentes. Muchas universidades se establecieron por medio de esquemas de land grants, o concesiones de tierras pertenecientes al gobierno hasta ser otorgadas a una persona u entidad, en la historia temprana del país. El Estado entregó tierras para ser vendidas con el fin de financiar las universidades, no obstante, algunas áreas se reservaron para la investigación ecológica y continúan siendo APPs.

La conservación de tierras privadas en los Estados Unidos se caracteriza por hacer hincapié en la protección a perpetuidad y se promueve por medio de un amplio espectro de incentivos, sobre todo relacionados con beneficios fiscales que el propietario puede acumular. Sin embargo, sería errado concluir que la conservación de tierras se debe tan solo a una decisión económica. Muchos estudios han demostrado que las principales motivaciones de los propietarios no son económicas, sino intrínsecas, y que los incentivos permiten tomar una actitud administrativa (ver Principio 3.4) (por ejemplo, Farmer et al., 2016). De acuerdo con el propietario George Leonhard, la razón por la cual su hermano y él decidieron proteger su granja con una servidumbre de conservación, otorgada por Greenbelt, fue que "no podía soportar la idea de que la propiedad estuviera cubierta de casas".

\section{Resumen}

- Es posible adaptar leyes y regulaciones ya existentes con el fin de crear mecanismos e incentivos para la protección de la tierra (Buena práctica 3.7.4).

- Contar con un sistema de tenencia de tierra permite garantizar la protección permanente, aplicando restricciones sobre la escritura misma en lugar de hacerlo sobre un propietario en particular (Buena práctica 4.1.1).

- Los incentivos pueden ser duraderos si se basan en valor y están integrados con los sistemas de mercado (Buena práctica 3.2.1).

- La custodia personal y las organizaciones intermediarias profesionales son importantes para establecer, gestionar y monitorear áreas bajo protección privada (Buena práctica 8.2.1). 


\section{Estudio de caso 12 Cómo realzar a las APPs: Incorporación de APPs a la WDPA en el Reino Unido}

\section{Sue Stolton, IUCN UK National Committee}

El Reino Unido fue uno de los primeros países en el mundo en desarrollar un sistema para evaluar todas las áreas de conservación de la naturaleza y el paisaje, cubriendo todos los tipos de gobernanza según la definición, las categorías y los tipos de gobernanza de áreas protegidas de la UICN ('Directrices 2008'). Su proyecto Putting Nature on the Map (PNOTM, por su sigla en inglés) también creó un sistema para evaluar las áreas protegidas comunitarias, privadas y locales no reconocidas hasta entonces - de acuerdo con las Directrices de áreas protegidas 2008 de la UICN-y, a la vez, entregar información sobre ellas a la Base de Datos de Áreas Protegidas (WDPA, por su sigla en inglés). Este estudio de caso es un ejemplo de cómo llevar a cabo las buenas prácticas descritas en la Parte B, Sección 7, de estas Directrices.

\section{Contexto}

Los orígenes de la conservación de la naturaleza y el paisaje en el Reino Unido se remontan al siglo pasado y a tres motivos aislados: el primero, el llamado a proteger la naturaleza por motivos científicos y ecológicos; el segundo, la preocupación por el daño estético provocado por la industrialización, y, tercero, la exigencia de la gente por tener acceso al campo con fines recreativos. Estas inquietudes se aunaron en la National Parks and Access to the Countryside Act de 1949 y dieron pie a un fuerte movimiento de conservación de ONGs, que ha permitido proteger muchas áreas para la naturaleza y el paisaje tomando posesión de las tierras y ejerciendo influencia política.

El desarrollo de APPs en el Reino Unido se ha caracterizado por la participación de ONGs que buscan proteger la naturaleza y el paisaje. Entidades como el National Trust (NT, por su sigla en inglés), que hoy cuenta con más de cinco millones de miembros, y la Royal Society for the Protection of Birds (RSPB, por su sigla en inglés) con más de un millón de miembros, fueron creadas en el siglo XIX. Ambas comenzaron a proteger reservas naturales antes de 1900, y la cantidad de sitios que custodian ha crecido casi todos los años desde entonces. El primer wildlife trust dedicado a la geografía se estableció en 1926, y hoy existen más de 47 en todo el Reino Unido (principalmente ubicados en los condados de Inglaterra y Gales, con una entidad tanto en Escocia como en Irlanda del Norte). En total, estos trusts cuentan con más de 800.000 miembros y una red de más de 1.000 reservas naturales. Otras ONGs específicamente dedicadas a la conservación de humedales, vida silvestre, bosques, plantas y aves rapaces, por ejemplo, también han adquirido y formado sus propios sistemas de reservas naturales. Todas estas son entidades con membresía, que operan como organizaciones de beneficencia en concordancia con las leyes nacionales, y son totalmente independientes del gobierno. Además, miles de agricultores y propietarios están involucrados en la protección basada en sitios por medio de la legislación nacional. Las tierras de propiedad comunitaria, particularmente las áreas conocidas como commons, también ofrecen una serie de beneficios para la conservación.

\section{Cómo se pone en práctica la definición de la UICN en la conservación del Reino Unido}

\begin{abstract}
Si bien los datos sobre áreas protegidas en el Reino Unido eran registrados por organizaciones individuales y, en ocasiones, por entidades gubernamentales, la información entregada a la WDPA era deficiente en varios aspectos. Esto debido a que los datos no eran recolectados en consonancia con los estándares descritos por las Directrices 2008. Por el contrario, estaban incompletos, incluían áreas que no necesariamente cumplían con la definición de la UICN, o bien, áreas categorizadas en disonancia con los propósitos para los cuales se protegían, y, en muchos casos, registraban el tipo de gobernanza incorrecto. En 2010, el entonces Presidente de la Comisión Mundial de Áreas Protegidas (CMAP) le propuso al Comité Nacional de la UICN en el Reino Unido dirigir un proyecto para aplicar las Directrices 2008 a todos los tipos de gobernanza en el Reino Unido, lo que podría servir como ejemplo para otros países con un gran número de APPs y áreas
\end{abstract}

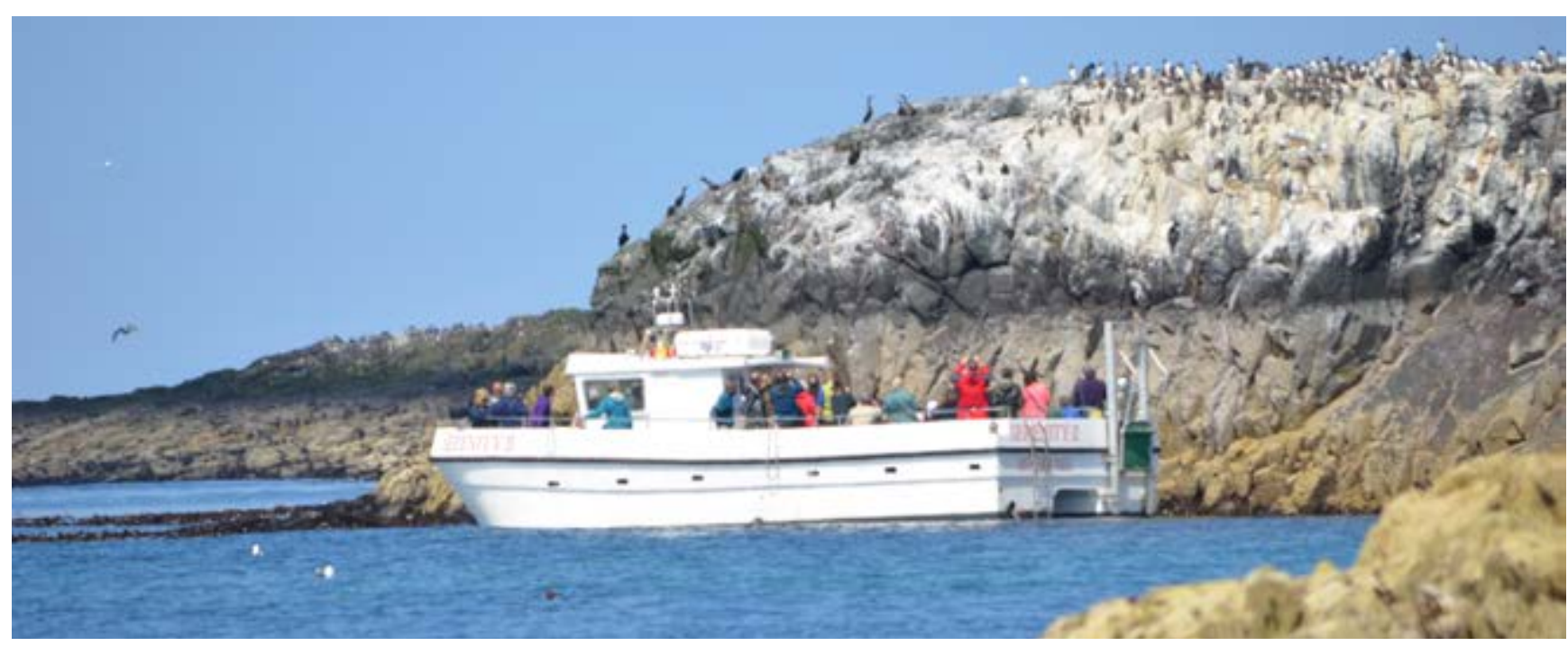

El National Trust cuenta con uno de los holdings más grandes de tierras privadas en el Reino Unido y administra cerca de 600 APPs @ Nigel Dudley 


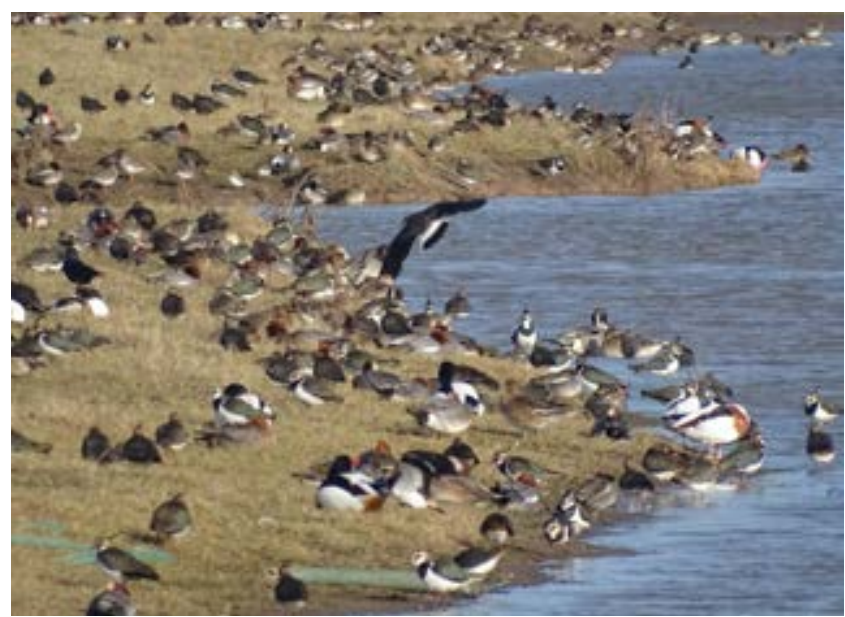

El Slimbridge Centre es manejado por el Wildfowl \& Wetlands Trust, una de las tantas ONGs que gestiona APPs en el Reino Unido (c) Nigel Dudley

conservadas por la comunidad, sobre las cuales la WDPA carecía de información adecuada.

Fue entonces que se creó el proyecto Putting Nature on the Map (PNOTM, por su sigla en inglés), cuyos objetivos eran identificar todos los lugares que cumplieran con la definición de área protegida de la UICN, y asignarles la categoría de gestión y tipo de gobernanza apropiada según los términos de la UICN. Para esto, el PNOTM desarrolló un proceso de cinco pasos:

1. Identificar todos los sitios que podrían ser áreas protegidas.

2. Desarrollar lineamientos específicos para el Reino Unido de acuerdo con las Directrices 2008.

3. Determinar qué es y qué no es un área protegida según la definición de la UICN.

4. Asignar categorías de gestión y tipos de gobernanza.

5. Recolectar y entregar información sobre datos, incluyendo a la WDPA.

En la medida en que el PNOTM se fue desarrollando, fue evidente que era necesario masificar el propósito del proyecto y asegurarse de que se adoptaran estándares consistentes. Para esto, el proyecto desarrolló tres innovaciones:

1. Manual para el Reino Unido. La creación de un documento que mostrara de qué modo aplicar las Directrices 2008 a ese contexto específico (Comité Nacional del Reino Unido de la UICN, 2012).

2. Declaraciones de conformidad (SoCs, por su sigla en inglés). Una declaración que describiera una evaluación de áreas protegidas según un grupo de preguntas estándar para examinar sistemáticamente si los sitios individuales o ciertas designaciones específicas cumplían con la definición de la UICN. Estas declaraciones fueron desarrolladas por los propietarios con la ayuda del PNOTM, quienes sabían que el propósito era incluir sus datos a la WDPA (Buena Práctica 7.1.6). Este proceso permitió detectar problemas clave, al identificar si un sitio individual o un grupo de sitios por designación cumplían o no con las Directrices 2008. Los SoCs son una fuente transparente y están disponibles en el sitio de la Comisión Nacional del Reino Unido ${ }^{144}$ para quienes deseen revisarlos.
3. Un Panel de Evaluación Nacional. El panel, formado por expertos de la CMAP del Reino Unido familiarizados con los estándares internacionales de la UICN, revisaron cada SoC en detalle y comentaron si los sitios/designaciones cumplían o no con las Directrices 2008. Esto cumplió con los requerimientos de verificación de datos de la WDPA (Buena práctica 7.1.8).

\section{Desafíos}

Una vez confirmado el estatus de área protegida, se invitó a los proveedores de datos a compilar listas de sus áreas protegidas de acuerdo con las categorías de gestión y tipos de gobernanza propuestos. En el caso de las entidades de conservación gubernamentales de carácter legal, se respetaron los protocolos establecidos. En cambio, en el caso de grupos de datos de ONGs, nunca antes incorporados, se recolectaron grandes volúmenes de nuevos datos sobre las áreas protegidas del Reino Unido, luego revisados por el Panel de Evaluación y comunicados al Centro de Monitoreo de la Conservación Mundial del Programa de las Naciones Unidas para el Medio Ambiente (UNEP-WCMC, por su sigla en inglés), a cargo del manejo de WDPA (Buena práctica 7.1.4).

La recolección de datos permanece siendo un desafío. En un comienzo, muchas de las partes interesadas se vieron enfrentadas por primera vez a los estándares de la WDPA, y las nuevas tareas no siempre fueron bien recibidas por el personal ya a cargo de otras tareas de gestión de datos. Para revertir esto, el PNOTM, junto con el Scottish Wildlife Trust, invirtió en un esquema piloto para poner a prueba y demostrar la practicidad de lo que se estaba pidiendo, sostuvo reuniones con el personal a cargo de los datos de varias ONGs y, también, le brindó apoyo a un taller de capacitación de la UNEP-WCMC y a un seminario web para gestores de datos (Buena práctica 7.13).

El PNOTM no solo generó cambios respecto del flujo de datos sobre áreas protegidas del Reino Unido a la WDPA, sino que también permitió conocer un panorama de la red de áreas protegidas distinto al que se le solía informar a la WDPA. Específicamente, en términos de este documento, se han identificado miles de APPs de propiedad de o manejadas por ONGs - equivalentes a casi 500.000 ha de tierras protegidasy diversos tipos de gobernanza antes no registradas con precisión. Debido a que los recursos públicos para la conservación son cada vez menor y que el compromiso de las políticas se ha debilitado en algunas áreas, entender esta contribución a la conservación es de suma importancia (Crofts \& Philips, 2013; Crofts et al., 2014).

\section{Resumen}

- La entrega de información sobre APPs facilita la comprensión en torno a las redes nacionales de áreas protegidas (Buena práctica 6.2.1).

- Los procesos nacionales llevados a cabo de manera simultánea pero independiente del gobierno (Buena práctica 7.1.1) pueden ayudar a los propietarios/administradores a entender y aplicar las Directrices 2018 y sus estándares en el contexto nacional.

- La recolección de datos no es siempre fácil y la cooperación cercana de la UNEP-WCMC es necesaria para brindarle apoyo a aquellas organizaciones que entregan datos por primera vez (Principio 7.1). 


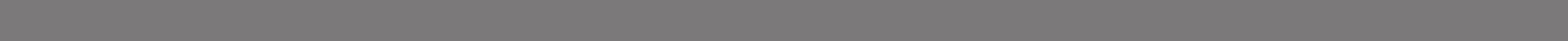




\section{Referencias}

Avalon Marshes Landscape Partnership (2011). Documento Suplementario - Lista Completa de Proyectos. Disponible en: http:// www.somersetwildlife.org/hres/Microsoft\%20Word\%20-\%201.11\%20 -\%20Full\%20Project\%20List\%2010\%2011\%2011_SML.pdf

Balaguera-Reina, S.A., Espinosa-Blanco A.S., Morales-Betancourt, M.A., Seijas, A.E., Lasso, C.A., Antelo, R. y Densmore III, L.D. (2017) 'Conservation status and regional habitat priorities for the Orinoco crocodile: Past, present, and future'. PLOS ONE 12(2): e0172439. Disponible en: https://doi.org/10.1371/journal.pone.0172439

Bernstein, J. y Mitchell, B.A. (2005). 'Land trusts, private reserves and conservation easements in the United States'. PARKS 15(2):48-60. Disponible en: http://parksjournal.com/wp-content/uploads/2017/07/ parks_15_2.pdf

Bezaury-Creel, J.E., Ochoa-Ochoa, L.M. y Torres-Origel, J.F. (2012). Base de Datos Geográfica de las Reservas de Conservación Privadas y Comunitarias en México Versión 2.1 Diciembre 31, 2012. The Nature Conservancy. 2 Capas ArcGIS 9.2 + 1 Capa Google Earth $\mathrm{KMZ}+1$ Archivo de Metadatos en texto. No publicado, disponible en formato $C D$.

Bingham, H., Fitzsimons, J.A., Redford, K.H., Mitchell, B.A., BezauryCreel, J. y Cumming, T.L. (2017). 'Privately protected areas: advances and challenges in guidance, policy and documentation'. PARKS 23(1):13-28. Disponible en: https://doi.org/10.2305/IUCN.CH.2017. PARKS-23-1HB.en (Accedido: 26 septiembre 2018).

BMUB (2017). Das Nationale Naturerbe. Naturschätze für Deutschland. Berlin, Germany: Bundesministerium für Umwelt, Naturschutz, Bau und Reaktorsicherheit (BMUB). Disponible en: https://www.bmu.de/fileadmin/Daten_BMU/Pools/Broschueren/ nat_naturerbe_bf.pdf (Accedido: 26 septiembre 2018).

Borrini-Feyerabend, G., Dudley, N., Jaeger, T., Lassen, B., Pathak Broome, N., Phillips, A. y Sandwith, T. (2013). Governance of Protected Areas: From understanding to action. Best Practice Protected Area Guidelines Series no. 20. Gland, Suiza: UICN. Disponible en: https://portals.iucn.org/library/node/29138 (Accedido: 26 septiembre 2018).

Centro de Monitoreo de la Conservación Mundial del Programa de las Naciones Unidas para el Medio Ambiente (UNEP-WCMC) (2017). World Database on Protected Areas User Manual 1.5. Cambridge, Reino Unido: UNEP-WCMC. Disponible en: www.wcmc.io/WDPA_ Manual (Accedido: 26 septiembre 2018).

Centro de Monitoreo de la Conservación Mundial del Programa de las Naciones Unidas para el Medio Ambiente y Unión Internacional para la Conservación de la Naturaleza (UNEP-WCMC Y UICN) (2018). Protected Planet: Base de Datos Mundial de Áreas Protegidas (WDPA) [On-line], octubre 2018, Cambridge, Reino Unido: UNEP-WCMC y UICN. Disponible en: www.protectedplanet.net

Clements, H.S., Selinske, M.J., Archibald, C.L., Cooke, B., Fitzsimons, J.A., Groce, J.E., Torabi, N. y Hardy, M.J. (2018). 'Fairness and transparency are required for the inclusion of privately protected areas in publicly accessible conservation databases'. Land 7: 96. Disponible en: https://doi.org/10.3390/land7030096. (Accedido: 26 septiembre 2018).

Cohen, S., Dengate, J., Morrell, L. y Lee, K. (2015). 'The media and protected areas'. En: G.L. Worboys, M. Lockwood, A. Kothari, S. Feary y I. Pulsford (eds.) Protected Area Governance and Management, pp. 441-472. Canberra, Australia: ANU Press. Disponible en: http://press-files.anu.edu.au/downloads/press/ p312491/pdf/CHAPTER15.pdf (Accedido: 26 septiembre 2018).
Colorado State Land Board (2017). Conservation Bank for Preble's Meadow Jumping Mouse. Disponible en: http://www.glo.texas.gov/ wslca/downloads/conferences/2017/winter/surface-committee/ CO_Prebles-Meadow-Jumping-Mouse-Conservation-Bank.pdf (Accedido: 6 octubre 2018).

Commonwealth of Australia and each of its States and Territories (2010). Australia's Strategy for the National Reserve System 20092030. Canberra. Disponible en: https://www.environment.gov.au/ system/files/resources/643fb071-77c0-49e4-ab2f-220733beb30d/ files/nrsstrat.pdf. (Accedido: 26 septiembre 2018).

Commonwealth of Massachusetts and the Nature Conservancy (2010). BioMap2 Conserving the Biodiversity of Massachusetts in a Changing World. Massachusetts Department of Fish \& Game y The Nature Conservancy. Disponible en: https://www.mass. gov/files/documents/2016/08/wi/biomap2-summary-report.pdf (Accedido: 26 septiembre 2018).

Conservation Measures Partnership (CMP) (2013). Open Standards for the Practice of Conservation. Disponible en: http://cmpopenstandards.org/wp-content/uploads/2017/06/CMP-OS-V3.0Final-minor-update-May-2107.pdf (Accedido: 26 septiembre 2018).

Convenio sobre la Diversidad Biológica (CDB) (2010). Convention on Biological Diversity Strategic Plan for Biodiversity 2011-2020. UNEP/ CBD/COP/DEC/X/2. Disponible en: https://www.cbd.int/doc/decisions/ cop-10/cop-10-dec-02-en.pdf (Accedido: 26 septiembre 2018).

Cowan, G.I., Mpongoma, N. y Britton, P. (eds.) (2010). Management effectiveness of South Africa's protected areas. Pretoria: Department of Environmental Affairs.

Crofts, R., Dudley, N., Mahon, C., Partington, R., Phillips, A., Pritchard, S. y Stolton, S. (2014). Putting Nature on the Map: A Report and Recommendations on the Use of the IUCN System of Protected Area Categorisation in the UK. Reino Unido: Comité Nacional UICN Reino Unido. Disponible en: https://portals.iucn.org/library/sites/library/files/ documents/2014-040.pdf (Accedido: 26 septiembre 2018).

Crofts, R. y Phillips, P. (2013). 'Putting Nature on the Map: Applying the IUCN Protected Areas Management Categories in the UK'. PARKS 19.1. Disponible en: https://doi.org/10.2305/IUCN.CH.2013. PARKS-19-1.RC.en

Crosthwaite, J., Fitzsimons, J., Stanley, J. y Greacen, J. (2013). "'Networking the networks": coordinating Conservation Management Networks in Victoria'. En: J. Fitzsimons, I. Pulsford, y G. Wescott (eds.) Linking Australia's Landscapes: Lessons and Opportunities from Large-scale Conservation Networks, pp. 209-220. Melbourne, Australia: CSIRO Publishing.

Cumming, T.L. (2007). 'Conservation incentives for private commercial farmers in the Thicket Biome, Eastern Cape, South Africa'. Tesis de maestría. Grahamstown, South Africa: Rhodes University. Disponible en: http://vital.seals.ac.za/vital/access/manager/Repository/vital:4745 (Accedido: 26 septiembre 2018).

De Vasconcellos Pegas, F. y Castley, G. (2015). 'Private reserves in Brazil: Distribution patterns, logistical challenges, and conservation contributions'. Journal for Nature Conservation 29:14-24. Disponible en: https://doi.org/10.1016/j.jnc.2015.09.007

Dinerstein, E., Olson, D., Joshi, A., Vynne, C., Burgess, N.D., Wikramanayake, E., Hahn, N., Palminteri, S., Hedao, P., Noss, R., Hansen, M., Locke, H., Ellis, E.C., Jones, B., Barber, C.V., Hayes, R., Kormos, C., Martin, V., Crist, E., Sechrest, W., Price, L., Baillie, J.E.M., Weeden, D., Suckling, K., Davis, C., Sizer, N., Moore, R., 
Thau, D., Birch, T., Potapov, P., Turubanova, S., Tyukavina, A., De Souza, N., Pintea, L., Brito, J.C., Llewellyn, O.A., Miller, A.G., Patzelt, A., Ghazanfar, S.A., Timberlake, J., Klöser, H., ShennanFarpón, Y., Kindt, R., Lillesø, J-P.B., van Breugel, P., Graudal, L., Voge, M., Al-Shammari, K.F. y Saleem, M. (2017). 'An ecoregionbased approach to protecting half the terrestrial realm'. BioScience 67:534-545. Disponible en: https://doi.org/10.1093/biosci/bix014 (Accedido: 26 septiembre 2018).

Dodds, R. (2012). 'Eco-tourism for Education and Marine Conservation: the Chumbe Island Coral Park in Zanzibar'. TÉOROS Edición especial: 91-97. Disponible en: https://journals.openedition. org/teoros/1990 (Accedido: 26 septiembre 2018).

Dudley, N. (ed.) (2008). Guidelines for Applying Protected Area Management Categories. Gland, Suiza: UICN. Disponible en: https://doi.org/10.2305/IUCN.CH.2008.PAPS.2.en (Accedido: 26 septiembre 2018).

Dudley, N. (2011). Authenticity in Nature: Making choices about the naturalness of ecosystems. Londres, Reino Unido: Earthscan.

Dudley, N., Bhagwat, S., Higgins-Zogib, L., Lassen, B., Verschuuren, B. y Wild, R. (2010). 'Conservation of biodiversity in sacred natural sites in Asia y Africa: a review of scientific literature'. En: B. Verschuuren, R. Wild, J. McNeely y G. Oviedo (eds.) Sacred Natural Sites, pp. 19-31. Londres, Reino Unido: Earthscan.

Ellwood, E., Crimmins, T. y Miller-Rushing, A. (eds.) (2017). 'The role of citizen science in biological conservation'. Biological Conservation. 208:1-188. https://doi.org/10.1016/j.biocon.2016.10.014

Farmer, J.R., Brenner, J.C., Drescher, M., Dickinson, S., y Knackmuhs, E.G. (2016). Perpetual private land conservation: the case for outdoor recreation and functional leisure. Ecology and Society 21(2):46. Disponible en: https://doi.org/10.5751/ES-08515-210246

Farmer, J.R., Knapp, D., Meretsky, V.J., Chancellor, C. y Fischer, B.C. (2011). 'Motivations influencing the adoption of conservation easements'. Conservation Biology 25:827-834. Disponible en: https://doi.org/10.1111/j.1523-1739.2011.01686.x (Accedido: 26 septiembre 2018).

Fitzsimons, J.A. (2006). 'Private Protected Areas? Assessing the suitability for incorporating conservation agreements over private land into the National Reserve System: A Case Study of Victoria'. Environmental and Planning Law Journal 23:365-385.

Fitzsimons, J.A. (2015). 'Private protected areas in Australia: Current status and future directions'. Nature Conservation 10:1-23. Disponible en: https://doi.org/10.3897/natureconservation.10.8739 (Accedido: 26 septiembre 2018).

Fitzsimons, J.A. y Wescott, G. (2007). 'Perceptions and attitudes of land managers in multi-tenure reserve networks and the implications for conservation'. Journal of Environmental Management 84:38-48. Disponible en: https://doi.org/10.1016/j.jenvman.2006.05.009 (Accedido: 26 septiembre 2018).

Fitzsimons, J.A. y Wescott, G. (2008a). 'Ecosystem conservation in multi-tenure reserve networks: The contribution of land outside of publicly protected areas'. Pacific Conservation Biology 14: 250-262. Disponible en: https://doi.org/10.1071/PC080250 (Accedido: 26 septiembre 2018).

Fitzsimons, J.A. y Wescott, G. (2008b). 'The role of multi-tenure reserve networks in improving reserve design and connectivity'. Landscape and Urban Planning 85:163-173. Disponible en: https://doi.org/10.1016/j.landurbplan.2007.11.001 (Accedido: 26 septiembre 2018).

Franks, P, Martin, A. y Schreckenberg, K. (2016). From livelihoods to equity for better protected area conservation. Briefing. Instituto Internacional para el Medio Ambiente y el Desarrollo (IIED). Disponible en: http://pubs.iied.org/pdfs/17370llED.pdf (Accedido: 5 octubre 2018).
Gilligan, B. y Syneca Consulting Pty Ltd (2007). Review and Evaluation of the Tasmanian Private Forest Reserves Program. Report for the Tasmanian Department of Primary Industries and Water, Hobart. Disponible en: https://dpipwe.tas.gov.au/Documents/PFRPEvaluation-Report.pdf (Accedido: 26 septiembre 2018).

Gobierno de Chile (2015). Declara lugar de interés científico para efectos mineros area ubicada en Región de Magallanes, Provincia de Tierra del Fuego, Comuna de Timaukel. Diario Oficial No. 41.219.

Gobierno de Sudáfrica (2010). National Protected Area Expansion Strategy for South Africa 2008. Priorities for expanding the protected area network for ecological sustainability and climate change adaption. Pretoria, Sudáfrica: Departamento Asuntos Medio Ambientales. Disponible en: https://www.environment.gov.za/sites/default/files/ docs/nationalprotected_areasexpansion_strategy.pdf (Accedido: 26 septiembre 2018).

Gobierno de Sudáfrica (2015a). The National Development Plan. Pretoria: Departamento: La Presidencia.

Gobierno de Sudáfrica (2015b). National Biodiversity Strategy and Action Plan. Pretoria, Sudáfrica: Departamento Asuntos Medio Ambientales. Disponible en: https://www.cbd.int/doc/world/za/zanbsap-v2-en.pdf (Accedido: 26 septiembre 2018).

Gordon, A., Bull, J.W., Wilcox, C. y Maron, M. (2015). 'Perverse incentives risk undermining biodiversity offset policies'. Journal of Applied Ecology. 52:532-537. Disponible en: https://doi. org/10.1111/1365-2664.12398 (Accedido: 26 septiembre 2018).

Greiber, T. (ed.) (2009). Payments for Ecosystem Services. Legal and Institutional Frameworks. Gland, Suiza: UICN. Disponible en: https:// portals.iucn.org/library/node/9497 (Accedido: 26 septiembre 2018).

Grêt-Regamey, A., Sirén, E., Brunner, S.H. y Weibel, B. (2017). 'Review of decision support tools to operationalize the ecosystem services concept'. Ecosystem Services 26:306-315. Disponible en: https://doi.org/10.1016/j.ecoser.2016.10.012

Gross, J.E., Woodley, S., Welling, L.A. y Watson, J.E.M. (eds.) (2016). Adapting to Climate Change: Guidance for protected area managers and planners. Best Practice Protected Area Guidelines Series no. 24. Gland, Suiza: UICN. Disponible en: https://doi.org/10.2305/IUCN. CH.2017.PAG.24.en (Accedido: 26 septiembre 2018).

Groves, C.R. y Game, E.T. (2016). Conservation planning: informed decisions for a healthier planet. Greenwood Village, Colorado, EE. UU.: Roberts and Co.

Halliday, L., Castley, J.G., Fitzsimons, J.A., Tran, C. y Warnken, J. (2012). 'Fire management on private conservation lands: Knowledge, perceptions and actions of landholders in eastern Australia'. International Journal of Wildland Fire 21:197-209. Disponible en: https://doi.org/10.1071/WF10148 (Accedido: 26 septiembre 2018).

Hardy, M.J., Bekessy, S.A., Fitzsimons, J.A., Mata, L., Cook, C., Nankivell, A., Smillie, K. y Gordon, A. (2018a). 'Protecting nature on private land using revolving funds: Assessing property suitability'. Biological Conservation 220:84-93. Disponible en: https://doi. org/10.1016/j.biocon.2018.01.026 (Accedido: 26 septiembre 2018).

Hardy, M.J., Fitzsimons, J.A., Bekessy, S.A. y Gordon, A. (2017). 'Exploring the permanence of conservation covenants'. Conservation Letters 10:221-230. Disponible en: https://doi.org/10.1111/ conl.12243 (Accedido: 26 septiembre 2018).

Hardy, M.J., Fitzsimons, J.A., Bekessy, S.A. y Gordon, A. (2018b). 'Factors influencing property selection for conservation revolving funds'. Conservation Biology 32:276-286. Disponible en: https://doi. org/10.1111/cobi.12991 (Accedido: 26 septiembre 2018).

Hardy, M.J., Fitzsimons, J.A., Bekessy, S.A. y Gordon, A. (2018c). 'Purchase, protect, resell, repeat: an effective approach for conserving biodiversity on private land?' Frontiers in Ecology and the Environment 16:336-344. Disponible en: https://doi.org/10.1002/fee.1821 (Accedido: 26 Septiembre 2018). 
Hockings, M., Stolton, S., Leverington, F., Dudley, N. y Courrau, J. (2006). Evaluating Effectiveness: A framework for assessing management effectiveness of protected areas, Segunda edición. Gland, Suiza: UICN CMAP y Brisbane, Australia: University of Queensland. Disponible en: https://doi.org/10.2305/IUCN.CH.2005. PAG.14.en (Accedido: 26 septiembre 2018).

Hora, B., Marchant, C. y Borsdorf, A. (2018). 'Private Protected Areas in Latin America: Between conservation, sustainability goals zand economic interests. A review'. eco.mont 1:87-94. Disponible en: https://doi.org/10.1553/eco.mont-10-1s87 (Accedido: 26 septiembre 2018).

Humann, D. (2012). 'A personal journey to innovation'. En: P. Figgis, J. Fitzsimons y J. Irving (eds.) Innovation for 21 st Century Conservation, pp. 16-23. Sídney, Australia: Comité Australiano de la UICN. Disponible en: https://www.iucn.org/sites/dev/ files/import/downloads/innovation_for_21st_century_conservation_ low.pdf (Accedido: 26 septiembre 2018).

Joint ANZECC/MCFFA National Forest Policy Statement Implementation Sub-Committee (JANIS) (1997). Nationally agreed criteria for the establishment of a comprehensive, adequate and representative reserve system for forests in Australia. Canberra, Australia: Joint ANZECC/MCFFA National Forest Policy Statement Implementation Sub-Committee. Disponible en: http://www. agriculture.gov.au/SiteCollectionDocuments/rfa/publications/nat_nac. pdf (Accedido: 26 septiembre 2018).

Jonas H.D., Barbuto, V., Jonas, H.C., Kothari, A. y Nelson, F. (2014). 'New steps of change: looking beyond protected areas to consider other effective area-based conservation measures'. PARKS 20(2):111128. Disponible en: https://doi.org/10.2305/IUCN.CH.2014. PARKS-20-2.HDJ.en (Accedido: 26 septiembre 2018).

Jonas, H.D., MacKinnon, K., Dudley, N., Hockings, M., Jesses, S., Laffoley, D., MacKinnon, D., Matallana-Tóbon, C.L., Sandwith, T., Waithaka, J. y Woodley, S. (2018). 'Editorial essay: Other Effective Area-based Conservation Measures: From Aichi Target 11 to the post-2020 biodiversity framework'. PARKS 24 (Edición especial): 9-16. Disponible en: https://doi.org/10.2305/IUCN.CH.2018. PARKS 24 SIHDJ.en.

Keppel, G., Morrison, C., Hardcastle, J., Rounds, I.A., Wilmott, I.K., Hurahura, F. y Shed, P.K. (2012). 'Conservation in tropical Pacific island countries: case studies of successful programmes'. PARKS 18(1):111-123. Disponible en: https://doi.org/10.2305/IUCN. CH.2012.PARKS-18-1.GK.en (Accedido: 26 septiembre 2018).

Knight, A.T., Cowling, R.M., Difford, M. y Campbell, B.M. (2010). 'Mapping human and social dimensions of conservation opportunity for the scheduling of conservation action on private land'.

Conservation Biology 24(5):1348-1358. Disponible en: https://doi. org/10.1111/j.1523-1739.2010.01494.x

Knight, A.T., Cowling, R.M., Rouget, M., Balmford, A., Lombard, A.T. y Campbell, B.M. (2008). 'Knowing but not doing: selecting priority conservation areas and the research-implementation gap'. Conservation Biology 22:610-617. Disponible en: https:// doi.org/10.1111/j.1523-1739.2008.00914.x (Accedido: 26 septiembre 2018).

Knight, A.T., Grantham, H., Smith, R.J., McGregor, G.K., Possingham, H.P. y Cowling, R.M. (2011). 'Land manager willingness-to-sell defines conservation opportunity for protected area expansion'. Biological Conservation 144:2623-2630. Disponible en: https://doi. org/10.1016/j.biocon.2011.07.013 (Accedido: 26 septiembre 2018).

Knight, A.T., Sarkar, S., Smith, R.J., Strange, N. y Wilson, K.A. (2011c). 'Engage the hodge-podge: management factors are essential when prioritising areas for restoration and conservation opportunity'. Diversity and Distributions 17(6):1234-1238. Disponible en: https://doi.org/10.1111/j.1472-4642.2011.00789.x (Accedido: 26 septiembre 2018).
Lafarge (2007). Driving Quarry Restoration. París, Francia: Lafarge. Disponible en: https://www.cbd.int/financial/privatesector/franceprivatewwflafarge.pdf (Accedido: 26 septiembre 2018).

Land Trust Alliance (2015). National Land Trust Census Report. Washington D.C., EE. UU.: Land Trust Alliance. Disponible en: http://s3.amazonaws.com/landtrustalliance. org/2015NationalLandTrustCensusReport.pdf (Accedido: 26 septiembre 2018).

Lausche, B. (2011). Guidelines for Protected Areas Legislation. Gland, Suiza: UICN. Disponible en: https://portals.iucn.org/library/ node/10133 (Accedido: 26 septiembre 2018).

Leménager, T., King, D., Eliott, J., Gibbons, H. y King, A. (2014). 'Greater than the sum of their parts: environmental complementarity between public, private and communities protected areas'. Global Ecology and Conservation 2:238-247. Disponible en: https://doi. org/10.1016/j.gecco.2014.09.009 (Accedido: 26 septiembre 2018).

Leung, Y.-F., Spenceley, A., Hvenegaard, G. y Buckley, R. (eds.) (2018). Tourism and Visitor Management in Protected Areas: Guidelines for Sustainability. IUCN Best Practice Protected Area Guidelines Series No. 27. Gland, Suiza: UICN. Disponible en: https:// portals.iucn.org/library/node/47646

Levitt, J.N. (ed.) (2014). Conservation catalysts. The academy as nature's agent. Cambridge, EE. UU.: Lincoln Institute of Land Policy. Disponible en: https://www.lincolninst.edu/sites/default/files/pubfiles/ conservation-catalysts-full_0.pdf (Accedido: 26 septiembre 2018).

Lopoukhine, N., Crawhall, N., Dudley, N., Figgis, P., Karibuhoye, C., Laffoley, D., Miranda Londoño, J., MacKinnon, K. y Sandwith, T. (2012). 'Protected areas: providing natural solutions to 21st Century challenges'. S.A.P.I.EN.S: 5(2).

Maphisa, D.H., Smit-Robinson, H., Underhill, L.G. y Altwegg, R. (2017). 'Management factors affecting densities of common grassland birds of high elevation grasslands of eastern South Africa: Ingula as a Case Study'. Avian Research 8(5). Disponible en: https://doi. org/10.1186/s40657-017-0063-8 (Accedido: 26 septiembre 2018).

Marnewick, M.D., Retief, E.F., Wright, D.R. y Theron, N.T. (2015). South Africa's Important Bird and Biodiversity Areas Status Report 2015. Johannesburgo, Sudáfrica: BirdLife Sudáfrica. Disponible en: https://www.birdlife.org.za/images/ IBA/Documents/IBA\%20Status\%20Report\%20low\%20res.pdf (Accedido: 26 septiembre 2018).

Mascia, M.B. y Pailler, S. (2011). 'Protected area downgrading, downsizing, and degazettement (PADDD) and its conservation implications'. Conservation Letters 4:9-20. Disponible en: https:// doi.org/10.1111/j.1755-263X.2010.00147.x (Accedido: 26 septiembre 2018).

Mascia, M.B., Pailler, S., Krithivasan, R., Roshchanka, V., Burns, D., Mlotha, M.J., Murray, D.R. y Peng, N. (2014). 'Protected area downgrading, downsizing, and degazettement (PADDD) in Africa, Asia, and Latin America and the Caribbean, 1900-2010'. Biological Conservation 169:355-361. Disponible en: https://doi.org/10.1016/j. biocon.2013.11.021 (Accedido: 26 septiembre 2018).

Mayorquín, A., Valenzuela, S. y Orlando Rangel Ch, J. (2010). 'Evaluación de la efectividad de manejo en reservas naturales de la sociedad civil: una propuesta metodológica' Caldasia 32:381-397. Disponible en: https://revistas.unal.edu.co/index.php/cal/article/ view/36230 (Accedido: 26 septiembre 2018).

Mesquita, C.A.B. y Weyland Vieira, M.C. (2004). Reservas Particulares do Patrimônio Natural da Mata Atlântica. São Paulo, Brasil: Conselho da Reserva da Biosfera da Mata Atlântica. Disponible en: http://www. rbma.org.br/rbma/pdf/caderno_28.pdf (Accedido: 26 septiembre 2018).

Mitchell, B.A. (2005). Editorial. PARKS 15(2):1-5. Disponible en: http:// parksjournal.com/wp-content/uploads/2017/07/parks_15_2.pdf (Accedido: 26 septiembre 2018). 
Mitchell, B.A., Fitzsimons, J.A., Stevens, C.M.D. y Wright, D.R. (2018). 'PPA or OECM? Differentiating between privately protected areas and other effective conservation measures on private land'. PARKS 24 (Edición especial):49-60. Disponible en: https://doi.org/10.2305/IUCN. CH.2018.PARKS-24-SIBAM.en (Accedido: 26 septiembre 2018).

Mitchell, B.A., Walker, Z. y Walker, P. (2017). 'A governance spectrum: Protected areas in Belize'. PARKS 23(1):45-60. https://doi. org/10.2305/IUCN.CH.2017.PARKS-23-1BAM.en

Monteferri, B. y Coll, D. (2009). Conservación Privada y Comunitaria en los Países Amazónicos. Lima, Perú: Sociedad Peruana de Derecho Ambiental (SPDA).

Natural Resource Management Ministerial Council (2005). Directions for the National Reserve System: A partnership approach. Canberra, Australia: Natural Resource Management Ministerial Council. Disponible en: https://www.environment.gov.au/system/files/ pages/35ded9a1-0a17-47fa-a518-05f7bfe045ce/files/directions.pdf (Accedido: 26 septiembre 2018).

Natural Resource Management Ministerial Council (2009). Australia's Strategy for the National Reserve System 2009-2030. Canberra, Australia: Natural Resource Management Ministerial Council. Disponible en: http://www.environment.gov.au/system/files/ resources/643fb071-77c0-49e4-ab2f-220733beb30d/files/nrsstrat. pdf (Accedido: 26 septiembre 2018).

Neugarten, R.A., Langhammer, P.F., Osipova, E., Bagstad, K.J., Bhagabati, N., Butchart, S.H.M., Dudley, N., Elliott, V., Gerber, L.R. Gutierrez Arrellano, C., Ivanić, K.-Z., Kettunen, M., Mandle, L., Merriman, J.C., Mulligan, M., Peh, K.S.-H., Raudsepp-Hearne, C., Semmens, D.J., Stolton, S. y Willcock, S. (2018). Tools for measuring, modelling, and valuing ecosystem services: Guidance for Key Biodiversity Areas, Natural World Heritage Sites, and Protected Areas. Gland, Suiza: UICN. Disponible en: https://doi.org/10.2305/IUCN. CH.2018.PAG.28.en (Accedido: 26 septiembre 2018).

Odendaal, N. y Shaw, D. (2010). 'Conservation and economic lessons learned from managing the NamibRand Nature Reserve'. Great Plains Research 20(1):29-36. Disponible en: https://www.jstor.org/ stable/23782173 (Accedido: 26 septiembre 2018).

Ojidos, F. (2017). Conservação em ciclo contínuo: modelo de gestão para financiamento de Reserva Particular do Patrimônio Natural. São Paulo, Brasil: Nazaré Paulista. Disponible en: https://escas. org.br/download/produtos-finais/nazare-15/Flavio-Silva-OJidos.pdf (Accedido: 26 septiembre 2018).

Organización de las Naciones Unidas (ONU) (2007). United Nations Declaration on the Rights of Indigenous Peoples. Disponible en: https://www.un.org/development/desa/ indigenouspeoples/declaration-on-the-rights-of-indigenous-peoples. html (Accedido: 26 septiembre 2018).

Organización de las Naciones Unidas para la Alimentación y la Agricultura (FAO) (2017). Free, Prior and Informed Consent: An indigenous peoples' right and a good practice for local communities: Manual for project practitioners. Roma, Italia: FAO. Disponible en: http://www.fao.org/3/a-i6190e.pdf. (Accedido: 26 septiembre 2018).

Organización Mundial del Turismo (OMT) (2016). The Transformative Power of Tourism: a paradigm shift towards a more responsible traveller. Affiliate Members Global Reports, Volume 14. Madrid, España: OMT.

Palmer, M. y Finlay, V. (2003). Faith in Conservation: New approaches to religion and the environment. Washington D. C., EE. UU.: The World Bank. Disponible en: http://siteresources.worldbank. org/INTBIODIVERSITY/214584-1112712965549/20480342/ FaithInConservationNewApproachesPreface2003.pdf (Accedido: 26 septiembre 2018).

Pasquini, L., Fitzsimons, J.A., Cowell, S., Brandon, K. y Wescott, G. (2011). 'The establishment of large private nature reserves by conservation NGOs: key factors for successful implementation'. Oryx 45:373-380. Disponible en: https://doi.org/10.1017/ S0030605310000876 (Accedido: 26 septiembre 2018).

Pellin, P. y Lima Ranieri, V.E. (2016). 'Voluntary preservation on private land in Brazil: characterisation and assessment of the effectiveness of managing Private Reserves of Natural Heritage'. Brazilian Geographical Journal: Geosciences and Humanities Research Medium 7(1):33-52

Pence, G.Q.K., Botha, M.A. y Turpie, J.K. (2003). 'Evaluating combinations of on- and off-reserve conservation strategies for the Agulhas Plain, South Africa: a financial perspective'. Biological Conservation 112(1-2):253-274. Disponible en: https://doi.org/10.1016/S0006-3207(02)00413-5 (Accedido: 26 septiembre 2018).

Rissman, A.R. y Butsic, V. (2011). 'Land trust defense and enforcement of conserved areas'. Conservation Letters 4:31-37. Disponible en: https://doi.org/10.1111/j.1755-263X.2010.00136.x (Accedido: 26 septiembre 2018).

Röttger, C., Strauss, A. y Horstmeyer, N. (eds.) (2016). Nature Conservation in Eastern Europe, Caucasus and Central Asia. Bonn, Alemania: Bundesamt für Naturschutz. Disponible en: https://www. bfn.de/fileadmin/BfN/service/Dokumente/skripten/Skript447.pdf (Accedido: 5 octubre 2018).

Ruseva, T., Farmer, J. y Chancellor, C. (2016). 'Networking for conservation: Social capital and perceptions of organizational success among land trust boards'. Ecology and Society, 21(2). Disponible en: https://doi.org/10.5751/ES-08618-210250 (Accedido: 26 septiembre 2018).

Saavedra, B., Simonetti, J.A. y Redford, K.H. (2011). 'Private conservation: the example that the Wildlife Conservation Society builds from Tierra del Fuego'. En: E. Figueroa B. (ed.). Biodiversity Conservation in the Americas: Lessons and Policy, pp. 357-392. Editorial FEN-Universidad de Chile. Santiago, Chile: Besegraf Ltda.

Sayre, R., Roca, E., Sedaghatkish, G., Young, B., Keel, S., Roca, R.L. y Sheppard, S. (eds) (2000). Nature in Focus: Rapid Ecological Assessment. Island Press, Washington D. C.

Selinske, M.J., Coetzee, J., Purnell, K. y Knight, A.T. (2015). 'Understanding the motivations, satisfaction, and retention of landowners in private land conservation programs'. Conservation Letters 8:282-289. Disponible en: https://doi.org/10.1111/conl.12154 (Accedido: 26 septiembre 2018).

Selinske, M.J., Cooke, B., Torabi, N., Hardy, M.J., Knight, A.T. y Bekessy, S.A. (2016). 'Locating financial incentives among diverse motivations for long-term private land conservation'. Ecology and Society 22(2):7. Disponible en: https://doi.org/10.5751/ES-09148220207 (Accedido: 26 septiembre 2018).

Selinske, M., Hardy, M., Gordon, A. y Knight, A. (2017). Policy brief for Privately Protected Areas Futures 2017: Supporting the long-term stewardship of privately protected areas. Disponible en: https://osf.io/ znsdq/download (Accedido: 26 septiembre 2018).

Servicio Nacional de Áreas Naturales Protegidas por el Estado SERNANP, Sociedad Peruana de Derecho Ambiental (2014). Documento de trabajo 10: Áreas de Conservación Privada. Perú: SERNANP. Disponible en: http://www.sernanp.gob.pe/docum ents/10181/255769/\%C3\%81reas-de-Conservaci\%C3\%B3nPrivada-Documento-de-trabajo-10.pdf/b77fd3a7-f235-40fa-839ab60889e343fe (Accedido: 26 septiembre 2018).

Shackleton, C.M., Cundill, G. y Knight, A.T. (2009). ‘Beyond just research: experiences from Southern Africa in developing social learning partnerships for resource conservation initiatives'. Biotropica 41:563-570. Disponible en: https://doi.org/10.1111/j.17447429.2009.00559.x (Accedido: 26 septiembre 2018). 
Solano, P. y Wust, W. (2005). Manos para mejores tiempos: experiencias exitosas de conservación en el Perú. Perú: Sociedad Peruana de Derecho Ambiental (SPDA). Disponible en: https://spda. org.pe/?wpfb_dl=103 (Accedido: 26 septiembre 2018).

South African National Biodiversity Institute (SANBI) (2015). The business case for biodiversity stewardship. A report produced for the Department of Environmental Affairs. Desarollado por Cumming, T., Driver, A., Pillay, P., Martindale, G., Purnell, K., McCann, y Maree, K. South African National Biodiversity Institute, Pretoria. Disponible en: https://www.sanbi.org/wp-content/uploads/2018/04/sanbibiodiversity-stewardship-business-case-factsheet.pdf (Accedido: 26 septiembre 2018).

South African National Biodiversity Institute (SANBI) (2016). Lexicon of Biodiversity Planning in South Africa. Beta Version, June 2016. Pretoria, South Africa: South African National Biodiversity Institute. Disponible en: http://biodiversityadvisor.sanbi.org/wpcontent/uploads/2016/06/2016_06_02-Lexicon.pdf (Accedido: 26 septiembre 2018).

Smith, F., Smillie, K., Fitzsimons, J., Lindsay, B., Wells, G., Marles, V., Hutchinson, J., O'Hara, B., Perrigo, T. y Atkinson, I. (2016). 'Reforms required to the Australian tax system to improve biodiversity conservation on private land'. Environmental and Planning Law Journal 33:443-450. Disponible en: http://hdl.handle.net/10536/DRO/ DU:30087854 (Accedido: 26 septiembre 2018).

Stolton, S., Hockings, M., Dudley, N., MacKinnon, K., Whitten, T. y Leverington, F. (2007). Management Effectiveness Tracking Tool. Reporting Progress at Protected Area Sites. Segunda edición. Gland, Suiza: WWF International.

Stolton, S., Redford, K.H. y Dudley, N. (2014). The Futures of Privately Protected Areas. Gland, Suiza: UICN. Disponible en: https://portals. iucn.org/library/node/44856 (Accedido: 26 septiembre 2018).

Tasos, H., Dieterich, M., Ibisch, P.L., Mihok, B. y Selva, N. (2014). The challenge of implementing the European network of protected areas Natura 2000. Conservation Biology 29(1):260-270. Disponible en: https://doi.org/10.1111/cobi.12366

Taylor, M.F.J., Fitzsimons, J. y Sattler, P. (2014). Building Nature's Safety Net 2014: A decade of protected area achievements in Australia. Sídney, Australia: WWF-Australia.

Taylor, P., Asner, G., Dahlin, K., Anderson, C., Knapp, D., Martin, R., Mascaro, J., Chazdon, R., Cole, R., Wanek, W., Hofhansl, F., Malavassi, E., Vilchez-Alvarado, B. y Townsend, A. (2015). 'Landscape-scale controls on aboveground forest carbon stocks on the Osa Peninsula, Costa Rica'. PloS One 10: e0126748. Disponible en: https://doi.org/10.1371/journal.pone.0126748 (Accedido: 26 septiembre 2018).

The Nature Conservancy (TNC) (2018). Private Lands Conservation: Conservation Buyer Program. Arlington, EE. UU.: The Nature Conservancy. Disponible en: https://www.nature.org/en-us/about-us/ who-we-are/how-we-work/private-lands-conservation/

(Accedido: 26 septiembre 2018).

The Nature Conservancy y Conservation International (TNC y Cl) (2012). Practitioner's Field Guide for Marine Conservation Agreements: Best Practices for Integrating Rights-based Incentive Agreements into Ocean and Coastal Conservation Efforts. Final V2. Narrangansett, Rhode Island: The Nature Conservancy. Disponible en: http://www. reefresilience.org/wp-content/uploads/Practitioners_Field_Guide for Marine_Conservation_Agreements_2012.pdf

Thompson Jr., B.H. (2004.) The Trouble with Time: Influencing the Conservation Choices of Future Generations, Natural Resources Journal, 44:601. Disponible en: http://digitalrepository.unm.edu/nrj/ vol44/iss2/13 (Accedido: 26 septiembre 2018).

Toft, R. y Larsen, T.H. (2010). Osa, where the Rainforest Meets the Sea. Zona Tropical Publications.
Tourenq, C., Field, T. y Searle, A. (2016). 'Restoration of Banrock Station Ramsar wetlands, South Australia: over 20 years of successful involvement by a private agribusiness'. En: M.J. Mulongoy y J. Fry (eds.) Restoring Life on Earth: Private-sector Experiences in Land Reclamation and Ecosystem Recovery. CBD Technical Series no. 88, pp. 25-36. Montreal, Canadá: SCBD. Disponible en: https://www.cbd.int/doc/publications/cbd-ts-88-en.pdf (Accedido: 26 septiembre 2018).

Unión Internacional para la Conservación de la Naturaleza (UICN) (2016a). A Global Standard for the Identification of Key Biodiversity Areas, Version 1.0. Primera edición. Gland, Suiza: UICN. Disponible en: https://portals.iucn.org/library/node/46259. (Accedido: 27 septiembre 2018).

Unión Internacional para la Conservación de la Naturaleza (UICN) (2016b). WCC-2016-Res-036-EN Supporting privately protected areas. Gland, Suiza: UICN. Disponible en: https://portals.iucn.org/ library/sites/library/files/resrecfiles/WCC_2016_RES_036_EN.pdf (Accedido: 6 febrero 2018).

Unión Internacional para la Conservación de la Naturaleza y la Comisión de Áreas Protegidas (UICN CMAP) (2016). IUCN Green List of Protected and Conserved Areas: User Manual, Version 1.0. Gland, Suiza: UICN. Disponible en: https://www.iucn.org/sites/dev/ files/content/documents/iucn_green_list_user_manual_version_1.0_ september_2016_nov.pdf. (Accedido: 26 septiembre 2018).

Unión Internacional para la Conservación de la Naturaleza Comité Nacional Reino Unido (UICN NCUK) (2012). Putting nature on the map identifying protected areas in the UK: A handbook to help identify protected areas in the UK and assign management categories and governance types to them. Mold, Reino Unido: Comité Nacional de la UICN Reino Unido. Disponible en: https://iucnuk.files.wordpress. com/2017/05/pnotm-handbook-small.pdf (Accedido: 26 septiembre 2018).

Wilson, K.A., Underwood, E.C., Morrison, S.A., Klausmeyer, K.R. Murdoch, W.W., Reyers, B., Wardell-Johnson, G., Marquet, P.A., Rundel, P.W., McBride, M.F., Pressey, R.L., Bode, M., Hoekstra, J.M. Andelman, S.J., Looker, M., Rondinini, C., Kareiva, P., Shaw, M.R. y Possingham, H.P. (2007). 'Conserving biodiversity efficiently: what to do, where and when'. PLoS Biology, 5: e223. Disponible en: https:// doi.org/10.1371/journal.pbio.0050223

Worboys, G.L., Lockwood, M., Kothari, A., Feary, S. y Pulsford, I. (eds.) (2015). Protected Area Governance and Management. Canberra, Australia: ANU Press. Disponible en: http://press-files. anu.edu.au/downloads/press/p312491/pdf/book.pdf?referer=372 (Accedido: 26 septiembre 2018) También disponible en: https:// doi.org/10.26530/OAPEN_569111 and https://doi.org/10.22459/ PAGM.04.2015

Worboys, G.L. y Trzyna, T. (2015). 'Managing protected areas'. En: G.L. Worboys, M. Lockwood, A. Kothari, S. Feary y I. Pulsford (eds) Protected Area Governance and Management, pp. 207-250. Canberra, Australia: ANU Press. Disponible en: https://doi. org/10.26530/OAPEN_569111and https://doi.org/10.22459/ PAGM.04.2015

Young, M.D., Gunningham, N., Elix, J., Lambert, J., Howard, B., Grabosky, P. y McCrone, E. (1996). Reimbursing the future: an evaluation of motivational voluntary, price-based, property-right, and regulatory incentives for the conservation of biodiversity, Partes 1 y 2. Serie Biodiversity, Paper no. 9. Canberra: Departamento de Medio Ambiente, Deporte y Territorios. 


\section{Notas al pie}

1. www.iucn.org/theme/protected-areas/ publications/best-practice-guidelines

2. www.conservacionpatagonica.org/home.htm\#

3. www.nps.gov/tapr/index.htm

4. www.iucn.org/theme/protected-areas/our-work/ iucn-green-list

5. www.iucn.org/sites/dev/files/content/documents/ ucn Ivapc manual de usuario version 1.0 septiembre_2016_espanol_3.pdf

6. www.sneeuberg.com/pages/conservation/

7. www.cbd.int/nbsap/

8. www.keybiodiversityareas.org/about

9. www.birdlife.org/worldwide/programmeadditional-info/important-bird-and-biodiversity-areasibas

10. www.ramsar.org

11. whc.unesco.org

12. www.unesco.org/new/en/natural-sciences/ environment/ecological-sciences/

13. www.conservamospornaturaleza.org/destino/ reserva-ecologica-chaparri/

14. www.fpwc.org

15. www.fpwc.org/caucasus-wildlife-refuge/

6. /portals.iucn.org/library/node/46447

17. portals.iucn.org/library/node/44188

18. portals.iucn.org/library/node/44114

19. singita.com/region/singita-grumeti/

20. www.chumbeisland.com/

21. caiman.com.br/en/

22. portals.iucn.org/library/node/46476

23. www.eskom.co.za/news/Pages/2018Jun3.aspx

24. www.iucn.org/pa_guidelines

25. papaco.org/moocs

26. www.environment.gov.za/sites/default/files/

egislations/nema amendment act57.pdf

27. www.protectedplanet.net/

28. WwW.gbif.org/

29. www.iucnredlist.org/

30. Www.nationalredlist.org/

31. www.keybiodiversityareas.org/home

32. earth.google.com/web/

33. earthengine.google.com/

34. www.globalforestwatch.org/

5. www.planet.com

36. www.bushheritage.org.au/

37. www.bushheritage.org.au/places-we-protect/

new-south-wales/naree

38. earthdata.nasa.gov/earth-observation-data/nearreal-time/firms/active-fire-data

39. fires.globalforestwatch.org/home/

40. frepesp.org.br/sim-rppn/

41. www.theconservationlandtrust.org/eng/el_cani. htm

2. www.seasonsinafrica.com/lodges-in-south-africa/ kruger-lowveld-lodges/the-outpost-kruger-nationalpark/makuleke-history/

43. www.theislandfoundation.com/

44. www.lafarge.co.ke/4_A_3-Haller_Park

45. www.bushheritage.org.au/

46. https://iris.thegiin.org/

47. cmp-openstandards.org/

48. www.miradi.org/

49. http://asiconservachile.cl/

50. www.protectedplanet.net/c/protected-areas-

management-effectiveness-pame

51. www.landtrustalliance.org/about-us

52. institutolife.org/en/

53. www.thelongrun.org/

54. knowhownonprofit.org/how-to/how-to-set-up-a-

volunteering-programme

55. www.rspb.org.uk

56. www.natureconservancy.ca/en/
57. www.facebook.com/CREWCitSciZA/

58. www.fjocotoco.org

59. www.conservamospornaturaleza.org/

60. www.conservamospornaturaleza.org/colabora/ dona-tu-talento/

61. www.conservamospornaturaleza.org/explora/

62. www.conservamospornaturaleza.org/accion/

dona/

63. naankuse.com/

64. www.fundacaogrupoboticario.org.br/en/whatwe-do/nature-preserves/pages/nature-preserver-

salto-morato-public-usage.aspx

65. www.natureconservancy.ca/en/

66. galianoconservancy.ca/

67. galianoconservancy.ca/walkalong/

68. www.americanprairie.org/

69. www.americanprairie.org/wild-sky-beef

70. www.colorado.gov/statelandboard

71. escas.org.br/download/produtos-finais/

nazare-15/Flavio-Silva-OJidos.pdf

72. thomasfoundation.org.au/the-david-thomas-

challenge/

73. busquedas.elperuano.pe/normaslegales/

reconocen-el-area-de-conservacion-privada-las-

naranjas-ub-resolucion-ministerial-no-147-2018-

minam-1637750-1/

74. iwjv.org/funding-opportunity/north-american-

wetlands-conservation-act-nawca)

75. www.fijiwater.com/company.htm

76. www.conservation.org/projects/Pages/

sustainable-development-for-fiji-people-sovi-basin. aspx

77. www.ecosystemmarketplace.com/

78. www.afoclt.org

79. www.bfn.de/en/activities/national-natural-

heritage.html

80. ec.europa.eu/environment/life/funding/lifeplus.

htm

81. chile.wcs.org/Karukinka.aspx

82. www.iucn.org/about/members/national-and-

regional-committees

83. www.borana.co.ke/

84. caiman.com.br/en/ecological-refuge/

85. www.sinaldovale.org/about-us

86. www.sixsenses.com/resorts/laamu/sustainability

87. www.upm.com/Responsibility/forests/

Biodiversity/Pages/default.aspx

88. federation.edu.au/research/technology-parks-

and-nanya-station/nanya-station

89. www.banrockstation.com.au/take-5-with-drchristophe-toureng/

90. www.isvolunteers.org

91. cedarcreek.umn.edu/about

92. www.attenboroughnaturecentre.co.uk

93. www.mvotma.gub.uy/component/k2

item/10010680-area-de-manejo-de-habitats-y-o-

especies-esteros-y-algarrobales-del-rio-uruguay-rio-

negro-proyecto-de-ingreso

94. www.segera.com/

95. tahinz.com/our-story/

96. www.wolwedans.com/

97. wwW.wolwedans.org

98. www.borana.co.ke/conservancy/

99. maasaimaraconservancies.co.ke/

100. cottars.com/

101. www.seedballskenya.com/cottars-wildlife-

conservation/4594243181

102. www.grootbos.com/en

103. www.fynbos.co.za/

104. caiman.com.br/en/ecological-refuge/

105. www.sospantanal.org.br/

106. cepeam.org.br/
107. www.arocha.org/en

108. www.norfolkwildlifetrust.org.uk/wildlife-in-norfolk/

churchyards

109. www.caringforgodsacre.org.uk

110. www.jabalmoussa.org/

111. Para ver ejemplos, visite: www.cali.gov.co/

dagma/publicaciones/131788/sistema-municipal-

de-areas-protegidas---simap/

112. Www.yolombo-antioquia.gov.co/NuestraAlcaldia/

SaladePrensa/Paginas/SISTEMAS-LOCALES-DE-

\%C3\%81REAS-PROTEGIDAS-SILAP.aspx

113. geo.sernanp.gob.pe/geoserver/principal.php

114. www.resnatur.org.co

115. www.fundacionpalmaritocasanare.org/

116. www.fundacionpalmaritocasanare.org/proyecto/

caiman-llanero/ y www.iucn.org/sites/dev/files/

content/documents/palmaritoprivatepas.pdf

117. www.cbd.int/

118. sustainabledevelopment.un.org/

119. protectedplanet.net/country/MX

120. wWw.protectedplanet.net

121. English: wcmc.io/WDPA Manual; Français:

wcmc.io/WDPA_Manual_FR; Español: wcmc.io/

WDPA Manual ES; русском: wcmc.io/WDPA

Manual_RU; عبرع: www.wcmc.io/WDPA_Manual_

AR

122. www.environment.gov.au/land/nrs/science/capad

123. www.landtrustalliance.org/

124. elcn.eu/elcn/summary

125. www.alca.org.au/

126. ampaperu.info/

127. Ver: fflorestal.sp.gov.br/programa-estadual-

de-apoio-as-reservas-particulares-do-patrimonio-

natural-completa-10-anos/ y frepesp.org.br/

representatividade-2/

128. www.landtrustalliance.org

129. www.landtrustaccreditation.org/index.php

130. reservasprivadas.org.ar

131. www.resnatur.org.co/sobre-resnatur/proyectos-

alianzas/proyecto-gef-g5/

132. www.landtrustaccreditation.org/

133. www.gstcouncil.org/gstc-criteria/gstc-

destination-criteria

134. www.thelongrun.org/

135. www.landconservationnetwork.org

136. Www.lincolninst.edu

137. www.landscapesnamibia.org/sossusvlei-namib/

138. www.lincolninst.edu/

139. www.namibrand.org/

140. www.pfi.org.cn/en/board/

141. www.laparios.com

142. www.bfn.de/en/activities/national-natural-

heritage.html

143. www.nrt-kenya.org

144. iucnuk.wordpress.com/projects/putting-nature-

on-the-map/

145. www cbd int/convention/articles.

shtml?a=cbd-02; Texto disponible adicionalmente en árabe, chino, inglés, francés, russo y español

146. www.cbd.int/doc/c/9b1f/759a/

dfcee171bd46b06cc91f6a0d/sbstta-22-I-02-en.

pdf; disponible en otros idiomas en el siguiente link: https://www.cbd.int/meetings/SBSTTA-22 


\section{Glosario}

Acuerdo de conservación: acuerdo, contrato o promesa escrita entre dos individuos que suele constituir un compromiso para hacer o dejar de hacer algo. El individuo que efectúa la promesa o acuerdo es el contratista, mientras que el individuo para quien se realiza la promesa es el contratante. Los acuerdos de conservación son un tipo de acuerdo contractual que, si se alcanzan de manera válida, pueden ser invocados ante un tribunal. Pueden ser redactados con el fin de prohibir ciertas acciones y, en esos casos, pueden ser llamados acuerdos negativos. Existen dos categorías principales de acuerdos de conservación en la ley que rige las transacciones de bienes raíces: los acuerdos de vigencia continua vinculados a la titularidad del predio y los acuerdos por el título. Se dice que un acuerdo está vinculado indisolublemente a la propiedad en cuestión cuando ese acuerdo está anexado al predio y no puede ser separado de este ni ser transferido sin él. Este tipo de acuerdo existe si tanto el propietario original como cada uno de los futuros propietarios están sujetos a su carga o tienen derecho a ser beneficiarios.

Adicionalidad: serie de impactos que no ocurren sin una intervención (Definiciones de la UICN). En el contexto de áreas bajo protección privada, son las acciones de actores no estatales que complementan, en lugar de completar, los sistemas de áreas protegidas gestionados por el gobierno (es decir, gobernanza a cargo del gobierno).

Áreas conservadas por pueblos indígenas y comunidades locales (ICCAs, por su sigla en inglés): ecosistemas naturales o modificados, con valores de biodiversidad, beneficios ecológicos y valores culturales significativos, conservados voluntariamente por los pueblos indígenas y comunidades locales, tanto sedentarios como nómades, por medio de leyes consuetudinarias $\mathrm{u}$ otros medios efectivos.

Autoridad de gobernanza: la institución, pueblos indígenas o grupos comunitarios u otras entidades reconocidas como autoridad responsable por la toma de decisión y la gestión de un área.

Beneficios equitativos: se refiere al impacto final de los esfuerzos de desarrollo en ambos géneros. Esto implica que los resultados deben ser igualmente accesibles y utilizados por hombres y mujeres. Sin embargo, la igualdad de oportunidades no necesariamente significa que ambos géneros reciban los mismos beneficios (Definiciones UICN).

\section{Cesión de derechos de desarrollo inmobiliario (TDR, por} su sigla en inglés): una técnica de zonificación utilizada para proteger recursos naturales y culturales de manera permanente, incluyendo terrenos agrícolas, que consiste en redirigir proyectos de desarrollo inmobiliario - que, de otro modo, serían llevados a cabo en estas áreas - a lugares diseñados para albergar este tipo de crecimiento y desarrollo. Los programas TDR permiten a los propietarios ser compensados financieramente cuando eligen no realizar proyectos de desarrollo en algunas partes o todas sus tierras. Según la zonificación municipal, estos propietarios tienen la opción de desvincular legalmente los 'derechos de desarrollo inmobiliario' de sus tierras y venderlos a otro propietario para ser utilizados en otro lugar. El predio al que se le suprimen los derechos de desarrollo queda protegido permanentemente por medio de una servidumbre de conservación u otro tipo de acuerdo de conservación apropiado, y el valor de desarrollo de la tierra a la que se transfirieron los derechos de desarrollo aumenta, permitiendo usos nuevos o especiales, mayor densidad o intensidad, $u$ otro tipo de flexibilidades regulatorias que la zonificación sin TDR no hubiese permitido.

Ciencia ciudadana: recolección y análisis de datos relacionados con el mundo natural por parte de miembros del público general, comúnmente como parte de un proyecto colaborativo realizado junto con científicos profesionales (Ellwood et al., 2017).

Conocimiento ecológico tradicional: constituye las creencias y el conocimiento acumulados traspasados de generación en generación sobre la relación de los seres vivos (incluyendo los seres humanos) con otros y su medio ambiente. Este tipo de conocimiento es característico de sociedades con continuidad histórica en las prácticas de uso de recursos; por lo general, son sociedades no industriales o menos desarrolladas tecnológicamente, muchas de las cuales son indígenas o tribales (International Development Research Centre, Canadá).

Conservación de la naturaleza: para fines de este documento, naturaleza siempre se refiere a la biodiversidad, a los niveles genéticos, de especies y ecosistémicos, y a la geodiversidad, formaciones terrestres o valores naturales más amplios. En el caso de las áreas protegidas, la conservación se refiere a la mantención in situ de los ecosistemas y hábitats naturales y seminaturales y de las poblaciones de especies viables en sus entornos naturales $y$, en el caso de especies domesticadas o cultivadas, en los entornos donde han desarrollado sus propiedades distintivas (Dudley, 2008).

Diversidad biológica/biodiversidad: variabilidad entre organismos vivos provenientes de todo tipo de fuentes, incluyendo, entre otros, ecosistemas terrestres, marinos y otros tipos de ecosistemas acuáticos y los complejos ecológicos a los que pertenecen. Esto incluye diversidad dentro de las especies, entre especies y de los ecosistemas. ${ }^{145}$

Ecoturismo: viaje responsable a áreas naturales, por medio del cual se conserva el medio ambiente y mejora el bienestar de las comunidades locales, involucra interpretación y educación (Leung et al., 2018).

Evaluación Ecológica Rápida (REA, por su sigla en inglés): de un área o región terrestre corresponde a un catastro flexible, acelerado y dirigido de los tipos de vegetación y especies. Las REAs utilizan una combinación de imágenes teledetectadas, sobrevuelos de reconocimiento, recolección de datos de campo y visualización 
de información espacial para generar información útil para la planificación de conservación en distintas escalas (Sayre et al., 2000).

Fondo rotatorio: un fondo dedicado, operado por una entidad (usualmente una organización de conservación) para adquirir tierras privadas y, luego, revenderlas a compradores con mentalidad conservacionista, que además contempla la creación de un acuerdo de protección a perpetuidad (por ejemplo, un acuerdo de conservación o una servidumbre) para proteger el valor de conservación de la propiedad. Las ganancias provenientes de la venta se utilizan para reponer el fondo, lo que permite seguir reinvirtiendo en la protección de tierras (ver Hardy et al, 2018 a.b.c).

Gobernanza: en el caso de las áreas protegidas, la gobernanza se define como: "las interacciones dentro de las estructuras, procesos y tradiciones que determinan la manera en que se ejerce el poder, cómo se toman las decisiones en materia de opinión pública y de qué modo los ciudadanos o partes interesadas pueden dar su opinión y participar" (Borrini-Feyerabend et al., 2013, p. 10). Los acuerdos de gobernanza se manifiestan mediante marcos legales y políticos, estrategias y planes de manejo, e incluyen los acuerdos organizacionales mediante los que se monitorean las políticas y planes, y el desempeño. La gobernanza abarca las regulaciones que afectan la toma de decisiones, incluyendo quién tiene acceso a la información y participa en el proceso de toma de decisión, al igual que las decisiones mismas (Borrini-Feyerabend et al., 2004).

Igualdad: acceso a las mismas oportunidades y desarrollo de capacidades básicas. Esto significa eliminar las barreras que obstaculizan las oportunidades económicas y políticas, el acceso a educación y servicios básicos, para que las personas (mujeres y hombres de todas las edades, condiciones y posiciones) puedan disfrutar dichas oportunidades y beneficiarse de ellas. Esto dice relación con el concepto de justicia, es decir, otorgarle a cada persona o grupo lo que corresponde por derecho, reconociendo las condiciones o características específicas de cada individuo o grupo humano (sexo, género, clase, religión, edad). En otras palabras, consiste en el reconocimiento de la diversidad, sin dar pie a la discriminación (Definiciones UICN).

Land trust: una institución de conservación permanente de la tierra, cuyo objetivo es proteger los territorios terrestres y marinos que definen a las comunidades y enriquecen su calidad de vida. Un land trust debe lograr esto mediante el establecimiento y monitoreo de las servidumbres de conservación permanentes, asegurándose que las protecciones se mantengan, independiente de quién sea propietario de la tierra en el futuro. Los land trusts trabajan con los propietarios para proteger los valores naturales de su propiedad y garantizar que la belleza escénica del área se mantenga para las generaciones futuras. Además, la propiedad protegida puede ser donada por los propietarios, o el trust puede adquirir la propiedad.

Partes interesadas: en el caso de las áreas protegidas, las partes interesadas son aquellos actores interesados y preocupados directa o indirectamente por estas áreas, pero que no necesariamente cuentan con derechos reconocidos legal o socialmente.

Pleno dominio: titularidad absoluta de la tierra, libre de cualquier condición, limitación, restricción u otras pretensiones o reclamos sobre el título, el que puede ser vendido o traspasado a otros por medio de un testamento o herencia. Un título de pleno dominio tiene prácticamente una duración indefinida. También se le conoce como pleno dominio absoluto. Actualmente, la ley presume una intención de otorgar un predio bajo pleno dominio a menos que se indique claramente que se deben imponer condiciones o limitaciones. Esta es la forma de propiedad más común de bienes raíces en los países bajo common law (derecho consuetudinario), y constituye el interés de propiedad más completo en bienes raíces. Las iniciativas independientes de APPs basadas en el pleno dominio suelen no ser verificables por terceros y, por lo tanto, la transparencia de su propósito no siempre es evidente. En este caso, las buenas prácticas deben incluir el establecimiento de restricciones de conservación vinculadas ineludiblemente a la tierra y verificables públicamente, además de mecanismos de respaldo financiero a largo plazo como los trust funds cuyo objetivo es proveer recursos para futuros costos de gestión.

Propietario: en el contexto de estas directrices, se refiere a la principal entidad de gobernanza responsable por la APP. Dado que existen pocos ejemplos de APPs en biomas marinos, estas directrices generalmente utilizan el término para referirse a todos los tipos de APPs, cualquiera sea el tipo de bioma o ecosistema (marino, terrestre o de agua dulce) en el que se ubican. Aquí, el concepto 'propietario' se utiliza cuando la propiedad es claramente clave para la buena práctica que se está discutiendo.

Redes: diversos tipos de redes de conservación privada en las que participan los propietarios de las APPs establecidas en el mundo. Las buenas prácticas para este tipo de redes se exploran en la Parte B, Sección 8, de estas directrices, y se ejemplifican en el Estudio de caso 8 de Perú.

Servidumbre anexa: derecho a hacer uso de la propiedad adyacente transferido con la tierra. La servidumbre beneficia al predio dominante. El predio sivviente es el que otorga la servidumbre. Este tipo de servidumbre siempre se transfiere con la tierra, salvo que el propietario del predio dominante la ceda. El predio sujeto a la servidumbre anexa corresponde al predio sirviente, mientras que el beneficiado corresponde al dominante. No obstante, si la servidumbre es inherente a la propiedad de algunas tierras, entonces corresponde a una servidumbre anexa. Las servidumbres anexas suelen ser las únicas herramientas legales de fácil acceso para implementar servidumbres a APPs donde predominan los sistemas de derecho civil. Los sistemas de derecho civil son más comunes que los de common law (derecho consuetudinario), los que solo se encuentran en países que han sido colonias inglesas o influenciados por la tradición anglosajona.

Servidumbre de conservación: transferencia de la escritura de un bien raíz a una entidad de beneficencia calificada, que deriva en un beneficio fiscal a cambio de aquella contribución. Su propósito es conservar o proteger la tierra o sus recursos para futuras generaciones. No obstante, la servidumbre de conservación permite a los propietarios mantener otros derechos de propiedad privada, además de habitar ahí y hacer uso de la tierra. Las servidumbres de conservación son legalmente vinculantes. La servidumbre crea un acuerdo de conservación de la tierra legalmente exigible entre un propietario y una agencia de gobierno. Las restricciones de la servidumbre están vinculadas a la titularidad 
de la tierra. Las servidumbres de conservación son vinculantes para todos los titulares futuros de la propiedad. En el caso de las APPs, las servidumbres de conservación se deben habilitar mediante legislaciones específicas como un tipo de servidumbre personal (ver a continuación) transferida con la tierra, o creadas entre dos predios por medio de una servidumbre anexa.

Servidumbre personal: servidumbre que beneficia a un individuo y no está vinculada a la tierra. Es un derecho personal del titular que le permite hacer uso de la tierra de otra persona y que no depende de la titularidad de un predio dominante. Las servidumbres personales no se transfieren con la propiedad cuando esta se vende. El individuo que se beneficia de la servidumbre no puede transferirla. Es necesario documentar las servidumbres personales para proteger a ambas partes. Documentar el acuerdo de servidumbre por escrito y definir su alcance y duración puede ayudar a evitar futuros malentendidos. Las empresas de servicios básicos suelen utilizar servidumbres personales. En el caso de las APPs, las servidumbres de conservación personales deben ser habilitadas específicamente por la legislación como un tipo de servidumbre traspasada con la tierra cuando hay cambios de propietario.

Tipo de gobernanza: los tipos de gobernanza se definen de acuerdo con "quién tiene la autoridad, está a cargo de la gestión y debe además rendir cuentas" sobre un área protegida específica (Borrini-Feyerabend, 2004).

Titulares de derecho: en el caso de las áreas protegidas, los titulares de derechos son aquellos actores socialmente dotados de derechos legales o consuetudinarios con respecto a la tierra, el agua y los recursos naturales.

Turismo basado en la naturaleza: formas de turismo que utilizan los recursos naturales de manera silvestre o exentas de desarrollo inmobiliario. Este tipo de turismo tiene como propósito disfrutar de áreas naturales o silvestres no intervenidas por el desarrollo inmobiliario (Leung et al., 2018).
Usufructo: el derecho sobre la propiedad de otro individuo, normalmente por un periodo limitado o hasta su muerte. Este derecho permite hacer uso de la propiedad, sus frutos y de las ganancias generadas en ella, además de arrendarla y recolectar las rentas, sin excluir al usufructuario. El usufructuario tiene pleno derecho a hacer uso de la propiedad, pero no puede disponer de ella ni destruirla. El grado de usufructo se define mediante un acuerdo y puede: establecerse por un periodo de tiempo definido, cubrir solo cierto tipo de propiedades, estar condicionado a término de no cumplirse ciertas condiciones (por ejemplo, nupcias de un hijo o segundas nupcias de uno de los esposos), otorgársele a varias personas para que lo compartan, ser entregado a un individuo por un periodo de tiempo y luego a otro de ocurrir ciertos eventos. Dado que los usufructos no están ineludiblemente vinculados a la tierra, sino que solo se refieren al derecho de hacer uso de la tierra y beneficiarse de ella, además de tener una duración y alcance limitados, su uso en APPs debe considerarse como una herramienta de protección transitoria, hasta que otra herramienta legalmente vinculante permanente y más robusta pueda ser implementada. 


\section{Apéndice 1: APPs y otras medidas eficaces de conservación basadas en áreas}

Durante la última década, ha surgido una nueva clasificación de gestión para la conservación basada en áreas. La Meta Aichi 11 para la Biodiversidad del CDB se refiere a las "áreas protegidas u otras medidas de conservación eficaces basadas en áreas". La UICN ha jugado un papel clave en definir otras medidas efectivas de conservación basadas en áreas (OECMs, por su sigla en inglés). Según la recomendación del CDB en 2018, el Centro de Monitoreo de la Conservación Mundial del Programa de las Naciones Unidas para el Medio Ambiente (UNEP-WCMC, por su sigla en inglés) comenzará a reunir datos sobre OECMs para integrarlos a su Base de Datos Mundial de Áreas Protegidas o a una base de datos paralela. Uno de los resultados de esta recomendación es que las iniciativas de conservación que cumplen con la definición de OECM, pero no de APP, serán aptas para la entrega de información a la UNEP-WCMC bajo la nueva definición de OECM.

\section{¿Qué significa 'otras medidas efectivas de conservación basadas en áreas'?}

En el borrador de recomendación de la Conferencia de la Partes del CDB este concepto se define como: "un área definida geográficamente distinta a un área protegida, gobernada y gestionada para lograr resultados positivos y a largo plazo para la conservación de la biodiversidad in situ, con funciones ecosistémicas y servicios asociados y, en caso de ser aplicable, valores culturales, espirituales, socioeconómicos, y otro tipo de valores relevantes localmente". ${ }^{146}$

\section{Cómo distinguir las APPs de las OECMs privadas}

El informe Áreas bajo protección privada: Mirando al futuro (Stolton et al., 2014) y las orientaciones publicadas a continuación por el Grupo de Especialistas en APPs de la Comisión Mundial de Áreas Protegidas (CMAP) (Bingham et al., 2017) explicitan que las APPs son áreas que cumplen con la definición de área protegida de la UICN. Una APP no puede ser una OECM y una APP simultáneamente; si cumple con la definición de área protegida de la UICN, entonces, es un área protegida. Pese a que se reconoce la existencia de problemas en torno a la entrega de información sobre APPs a las bases de dato nacionales y a la Base de Datos Mundial de Áreas Protegidas (Bingham et al., 2017), esto no tiene repercusiones en la clasificación de un área.

El borrador Guidelines for Recognising and Reporting Other Effective Area-Based Conservation Measures (UICN, 2018) sugiere que: "El criterio distintivo es que las areas protegidas deben tener un objetivo principal de conservación, mientras que las OECMs deben lograr la conservación de la biodiversidad in situ, independientemente de sus objetivos". Algunas jurisdicciones, incluyendo Australia y Sudáfrica, ya han determinado el tipo de acuerdos de conservación de tierras privadas que calificarían como APP y OECM según categorías de tierra privada (Mitchell et al., 2018).

Tanto las áreas protegidas privadas como las OECMs privadas tienen el potencial de complementarse dentro de los paisajes terrestres y marinos, además de contribuir de manera significativa a los aspectos cualitativos y cuantitativos de la Meta 11 de Aichi. Además, las OECMs pueden servir como punto de partida para asegurar APPs (ver Cuadro 9).

\section{Cuadro 9}

\section{De OECM a APP: Un ejemplo sudafricano}

Si bien existe una clara distinción entre las OECMs y las APPs, las OECMs pueden servir como punto de partida para el establecimiento de APPs. Un ejemplo es el caso de un propietario privado en Sudáfrica, interesado en declarar su propiedad -1.900 ha de pastizales fragmentados, ubicados en el cinturón de niebla - en KwaZulu-Natal como una APP, mediante el programa de custodia de la biodiversidad (ver Caso 10 de Sudáfrica). A pesar de su interés, no estaba seguro de que el gobierno fuera capaz de cumplir con sus obligaciones para apoyar la APP. Entonces, por medio de BirdLife South Africa, primero optó por firmar un acuerdo de biodiversidad, el que según los parámetros de custodia de la biodiversidad, constituye una categoría más baja, además de cumplir con la descripción de OECM. Luego de dos años, durante los que el propietario fortaleció su relación con el gobierno y las ONGs socias, se sintió lo suficientemente cómodo como para comenzar a negociar una declaración de reserva natural con el gobierno por medio de BirdLife South Africa (Mitchell et al. 2018). 


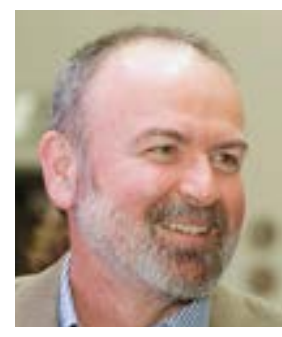

Brent A. Mitchell es Vicepresidente Ejecutivo del Quebec Labrador Foundation Atlantic Center for the Environment (QLF, por su sigla en inglés), ubicado en Massachusetts, EE. UU. A comienzos de su carrera, se desempeñó como biólogo de campo para el land trust más antiguo de los Estados Unidos, The Trustees of Reservation. Desde su incorporación al QLF en 1987, se ha dedicado a promover formas privadas de custodia de la naturaleza mediante proyectos e intercambios en más de 50 países. Además de presidir el Grupo de Especialistas en Áreas Bajo Protección Privada y Gestión de la Naturaleza de la Comisión Mundial de Áreas Protegidas (CMAP) de la UICN, es uno de los socios fundadores del National Park Service's Stewardship Institute en los EE. UU.

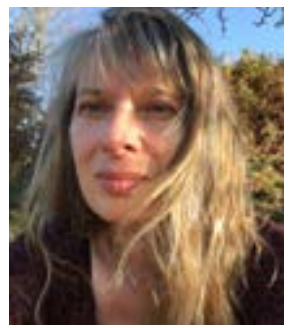

Sue Stolton cofundó Equilibrium Research, junto a Nigel Dudley, en 1991. Su interés por las APPs se remonta a más de veinte años. En 1999, coeditó con Nigel Dudley el volumen Partnerships for Protection, donde describen nuevas estrategias para la planificación y gestión de áreas protegidas, haciendo hincapié en la necesidad de incorporar un sector más amplio de la sociedad a la gobernanza de áreas protegidas. Tras ello, realizó un informe sobre APPs de empresas para el WWF. En 2013-2014, junto con Kent Redford y Nigel Dudley, dirigió el informe Áreas bajo protección privada: Mirando al futuro que sentó las bases para estas directrices. Stolton y Dudley esperan algún día convertirse en dueños/ colaboradores de una APP, en el intertanto participan activamente en varias de las APPs que conforman la Dyfi Biosphere Reserve en Gales central, Reino Unido.

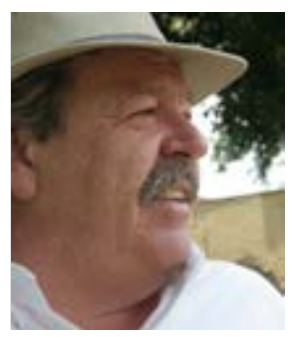

Juan E. Bezaury-Creel es Representante y Director de Asuntos Exteriores de The Nature Conservancy (TNC) en México. Antes de unirse a esta organización, Bezaury-Creel se desempeñó como Representante y Director del Programa México del WWF, Director Ejecutivo de la ONG mexicana Amigos de Sian Ka'an en la costa caribeña del país, además de trabajar con agencias gubernamentales a cargo de áreas protegidas de México. Procedente de aquel país y arquitecto con experiencia en planificación urbana y regional, es miembro del Consejo Nacional de Áreas Protegidas, el Consejo Técnico del Fondo de Mariposas Monarca, el Fondo del Arrecife Mesoamericano y del Fondo Patrimonial de Biodiversidad de la Comisión Nacional Forestal. También pertenece al consejo directivo de varias ONG mexicanas. En 1974, comenzó a administrar una pequeña APP familiar. También diseñó e implementó un mecanismo de transferencia de derechos de desarrollo que limita las iniciativas inmobiliarias en la costa de la Reserva de la Biósfera Sian Ka'an y prohíbe cualquier tipo de desarrollo en los predios con mayor valor biológico, permitiéndole a los propietarios recibir una compensación por vender su derecho de desarrollo. Luego, colaboró con legisladores y agencias ambientales mexicanas para definir y establecer un proceso de certificación que reconoce el valor de los esfuerzos de conservación privados y comunitarios, junto con participar activamente en la incorporación de una parte considerable de las APPs certificadas de México. Ha participado, además, en otros importantes esfuerzos como en la implementación de la Iniciativa de Conservación de Tierras Privadas de México de TNC y de ONGs para la conservación locales, la mayoría de las cuales ha desarrollado importantes redes regionales de conservación privadas y sociales de tierras.

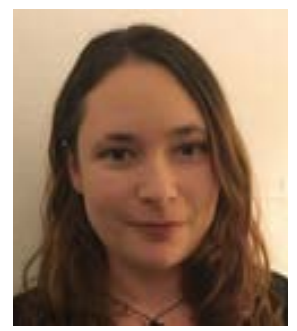

Heather C. Bingham trabaja en el Centro Mundial de Vigilancia de la Conservación (UNEP-WCMC, por su sigla en inglés), donde por cinco años se ha dedicado a mantener la Base de Datos Mundial de Áreas Protegidas (WDPA, por su sigla en inglés). Bingham está a cargo de coordinar el trabajo de la UNEP-WCMC relativo a la documentación de áreas protegidas bajo gobernanza de pueblos indígenas, comunidades locales y actores privados. Ha supervisado el desarrollo de los procesos de verificación de datos provenientes de fuentes no gubernamentales y el rediseño del esquema de la WDPA para reflejar de manera más efectiva la diversidad de las áreas protegidas. Estos avances le han permitido a la WDPA registrar, de forma directa, datos provenientes de un amplio rango de actores de gobernanza y, al mismo tiempo, proteger la calidad y precisión de la base de datos. Bingham cuenta con una maestría en Biología con Conservación y Biodiversidad de la Universidad de Sheffield. 


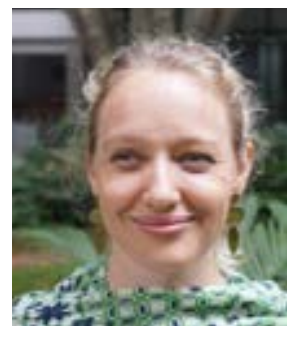

Tracey Cumming es Asesora Técnica de la Iniciativa Finanzas para la Biodiversidad (BIOFIN, por su sigla en inglés) del Programa de las Naciones Unidas para el Desarrollo (PNUD). Proveniente de Sudáfrica, cuenta con más de quince años de experiencia en los ámbitos de políticas y finanzas para la biodiversidad, con especial énfasis en áreas protegidas privadas y comunales, incentivos e inclusión de la biodiversidad dentro de la agenda nacional de desarrollo. Ocupó muchos años el cargo de Asesora de Políticas para la Custodia de la Biodiversidad de SANBI en Sudáfrica, donde lideró la entrega de asesoría técnica, estratégica y legal como parte del programa nacional de Custodia de la Biodiversidad a las partes interesadas a nivel nacional, provincial y de ONGs, incluyendo la creación de una comunidad de práctica en torno a la custodia de la biodiversidad a lo largo del país. Realizó su pregrado en Economía y Ciencia Ambiental y tiene una maestría en Ciencia Ambiental.

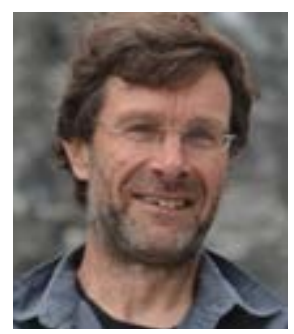

Nigel Dudley ha trabajado de forma independiente la mayor parte de su carrera profesional y por varios años junto a Sue Stolton en la consultora Equilibrium Research, fundada por ambos. Se ha destacado por su colaboración en ONGs, agencias de la ONU, donantes internacionales y gobiernos de más de 70 países, y por la publicación de diversos artículos, informes y libros. Fue editor de la publicación Applying Protected Area Management Categories y coautor de la guía de buenas prácticas Governance of Protected Areas: From Understanding to Action, las que tratan temas relacionados con quienes están a cargo de tomar decisiones en torno a la protección. Formó, también, parte del equipo tras el informe que sirvió de referente para las presentes directrices, Áreas bajo protección privada: Mirando al futuro, volumen que refleja su largo interés en las iniciativas privadas de conservación como voluntario de áreas, miembro de ONGs y activista. Es profesional adjunto en la Universidad de Queensland y miembro del Comité Directivo de la Comisión Mundial de Áreas Protegidas de la UICN.

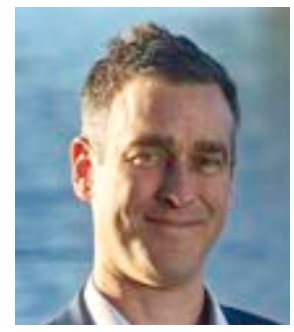

James Fitzsimons es Director de Conservación de The Nature Conservancy Australia, donde supervisa las funciones de planificación, ciencia, implementación y políticas de conservación de la organización en el país. Esto incluye importantes programas de conservación para las vastas sabanas tropicales en el norte de Australia, los diversos desiertos centrales, los temperados estuarios del sur de Australia, los humedales y terrenos inundables de la cuenca del Murray-Darling y paisajes urbanos. Es profesor adjunto de la Universidad de Deakin y a menudo publica en torno a los ámbitos de planificación de conservación práctica y de políticas y legislaciones para la conservación. Ha coeditado cuatro libros: Innovation for 21st Century Conservation, Linking Australia's Landscapes, Valuing Nature: Protected Areas and Ecosystem Services y Big, Bold and Blue: Lessons from Australia's Marine Protected Areas. Dentro de sus prácticas frecuentes está asesorar a gobiernos sobre temas relacionados con políticas de áreas privadas de carácter estatal, nacional e internacional. Antes de unirse a The Nature Conservancy, ejerció como Director Ejecutivo de Proyectos en el Victorian Environmental Assessment Council, donde desarrolló recomendaciones para áreas protegidas y usos de suelo público a lo largo del río Murray, el más grande del país. Previamente, formó parte del Victorial Department of Sustainability and Environment, donde trabajó en temas relativos a áreas protegidas y políticas de conservación, además de participar en la selección y compra de pastizales, bosque de pastizal y humedales que serían incluidos al Sistema Nacional de Reservas, con el objetivo de aumentar de forma significativa la reserva de estos ecosistemas en el sureste de Australia. Además, es dueño y administrador de una APP de 130ha, con diversos ecosistemas amenazados del sureste de Australia y donde conduce investigaciones. 


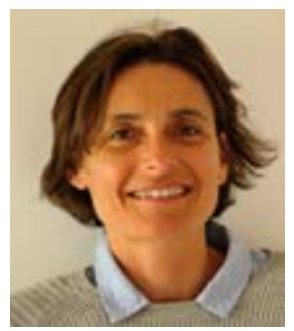

Delphine Malleret-King dirige The Long Run, una organización de beneficencia del Reino Unido que apoya una red global de APPs basadas en turismo. La organización constituye una plataforma desde la cual sus miembros pueden intercambiar conocimientos y ejercer una incidencia política. Además, The Long Run brinda un estándar de excelencia para APPs, el Global Ecosphere Retreats®. Malleret-King estudió Economías del Desarrollo en Francia, y luego continuó sus estudios de posgrado en conservación marina en el Reino Unido y Kenia. En este último país, ha trabajado, por más de veinte años, como consultora independiente, explorando el cruce entre áreas protegidas (gubernamentales, comunitarias y APPs) y las comunidades tanto africanas como de otras partes del mundo. Durante ese periodo, se enfocó en la conservación marina y terrestre, la participación comunitaria y el impacto socioeconómico, como supervisora para organizaciones locales, nacionales e internacionales. Previo a ocupar el cargo de Directora de Asistencia Técnica de The Long Run en 2014, participó en la dirección del Laikipia Wildfire Forum (Kenia) por seis años, congregando a áreas protegidas comunitarias, APPs y otros usuarios de tierras, con el propósito de proteger la integridad del ecosistema Ewaso, además de apoyar el desarrollo social y económico. En 2016, se mudó al Reino Unido para asumir la dirección de The Long Run.

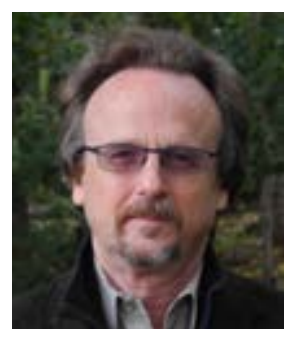

Kent H. Redford es Director de Archipelago Consulting, una consultora ubicada en Portland, Maine, EE. UU., y diseñada (en 2012) con el objetivo de ayudar tanto a individuos como a organizaciones - Global Environment Facility, US National Park Service, Moore Foundation, MacArthur Foundation, Packard Foundation y American Zoo and Aquarium Association, entre otras - a mejorar sus prácticas de conservación. Previo a Archipelago Consulting, trabajó durante catorce años en Wildlife Conservation Society (WCS, por su sigla en inglés) en Nueva York. Antes de ello, estuvo cinco años a cargo de la dirección de la División Latinoamericana de The Nature Conservancy, donde lideraba el programa Parks in Peril. Al comienzo de su carrera, estuvo adscrito a la facultad de la Universidad de Florida, donde cofundó el Program for Studies in Tropical Conservation (PSTC) y la especialización Tropical Conservation and Development (TCD). Además, es doctor en biología de la Universidad de Harvard. Ha dedicado su trabajo a temas relacionados con áreas protegidas, siendo coautor del informe de la UICN Áreas bajo protección privada: Mirando al futuro (2014). Actualmente, es el Presidente del Grupo de Trabajo sobre Biología Sintética y Conservación de la Biodiversidad de la UICN.

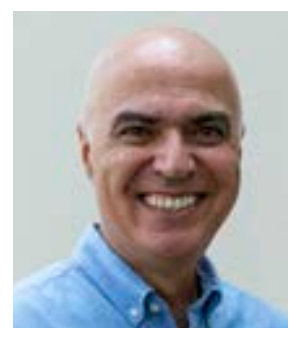

Pedro Solano es especialista en derecho ambiental y cuenta con más de treinta años de experiencia en temas relacionados con la conservación. A lo largo de su carrera, se ha especializado en ámbitos asociados a las áreas naturales protegidas, estrategias de conservación basadas en esfuerzos privados y comunitarios, ecoturismo, cambio climático y gobernanza ambiental. También, ha participado directamente en el diseño y la formulación del marco legal peruano para el Sistema de Áreas Naturales Protegidas y las regulaciones para el patrimonio natural, junto con lanzar la Iniciativa de Conservación Privada y Comunal en 2005 para promover el diseño y la gestión de APPs en Perú. Esto último aumentó el número de APPs de 2 a las casi 250 que hoy existen. Suele ser invitado a impartir cátedras, dictar conferencias y dirigir cursos para universidades y agencias nacionales e internacionales. Ha publicado más de diez libros y numerosos artículos en torno al patrimonio nacional, las áreas protegidas, la conservación voluntaria, el cambio climático y el derecho ambiental. Forma parte de la UICN-CMAP y la Comisión Mundial de Derecho Ambiental, como también del Grupo de Especialistas en APPs de la UICN. Actualmente, es Director Ejecutivo de la Sociedad Peruana de Derecho Ambiental (SPDA), una organización fundada en 1986 y precursora en América Latina. Solano trabaja allí desde 1988. Además, es miembro de la Amazon Conservation Association (ACA), la Asociación para la Conservación de la Cuenca Amazónica (ACCA) y la Asociación Interamericana para la Defensa del Ambiente (AIDA). 



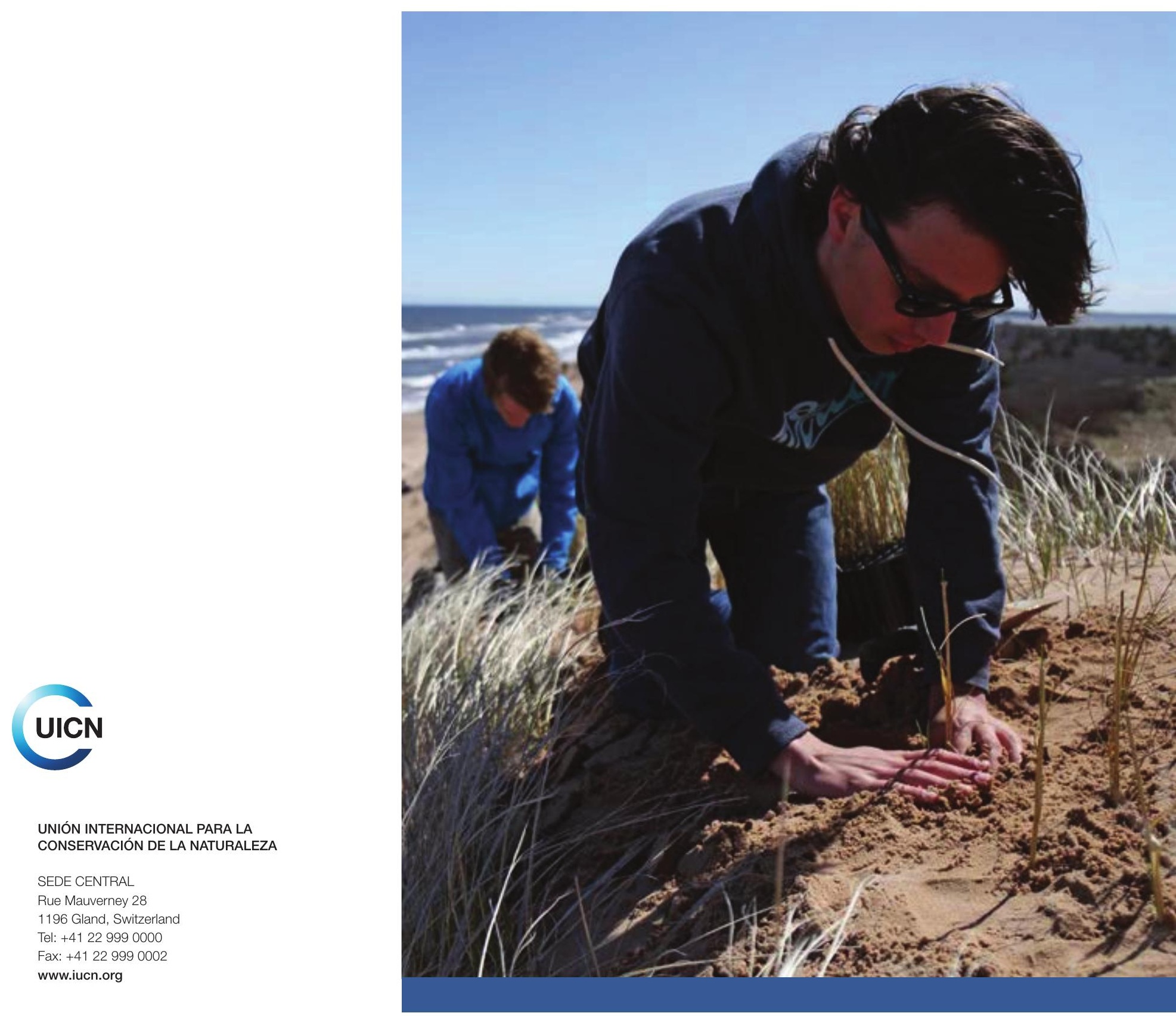

